\title{
G x S x I : gene-stress-immune activation interplay in depression
}

Citation for published version (APA):

Wichers, M. C. (2005). G x S x I : gene-stress-immune activation interplay in depression. [Doctoral Thesis, Maastricht University]. Datawyse / Universitaire Pers Maastricht. https://doi.org/10.26481/dis.20050526mw

Document status and date:

Published: 01/01/2005

DOI:

10.26481/dis.20050526mw

Document Version:

Publisher's PDF, also known as Version of record

\section{Please check the document version of this publication:}

- A submitted manuscript is the version of the article upon submission and before peer-review. There can be important differences between the submitted version and the official published version of record.

People interested in the research are advised to contact the author for the final version of the publication, or visit the DOI to the publisher's website.

- The final author version and the galley proof are versions of the publication after peer review.

- The final published version features the final layout of the paper including the volume, issue and page numbers.

Link to publication

\footnotetext{
General rights rights.

- You may freely distribute the URL identifying the publication in the public portal. please follow below link for the End User Agreement:

www.umlib.nl/taverne-license

Take down policy

If you believe that this document breaches copyright please contact us at:

repository@maastrichtuniversity.nl

providing details and we will investigate your claim.
}

Copyright and moral rights for the publications made accessible in the public portal are retained by the authors and/or other copyright owners and it is a condition of accessing publications that users recognise and abide by the legal requirements associated with these

- Users may download and print one copy of any publication from the public portal for the purpose of private study or research.

- You may not further distribute the material or use it for any profit-making activity or commercial gain

If the publication is distributed under the terms of Article $25 \mathrm{fa}$ of the Dutch Copyright Act, indicated by the "Taverne" license above, 
(c) M.C. Wichers, Maastricht 2005

cover design: Liesbeth Wichers

lay-out: Tiny Wouters

G x S x I Gene-stress-immune activation interplay in depression

ISBN: 9052784566

Universitaire Pers Maastricht

Production: Datawyse 


\section{G x S x I}

\section{Gene-stress-immune activation interplay in depression}

\section{PROEFSCHRIFT}

ter verkrijging van de graad van doctor

aan de Universiteit Maastricht,

op gezag van de Rector Magnificus, Prof. mr. G.P.M.F. Mols, volgens het besluit van het College van Decanen,

in het openbaar te verdedigen

op donderdag 26 mei 2005 om 14.00 uur

door

Maria Catharina Wichers

geboren op 6 december 1977 te Deventer

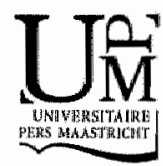




\section{Promotor}

Prof. dr. J. van Os

\section{Co-promotor}

Dr. G.H. Koek

\section{Beoordelingscommissie}

Prof. dr. H. Steinbusch (voorzitter)

Dr. M. De Baets

Prof. dr. B.E. Leonard (National University of Ireland, Gallway)

Dr. J.G.M. Rosmalen (Rijksuniversiteit Groningen)

Prof. dr. R.W. Stockbrügger

The publication of this thesis was financially supported by: AstraZeneca, Lundbeck BV and the "Centrum Chronische Stress Reversal (CSR)", Delft 


\section{Contents}

$\begin{array}{lr}\text { Abbreviations } & 8\end{array}$

Chapter 1 General introduction

Part 1 Twin research and risk factors for child psychopathology

Chapter 2 Chorion type and twin similarity for child psychiatric symptoms

Chapter 3 Associations between nonshared environment and child problem behaviour

Chapter 4 A prospective twin study of birth weight discordance and child problem behavior

Chapter 5 Prenatal life and post-natal psychopathology: evidence for negative gene-birth weight interaction

\section{Part 2 Role of immune activation in depression}

Chapter 6 The psychoneuroimmuno-pathophysiology of cytokine-induced depression in humans

Chapter 7 The role of indoleamine 2,3-dioxygenase (IDO) in the pathophysiology of interferon- $\alpha$-induced depression

Chapter 8 Early increase in vegetative symptoms predicts interferon$\alpha$-induced cognitive-depressive changes

Chapter 9 Interferon- $\alpha$-induced depressive symptoms are accompanied by cytokine changes but not mediated by HPA axis activation 
Chapter 10 IDO and interferon- $\alpha$-induced depressive symptoms: a shift in hypothesis from tryptophan depletion to neurotoxicity

Chapter 11 Baseline immune activation as risk factor for the onset of depression during interferon- $\alpha$ treatment

\section{Part 3 Genes, stress and immune function}

Chapter 12 Early adversity and genetic sensitivity to adult stress exposure

Chapter 13 General discussion

Summary

Samenvatting

Dankwoord

Publications 


\section{Abbreviations}

3-OH-KYN 3-hydroxy-kynurenine

5-HIAA 5-hydroxyindoleacetic acid

5-HT serotonin

5-HTP

5-hydroxytryptophan

5-HTT

5-HT transporter

ACTH

adrenocorticotropin hormone

ADHD

attention deficit hyperactivity disorder

AIC

Akaike information criterion

ARs

adrenoreceptors

AUC

area under the curve

AVP

arginine vasopressin

BBB

blood-brain-barrier

BDI

BDNF

CAA

Beck Depression Inventory

brain-derived neurotrophic factor

CBCL

$\mathrm{Ch}$

CNS

CRH

CSF

DAC

DC

competing amino acids

child behaviour checklist

chorionicity

central nervous system

corticotropin-releasing-hormone

cerebrospinal fluid

daily average cortisol

dichorionic

DPP IV

DRN

dipeptidyl peptidase IV

dorsal raphe nucleus

DST

DZ

ECS

dexamethasone suppression test

dizygotic

electroconvulsive shock

ECT

ELISAS

electroconvulsive therapie

enzyme linked immunosorbent assays

ESM

experience sampling method

GM-CSF

granulocyte-macrophage colony-stimulating factor

GR

GXE

glucocorticoids receptors

HAM-A

genotype $\mathrm{x}$ environment interaction

Hamilton Anxiety Rating Scale

HAM-D

$\mathrm{HCV}$

Hamilton Depression Rating Scale

hepatitis $\mathrm{C}$ virus

HPA axis hypothalamic-pituitary-adrenal axis

TBD

inflammatory bowel disease

IDO

indoleamine 2,3 dioxygenase

IFN- $\alpha$

interferon- $\alpha$ 
IL

IL-1RA

IRS

IVDU

KA

KAT

KYN

KYNA

LBW

LC

LPS

$M C$

MADRS

MAO

MDD

MFI

MHC

MRN

MZ

$\mathrm{NE}$

NK

NMDA

NTS

OVLT

PBCs

PEG

PEP

PET

PGI

PUFA

PVN

$\mathrm{QA}$

rGE

RN

ROS

SIDE

SGA

SIL

SLE

STAI

TCA

TDS interleukin

interleukin-1 receptor antagonist

inflammatory response system

intravenous drug use

kynurenic acid

kynurenine aminotransferase

kynurenine

kynurenate

lower birth weight

locus coeruleus

lipopolysaccharide

monochorionic

Montgomery Depression Rating Scale

monoamine oxidase

major depressive disorder

multidimensional fatigue inventory

major histocompatibility complex

median raphe nuclei

monozygotic

noradrenaline

natural killer

$\mathrm{N}$-methyl-D-aspartate

nucleus tractus solitarius

organum vasculosum of the lamina terminalis

pregnancy and birth complications

pegylated

prolylendopeptidase

photon emission tomography

paragigiantocellularis

polyunsaturated fatty acid

paraventricular nucleus

quinolinic acid

genotype-environment correlation

raphe nuclei

reactive oxygen species

Sibling Inventory of Differential Experience

small for gestational age

soluble interleukin

stressful life events

state-trait anxiety inventory

tricyclic antidepressant

time-dependent sensitisation 
TGF

Th cell

TNF

TRP

WHO transforming growth factor

T-helper cell

tumour necrosis factor

tryptophan

World Health Organisation 
Chapter 1

General introduction 


\section{Depression}

Depression is one of the most common psychiatric disorders. Depressed patients suffer from a persistent depressed mood and/or an inability to experience pleasure. Other prominent symptoms are decreased appetite, sleeping problems, fatigue, feelings of guilt and worthlessness, and concentration problems. In the general population around $13 \%$ report a lifetime history of major depressive disorder and around $4 \%$ experienced major depression in the past 12 months'. According to the Global Burden of Disease study, conducted by the World Health Organisation (WHO), the World Bank, and the Harvard School of Public Health, major depression will be the second leading cause of disease burden and the most important cause of disability worldwide by $2020^{2}$.

Depression is a complex disease and is associated with multiple risk factors. Psychosocial risk factors are 1) childhood adversity, such as bullying and physical or sexual abuse, poor parental bonding with, or early separation from, one or both of the parents; 2) recent stressful. life events, such as death of a close friend or relative, marital difficulties or financial crisis and 3) lack of social support. ${ }^{3}$. Other risk factors for depression are neuroticism, female sex $^{3-5}$ birth problems such as low birth weight, prenatal stress, small for gestational age and pre-term delivery ${ }^{6.9}$, and developmental deviance $^{10}$. In addition, children from lower income households are more at risk for child problem behaviour ${ }^{11}$ as are children living in a more deprived neighbourhood, controlled for social economic status ${ }^{12}$. As child problem behaviour in itself creates enduring developmental. liabilities over time that contribute to adult iliness onset and persistence, these findings are of great significance in predicting depressive disorder. In a group of children with very low birth weight that showed increased problem behaviour at the age of 8 years, evidence was found that psychopathological problems persisted, as increased prevalence of depression was reported at adolescence ${ }^{13}$.

\section{Genes and environment}

\section{Twin methodology}

Genetic factors contribute to the causation of depression as well ${ }^{14.16}$ and add to or interact with environmental factors. Twin studies provide a good means to discriminate between effects of genes and environment, where environmental factors again can be separated in shared (e.g. same school) and nonshared (e.g. different friends) environmental factors. By comparing the similarity within monozygotic (MZ) twins, who share $100 \%$ of their genes, to dizygotic (DZ) twins, who share only $50 \%$ of their genes, estimations can be made concerning the amount of variance that can be attributed to genetic, shared environmental and nonshared environmental effects ${ }^{17.18}$. Structural equation modelling is used to estimate the variance components, using a path model that represents a hypothetically causal model in which a manifest variable (a phenotypical trait) is influenced by a number of latent factors (figure 1.1). Possible 
latent factors are additive genetic $(A)$ dominant genetic (D) shared environmental (C) and nonshared environmental $(\mathbb{E})$ effects. However, due to technical reasons $D$ and $C$ can never be estimated together in the same model. Effects (regression coefficients) of these latent variables on the phenotypic trait are expressed as variances ${ }^{18}$. A criticism on the twin method is that MZ twins may not only share more genetic material, but also be more likely to share environmental factors. Prenatally, for example, $\mathrm{MZ}$ twins are twice as likely to share their chorion than $D Z$ twins and thus share more aspects of the intra-uterine environment ${ }^{19}$. In this case estimated effects of genes and environment can be distorted. Therefore, it is important that twin research takes into account the possibility that $\mathrm{MZ}$ and $\mathrm{DZ}$ twins differ in prenatal environment. Another criticism is that effects of nonshared environment and the error term cannot be separated using this method. Estimating pure nonshared environmental effects should therefore be done using direct measures instead of estimating nonshared environmental effects using a latent factor that also includes error of measurement.

\section{Gene-environment interaction and correlation}

There are several different ways in which genes may affect a psychiatric disorder ${ }^{20-25}$. Next to influencing overall liability to disorder ('main effect" of genes), they may also affect liability to disorder by influencing the sensitivity of an individual to environmental factors ('genotype $x$ environment interaction', $G \times \mathrm{E}$ ). For example, the effect of stressful life events on depression depends on the genetic make-up ${ }^{26}$. In addition, genes may affect the probability of exposure to environmental risk factors ('genotype-environment correlation', rGE). Individuals may select or create environments that correlate with their genotype. For example experiencing major life events has been shown to be partly under genetic control. Thus, genetic factors increase the likelihood to be exposed to certain environments that in turn increase the risk for depression $^{27.28}$. Furthermore, the expression of genetic and environmental effects may change during development. The same genes may have different effects at different stages of development. Genes that contribute to juvenile anxiety may also contribute to later depression ${ }^{2 !}$.

Ignoring the effects of $\mathrm{G} \times \mathrm{E}$ and $\mathrm{rGE}$ leads to imprecise estimations of genetic and environmental effects and may block the way to a comprehensive model for the roles of genes and environment in human behaviour and risk factors for psychiatric disorders ${ }^{2}$. In this thesis, we wished to examine the contributions of genetic and environmental effects to psychopathology in children, as childhood psychopathology anticipates development of adult psychiatric disorders, including depression. However, we tried to take into account the afore mentioned methodological issues, by 1) examining the effect of chorionicity, 2) assessing nonshared environmental effects using direct measures and 3) incorporating the possibility of $\mathrm{G} \times \mathrm{E}$ into the structural equation model. 


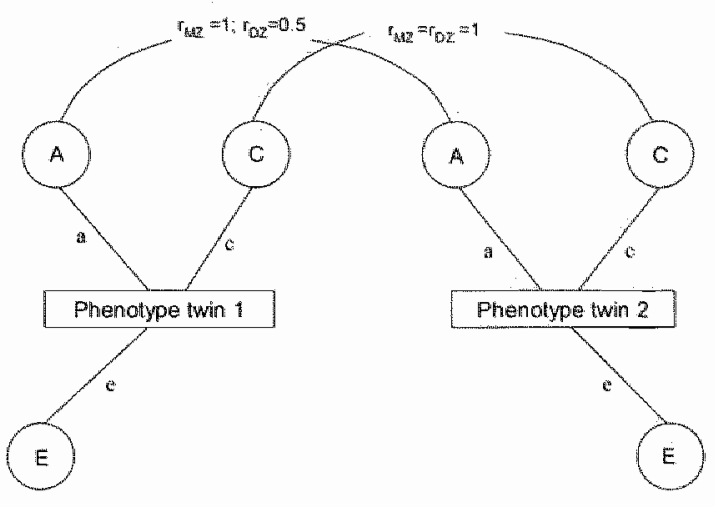

Figure 1.1 A: additive genetic effects; C: shared environmental effects; E: non-shared environmental effects; $r M Z=1$ : the correlation ( $r$ ) between the additive genetic effects of a monozygotic (MZ) twin pair is fixed at $1 ;, \mathrm{rDZ}=0.5$ : the correlation between the additive genetic efflects of a dizygotic (DZ) twin pair is fixed at $0.5 ; \mathrm{rMZ}=\mathrm{DZ}=1$ : the correlation between the shared environmental effects is fixed at 1 for both $M Z$ and $D Z$ twins, as long as they are reared together, $a_{2} c$ and $e$ : represent the regression coefficients of the latent variables $A, C$ and $E$, respectively.

\section{Biological determinants of depression}

Effects of genes and environment may act on liability to depression through their effects on biological systems linked to the regulation of mood. Several biological systems are implicated in the pathophysiology of depression. Serotonin (5-HT) metabolism is important in the regulation of mood and known to be deregulated in depressed patients $\mathrm{s}^{29,30}$. Depletion of tryptophan (TRP), the precursor of 5-HT, induces depressive symptoms in healthy volunteers, in particular those with a family history of depression $^{31,32}$. Furthermore, a subgroup of depressed patients show lowered concentrations of 5-hydroxyindoleacetic acid (5-HIAA), the major degradation product of 5-HT, in the cerebrospinal fluid (CSF), reduced tryptophan availability in plasma ${ }^{33}$ and reduced central 5-HT1A receptor binding ${ }^{33,34}$.

Abnormal hypothalamic-pituitary-adrenal (HPA) axis activity is also implicated in the pathophysiology of depression. Depressed patients exhibit elevated CSF corticotropinreleasing-hormone $(\mathrm{CRH})$ concentrations ${ }^{35}$, a blunted adrenocorticotropin hormone (ACTH) response after intravenous administration of $\mathrm{CRH}^{36,37}$, and a more chaotic diurnal pattern of cortisol secretion ${ }^{38}$. In addition, they exhibit a lack of cortisol suppression by dexamethasone, which is indicative of an impaired negative feedback function due to impaired corticosteroid receptor signalling ${ }^{39,40}$. In addition, successful treatment with antidepressants may restore this negative feedback by increasing corticoid receptor sensitivity ${ }^{41}$. 
In 1991 , Smith $^{42}$ was the first to propose the macrophage theory of depression, based on the reported association between pathological states of immune activation and depression. He proposed that excessive secretion of interleukin-1 (IL-1), a proinflammatory cytokine, and other macrophage products causes depression. In that time, the predominant view was that depressed patients suffered from immune-suppression, since they exhibit reduced natural killer (NK) cell activity and lymphocyte proliferation in response to mitogens ${ }^{43,44}$. Only by 1995 , enough evidence was collected ${ }^{45}$ that supported the notion that depression was not associated with immune-suppression only, but with an imbalance of the immune system, which was also characterised by an activation of T-helper ( $\mathrm{Th}$ )-1 cells, which stimulates the production of proinflammatory cytokines. These cytokines selectively activate T-cytotoxic cells and increase macrophage activity. Further studies have been performed showing that depressed patients show indeed increased levels pro-inflammatory cytokines and other indicators of an immune response, including neopterin, prostaglandin E2, increased concentrations of complement proteins and positive acute phase proteins (APPs) ${ }^{46-50}$.

\section{Biological pathways from immune activation to depressive symptoms}

As already mentioned, the role of immune activation in the pathophysiology of depression has become increasingly recognized. Mechanisms by which increased immune activation is linked to depression are yet unknown. However, evidence is accumulating that the immune system is not an isolated, stand alone system, but that it has bi-directional links with neuro-endocrine and neurotransmitter systems. This fact opens possibilities for hypotheses about the mechanisms where by immune activation may induce depressive symptoms.

\section{The immune system and neuro-endocrine functioning}

The immune system functions not as a isolated system in the body, but is heavily interconnected with neuro-endocrine functioning. Immune cells contain receptors for corticosteroids and neurotransmitters ${ }^{51,52}$. Brain cells, including neurons, astrocytes and microglia contain cytokine receptors and the latter two can produce and release cytokines after activation ${ }^{53}$. Although cytokines are quite large molecules and do not readily pass the blood-brain-barrier (BBB) cytokines are able to pass their signals on to the brain by pathways as described in chapter $6^{54-56}$. Pro-inflammatory cytokines as IL1 , tumour necrosis factor- $\alpha$ (TNF- $\alpha$ ) and IL- 6 have the ability to trigger the activation of the HPA axis by provoking the release of corticotropin-releasing-hormone (CRH) and arginine vasopressin (AVP) ${ }^{57,58}$. This activation results in the release of glucocorticoids that in turn temper both the immume response and CRH release ${ }^{57,59}$.

The link between immune activation and depression may also be mediated by the 5-HT system. Pro-inflammatory cytokines, mainly interferon- $\gamma$ (IFN- $\gamma)$ may reduce central 5- 
HT concentration by stimulating an enzyme called indoleamine 2,3 dioxygenase (IDO), which converts TRP, the precursor of 5-HT, into kymurenine. Overstimulation of IDO leads to depletion of plasma concentrations of TRP and therefore to reduced synthesis of 5-HT in the brain ${ }^{60}$. In addition, cytokines directly affect extraceltular 5-HT concentrations and modulate the 5-HT transporter activity ${ }^{61-6.3}$ The effects of cytokines on the HPA axis and the 5-HT system are described in more detail in Chapter 6).

\section{The immune system and neurodegeneration}

Another hypothesis is that immune activation does not act indirectly on depression by influencing the HPA ax is or 5-HT system, but that the immune activation itself causes neuronal damage. Pro-inflammatory cytokines, such as IL-1 $\beta$ and TNF- $\alpha$ may directly induce brain damage by binding to their receptors, TNF-RI and IL-1R respectively, which stimulates pathways of neuronal cell death as apoptosis and overstimulation of the N-methyl-D- aspartate NMDA receptor ${ }^{64}$. Furthermore, pro-inflammatory cytokines stimulate the enzyme IDO, which increases the production of the neurotoxic metabolites quinolinic acid (QA) and kymurenic acid (KA). Depression is associated with diffuse cortical and subcortical atrophy. Studies reported changes in the hippocampus ${ }^{65,66}$, striatum ${ }^{67,68}$ and the prefrontal cortex ${ }^{69,70}$. Therefore, it may be likely that neurodegeneration is implicated in the development of depressive symptoms. (the hypothesis that IDO increases neurotoxicity which may influence depressive symptoms is described in more detail in chapter 8 )

\section{Study design}

It is very difficult to find a good study design to examine the relationships between immune activation and depression, since cross-sectional. relationships in healthy subjects would not give information about causality. Therefore, we chose as subjects hepatitis $C$ patients that were eligible for interferon- $\alpha$ (IFN- $\alpha$ ) treatment. In this design, we were able to examine the effects of immune activation (induced by administration of IFN- $\alpha$ ) on depressive symptoms and biological changes, prospectively. To examine immune activation during treatment we decided to measure a range of cytokines since cytokines operate as a network with one cytokine stimulating a bunch of other cytokines. Second, cytokines are divided into pro- and anti-inflammatory cytokines, which together regulate the balance of immune activation. Therefore, knowledge of the activity of both groups is necessary. Furthermore, although cytokines operate using the principle of redundancy, each cytokine still has its own specialisation. The proin Tammatory cytokines IL-1, TNF- $\alpha$ and $1 \mathrm{~L}-6$ are involved in HPA axis activation ${ }^{57.58}$, the soluble IL-6 receptor may add to the biological activity of IL- $6^{71}$. Furthermore, IL-1 and TNF- $\alpha$ both have been associated with neurodegenerative effects ${ }^{64}$. The soluble IL-2 receptor is a marker for $\mathrm{T}$ cell activation ${ }^{72}$ and IL-8, another pro-inflammatory cytokine, was measured since IL-8 is a major participant in acute inflammatory reactions because of its chemo-attractant activity for leukocytes and its ability to 
activate neutrophils ${ }^{72}$. As a measure of ani-inflammatory activity $1 L-1$ receptor antagonist and $I L-10$ were measured.

\section{Impact of stress on biological systems linked to depression}

If it is true that risk factors increase the risk of depression through their effect on the above mentioned biological systems, then the risk factors should be capable of causing a long-lasting disorganisation within these systems. Stress is known to provoke physiological responses in several systems. Allostasis, the ability to achieve stability through change, is responsible for compensating responses in cardiovascular, metabolic, immune, autonomic nervous system and HPA axis in response to stress. The price of this accommodation to stress is allostatic load: cumulative lasting physiological changes ${ }^{73}$. Stress is very closely linked to neuro-endocrine changes. In fact, $\mathrm{CRH}$, the main regulating hormone of the HPA axis, plays a central role in the adaptation to stress ${ }^{74}$. Acute stress causes an increase in CRH and AVP, resulting in increased HPA axis activity and secretion of ACTH and contisol. Negative feedback control is exerted by corticosteroids causing inhibition of HPA ax is activity. In chronic stress, a consistent increase in the central drive has been reported that is characterized by increased expression of CRF $\mathrm{mRNA}$ and/or AVP MRNA, together with downregulation in the corticosteroid receptors which mediate negative feedback regulation ${ }^{75}$. Furthermore, stress impacts strongly on immune functioning, depending on the type and duration of the stressor. Acute stressors upregulate natural immunity, as reflected by increased number of $\mathrm{NK}$ cells, neutrophil numbers and increased production of the pro-inflammatory cytokines IL-6 and IFN- $\gamma$, and downregulate specific immunity, indicated by decreased proliferative responses. On the other hand, chronic stress has negative effects on both natural and specific immunity. Also, both Th1 (responsible for regulation of cellular immunity (cytotoxic $T$ cell activation)) and $T$ h 2 (responsible for regulation of humoral immunity ( $\mathrm{B}$ cell activation)) cell function is decreased during chronic stress $^{76}$. Stress may also affect the 5-HT system by causing an increase in 5-HT the median raphe nuclei (MRN) and decreases in the ventral hippocampus and medial prefrontal cortex 7 .

Early stress in particular, experienced during childhood, may bring about a cascade of neurobiological events that have the potential to cause long-lasting disorganisation of CRH circuitry, resulting in hyperresponsivity of the HPA axis when such individuals are exposed to stressful life events in adult life ${ }^{78}$. In addition, enduring changes in brain development are associated with exposure to early stress, such as reduced corpus callosum size, attenuated development of the left neocortex, hippocampus and amygdala $^{79}$. Furthermore, it is known that prenatal stress may have profound long-term consequences in HPA axis functioning. Unbalanced maternal nutrition or other stressors may induce glucocorticoid exposure to the foetus and affect the 'setting' of the HPA axis. In addition, foetal growth is slowed down by glucocorticoids ${ }^{80}$, which 
explains the relationship that exists between prenatal stress, low birth weight, altered HPA axis function and adult disease including depression and cardiovasculair disease $^{9,80-83}$. Malnutrition and prenatal stress impacts on serotonergic neurotransmission ${ }^{84-87}$ and may impact on inmune function as well. Cytokines can cross the placenta and affect the foetus ${ }^{8}$, which may induce long-lasting altered immune responses $^{89-93}$. Thus, during the whole life span, from as early as the prenatal life, allostatic load may accumulate as a consequence of stress exposure and render subjects more vilnerable to depression and other diseases. 


\section{Aims of the thesis}

In this thesis, we wished to address several topics concerning the pathophysiology of depression and contributors to the risk for depression and psychopathology. The thesis consists of three sections corresponding to our three research aims:

1) Our first aim was to examine effects of environmental and genetic risk factors on psychopathology in children

2) The second aim was to explore in depth the role of immune activation in depression

3) The third aim was to assess the effects of stress, the main risk factor for clepression, on biological systems that are linked to depression.

\section{Outline of the thesis}

\section{Part 1}

Prenatal environmental differences between $M Z$ and $D Z$ twins may cause distortion in estimated effects of genes and environment on the outcome variable. In Chapter 2, we examined whether chorion type influenced model-fitting results on child psychopathology.

In Chapter 3, we examined the effects of nonshared environmental risk factors on child psychopathology using the Sibling Inventory of Differential Experience (SIDE), a questionnaire that directly assesses the amount of differential environment. Chapter 4 and 5 describe the effects of birth weight on child psychopathology and examine genebirth weight correlation and interaction, respectively.

\section{Part 2}

This section concerns the role of inmune activation in the pathophysiology of depression. In chapter 6 an overview is given of the mechanisms by which administration of IFN- $\alpha$, a pro-inflammatory cytokine, may induce depressive symptoms. In chapter 7 another mechanism is hypothesised, namely that increased activity of the enzyme indoleamine 2,3 dioxygenase (IDO) during immune activation causes neurotoxicity that leads to depressive symptoms.

Chapter 8 describes the effects of IFN- $\alpha$ treatment in hepatitis $\mathrm{C}$ patients on the development of depressive symptoms. Chapter 9 examines the relationships between increased cytokine concentrations and depressive symptoms and the possible mediating role of the HPA axis. Chapter 10 concerns the role of IDO in the development of depressive symptoms. IDO may be involved since its activity decreases TRP concentrations leading to decreased 5-HT synthesis in the brain, and/or IDO may affect mood due to the production of toxic kynurenine metabolites. Chapter 11 examines 
whether baseline immune activation is a risk factor for developing depression during IFN- $\alpha$ treatment.

\section{Part 3}

Stress is a major risk factor for depression. The accumulation of stress throughout one's life may result in lasting changes in the HPA axis and immune system. Chapter 12 examines the effects of current stressful life events on cortisol and cytokine concentrations and examines interaction effects between early adverse experiences and genetic factors on the one hand and current stress on the other hand. 


\section{References}

1. Alonso J, Angermeyer MC, Bernert $\mathrm{S}$, et al. Prevalence of mental disorders in Europe: results from the European Study of the Epidemiology of Mental Disorders (ESEMeD) project. Acta Psychiatr Scand Suppl 2004(420):21-7.

2. Murray $C$, Lopez A. The goball burden of diseases: a comprehensive assessment of mortality and disability from diseases, injuries and risk factors in 1990 and projected to 2020. Cambridge: Harvard School of Public Health, 1996.

3. OSullivan C. The psychosocial determinants of depression: a lifespan perspective. $J$ Nerv Ment Dis 2004; $192(9): 585-94$.

4. Van Os $J$, Jones PB. Early risk factors and adult person--environment relationships in affective disorder. Psychol Med 1999;29(5):1055-67.

5. van Os J, Park SB, Jones PB. Neuroticism, life events and mental health: evidence for person-environment correlation. BPJ Psychiaty Suppl 2001;40:s72-7.

6. Gale $\mathrm{CR}$, Martyn $\mathrm{CN}$. Birth weight and later risk of depression in a national birth cohort. $\mathrm{Br}$ $J$ Pschiatry 2004:184:28-33.

7. Patton GC, Coffey C, Carlin JB, Olsson CA, Morley R. Prenaturity at birth and adolescent depressive disorder. BrJ $J$ Sychiary 2004;184:446-7.

8. Fan AP, Eaton WW. Longitudinal study assessing the joint effects of socio-economic status and birth risks on adult emotional and nervous conditions. Br J Psychiary Suppl 2001:40:s78-83.

9. Brown AS, van Os J, Driessens C, Hoek HW, Susser ES. Further evidence of relation between prenatal lamine and major affective disorder Am I P sychiatry 2000; 157(2):190-5.

10. van Os J, Jones $P$, Lewis $G$, Wadsworth $M$, Murray $R$. Developmental precursors of affective illness in a general population birth cohort. Arch Gen Psychiarry 1997;54(7):62531.

11. Johnson JG, Cohen P, Dohrenwend BP, Link BG, Brook JS. A longitudinal investigation of social causation and social selection processes involved in the association between socioeconomic status and psychiatric disorders. J Abnorm Psychol 1999;108(3):490-9.

12. Kalff $A C$, Kroes M, Vles JS, et al. Neighbourhood level and individual level SES effects on child problem behaviour: a multilevel analysis. $J$ Epidemiol Community Health $2001,55(4): 246-50$.

13. Saigal S, Pinelli J, Hoult L, Kim MM, Boyle M. Psychopathology and social competencies of adolescents who were extremely low birth weight. Pediatrics 2003:111(5 Pt 1$): 969-75$.

14. Cadoret RI. Evidence for genetic inheritance of primary affective disorder in adoptees. Am J Psychatry 1978;135(4):463-6.

15. Kendler KS, Pedersen NL, Neale MC, Mathe AA. A pilot Swedish win study of affective ilness including hospital- and population-ascertaned subsamples: results of model fitting. Behav Genet 1995;25(3):2:7-32

16. McGufin $\mathrm{P}$, Katz $\mathrm{R}$, Watkins $\mathrm{S}$, Rutherford I. A hospital-based iwin register of the heritability of DSM-IV unipolar depression. Arch Gen Psychiaty 1996;53(2):129-36.

17. Neate MC, Heath AC, Hewitt JK, Eaves LX, Fulker DW. Finting genetic models with LISREL: hypothesis testing. Behav Genet 1989;19(1);37-49.

18. Sham P. The analysis of continuous and quasi-continuous characters. Statistics in human genetics. London: Arnold Applications of statistics, 1998.

19. Philhips DI. Twin studies in medical research: can they tell us whether diseases are genetically determined? Lamcet $1993 ; 34$ (8851):1008-9.

20. Kendler $\mathrm{KS}$, Eaves LJ. Models for the joint effect of genotype and environment on liability to psychiatric illness. Am J Psychiatry 1986;143(3):279-89. 
21. Eaves $\mathbb{L}$, Silberg $\mathfrak{J}$, Erkanli A. Resolving multiple epigenetic pathways to adolescent depression. J Child Psychol Psychiatry 2003;44(7):1006-14.

22. van Os J, Marcelis M. The ecogenetics of schizophrenia: a review, Schizophr Res 1998;32(2):127-35.

23. van OS $J$, Sham $P$. Gene-environment interaction. In: Murray RM, Jones PB, Susser E, Van Os J, Cannon $M$, eds. The epidemiology of Schizophrenia. Cambridge: Cambridge University Press, 2003.

24. van Praag $H$, De Kloet ER, Van Os J. Genetics of depression. Stress, the brain and depression. Cambridge: Cambridge University Press, 2004.

25. van Praag H, De Kloet ER, Wan Os J. Gene-environment correlation and interaction in depression. Stress, the brain and depression. Cambridge: Cambridge University Press, 2004.

26. Caspi A, Sugden K, Moffutt TE, et al. Influence of life stress on depression: moderation by a polymorphism in the 5-HTT gene. Science 2003;301(5631):386-9.

27. Plom in R, Lichtenstein P, Pedersen NL, McClearn GE, Nesselroade JR. Genetic influence on life events during the last half of the life span. Psychol Aging 1990;5(1):25-30.

28. Kendler KS, Neale M, Kessler R, Heath A, Eaves L. A twin study of recent life events and difficulties. Arch Gen Psychiatry 1993;50(10):789-96.

29. Lesch KP, Beckmann H. [The serotonin hypothesis of depression]. Fortsch Newnol Psychiatr 1990;58(11):427-38.

30. van Praag H, De Kloet R, Van Os J. Monoamines and depression. Stress, the brain and depression. Cambridge: Cambridge university press, 2004.

31. Young SN, Smith SE, Pihl RO, Ervin FR. Tryptophan depletion causes a rapid lowering of mood in normal males. Psychopharmacology (Berl) 1985;87(2):173-7.

32. Benkelfat C, Ellenbogen MA, Dean P, Palmour RM, Young SN. Mood-lowering effect of tryptophan depletion. Enhanced susceptibility in young men at genetic risk for major affective disorders. Arch Gen Psychiatry 1994;51(9):687-97.

33. Maes M, Jacobs MP, Suy E, et al. Suppressant effects of dexamethasone on the availability of plasma $\mathrm{L}$ - tryptophan and tyrosine in healthy controls and in depressed patients. Acta Psychiatr Scand 1990;81(1):19-23.

34. Sargent PA, Kjaer $\mathrm{KH}$, Bench $\mathrm{Cl}$, et al. Brain serotonin $\mathrm{AA}$ receptor binding measured by positron emission tomography with [11C]WAY-100635: effects of depression and antidepressant treatment. Arch Gen Psychiary 2000;57(2):174-80.

35. Nennerof CB, Widerlow E, Bissette G, et al. Elewated concentrations of CSF corticotropinreleasing factor-like immunoreactivity in depressed patients. Science 1984;226(4680); 13424.

36. Holsboer $F$, Gerken $A$, von Bardeleben $U_{\text {, }}$ et al. Human corticotropin-releasing hormone in depression--correlation with thyrotropin secretion following thyrotropin-releasing hormone. Biol Psychiatry 1986;21(7):601-11.

37. Gold PW, Loriaux DL, Roy A, et al. Responses to corticotropin-releasing hormone in the hypercortisolism of depression and Cushing's disease. Pathophysiologic and diagnostic implications. N Engl J Med 1986;314(21):1329-35.

38. Peeters F, Nicolson NA, Berkhof J. Levels and variability of daily life cortisol secretion in major depression. Psychiary Res 2004;126(1):1-13.

39. Carroll, Curtis GC, Mendels J. Neuroendocrine regulation in depression. $\mathbb{~} \mathrm{G}$. Limbic systemadrenocortical dysfunction. Arch Gen Psychiatry 1976;33(9):1039-44.

40. Holsboer F. The corticosteroid receptor hypothesis of depression. Neuropsychopharmacology 2000;23(5):477-501. 
41. Rowe W, Steverman $A_{x}$ Walker $M$, et al. Antidepressants restore hypothalamic-pituitaryadirenal feedback function in aged, cognitively-impaired rats. Neurobiol Aging 1997;18(5): $527-33$.

42. Smith RS. The macrophage theory of depression. Med Hypotheses 1991;35(4):298-306.

43. Evans DL, Pedersen CA, Folds JD. Major depression and immunity: preliminary evidence of decreased natural killer cell populations. Prog Neuropsychopharmacol Biol Psychiatry $1988: 12(5) \times 739-48$.

44. Irwin $M$, Lacher $U_{\text {, }}$ Caldwell $C$. Depression and reduced natural killer cytotoxicity: a longitudinal study of depressed patients and control subjects. Psychol Med 1992;22(4): $1045-50$.

45. Maes M. Evidence for an immune response in major depression: a rewiew and hypothesis. Prog Neuropsychopharmacal Biol Psychiatry 1995;19(1):11-38.

46. Sluzewska $A$, Rybakowski J, Bosmans $\mathbb{E}$, et al. Indicators of immune activation in major depression. Psychiatry Res 1996;64(3):161.-7.

47. Mikova O, Yakimova R, Bosmans $\mathbb{E}$, Kenis G, Maes M. Increased serum tumor necrosis factor alpha concentrations in major depression and multiple sclerosis. Eur Newropsychopharmacol 2001;11(3):203-8.

48. Lanquillon $\mathrm{S}$, Krieg $\mathrm{JC}$, Bening-Abu-Shach $U$, Vedder $\mathrm{H}$. Cytokine production and treatment response in major depressive disorder. Neuropsychopharmacology $2000 ; 22(4): 370-9$.

49. Hestad KA, Tonseth $S$, Stoen $C D$, Ueland $T$, Aukrust P. Raised plasma levels of tumor necrosis factor alpha in patients with depression: normallization during electroconvulsive therapy. I Ect 2003; 19(4): 183-8.

50. Zorrilla EP, Luborsky L, McKay JR, et al. The relattonship of depression and stressors to immunological assays: a meta-analytic review. Brain Behov Immun 2001,15(3):199-226.

51. Besedorsky HO, del Rey A. Immune-neuro-endocrine interactions: facts and hypotheses. Endoct Rev 1996;17(1):64-102.

52. Mossner R. Lesch KP. Rolle of serotonin in the immune system and in neuroimmune interactions. Brain Behav Immun 1998; 12(4):249-71.

53. Muller N, Ackenhell M. Psychoneuroimmunology and the cytokine action in the CNS: implications for psychiatric disorders. Prog Neuropsychopharmacol Biol Psychiatry $1998 ; 22(1): 1-33$.

54. Begley DJ. Peptides and the blood-brain barrier: the status of our understanding. Ann $N Y$ Acad Sci 1994;739:89-100.

55. Blatteis CM. The afferent signalling of fever. $J$ Physiol 2000;526 Pt 3:470.

56. Ek $M_{*}$ Kurosawa $M$, Lundeberg $T_{n}$ Ericsson $A$. Activation of vagal afferents after intravenous injection of interleukin- I beta: role of endogenous prostaglandins. $J$ Neurosci $1998 ; 18(22): 9471-9$.

57. John $\mathrm{CD}_{*}$ Buckingham JC. Cytokines: regulation of the hypothalamo-pituitaryadrenocortical axis. Cur Opin Pharmacol 2003;3(1):78-84.

58. Tumbull AV, Rivier CL. Regulation of the hypothalamic-pituitary-adrenal axis by cytokines: actions and mechanisms of action. Physiol Rev 1999;79(1):1-71.

59. Miller DB, O'Callaghan JP. Neuroendocrine aspects of the response to stress. Metabolism 2002;5\|(6 Supp》1):5-10.

60. Heyes MP, Saito K, Crowley IS, et al. Quinolinic acid and kynurenine pathway metabolism in inflammatory and non-inflammatory neurological disease. Brain 1992;115(Pt 5):1249 73.

61. Clement HW, Buschmann J, Rex S, et al. Effects of interferon-gamma, interleukin- 1 beta, and tumor necrosis factor-alpha on the serotonin metabolism in the nucleus raphe dorsalis of the rat. J Neural Transm 1997;104(10):981-91. 
62. Mossner R, Heils A, Stober G, Okladnova O. Damel S, Lesch K.P. Enhancement of serotonin transporter function by tumor necrosis factor alpha but not by interleukin-6. Newrochem Int 1998; 33(3):251-4.

63. Mossner R, Daniel S, Schmitt A, Albert D, Lesch KP. Modulation of serotonin transporter function by interleukin-4. Life Sci $2001 ; 68(8): 873-80$.

64. Viviani $B$, Bartesaghi $S$, Corsini $E_{s}$ Galli $C L$, Marinovich M. Cytokines role in neurodegenerative events. Toxicol Let 2004;149(1-3):85-9.

65. Sheline YI, Sanghavi M, Mintun MA, Gado MH. Depression duration but not age predicts hippocampal volume loss in medically healthy women with recurrent major depression. $J$ Newrosci $1999 ; 19(12): 5034-43$.

66. Bremner JD, Narayan M. Anderson ER, Staib LH, Miller HL, Charney DS. Hippocampal volume reduction in major depression. Am I Psychiary 2000;157(1):115-8.

67. Krishnan KR, McDonald WM, Escalona PR, et al. Magnetic resonance imaging of the caudate nuclei in depression. Preliminary observations. Arch Gen Psychatry 1992;49(7): $553-7$.

68. Husain MM, McDonald WM, Doraiswamy PM, et al. A magnetic resonance imaging study of putamen nuclei in major depression. Psychiary Res 1991;40(2):95-9.

69. Ongur D, Drevets WC, Price JL. Glial reduction in the subgenual prefrontal cortex in mood disorders. Proc Nat Acad Sci U S A 1998;95(22):13290-5.

70. Rajkowska $\mathrm{G}$, Miguel-Hidalgo $J \mathrm{~J}$, Wei $\mathrm{J}$, et al. Morphometric evidence for neuronal and glial prefrontal cell pathology in major depression. Biol Psychiatry 1999;45(9):1085-98.

71. Peters M, Muller AM, Rose-John S. Interleukin- 6 and soluble interleukin-6 receptor: direct stimulation of gp130 and hematopoiesis. Blood 1998;92(10):3495-504.

72. Oppenheim JJ, Ruscetti FW, Faltynek C. Cytokines. In: Stites DP, Terr Al, Parslow T, eds. Basis \& clinical immunology. Stamford, Connecticut: Appleton \& Lange, 1994: 870.

73. McEwen BS. Protective and damaging effects of stress mediators. $N$ Eng/ J Med $1998 ; 338(3): 171-9$.

74. Claes SJ. Corticotropin-releasing hormone (CRH) in psychiatry: from stress to psychopathology. Ann Med 2004;36(1):50-61.

75. Checkley S. The neuroendocrinology of depression and chronic stress. Br Med Bull 1996,52(3):597-617.

76. Segerstrom SC, Miller GE. Psychological stress and the human immune system: a metaanalytic study of 30 years of inquiry. Psychol Bull 2004;130(4):601-30.

77. Adell A, Casanovas JM, Artigas F. Comparative study in the rat of the actions of different types of stress on the release of 5 -HT in raphe nuclei and forebrain areas. Newopharmacology 1997;36(4-5):735-41.

78. Gutman DA, Nemeroff CB. Persistent central nervous system effects of an adverse early environment: clinical and preclinical studies. Physiol Behav 2003;79(3):471-8.

79. Teicher $\mathrm{MH}_{3}$ Andersen SL, Polcari A, Anderson CM, Navalta CP, Kim DM. The neurobiological consequences of early stress and childhood maltreatment. Neurosci Biobehav Rev 2003;27(1-2):33-44.

80. Bertram CE, Hanson MA. Prenatal programming of postnatal endocrine responses by glucocorticoids. Reproduction 2002;124(4):459-67.

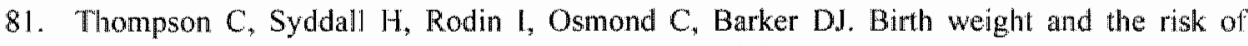
depressive disorder in late life. Br. J Psychiarry 2001;179:450-5.

82. Hamption T. Fetal environment may have profound long-term consequences for health. Jama 2004;292(1.1):1285-6.

83. Strik JJ, Honig A, Maes M. Depression and myocardial infarction: relationship between heart and mind. Prog Neuropsychopharmacol Biol Psychiatry 2001;25(4):879-92. 
84. Kelioe P, Mallinsen K, Bronzino J, MeCormick CM. Effects of prenatal protein malmutrition and neonatal stress on CNS responsiveness. Brain Res Dev Brain Res 2001; 132(1):23-31.

85. Mokler DJ, Galler JR, Morgane P\&. Modulation of 5-HT release in the hippocampus of 30 day-old rats exposed in utero to protein malnutrition. Brain Res Dev Brain Res $2003: 142(2): 203-8$.

86. Peters DA. Matemal stress increases fetal brain and neonatal cerebral cortex 5 hydroxytryptamine synthesis in rats: a possible mechanism by which stress influences brain development. Pharmacol Biachem Behav 1990;35(4):943-7.

87. Slotkin TA, Bames GA, McCook EC, Seidler FJ. Programming of brainstem serotonin transporter development by prenatal glucocorticoids. Brain Res Dev Brain Res 1996;93 $(1-2): 155-61$.

88. Urakubo A, Jarskog LF, Lieberman JA, Gilmore JH. Prenatal exposure to matemal infection alters cytokine expression in the placenta, amniotic fluid, and fetal brain. Schizophr Res 2001;47(1):27-36.

89. Vance GH, Holloway JA. Early life exposure to dietary and inhalant allergens. Pediatr Allergy Inwmonol 2002;13 Suppl 15:14-8.

90. Warner JA, Jones CA, Jones AC, Wamer JO. Prenatal origins of allergic disease. J Allergy Clin Immunol 2000;105(2 Pt 2):5493-8.

91. Holladay SD. Prenatal immunotoxicant exposure and postnatal autommune disease. Environ Health Perspect 1999;107 Suppl 5:687-91.

92. McDade TW, Beck. MA, Kuzawa CW, Adair LS. Prenatal undernutrition and postnatal growth are associated with adolescent thymic function. I Nutr 2001;131(4):1225-31.

93. Kay G, Tarcic N, Poltyrev $T$, Weinstock M. Prenatal stress depresses immune function in rats. Physiol Behow 1998;63(3):397-402. 


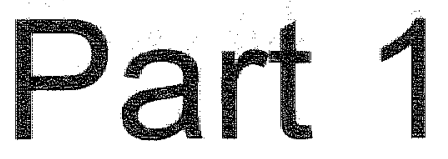

Twin research and risk factors for child psychopathology 


\section{Chapter}

\section{Chorion type and twin similarity for child psychopathology}

Marieke Wichers, Marina Danckaerts, Sofie Van Gestel, Catherine Derom, Robert Vlietink, Jim van Os

Archives of General Psychiatry 2002;59:562-4 


\section{Abstract}

\section{Background}

Twin studies suggest significant genetic influence on childhood psychiatric symptoms. However, as the prenatal enwironments of monozygotic and dizygotic twins are not similar, estimates of heritability may be unteliable. Most monozygotic twins are monochorionic, whereas the remaining monozygotic twins and all dizygotic twins are dichorionic, resulting in differences in placentation between monochorionic and dichorionic twins.

\section{Methods}

The East Flanders Prospective Twin Survey is unique, in that placentation and zygosity is recorded at birth for all twin pairs born in East Flanders, Belgium. We used structural equation modelling to examine the influence of zygosity and chorionicity on parent-rated Child Behaviour Checklist total problem scores in 760 twin pairs aged $6-17$ years.

\section{Results}

The best fitting model for the total problem score was one that included the influences of additive genetic (A), shared environmental (C) and umique environmental (E) influences. There was no suggestive or significant contribution of the latent variable, $\mathrm{Ch}$, representing chorionicity, to the model of childhood psychopathology.

\section{Conclusions}

Chorionicity may not be a confounding factor in twin studies of childhood psychiatric symptoms. Given the evidence of continuty between childhood and adult psychopathology, these findings may also have relevance for twin studies of adult mental health. 


\section{Introduction}

Twin studies suggest significant genetic influence on all dimensions of childhood problem behaviour measured with the Child Behaviour Checklist (CBCL)', which may increase with $\operatorname{age}^{2-5}$. However, such twin studies have been criticised for assuming that monozygotic (MZ) and dizygotic (DZ) twins have similar prenatal environment $\mathrm{s}^{6-8}$. $\mathrm{MZ}$ twins share the same chorion in the majority of cases (monochorionic - MC), whereas all $\mathrm{DZ}$, and around a third of all $\mathrm{MZ}$ twins are of the dichorionic (DC) type $\mathrm{e}^{6,9}$. The importance of these differences lies in the effects they have on placental development. Because the placenta is formed of chorionic tissue, DZ and MZ-DC twins will have separate placentas. Although these placentas may fuse macroscopically, fusion of two separate placentas only rarely results in direct vascular anastomoses in human twins $s^{6,70,11}$ suggesting that their placentas remain functionally separate. However, MZ-MC twins share the same placenta. This results in competition between the twins for nutritions, which makes them substantially lighter at birth than other twins ${ }^{6}$. In addition, sharing the same placenta may more often result in shared exposure to a prenatal environmental risk factor for psychopathology, resulting in "environmental" concordance ${ }^{12-14}$. Earlier studies suggested higher concordance rates for schizophrenia ${ }^{15}$ and less intrapair differences for poor self-control, social incompetence and internalising symptoms ${ }^{16}$ in $\mathrm{MC}$ than in DC co-twins.

On the other hand, the occurrence of the twin transfusion syndrome in MZ-MC twins may result in greater within-pair variability for a range of birth outcomes that could influence subsequent mental health, and thus contribute to a greater degree of discordance for childhood psychiatric symptoms in MZ-MC twins.

If twin studies do not consider differences in prenatal environment occasioned by chorionicity, too much causal influence could be attributed to either genetic or environmental factors. Because childhood psychiatric symptoms are a risk factor for adult psychiatric outcomes ${ }^{17,18}$, adult heritability estimates could be similarly confounded.

\section{Methods}

\section{Subjects}

The "East Flanders Prospective Twin Survey" collects information, since 1964, on the mother, the placenta and the child in $98 \%$ of multiple births in East Flanders, Belgium. At present, the register counts more than 5600 twin pairs ${ }^{19}$. Zygosity and chorionicity are determined by examination of foetal membranes, blood groups and, since 1982, by examination of five highly polymorphic DNA markers ${ }^{20}$. Probabillity of zygosity in same-sex DC pairs is calculated by sequential analysis ${ }^{20}$. To be included in the analysis, all the DC-MZ pairs had to reach a probability of monozygosity of at least $95 \%$. Twins aged 6 to 17 years were selected for the present study. Questionnaires 
were sent to the 1436 parents of these twin pairs, of which 760 returned the questionnaires. Of these, 425 were DZ (217 same-sex and 208 opposite sex pairs), 125 were MZ-DC and 202 were MZ-MC. Six pairs with major congenital malformations were excluded, as were 2 pairs with unknown zygosity and an implausible registered birth weight.

\section{Measures}

Parents gave written informed consent, and completed the $\mathrm{CBCL}^{21}$. This questionnaire measures the extent to which children have behavioural and emotional problems as seen by the parents. Although the CBCL allows for the calculation of 8 separate scores corresponding to several behavioural dimensions, large-scale population studies show inadequate empirical support for these syndromes and their differentiation ${ }^{22}$. Instead, a general problem behaviour factor appears to underlie CBCL data across different age groups ${ }^{22,23}$. We therefore examined the total amount of psychiatric symptoms, as measured by the total problem score, subjected to a square-root transformation to achieve normality.

\section{Statistical analysis}

Structural equation modelling was used to fit theoretically motivated models to the CBCL data ${ }^{24,25}$. Twin models of psychiatric symptoms usually assume an effect of 4 latent variables on observed phenotypic variance: additive genetic effects (A), dominance genetic effects (D), effects of shared environment (C) and effects of nonshared environment (E). Model fitting is used to determine which model best fits the data. Models assuming influences of different latent variables, such as $\mathrm{AE}, \mathrm{ACE}$ or ADE models, are compared with each other to determine which one represents the best compromise between goodness of fit (using model $\chi^{2}$-values) and parsimony (using some information criterion such as the Akaike information criterion ${ }^{24.26}$ ). The relationship between the latent variables and the observed data is usually examined in 2 populations: $\mathrm{MZ}$ and $\mathrm{DZ}$ twins. In the present study, 3 populations were used: $\mathrm{MZ}-\mathrm{MC}$, $M Z-D C$ and $D Z$. In addition, we added a fifth latent variable, Ch, representing chorionicity, which was shared between MZ-MC twins (correlation, 1) and nonshared between MZ-DC and DZ twins (correlation, 0).

\section{Results}

The correlation for CBCL scores was 0.64 in DZ pairs, 0.82 in MZ-DC pairs and 0.83 in MZ-MC pairs. The AE-model in the table assumes that the variance consists of only 2 factors: the additive genetic $(A)$ and the nonshared environmental $(E)$ factors. This model had a low goodness of fit $(p<0.001)$. The models $C E, E$ and $A D E$ could be rejected as well. The fifth model included the additive genetic factor $(A)$, the shared 
environmental factor (C) and the nonshared environmental factor (E). The goodness of fit of this model was high $(\mathrm{p}=0.53)$. When the factor chorionicity $(\mathrm{Ch})$ was added to the ACE-model the $\chi^{2}$-value did not significantly worsen, but this factor did not contribute anything to the variance of the total $C B C L$ problem score (table 2.1). Therefore, the ACE model was the best compromise between goodness of fit and parsimony, as indicated by the smallest Akaike information criterion. Splitting up the sample into twins younger and older than the median age revealed similar results for both groups.

Table 2.1 Variance components and fit statistics of several models for CBCL total phoblem score".

\begin{tabular}{lccccccccc}
\hline Model & $\mathrm{a}^{2}$ & $\mathrm{c}^{2}$ & $\mathrm{~d}^{2}$ & $\mathrm{e}^{2}$ & $\mathrm{ch}^{2}$ & $\chi^{2}$ & $\mathrm{AIC}$ & $\mathrm{df}$ & $\mathrm{P}$ \\
\hline $\mathrm{AE}$ & 0.84 & $\ldots \ldots$ & $\ldots \ldots$ & 0.16 & $\ldots \ldots$ & 42.76 & 34.76 & 4 & 0.001 \\
$\mathrm{CE}$ & $\ldots \ldots$ & 0.72 & $\ldots \ldots$ & 0.28 & $\ldots \ldots$ & 59.40 & 51.40 & 4 & $<0.001$ \\
$\mathrm{E}$ & $\ldots \ldots$ & $\ldots \ldots$ & $\ldots \ldots$ & 1.00 & $\ldots \ldots$ & 596.56 & 586.56 & 5 & $<0.001$ \\
$\mathrm{ADE}$ & 0.84 & $\ldots \ldots$ & 0.00 & 0.16 & $\ldots \ldots$ & 42.78 & 36.78 & 3 & $<0.001$ \\
$\mathrm{ACE}$ & 0.41 & 0.43 & $\ldots \ldots$ & 0.17 & $\ldots \ldots$ & 2.21 & -3.80 & 3 & 0.53 \\
ACE-Ch & 0.41 & 0.42 & $\ldots \ldots$ & 0.16 & 0.00 & 4.96 & 0.96 & $2^{\circ}$ & 0.42 \\
\hline
\end{tabular}

"CBCL indicates Child Behaviour Checklist; AlC, Akaike information criterion; A, additive genetic effects; $\mathrm{E}$, eflects of nonshared environment; $\mathrm{C}$, effects of shared environment; $\mathrm{D}$, dominance genetic effects; Ch, chorionicity; $\mathrm{a}^{2}, \mathrm{c}^{2}, \mathrm{~d}^{2}, \mathrm{e}^{2}, \mathrm{ch}^{2}$ proportion of variance; and ellipses, data not applicable

- Rectified data, different from publication in Archives of General Psychiatry 2002

\section{Comment}

Previous work in much smaller samples suggests that chorionicity does not affect measures of temperament and cognition in children", although it may possibly influence some dimensions of personality ${ }^{9,16}$. The present results suggest that chorionicity is not a confounding factor in twin studies of childhood psychopathology using the $\mathrm{CBCL}$, and that causal influence may be rightly distributed over environmental and genetic factors. In as much as childhood psychiatric symptoms are a risk factor for adult psychopathological outcomes ${ }^{17,18}$, similar unconfounded environmental and genetic effects on risk can be postulated. 


\section{References}

1. Achenbach TM. Integrative guide for the 1991 CBCL/4-18, YSR, and TRF profiles. Burlington: University of Vermont, Department of Psychiatry, 1991.

2. Edelorock $C_{3}$ Rende R. Plomin R, Thompson LA. A twin study of competence and problem behavior in childhood and early adolescence. J Child Psychol Psychiatry 1995;36(5): $775-85$.

3. Schmitz S, Fulker DW, Mrazek DA. Problem behavior in early and middle childhood: an initial behavior genetic analy sis. J Child Psychol Psychictry 1995;36(8):1443-58.

4. wan der Valk JC, Verhulst FC, Stroet TM, Boomsma DI. Quantitative genetic analysis of internalising and externalising problems in a large sample of 3-year-old twins. Twin Res 1998; (1):25-33.

5. van den Oord EJ, Verhulst FC, Boomsma DI. A genetic study of maternal and paternal ratings of problem behaviors in 3-year-old twins. J Abnorm Psychol 1996; 05(3):349-57.

6. Pbillips DI. Twin studies in medical research: can they tell us whether diseases are genetically determined? Lancer 1993;341(8851):1008-9.

7. Prescott CA, Johnson RC, McArdle JJ. Chorion type as a possible influence on the results and interpretation of twin study data. Twin Res 1999;2(4):244-9.

8. Piontelli A, Bocconi L, Boschetio C, Kustermann A, Nicolini U. Differences and similarities in the intra-uterine behaviour of monozygotic and dizygotic twins. Twin Res 1999;2(4):264-73.

9. Riese ML. Effects of chorion type on neonatal temperament differences in monozygotic twin pairs. Behow Genet 1999;29(2):87-94.

10. Benirschke $K$. The biology of the twinning process: how placentation influences outcome. Sewin Perinatol 1995;19(5):342-50.

11. Bhargava 1, Chakravarty $\mathrm{A}$. Vascular anastomoses in twin placentae and their recognition. Acra Anar 1975;93(3):471-80.

12. Glover V. Matemal stress or anxiety in pregnancy and emotional development of the child. Br.J Psychiary 1997;171:105-6.

13. Brown AS, van Os J, Driessens C, Hoek HW, Susser ES. Further evidence of relation between prenatal famine and major affective disorder. Am J Psychiory 2000;157(2):190-5.

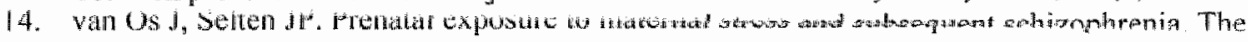
May 1940 invasion of The Netherlands. BP J Psychiatry 1998;172:324-6.

15. Davis JO, Phelps JA, Bracha HS. Prenatal development of monozygotic twins and concordance for schizophrenia. Schizophr Bull 1995;21(3):357-66.

16. Sokol DK, Moore CA, Rose R.J, Williams CJ, Reed T, Christian JC. Intrapair differences in personality and cognitive ability among young monozygotic twins distinguished by chorion type. Behaw Genet 1995;25(5):457-66.

17. Jones $P$, Rodgers $B$, Murray $R$, Marmot M. Child development risk factors for adult schizophrenia in the British 1946 birth cohort. Lancel 1994;344(8934):1398-402.

18. van Os J, Jones $P$. Lewis $G$, Wadsworth $M$, Murray $R$. Developmental precursors of affective illness in a general population birth cohort. Arch Gen Psychiatry 1997;54(7): 625-31.

19. Loos R, Derom C, Vlietinck R, Derom R. The East Flanders Prospective Twin Surwey (Belgium): a population-based register. Twin Res 1998; 1(4):167-75.

20. Vlietinck R. Determination of the zygosity of twins. Doctoral thesis: KU, 1986.

21. Verhulst FC, van der Ende J, Koot HM. Handleiding voor de CBCL/4-18. Rotterdam: adeling kinder- en jeugdpsychiatrie, Sophia Kinderziekenhuis/Academisch Ziekenhuis Rotterdam, Erasmus Universiteit Rotterdam, 1996. 
22. Hartman CA, Hox J, Auerbach J, et al. Syndrome dimensions of the child behavior checklist and the teacher report form: a critical empinical evaluation. I Child Psychol Psychiatry 1999;40(7):1095-116.

23. Greenbaum PE, Dedrick RF. Hierarchical confirmatory factor analysis of the Child Behavior Checklist/4-18. Psychological Assessment 1998;10(2):149-55.

24. Sham P. Statistics in human genetics. London: Arnold Applications of statistics, 1998.

25. Neale $\mathrm{MC}$, Heath $\mathrm{AC}$, Hewitt JK, Eaves LJ, Fulker DW. Fitting genetic models with LISREL: hypothesis testing. Behov Genet 1989;19(1):37-49.

26. Akaike H. Factor analysis and AIC. Psychomerika 1987;52:317-332. 


\section{Associations between nonshared environment and child problem behaviour}

Marieke Wichers, Jim van Os, Marina Danckaerts, Sofie Van Gestel, Catherine Derom, Robert Vlietinck

Social Psychiatry and Psychiatric Epidemiology 2001:36:319-23 


\section{Abstract}

\section{Background}

Twin studies suggest that environmental effects on the development of child psychopathology largely involve nonshared environmental processes. However, the influence of the nonshared environment may have been overestimated, as the relationship between environment and behaviour may be genetically mediated. A direct measure of the nonshared environment (using the Sibling Inventory of Differential Experience -SIDE) was investigated in relation to child psychopathology, and tested for possible genetic mediation.

\section{Methods}

Parent-rated wersions of the Child Behaviour Checklist (CBCL) and the SIDE were collected in 760 twin pairs aged 6-17 years. Multilevel regression analysis was used to assess the influence of SIDE scores on CBCL total problem scores, internalising symptoms, externalising symptoms and depressive symptom scores. Genetic mediation was assessed by examining interaction with zygosity in the association between SLDE scores and differences in CBCL scores (absence of interaction indicating no genetic mediation).

\section{Results}

The results revealed significant associations between SIDE dimensions on the one hand, and degree of internalising, externalising, depression and total symptom scores on the other. However, the effects were non-linear, and especially apparent for the extremes of differential. environmental experience within twin pairs. Overall, there was no strong evidence for genetic mediation of associations between nonshared environment and symptoms.

\section{Conclusions}

Direct, genetically unconfounded but skewed relationships may exist between nonshared environment on the one hand and behavioural differences on the other, although longitudinal data are necessary to determine the direction of effects. 


\section{Introduction}

Most forms of childhood psychopathology are subject to substantial genetic influences'. However, behavioural-genetic research seldom finds evidence that more than half of the variance for complex behavioural traits is due to genetic differences among individuals, suggesting an important role of the environment ${ }^{2}$.

Environmental influences on phenotypic variance can be separated into its shared and nonshared components. According to Plomin and Daniels ${ }^{2}$, the environmental effects on the development of child behaviour largely involve nonshared environmental processes that make children in the same family different from one another ${ }^{2}$. The most direct evidence for the importance of the nonshared environment comes from the relatively low correlations and concordance rates in identical twins for depression, schizophrenia and personality ${ }^{3}$. In addition, previous studies using structural equation modelling of child problem behaviour showed substantial influences of the nonshared environment ${ }^{3 \sim 5}$.

However, the nonshared environmental contribution identified in traditional behavioural studies includes error of measurement ${ }^{6}$. Recent data showed that nonshared environmental effects are greatly reduced when measurement error is eliminated ${ }^{7,8}$. Another problem that occurs when estimating the importance of nonshared environmental influences is that there are genetic influences on individual differences in measures of environmental experience ${ }^{7}$. Thus, genetic factors may be involved in the way children select, modify and create the environments that they experience?. Baker and Daniels ${ }^{\| 0}$ conducted a twin study, in which differences in self-reported environments of monozygotic $(M Z)$ twins were compared to those of dizygotic $(D Z)$ twins. MZ twins' reports showed consistently less difference than those of DZ twins, especially for characteristics of the siblings' peer groups ${ }^{10}$. These data suggest that youngsters may select their peer groups according to their own heritable characteristics", assuming that the equal environment assumption is walid. If environmental measures are influenced genetically, then it is possible that associations between environmental measures and behavioural outcomes are mediated genetically as well.

In the great majority of studies, no direct measures of the nonshared environment are available. In the present twin study, the influence of the nonshared environment was measured using the Sibling Inventory of Differential Experience (SIDE). The SIDE compares the experiences of individuals with those of his or her sibling in the domains of sibling interaction, parental treatment, peer characteristics and events specific to the individual ${ }^{12}$. The SIDE should thus provide a direct measure of nonshared environmental effects. Previous work suggests that SIDE measures of nonshared enviromment have an influence on externalising behaviour ${ }^{3,6,13,14}$, internalising behaviour ${ }^{6,13}$ and depression ${ }^{3,6,10,13}$.

To test for genetically mediated relationships between nonshared enviromment and child psychopathology, the relationship between experiential differences within $M Z$ 
twin pairs and their degree of problem behaviour was compared with the relationship within $D Z$ twin pairs. If the association between experiential differences and degree of problem behaviour in a mixed population of $M Z$ and $D Z$ twins is due to a shared genetic factor that influences both characteristics, the correlations between both traits will be greater for $D Z$ than for $M Z$ twins. For example, let differences in a measure of the nonshared environment (the exposure) only be associated with degree of child problem behaviour (the outcome) in a population of $\mathrm{MZ}$ and $\mathrm{DZ}$ twins because some underlying genetic factor influences both traits. In this case, the apparent effect of the nonshared environmental exposure is confounded by the real effect of the genetic exposure. Therefore, within $\mathrm{MZ}$ twin pairs, no matter how discordant they are for the apparent exposure, the apparent exposure will not be associated with the outcome. This is because even though the MZ twins may be discordant for the apparent exposure, they are still completely concordant for the real (genetic) exposure as they share $100 \%$ of their genes. In DZ twin pairs, however, discordance in general not only reflects environmental influences, like it does in MZ twins, but also genetic differences, so that within-pair discordance for the apparent exposure will be associated with discordance for the outcome to the degree that it reflects genetic differences in the real exposure ${ }^{2}$.

\section{Subjects and methods}

\section{Subjects}

Since 1964, the 'East Flanders Prospective Twin Survey' collects information on the mother, the placenta and the child in 98\% of multiple births in East Flanders, Belgium. At present, the register counts more than 5600 twin pairs ${ }^{15}$. The zygosity and chorionicity of the twins are determined by examination of the fetal membranes, blood groups and, since 1982 , by examination of five highly polymorphic DNA markers ${ }^{16}$. Probability of zygosity in same-sex DC pairs is calculated by sequential analysis ${ }^{16}$. To be included in the analysis, all the dichorionic $\mathrm{MZ}$ pairs had to reach a probability of monozygosity of at least 95\%. Twins aged 6-17 years were selected for the present study. Questionnaires were sent to the 1436 parents of these twin pairs, of which 760 returned the questionnaires. Of the 760 pairs, $425(57 \%)$ were DZ and $326(43 \%)$ were MZ twins. Nine pairs were excluded from the analyses because of major congenital malformations (six pairs), missing zygosity (one pair), implausible birth weight data (one pair) and an implausibly high total SIDE score (one pair).

\section{Measures}

Parents gave written informed consent in accordance with the local ethics committee guidelines. Parents lilled in the Child Behaviour Checklist (CBCL) ${ }^{17}$. This questionnaire was developed to examine the extent to which children have behavioural and emotional problems as perceived by the parents. The total amount of 
psychopathology is measured by the total problem score. In addition, the CBCL allows for the calculation of eight separate scores corresponding to the following behavioural dimensions: withdrawn, somatic complaints, anxious/depressed, social problems, thought problems, attention problems, delinquent behaviour and aggressive behaviour. From these eight scores, two dimensions of internalising and externalising symptoms with high face validity can be constructed. For internalising symptoms, scores of three dimensions are added: withdrawn, somatic complaints and anxious/depressed; for externalising symptoms the scores of two dimensions - delinquent behaviour and aggressive behaviour - are added ${ }^{17}$. Guided by the previous literature ${ }^{3,6,10,13,14}$ we included, apart from the CBCL total score, three other CBCL dimensions: i) internalising symptom score, ii) externalising symptom score and iii) the anxiety/depression score.

Total problem score, internalising, externalising and anxiety/depression scores were subjected to a square-root transformation to achieve normality. A measure of the relative differences in total child psychopathology, internalising symptoms, externalising symptoms and anxiety/depressive symptoms within twin pairs was constructed, calculated as follows: [CBCL score of twin with higher score-CBCL score of twin with lower score] / [CBCL score of twin with higher score].

The SIDE $^{12}$ is designed to assess nonshared family environmental differences between two siblings. The SIDE contains 73 statements describing differences in parental treatment, sibling interactions, peer group characteristics and specific events ${ }^{12}$. However, in this study a slightly abbreviated version of the SIDE was used (12 items not suitable for younger children such as "breaking up with boyfriend" and "use of marijuana" were eliminated). A parent-rated version of the SIDE questionnaire was used, in which parents of all twins were asked to respond to each of these items on a five-point scale indicating the amount and direction of difference between the two siblings. Previous work has shown that by averaging several related items, 12 dimensions can be derived: sibling antagonism, sibling care taking, sibling jealousy, sibling closeness, maternal affection, maternal control, paternall affection, paternal control, peer college orientation, peer delinquency, peer popularity and events specific to the individual ${ }^{10,12}$. Missing values were taken into account by constructing the dimensional scores on the basis of non-missing items only, and dividing the subsequent score by the number of items contributing to the score.

The five-point rating scale results in a relative scoring system of differential sibling experience and provides information on the amount and the direction of differential experience as seen by the parents: which sibling has more conflict and how much more, which sibling is receiving less parental love and how much less, which sibling has more popular peers and how much more and so forth ${ }^{12}$. 


\section{Statistical analysis}

Mean SIDE scores for $M Z$ and $D Z$ twins were computed for each SIDE dimension. Associations between nonshared environmental influences and child psychopathology were assessed by regression analysis. Because the members of one twin pair cannot be considered independent statistically, a multilevel random regression procedure was carried out using the XTREG procedure in STATA ${ }^{18}$, thus taking account of the fact that level-one units (level of individual twins) were clustered into level-two units (level of the pairs). This procedure gives more realistic estimates of standard errors that otherwise might be underestimated, giving rise to spuriously low p-values. All analyses were corrected a priori for the possible confounders age, zygosity, same-sex or opposite-sexpair, and individual sex of the siblings.

First, regression analyses were performed for all SIDE dimensions and the dimensions of internalising, externalising symptoms, anxiety/depression symptoms and total symptom score, using relative SIDE scores, to examine the associations of relative within-pair differences in nonshared environment on the one hand and individual degree of child psychopathology on the other. Second, for all significant associations, squared SIDE dimension variables were added to the equation in order to assess departure from linearity. Interaction effects were hypothesised for zygosity as described above. In addition, we tested for interaction with sex.

In order to examine the possibility of type I errors due to multiple comparisons, the expected number of significant $p$-values based on chance was compared with the actual number.

\section{Results}

The means of the relative SIDE scores for $\mathrm{MZ}$ and $\mathrm{DZ}$ twins are depicted in table 3.1. Significant associations between differential sibling jealousy and all dimensions of problem behaviour i.e. externalising, internalising, depression and total symptom score, were found (table 3.2). The more jealous the proband was of the other sibling, the more psychopathology he or she displayed. The same was true for the dimension of specific events (being differentially influenced by an accident, illness, death of al loved one etc): the more events impacted more specifically on the proband, relative to the other sibling, the more psychopathology he or she was likely to display.

More sibling antagonism, maternal control, paternal control, peer delinquency and less peer college orientation relative to the other sibling was significantly associated with a higher externalising and total symptom score. In addition, less peer popularity relative to the other sibling was associated with a higher internalising and depression symptom score. Furthermore, less sibling care taking was associated with a higher total symptom score, less sibling closeness with a higher externalising symptom score and more maternal affection with a higher depression symptom score. 
Table 3.1. Mean scores and standard deviations of all Sibling lnventory or Diferential Experience (SIDE) dimensions for monozygotic (MZ) and dizygotic (DZ wins).

\begin{tabular}{lcccc}
\hline Side dimensions & \multicolumn{2}{c}{$\mathrm{MZ}$} & \multicolumn{2}{c}{$\mathrm{DZ}$} \\
& mean & sd & mean & sd \\
\hline Sibling antagonism & 0.68 & 0.40 & 0.80 & 0.41 \\
Sibling cartaking & 0.85 & 0.41 & 0.98 & 0.44 \\
Sibling jealousy & 0.60 & 0.38 & 0.72 & 0.45 \\
Sibling closeness & 0.56 & 0.47 & 0.71 & 0.50 \\
Matemal affection & 0.17 & 0.28 & 0.23 & 0.30 \\
Maternal control & 0.19 & 0.30 & 0.28 & 0.36 \\
Paternal affection & 0.15 & 0.24 & 0.25 & 0.32 \\
Paternal control & 0.17 & 0.30 & 0.33 & 0.42 \\
Peer college orientation & 0.28 & 0.33 & 0.52 & 0.45 \\
Peer delinquency & 0.16 & 0.26 & 0.30 & 0.37 \\
Peer popularity & 0.33 & 0.41 & 0.56 & 0.49 \\
Specific events & 0.59 & 0.59 & 0.77 & 0.56 \\
\hline
\end{tabular}

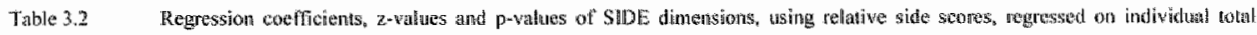
problem soore, externalising, internatising and depression symptom seore.

\begin{tabular}{|c|c|c|c|c|c|c|c|c|c|c|c|c|}
\hline \multirow[t]{2}{*}{ Side dimensions } & \multicolumn{2}{|c|}{ Total CBCL score } & \multicolumn{3}{|c|}{ Exturnathinsing swoune } & \multicolumn{3}{|c|}{ Internalising seore } & \multicolumn{4}{|c|}{ Deplession swone } \\
\hline & regrectider & $z$-value & p-value & regronef & z-value & p-value & regrecer & z-value & poxalue & thengent & fowalno & p vatuce \\
\hline Sibing antagonlss:n: & 0.247 & 3.28 & $0.001^{\mathrm{c}}$ & 0,368 & 6.60 & $0.0100^{4 / 4}$ & 0.099 & 1.95 & 0.052 & 0.068 & 1.54 & 0,124 \\
\hline Sibling cartaking & -1.487 & -2.19 & $0.028^{2}$ & -0.027 & -0.53 & 0.595 & -0.674 & -1.61 & 0.107 & -0.029 & -0.78 & 0.465 \\
\hline Sibling jallousy & 0.475 & 24.47 & $0,0000^{\mathrm{d}}$ & 0.287 & 3.58 & $0.0000^{65}$ & 0.306 & 4.32 & $0.000^{d}$ & 0.284 & 4.61 & $0.000^{\prime}$ \\
\hline Sibling cluseresess & -0.01 .4 & $-0 ;: 214$ & 0.831 & $\times 196$ & .3 .06 & $0.0002^{6}$ & 0.0008 & 0.17 & 0.868 & 0.025 & 0.63 & 0.529 \\
\hline Maternall ancorion & -0.001 & -0.01 & 0.993 & -0.168 & -1.35 & 0.170 & 0.191 & 1.76 & 0.078 & 0.216 & 2331 & $(0.0)^{32}$ \\
\hline Maternall eontrol & $0.45 x^{2}$ & 3.81 & $0.000^{\mathrm{s}}$ & 0.562 & 6.23 & $0.000^{\mathrm{d}}$ & 0,026 & 0.37 & 0.745 & 0.040 & $0,5 \%$ & 0,571 \\
\hline Parernal a fection: & $-0.07 \%$ & -0.50 & 0.621 & -01013 & $m 0 ! 1$ & 0.915 & -0.060 & .0 .56 & 0.579 & -0.044 & $=0,40$ & $0,64,4$ \\
\hline Homemal control & 0.402 & 3.59 & $0.000^{\mathrm{d}}$ & 0.418 & 4.90 & $0000^{4}$ & 0.060 & $D_{3} 7 \%$ & 0.430 & 0.095 & 1.43 & 0.15 \\
\hline Perer collate ortientation & $-0,380$ & 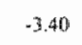 & $0.001^{*}$ & (1) 224 & $-2,64$ & $0.008^{b}$ & -0.0604 & 0.186 & 0.388 & -0.055 & $-0,83$ & 0,498 \\
\hline Peer dal inglugrtoy & 0.452 & 2.76 & $0.066^{\mathrm{b}}$ & 0.491 & 3.98 & $0.0000^{\circ}$ & 0.107 & 0.95 & 0.340 & 0.151 & 1.54 & 0.123 \\
\hline Pet popularity & -0.165 & -1.67 & 0.095 & -0.025 & $-0) .33$ & 0.741 & -0.277 & -4.23 & $0.0009^{\mathrm{th}}$ & -0.182 & -3.18 & $0.001^{8}$ \\
\hline Specilin events & 0,926 & 3,30 & 0.001 & 0.473 & 2.29 & $0.022^{\text {म }}$ & 0.603 & 3,19 & $0.0001^{\circ}$ & 0.485 & 3.068 & $0.002^{\circ}$ \\
\hline
\end{tabular}

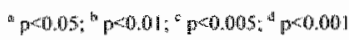

Departure from linearity was found for almost all analyses in that addition of squared side scores significantly improved 22 out of the 23 models, with positive associations between squared SIDE variables and CBCL problem behaviour. No significant interactions with zygosity were found for externalising and depression symptom scores. However, interactions were found for differential peer delinquency with internalising 
$(\beta=0.541, p=0.044)$ and total symptom score $(\beta=0.635, p=0.052)$. In addition, suggestive interactions were found for differential maternal and paternal affection with internalising symptom score (respectively: $\beta=-0.391, p=0.073$ and $\beta=-0.412, p=0.060$ ). Stratified analyses revealed a much stronger association between differential peer delinquency and degree of psychopathology for $D Z$ than for $M Z$ twins (respectively: $\beta=0.348, p=0.036$ and $\beta=-0.116, p=0.436$ ). Also, for maternal affection, a much stronger association was apparent for $\mathrm{DZ}$ than for $\mathrm{MZ}$ twins (respectively: $\beta=0.370$, $p=0.014$ and $\beta=-0.023, p=0.882$ ). However, for the association between paternal affection and internalising symptom score the direction of effect differed for $D Z$ and $\mathrm{MZ}$ twins. Results revealed a positive non-significant association for $\mathrm{DZ}$ twins, but a significant negative association for $\mathrm{MZ}$ twins $(\beta=-0.320, \mathrm{p}=0.041)$.

No significant or suggestive interactions were found with sex.

\section{Discussion}

The results revealed significant associations between nonshared environment on the one hand and degree of internalising, externalising, depression and total symptom scores on the other. The effects of the non-shared environment were non-linear, indicating that effects were mostly operating at the extremes of relative SIDE scores, not at the level of more moderate values.

No evidence was found for genetic mediation of associations between nonshared environment and externalising and depressive symptoms, as associations between the SIDE dimensions and differences in externalising and depressive symptoms were similar for $\mathrm{MZ}$ and $\mathrm{DZ}$ twins. However, the results suggest that associations between differential peer delinquency on the one hand and internalising and total symptom scores on the other may be genetically mediated, since associations were much stronger for $\mathrm{DZ}$ than for $\mathrm{MZ}$ twins. The same is true for the association between differential maternal affection and internalising symptoms.

\section{Methodological issues}

This study should be interpreted in the light of several potential limitations. Twins share more environmental influences than do non-twin siblings. Therefore, the twin method might not be a powerfull approach to the study of relationships between nonshared environmental influences and behavioural differences ${ }^{2}$. Consequently, it is possible that some zygosity interactions were not detected at the conventional alpha level, also because tests for interaction are not powerful.

A further limitation is that both the exposure (experiential differences) and the outcome (CBCL scores) were assessed by the same individuals, which may have contributed to the formation of spurious associations. Although such a bias cannot be excluded, our findings are in broad agreement with previous reports using different methodologies. 
Although the CBCL allows for the calculation of separate scores corresponding to several behavioural dimensions based on exploratory factor analysis, confirmatory factor analytic studies have shown inadequate empirical support for these syndromes and their differentiation ${ }^{19,20}$. Instead, a general problem behaviour factor may underlie $\mathrm{CBCL}$ data across different age groups ${ }^{10,20}$. The dimensions used in this study were included to facilitate comparisons with previous work, but the risk exists that by doing so the findings were over-interpreted. Replication with clinical interview measures is therefore necessary.

The probability of false-positive results is low for tests of main effects. We conducted 341 tests of main effects, and therefore would have expected, on the basis of chance alone, around 17 significant associations at $p=0.05$ and 3 or 4 associations at $p=0.01$. The fact that we found 112 significant associations at $p<0.05$ and 79 at $p<0.01$ indicates that chance is not a likely explanation for our findings. However, we conducted 46 tests for interaction and we found only one assaciation at $p<0.05$. Therefore, in case of the interaction tests, results are most likely to reflect a type I error.

\section{Interpretation of findings}

The mean scores on SIDE dimensions for $\mathrm{DZ}$ and $\mathrm{MZ}$ twins are comparable to those found in earlier studies. However, the means of SIDE differential parental treatment are lower for both $\mathrm{DZ}$ and $\mathrm{MZ}$ twins than reported by Baker and Daniels ${ }^{10}$. This may be related to the fact that they used twin-reported perceptions of their environments, while in the current study parent-rated perceptions were used.

Previous studies also reported effects of differential sibling interactions and differential peer college orientation on behavioural outcomes ${ }^{1021}$. However, much more literature is dedicated to the effects of differential parental treatment. The results of this study are compatible with previous work reporting an association between parental control and antisocial behaviour ${ }^{3,13,14}$. However, in contrast with findings reported by Dunn $^{22}$, this study found that more maternal affection is associated with a higher and not with a lower depression symptom score. This may suggest that the association does not express a causal influence of differential environment on behaviour, but rather that depressive behaviour provokes a parental reaction or that the association is genetically mediated. This study is comparable to earlier studies in that no sex interactions were apparent $^{13}$.

Overall, the results offer no strong indication of a genetic factor influencing both differences in environmental experience and problem behaviour. Therefore, a direct relationship can be postulated between nonshared environment and differences in problem behaviour. However, the results suggest that subtle differences in environmental experience do not impact on behaviour, but rather that associations only become apparent at the extremes of differential experience. However, as cross-sectional data were used, little can be concluded about the direction of these presumed direct relationships. Nonshared environment may influence differences in child problem 
behaviour, and these behavioural differences, in turn, may influence nonshared environment. For example, with regard to externalising behaviour, it is most likely that the associations that were detected represented the influence of differences in behaviour on nonshared environment. It may be more logical to assume that externalising symptoms provoke parental control, sibling antagonism, jealousy, and less sibling closeness and peer college orientation than the other way around. For internalising symptoms like depression, both directions of effect have face validity. Differential environmental influences may cause depressive symptoms, but depressive symptoms in their turn may be able to provoke affective reactions in parents. Longitudinal data should be used in future research to clarify the direction of these effects. 


\section{References}

1. Verhulst FC, Koot HM. The epidemiology of child and adolescent psychopathology. Oxford: Oxford University Press, 1995.

2. Plomin R, Daniels D. Why are children in the same family so different fiom one another? Behav Brain Sci 1987;10:1-16.

3. Plomin R. The Emanuel Miller Memorial Lecture 1993. Genetic research and identification of envirommental influences. J Child Psychol Psychiatry 1994;35(5):817-34.

4. van den Oord EJ, Verhulst $\mathrm{FC}$, Boomsma DI. A genetic study of maternal and paternal ratings of problem behaviors in 3-year-old twins. J Abnorm Psychol 1996;105(3):349-57.

5. Silberg JL, Erickson MT, Meyer JM, Eaves LJ, Rutter ML, Hewitt JK. The application of structural equation modeling to maternal ratings of twins' behavioral and emotional problems. I Consult Clin Psychal 1994;62(3):510-21.

6. Pike A, Plomin $\mathbb{R}$. Importance of nonshared environmental factors for childhood and adolescent psychopathology. J Am Acad Child Adolesc Psychictry 1996;35(5) 560-70.

7. Rutter M, Pickles A, Murray $R$, Eaves L. Testing hypotheses on psychopathology risk mechanisms. Psychological Bulletin 1999; submitted.

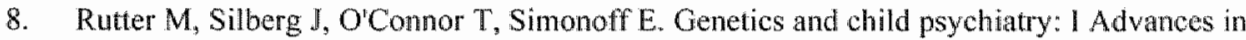
quantitative and molecular genetics. J Child Psychol Psychiatry 1999;40(1):3-18.

9. Plomin $R$, Reiss D, Hetherington EM, Howe GW. Nature and nurture: genetic contributions to measures of the family environment. Developmental Psychology 1994;30:32-43.

10. Baker LA, Daniels D. Nonshared envirommental influences and personality differences in adult twins. $J$ Pers Soc Psychol 1990;58(1):103-10.

11. Reiss $\mathbb{D}$, Plomin R, Hetherington EM. Genetics and psychiatry: an unheralded window on the environment. Am J Psychiary 1991; 148(3):283-91.

12. Daniels D, Plomin R. Differential experience of siblings in the same family. Developmenal Psychology 1985;21(5):747-60.

13. Reiss D, Hetherington EM, Plomin $\mathbb{R}$, et al. Genetic questions for environmental studies. Differential parenting and psychopathology in adolescence. Arch Gen Psychiary 1995; 52(I1):925-36.

14. Pike A, Reiss D, Hetherington EM, Plomin R. Using MZ differences in the seareh for nonshared environmental effects. J Child Psychol Psychiary 1996;37(6):695-704.

15. Loos R, Derom C, Vlietinck R, Derom R. The East Flanders Prospective Twin Survey (Belgium): a population-based register. Twin Res 1998;1(4):167-75.

16. Wlietinck R. Determination of the zygosity of twins. Doctoral thesis: KU, $\| 986$.

17. Achenbach TM. Integrative guide for the $1991 \mathrm{CBCL} / 4-18, \mathrm{YSR}$, and TRF profiles. Burlington: University of Vermont, Department of Psychiatry, 1991.

18. StataCorp SSS. Release 6.0 Stata Corp. 1999.

19. Hartman CA, Hox J, Auerbach J, et al. Syndrome dimensions of the child behavior checklist and the teacher report form: a critical empirical evaluation. $J$ Child Psychol Psychiatry $\llbracket 999 ; 40(7): 1095-116$.

20. Greenbaum PE, Dedrick RF. Hierarchical confirmatory factor analysis of the Child Behavior Checklist/4-18. Psychological Assessment 1998;10(2):149-55.

21. Daniels D. Differential experiences of siblings in the sane family as predictors of adolescent sibling personality differences. J Pers Soc Psychol 1986:51(2):339.46.

22. Dunn J, Stocker $\mathrm{C}$, Plomin R. Assessing the relationship between young siblings: a research note. J Child Psychol Psychiatry 1990;3] (6):983-91. 


\section{Chapter 4}

\section{A prospective twin study of birth weight discordance and child problem behaviour}

Jim van Os, Marieke Wichers, Marina Danckaerts, Sofie Van Gestel, Catherine Derom, Robert Vlietinck

Biological Psychiatry 2001;50:593-9 


\section{Abstract}

\section{Background}

We investigated whether low birth weight constitutes a causal risk factor for child problem behaviour, using a variation of the co-twin control method.

\section{Methods}

In a representative sample of 745 twin pairs (MZ: 324 pairs), birth weight was recorded at birth and child problem behaviour at mean age 10 years was measured with the Child Behaviour Checklist (CBCL).

\section{Results}

Lower birth weight was a continuous risk factor for later child problem behaviour (adjusted regression coefficient over units of $500 \mathrm{~g}: \beta=0.15, \mathrm{p}=0.046$ ), and greater levels of $\mathrm{CBCL}$ discordance did not result in a reduced effect size. Greater within-pair birth weight discordance was associated with greater within-pair CBCL score discordance $(\beta=0.35, \mathrm{p} \approx 0.001)$. This latter effect was similar in $M Z(\beta=0.34, p=0.005)$ and $D Z$ twins $(\beta=0.37, p=0.003)$.

\section{Conclusions}

The fact that (i) the effect size of the assaciation between low birth weight and child problem behaviour was not reduced in pairs with greater levels of CBCL discordance, and (ii) similar effect sizes were found in monozygotic and dizygotic twins for the within-pair association between birth weight discordance and CBCL score discordance, suggests that the observed relationship between low birth weight and child problem behaviour is not due to a shared environmental or genetic variable that influences both characteristics. Lower birth weight is a causal risk factor for child problem behaviour, the effects of which may well extend into adulthood. 


\section{Introduction}

Biometrical models of psychopathology in childhood have repeatedly shown that, apart from genetic influences, both the shared and the nonshared environment strongly contribute to individual differences in a range of outcomes ${ }^{1-3}$. However, genetic studies have generally been uninformative about which aspects of the environment contribute to variation in psychopathology. As environmental risks may be modified by therapeutic or preventive interventions, and may set off a cascade resulting not only childhood, but also adult psychopathology, the further identification of these early environmental risk factors is now required ${ }^{4}$.

There is evidence that lower birth weight (LBW) increases the risk for childhood psychopathology. LBW children have been reported to be at increased risk of psychiatric disorders such as $\mathrm{ADHD}^{5-8}$, depressive symptomatology ${ }^{9,10}$ and behavioural problems ${ }^{11,12}$. Low birth weight has also been associated with adult psychiatric outcomes such as schizophrenia ${ }^{13-15}$. Birth weight is influenced by environmental factors such as gestational age, maternal age, parity, chorion type, placental proximity and presence or absence of vascular anastomoses, whereas around $40 \%$ of variation in weight has been associated with genetic factors ${ }^{16,17}$. Factors that have been associated with LBW are number of previous LBW babies, premature rupture of membranes, multiple births, heavy smoking, early and late pregnancy bleeding, low maternal weight, short maternal height, older maternal age, pre-eclampsia, history of a previous stillbirth, primiparity, exposure to stressors and difficulties, chronic illness, foetal female gender and congenital anomalies ${ }^{18-25}$.

As birth weight itself is subject to both genetic and environmental influences, any explanation for the apparent association between birth weight and childhood psychopathology should consider genetic and environmental mechanisms ${ }^{26}$. Thus, the association between low birth weight and childhood psychopathology may represent I) a true causal influence, or ii) the effect of a third, non-causal variable influencing both characteristics. This third variable could be either a shared familial environmental factor or a genetic factor. For example, a common set of genes (shared genetic factor) or low parental social class (shared environmental factor) may influence pleiotropically both birth weight and childhood psychopathology.

To examine the hypothesis that low birth weight represents a causal environmental influence on childhood psychopathology, a population-based sample of monozygotic (MZ) and dizygotic (DZ) twins, whose weight was recorded at birth, was examined again in middle childhood. First, we wished to establish whether low birth weight is a risk factor for child problem behaviour in a population of twins. Second, we examined predictions, derived from the co-twin control method ${ }^{27}$, regarding the likely causal influence of birth weight on childhood psychopathology. If birth weight is associated with childhood psychopathology but within-pair birth weight discordance in $M Z$ twins 
does not predict within-pair discordance for psychopathology, a causal explanation is unlikely. The reason for this is that if birth weight reflects a causal mechanism, discordance for the causal factor in genetically identical individuals must be associated with discordance for the outcome. Therefore, if discordance for birth weight predicts discordance for childhood psychopathology to the same degree in genetically identical $\mathrm{MZ}$ twins and genetically non-identical $\mathrm{DZ}$ twins, the mechanism whereby birth weight affects childhood psychopathology is likely to be causal and environmental. This causal influence may either be direct, or indirect through potentiation of a genetic influence (gene-environment interaction).

\section{Methods and materials}

\section{Subjects}

The 'East Flanders Prospective Twin Survey" collects, since 1964, information on the mother and the child in $98 \%$ of multiple births in East Flanders, Belgium. This twin register is unique, in that detailed records are kept of birth and pregnancy variables, making it particularly suitable for the study of early risk factors on later psychiatric and somatic outcomes. At present, the register counts more than 5600 twin pairs ${ }^{28}$. The zygosity of the twins is determined by gender, placentation, blood groups and, since 1982, by examination of five highly polymorphic DNA markers. Unlike-gender twins and same-gender twins with at least one different genetic marker were classified as dizygotic; monochorionic twins were classified as monozygotic. For all same-gender dichorionic twins with the same genetic markers a probability of monozygosity was calculated using a lod-score method ${ }^{29}$. After DNA fingerprinting, a probability of monozygosity of 0.999 was reached. To be included in the analysis, dichorionic MZ pairs had to reach a probability of monozygosity of at least $95 \%$. Twins aged 6-17 years were selected for the present study $(n=1520)$. Questionnaires were sent to 1436 parents with known addresses of these twin pairs, of which 760 returned the questionnaires. Fifteen pairs were excluded from the analyses because of major congenital malformations (six pairs), implausible birth weight data (one pair) and missing birth weight and/or zygosity data (eight pairs).

\section{Measures}

Parents gave written informed consent conforming to the local ethics committee guidelines. Parents filled in the Child Behaviour Checklist $(\mathrm{CBCL})^{30}$. This questionnaire is developed to examine the extent to which children have behavioural and emotional problems as seen by the parents. Although the $\mathrm{CBCL}$ allows for the calculation of eight separate scores corresponding to several behavioural dimensions, large-scale population studies show inadequate empirical support for these syndromes and their differentiation ${ }^{31}$. Instead, a general problem behaviour factor appears to 
underlie $\mathrm{CBCL}$ data across different age groups ${ }^{31,32}$. We therefore examined the total amount of psychopathology, as measured by the total problem score, subjected to a square-root transformation to achieve normality.

\section{Analysis}

\section{Possible non-causal contribution of shared genes}

Two types of analyses were conducted using STATA ${ }^{33}$. In the first analysis, a file was compiled in which each individual contributed one observation (total of $745 \times 2=1490$ observations). In this file, the association between CBCL-score and birth weight (in units of $500 \mathrm{~g}$ ) was examined. As observations of individual twins were clustered within pairs, the CLUSTER and ROBUST options were used in the STATA regression analyses. The CLUSTER option combined with the ROBUST option allows for the use of observations which are not independent within clusters (in this case: twins within pairs) and obtains the Huber/White/Sandwich estimator of variance instead of the traditional variance estimator. These procedures result in standard errors that are adjusted for clustering within persons ${ }^{33}$. All the analyses were adjusted for zygosity, individual gender, gender concordance of the pair (same gender or opposite gender), maternal age, and gestational age. These confounders were chosen a priori and not on the basis of statistical significance ${ }^{34}$.

In the second analysis, a file was compiled in which each pair contributed one observation ( $n=745$ observations). For each pair, variables were constructed indicating the degree of concordance in I) birth weight and ii) CBCL score. Discordance was defined as (birth weight of larger twin - birth weight of smaller twin/birth weight of larger twin) $\times 100^{35}$. Discordance for CBCL score was defined similarly. Subsequently, the $\mathrm{CBCL}$-discordance score was regressed on the birth weight-discordance score, adjusting (a priori) for zygosity, genders of the index and co-twin, gender concordance of the pair (same gender versus opposite gender), gestational age and maternal age. In order to examine whether any effect of birth weight discordance on CBCL score discordance was similar for $\mathrm{MZ}$ and $\mathrm{DZ}$ twins, interactions with zygosity were assessed with the likelihood ratio test. Adding squared exposure variables to the equation assessed departure from linearity. Differences in means were examined with unpaired ttests, setting alpha at $5 \%$.

\section{Possible non-causal contribution of the shared environment}

If, as explained in the introduction, birth weight discordance is associated with $\mathrm{CBCL}$ discordance to the same degree in $M Z$ and $D Z$ twins, the explanation must be causal and non-genetic. However, part of the association may still be non-causal and of shared environmental origin. To the degree that this is the case, the association between birth weight and $\mathrm{CBCL}$ would be more strongly associated with each other in the entire sample of twins than in a sample of $M Z$ and $D Z$ twins selected for discordance on the 
CBCL outcome. For example, if exposure to maternal hypertension during pregnancy entirely determined both birth weight and problem behaviour (i.e. a non-causal shared environmental explanation of the association between birth weight and problem behaviour), birth weight and problem behaviour would be strongly associated with each other in any general population sample of twins or singletons. However, in twin pairs selected for extreme CBCL discordance there would be no association, because the twin with low birth weight would have experienced exactly the same exposure to maternal hypertension as the twin with high birth weight.

To address this possibility in our sample, we not only examined the association between birth weight and CBCL score in the total general population twin sample as described above, but also additionally in selected $\mathrm{MZ}$ and $\mathrm{DZ}$ twin pairs who were more than $\mathbb{S} \mathrm{SD}$ discordant for the CBCL total score. If the association between birth weight and $\mathrm{CBCL}$ score were less strong in both the discordant $\mathrm{MZ}$ and $\mathrm{DZ}$ samples than in the general sample, a non-causal contribution of the shared environment would be likely.

\section{Results}

\section{Sample}

The mean age of the sample was $\mathbb{1 0 . 3}$ years ( $\mathrm{SD}=3.3$ ), and consisted of $539(72 \%)$ same-gender pairs, and $206(28 \%)$ opposite gender pairs. Of the same-gender pairs, 255 were male $(47 \%)$ and 284 female $(53 \%)$. The number of monozygotic pairs was 324 (44\%). The mean birth weight discordance was $11.3 \%(\mathrm{SD}=9.2)$; the mean $\mathrm{CBCL}$ discordance was $23.3 \%(\mathrm{SD}=21.0)$. Birth weight and/or $\mathrm{CBCL}$ score were associated with gender, gender concordance, gestational age and maternal age (table 4.1). Similarly, CBCL discordance and/or birth weight discordance were associated with zygosity, gender concordance and maternal age (table 4.1).

\section{Sample representativeness}

Out of the total sample of 1520 eligible pairs, included and non included pairs were similar with regard to father's age (mean included: 29.1, mean non-included: 29.4), mother's age (mean included: 27.2 , mean non-included: 27.0 ), gestational age (mean included: 37.0, mean non-included: 36.6), parity of mother (proportion primipara included: 48.6, non-included: 48.3), proportion with two placenta's (included: 37.1, non-included: 39.2 ), proportion male gender (included: 48.1 , non-included: 49.8 ), mean birth weight (included: 2532, non-included: 2430 ) and propottion monozygotic (included: $43.5 \%$, non-included: $38 \%$ ). The mean birth weight discordance in the included sample was $11.3 \%(\mathrm{SD}=9.2)$, the same as in the non-included group $(11.4 \%$, $\mathrm{SD}=9.3)$. 
Table 4. 1. Univariate analyses of CBCL score, birth weight, and their mean \% discordance (SD).

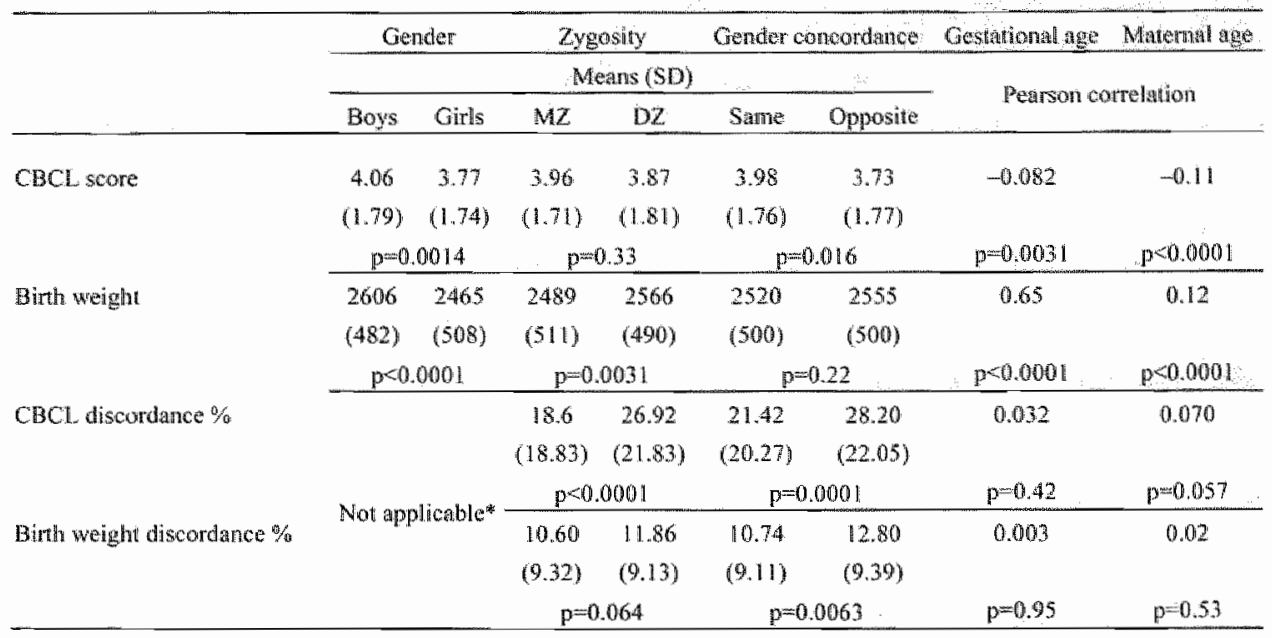

*Not applicable as CBCL and birth weight discordance are pair-level variables and gender is an individuallugel variable.

\section{Effects of birth weight and birth weight discordance}

CBCL scores increased with decreasing birth weight (table 4.2 ; adjusted regression coefficient from regression model: $\beta=0.15,95 \% \mathrm{Cl}:-0.29,-0.003 ; \mathrm{p}=0.046)$. There was no evidence for an interaction with zygosity $\left(\chi^{2}=0.64, \mathrm{df}=1, \mathrm{p}=0.43\right)$, nor was there strong evidence for departure from linearity (likelihood ratio test: $\chi^{2}=0.70, \mathrm{df}=\mathbb{1}$, $\mathrm{p}=0.41$ ). The effect of birth weight on CBCL scores in $\mathrm{MZ}$ and $\mathrm{DZ}$ twins who were more than $1 \mathrm{SD}$ discordant for $\mathrm{CBCL}$ score was, if anything, greater rather than weaker in comparison with the association in the total sample ( $M Z$ discordant twins: 52 pairs, $\beta=-0.70,95 \% \mathrm{Cl}:-1.24,-0.15, \mathrm{p}=0.015 ; \mathrm{DZ}$ discordant pairs: 154 pairs, $\beta=0.28$, $95 \% \mathrm{Cl}:-0.69,0.14, \mathrm{p}=0.19$ ).

CBCL discordance increased with the degree of birth weight discordance (adjusted regression coefficient: $\beta=0.35,95 \% \mathrm{Cl}: 0.18,0.52 ; \mathrm{p}<0.001$ ), and again there was no evidence for an interaction with zygosity (likelihood ratio test: $\chi^{2}=0.03, \mathrm{df}=1, \mathrm{p}=0.87$ ) or departure from linearity (likelihood ratio test: $\chi^{2}=0.07, \mathrm{df}=1, \mathrm{p}=0.79$ ). Thus, the effect of birth weight discordance in the stratified analyses was similar for $\mathrm{MZ}$ and $\mathrm{DZ}$ twins (MZ: $\beta=0.34 ; 95 \% \mathrm{CI}: 0.10,0.57 ; \mathrm{p}=0.005 ; \mathrm{DZ}: \beta=0.37 ; 95 \% \mathrm{CI}: 0.12,0.61$; $\mathrm{p}=0.003$ ). 


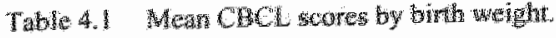

\begin{tabular}{|c|c|c|c|}
\hline 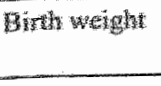 & 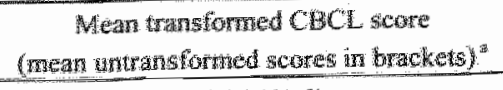 & 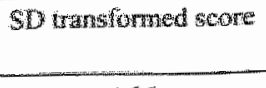 & W \\
\hline $50 \% / 1500$ & $6.24(4) .5)$ & 1.86 & 4 \\
\hline $3001 / 1500$ & $4.30(212)$ & 2.11 & 32 \\
\hline $1901 / 2000$ & $4.19121 .69)$ & 1.89 & 145 \\
\hline $2001 / 2500$ & $3.93(18.43$ & 1.70 & 463 \\
\hline $2591 / 2900$ & $388(12.2)$ & 3.77 & 588 \\
\hline $30101 / 9500$ & $3.78(17.4)$ & 1.76 & 213 \\
\hline $3501 / 4000$ & $337(13.7)$ & 1.53 & 41 \\
\hline $4001 / 4560$ & $3.16(10)$ & a & b \\
\hline \multicolumn{4}{|c|}{ 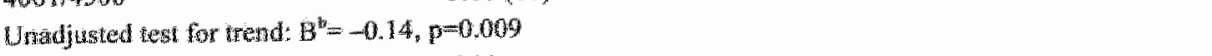 } \\
\hline \multicolumn{4}{|c|}{ 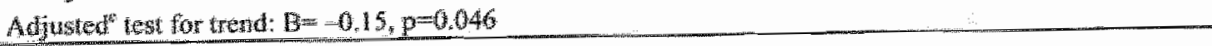 } \\
\hline
\end{tabular}

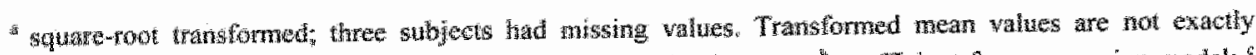

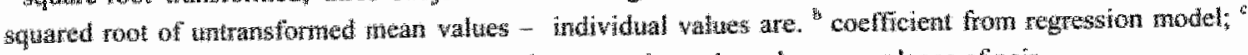
adjusted for $2 y g o s i t$, gexthional age, maternal age, gender and gender comcordance of par.

\section{Discussion}

Lower birth weight was associated with progressively greater child problem behaviour. The effect size of this association was not reduced as a function of problem behaviour discordance, making it unlikely that a third, shared environmental variable contributes to both low birth weight and child problem behaviour. The greater the degree of birth weight discordance within twin pairs, the greater the degree of discordance for child problem behaviour. This finding held for both $\mathrm{MZ}$ and $\mathrm{DZ}$ pairs, making it unlikely that a third, shared genetic variable contributes to both low birth weight and child problem behaviour. Thus, the results suggest that lower birth weight represents a causal risk factor for child problem behaviour.

Previous studies on birth weight have focussed almost exclusively on special groups of children with low or very low birth weight, or on children with established psychiatric discrders ${ }^{5}$. Our study, however, suggests that lower birth weight is a continuous risk factor for the distribution of problem behaviour in the general population of chitdren.

Lower birth wetght has also been associated with adult psychiatric outcomes such as sohizophrenia ${ }^{\text {k3-15 }}$. As adult psychtatric outcomes such as depression and schizophrenia are associnted with childhood behavioural characteristics ${ }^{36-35}$, a causal pathway from low birth weight through chld problem behaviour and adut psychiatric outcomes can be envisaged. The need for a lifespan developnental approach to the stressor-related psychiatric ilness has been advocated ${ }^{39}$. One study reported that emotional or behavioural disturbance in childhood was associated with a marked increase in the rate of severely negative events and difficulties some two decades later ${ }^{40}$. In another study, individuals who as children had high levels of symptoms of anxiety and depression, 
were shown to have higher levels of stressful life events as adults more than 25 years later ${ }^{4}$. In addition, early experience of poor mental health not only influenced adult exposure to life events, but also the adult response to life events in that poorer childhood mental health predicted greater sensitivity to the depressogenic effect of life events occurring in adulthood ${ }^{4}$.

Our finding that the association between low birth weight child problem behaviour is not the result of a higher-order association with a third variable does not preclude the possibility that low birth weight is on the causal pathway involving earlier causa: influences. Is has thus been suggested that low birth weight itself is on a causal pathway from maternal exposure to stress during pregnancy, low birth weight and adverse behavioural outcomes ${ }^{42}$. Psychosocial stressors during pregnancy have been associated with low birth weight ${ }^{43,44}$, as well as with childhood adverse behavioural outcomes $^{45,46}$ and adult psychiatric outcomes47,48. Prenatal stress through low birth weight may have long-term effects on HPA activity, thus rendering individuals more vulnerable to adversity and poor mental health ${ }^{49,50}$.

These results should be viewed in the light of several limitations. First, although the CBCL may be useful in identifying individuals with high levels of problem behaviour, it is not a diagnostic instrument ${ }^{51}$. In addition, child problem behaviour was assessed using parental reporting, which only is one dimension of problem behaviour. A useful addition would have been teacher-derived or self report-derived dimensions of problem-behaviour, for which different pattern of associations with birth weight could conceivably have emerged. Second, a single cross-sectional measurement of problem behaviour is arguably not a precise measure to associate with subtle effects of very early exposures. Third, the age range of the children was wide, from 6-17 years. However, there is no reason to assume that within pair differences in birth weight or problem behaviour are associated with age. Post hoc analyses in our data revealed that these correlations were negligible $(-0,03$ and -0.02 respectively). Fourth, the sample represented only $50 \%$ of all eligible individuals. However, comparisons between included and non-included subjects with regard to key variables did not suggest major differences. Although the non-included individuals had slightly lower birth weights, these differences were small and, most mportantly, within-pair birth weight discordance was the same in included and non-included pairs, making it unlikely that selection bias produced spurious results. Fifth, the analyses with pairs with significant levels of CBCL discordance created small groups of twins (52 MZ twins and $154 \mathrm{DZ}$ twins), and the lack of statistical resolution of these particular analyses should lead to caution in interpreting the results. However, even if a shared enwironmental infuence does influence both birth weight and problem behaviour, the significant association between birth weight differences and problem behaviour differences in $\mathrm{MZ}$ twins does suggest that at least part of the association in general population samples is causal and not due to a shared environmental or genetic variable. Finally, twins have lower birth 
weight and are more at risk of very low birth weight and other pregnancy and obstetric complications than singletors, so that caution must be exercised in generalising the results.

\section{Grant support}

This work was supported by grant nr. 3.0130.94 of the Fund for Scientific Research, grant I.U.A.P.- P4/17 and the Association for Scientific Research in Multiple Births. 


\section{References}

1. Schmitz S, Fulker DW, Mrazek DA. Problem behavior in early and middle childhood: an initial behavior genetic analysis. J Child Psychol Psychiatry 1995;36(8):1443-58.

2. van den Oord EJ, Boomsma DI, Verhulst FC. A study of problem behaviors in 10 - to 15 year-old biologically related and unrelated intemational adoptees. Behav Gever $1994 ; 24(3)$ : 193-205.

3. van der Valk JC, Verhulst FC, Stroet TM, Boomsma DI. Quantitative genetic analysis of internalising and externalising problems in a large sanple of 3-year-old twins. Twin Res $1998 ; 1(1): 25-33$.

4. Rutter M, Pickles A, Murray R, Eaves L. Testing hypotheses on specilic environmental risk mechanisms for psychopathology. submitted manuscript 2001.

5. Botting $\mathrm{N}$, Powls $\mathrm{A}$, Cooke RW, Marlow $\mathrm{N}$. Attention deficit hyperactivity disorders and other psychiatric outcomes in very low birthweight children at 12 years. $J$ Child Psychol Psychiatry 1997;38(8):931-41.

6. McCormick $\mathrm{MC}_{3}$ Gortmaker SL, Sobol AM. Very low birth weight children: behavior problems and school difficulty in a national sample. J Pediarr 1990;117(5):687-93.

7. Szatmari P, Saigal S, Rosenbaum P, Campbell D, King S. Psychiatric disorders at five years among children with birthweights less than 1000g: a regional perspective. Dev Med Child Neurol 1990;32(11):954-62.

8. Gjone H, Novik TS. Parental ratings of behaviour problems: a twin and general population comparison. J Child Psychol Psychiatry 1995;36(7):1213-24.

9. Frost AK, Reinherz HZ, Pakiz-Camras B, Giaconia RM, Lefkowitz ES. Risk factors for depressive symptoms in late adolescence: a longitudinal community study. Am $J$ Orthopsychiatry 1999;69(3):370-81.

10. Hoy EA, Sykes DH, Bill JM, Halliday HL, McClure BG, Reid MM. The social competence of very-low-birthweight children: teacher, peer, and self-perceptions. $J$ Abnown Child Psychol 1992;20(2):123-50.

11. Horwood LJ, Mogridge N, Darlow BA. Cognitive, educational, and behavioural outcomes at 7 to 8 years in a national very low birthweight cohort. Arch Dis Child Fetal Neonatal Ed 1998; 79(1):F12-20.

12. Sommerfelt K, Troland K, Ellertsen B, Markestad T. Behavioral problems in lowbirthweight preschoolers. Dev Med Child Neurol 1996;38(10):927-40.

13. Cannon $\mathrm{M}$, Jones $\mathrm{P}$, Gilvarry $\mathrm{C}$, et al. Premorbid social functioning in schizophrenia and bipolar disorder: similarities and differences. Am J Psychiatry 1997; 154(11):1544-50.

14. Jones PB, Rantakallio P, Hartikainen AL, Isohanni M, Sipila P. Schizophrenia as a longterm outcome of pregnancy, delivery, and perinatal complications: a 28-year follow-up of the 1966 north Finland general population birth cohort. Am I Psychiary 1998;155(3): $355-64$

15. Rifkin L, Lewis S, Jones P, Toone B, Murray R. Low birth weight and schizophrenia. Br J Psychiatry 1994;165(3):357-62.

16. Corey LA, Nance WE, Kang KW, Christian JC. Effects of type of placentation on birthweight and its variability in monozygotic and dizygotic twins. Acta Genet Med Gemellol 1979;28(1):41-50.

17. Vlietinck R, Derom R, Neale MC, et al. Genetic and environmental variation in the birth weight of twins. Behav Genet 1989;19(1):151-61.

18. Abdulrazzaq YM, Bener A, Dawodu $A$, et al. Obstetric risk factors affecting incidence of low birth weight in live-born infants. Biol Neonate 1995;67(3):160-6.

19. Bjerre B, Bjerre I. Significance of obstetric factors in prognosis of low birthweight children. Acra Paediatr Scand 1976;65(5):577-83. 
20. Herceg $A$, Simpson $\mathrm{MM}$, Thompson JF. Rusk factors and outcomes associated with low birthweight delivery in the Australian Capital Territory 1989-90. I Paediatr Child Health $1994: 30(4) ; 331-5$.

21. Meis PJ, Michiclutte R., Peters TJ, et al. Factors associated with term low birthweight in Cardiff, Wales. Paediatr Perinar Epideniol 1997;11(3):287-97.

22. Orr ST, James SA, Miller CA, et al. Psychosocial stressors and low birthweight in an urban population. An J Prev Med 1996;12(6):459-66.

23. Pritchard CW, Teo PY. Preterm birth, low birthweight and the stressfulness of the household role for pregnant women. Soc Sci Med 1994;38(1):89-96.

24. Shu XO, Hatch MC, Mills J, Clemens J, Susser M. Maternal smoking, alcohol drinking, caffeine consumption, and fetal growth: results from a prospective study. Epidemiology $1995 ; 6(2): 115-20$.

25. Wadhwa PD, Sandman CA, Porto M, Dunkel-Schetter C, Garite TJ. The association between prenatal stress and infart birth weight and gestational age at birth: a prospective investigation. An J Obster Gynecol 1993;169(4):858-65.

26. Marcelis $M$, van $O$ s $\|$, Sham $P$, et al. Obstetric complications and familial morbid risk of psychiatric disorders. Am J Med Genet 1998;81(1) 29-36.

27. Cederlof R, Friberg L, Lundman $T$. The interactions of smoking, environment and heredity and their implications for disease etiology. A report of epidemiological studies on the Swedish twin registries. Acta Med Scand Suppl 1977;612:1-128.

28. Loos $R$, Derom $C$, Vlietinck $R$, Derom R. The East Flanders Prospective Twin Survey (Belgium): a population-based register. Twin Res 1998;1(4):167-75.

29. Vlietinck R. Determination of the zygosity of twins. Doctoral thesis: KU, 1986.

30. Verhulst $\mathrm{FC}$, wan der Ende J, Koot HM. Handleiding voor de CBCL/4-18. Rotterdam: afdeling kinder- en jeugdpsychiatrie, Sophia Kinderziekenhuis/Academisch Ziekenhuis Rotterdam, Erasmus Universiteit Rotterdam, 1996.

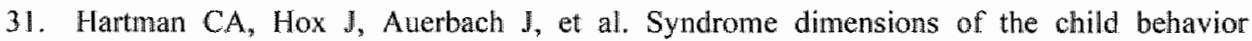
checklist and the teacher report form: a critical empirical evaluation. $J$ Child Psychol Psychiatry 1999;40(7):1095-116.

32. Greenbaum PE, Dedrick RF. Hierarchical confirmatory factor analysis of the Child Behavior Checklist/4-18. Psychological Assessment 1998;10(2):149-55.

33. StataCorp SSS. Release 6.0 Stata Corp. 1999.

34. Clayton D, Hills $M$. Choice and interpretation of models. In: Clayton D, Hills $\mathrm{M}$, ads. Statistical models in epidemiology. Oxford: Oxford science publications, 1993:271-82.

35. Patterson RM, Wood RC. What is twir birthweight discordance? Am J Perinatol $1990 ; 7(3): 217-9$

36. Caspi A, Moffitt TE, Newman DL, Silva PA. Behavioral observations at age 3 years predict adult psychiatric disorders, Longitudinal evidence from a birth cohort. Arch Gen Psychiatry 1996.53(11):1033-9.

37. Jones $P$, Rodgers $B$, Murray $R$, Marmot M. Child development risk factors for adult schizophrenia in the British 1946 birth cohort. Lancet 1994;344(8934):1398-402.

38. Wan Os I, Jones $\mathrm{P}$, Lewis $\mathrm{G}$, Wadsworth $\mathrm{M}$, Murray R. Developmental precursors of affective illness in a general population birth cohort. Arch Gen Psychiary 1997:54(7):625-31.

39. Rutter M. Childhood experiences and adult psychosocial functioning. Ciba Found Symp 1991;156:189-200; discussion 200-8.

40. Champion LA, Goodall G, Rutter M. Behaviour problems in childhood and stressors in early adult life. I. A 20 year follow-up of London school children. Psychol Med $1995 ; 25(2): 231-46$. 
41. Van Os $J$, Jones PB. Early risk factors and adult person-enviromment relationships in affective disorder. Psychol Med 1999;29(5):1055-67.

42. Lou HC, Hansen D, Nordentoft M, et al. Prenatal stressors of human life affect fetal brain development. Dev Med Child Neurol 1994;36(9):826-32.

43. Brandt LP, Nielsen CV. Job stress and adverse outcome of pregnancy: a causal link or recall bias? Am J Epideniol 1992;135(3):302-11.

44. Paarlberg KM, Vingerhoets AJ, Passchier J, Dekker GA, Heinen AG, van Geijn HP. Psychosocial predictors of low birthweight: a prospective study. $B r J$ Obstel Gyncecol $1999 ; 106(8): 834-41$.

45. Glover $\mathrm{V}$. Maternal stress or anxiety in pregnancy and emotional development of the child. Br J Psychiatry 1997;171:105-6.

46. Meijer A. Child psychiatric sequelae of maternal war stress. Acta Psychiatr Scand 1985;72(6):505-11.

47. Susser $\mathrm{E}$, Neugebauer R, Hoek HW, et al. Schizophrenia after prenatal famine. Further evidence. Arch Gen Psychiatry 1996;53(1):25-31.

48. van Os J, Selten J.P. Prenatal exposure to maternal stress and subsequent schizophrenia. The May 1940 invasion of The Netherlands. Br J Psychiary 1998;172:324-6.

49. Clarke AS, Wittwer DJ, Abbott DH., Schneider ML. Long-term effects of prenatal stress on HPA axis activity in juvenile rhesus monkeys. Dev Psychobiol 1994;27(5):257-69.

50. Weinstock M, Matlina E, Maor Gl, Rosen H, McEwen BS. Prenatal stress selectively alters the reactivity of the hypothalamic-pituitary adrenal system in the female rat. Brain Res 1992;595(2):195-200.

51. Achenbach TM, Edelbrock C, Howell CT. Empirically based assessment of the behavioral/emotional problems of 2- and 3- year-old children. I Abnom Child Psychol $1987 ; 15(4): 629-50$. 


\section{Chapter}

\section{Prenatal life and postnatal psychopathology: evidence for negative gene-birth weight interaction}

Marieke Wichers, Shaun Purcell, Marina Danckaerts, Catherine Derom, Robert Derom, Robert Vlietinck, Jim van Os 


\section{Abstract}

\section{Background}

Many studies suggest that pregnancy and birth complications (PBCs) are environmental risk factors for child psychopathology. However, it is not known whether the effects of PBCs occur independently af genetic predisposition. The current study examined the possibility of geneenvironment interaction in a twin design.

\section{Methods}

The East Flanders Prospective Twin Survey prospectively records the births of all twin pairs born in East Flanders, Belgium. The current study included 760 twin pairs aged 6- 17 years. Multilevel regression analysis was used to assess the effects of several $P B C$ s collected around the time of bith. Using structural equation modelling, ACE models assuming additive genetic (A), shared environmental (C) and unique environmental (E) influences, were compared in order to examine whether the contribution of genetic factors to parent-rated child problem behaviour varied as a function of exposure to dichotomously and continuously defined PBCs.

\section{Results}

A main independent effect of lower birth weight, corrected for gestational age (small for gestational age - SGA), on child problem behaviour was found. In addition, there was an interaction between genetic influence and SGA, in that being smaller for gestationall age resulted in less influence of additive genetic factors on individual differences in problem behaviour.

\section{Conclusions}

Results are suggestive of negative gene-birth weight interaction. Children who are SGA are less sensitive to the genetic effects, and those with high genetic vumerability are less sensitive to the effects of being SGA in bringing about postnatal mental heath effects. 


\section{Introduction}

Twin studies suggest significant genetic influences on all dimensions of child problem behaviour measured with the Child Behaviour Checklist $(\mathrm{CBCL})^{1}$, which may increase with age ${ }^{2}$. Although there is broad agreement that in psychiatric phenotypes such as child problem behaviour gene-environment interactions play an important role ${ }^{3}$, the inclusion of such interactions in twin models of psychopathology is extremely rare. Failure to specify gene-environment interactions will result in overestimation of the genetic contribution to a trait ${ }^{4.5}$.

There is evidence that birth and pregnancy complications (PBCs) are important risk factors for childhood psychopathology. Complications at birth have been reported to increase the risk of childhood psychiatric disorders such as attention deficit hyperactivity disorder (ADHD) ${ }^{6,7}$, autism ${ }^{8,9}$ and depressive symptomatology ${ }^{10,11}$. PBCs have also been associated with adult psychiatric outcomes such as schizophrenia ${ }^{12-14}$. Low birth weight, corrected for gestational age (small for gestational age), is a risk factor for childhood psychopathology ${ }^{15-18}$. Birth weight itself is subject to both genetic and environmental influences. However, van Os et al. ${ }^{19}$ found that discordance in psychopathology increased with the degree of birth weight discordance and that this effect was similar for monozygotic (MZ) and dizygotic (DZ) twins, suggesting that birth weight represents a causal environmental risk factor.

PBCs may thus represent, at least in part ${ }^{20}$, an environmental risk factor. In addition, it has been suggested that these $\mathrm{PBCs}$ are likely candidates for gene-environment interaction $^{21,22}$. Gene-environment interaction in the context of PBCs indicates that the effect of genetic factors on the psychopathological outcome is not the same in individuals who differ in their exposure to PBCs. Koeppen-Schomerus ${ }^{23}$ found a negative interaction between birth weight and genetic factors in their effects on child cognitive development, indicating that the effect of genetic factors was stronger in the absence of simultaneous exposure to low birth weight than it would have been in the presence of exposure to low birth weight.

We used twin data with detailed, prospective information on a range of PBCs, to test the hypothesis that the effect of genetic factors on child problem behaviour varies as a function of exposure to PBCs.

\section{Methods}

\section{Subjects}

The 'East Flanders Prospective Twin Survey' collects information, since 1964, on the mother, the placenta and the child in $98 \%$ of multiple births in East Flanders, Belgium. At present, the register counts more than 5600 twin pairs ${ }^{24}$. The zygosity of the twins is determined by sex, placentation, blood groups and, since 1982, by examination of five highly polymorphic DNA markers. Unlike-sex twins and same-sex twins with at least 
one different genetic marker were classified as dizygotic; monochorionic twins were classified as monozygotic. For all same-sex dichorionic twins with the same genetic markers a probability of monozygosity was calculated using a lod-score method ${ }^{25}$. After DNA fingerprinting, a probability of monozygosity of 0.999 was reached. To be included in the analysis, dichorionic $\mathrm{MZ}$ pairs had to reach a probability of monozygosity of at least $95 \%$.

Within 24 hours after notification of a delivery, a trained midwife visits the hospital and registers data, including birth weight. Structured questionnaires, answered by the attending obstetrician and paediatrician, are used to provide information on the mode of delivery, mode of induction of ovulation, foetal presentation and gestational age, calculated as the number of completed weeks of pregnancy.

Twins aged 6-1.7 years were selected for the present study $(n=1520)$. Questionnaires were sent to 1436 parents with known addresses of these twin pairs, of which 760 returned the questionnaires. Of all the questionnaires, $90 \%$ were filled in by the twin's mother. There were no large differences between the 760 included twins, and the 760 (1520-760) non-included twins regarding father's age (mean included: 29.1 , mean nonincluded: 29.4), mother's age (mean included: 27.2, mean non-included: 27.0), gestational age (mean included: 37.0 , mean non-included: 36.6 ), parity of mother (proportion primipara included: 48.6, non-included: 48.3), proportion with two placenta's (included: 37.1 , non-included: 39.2 ), proportion male sex (included: 48.1, non-included: 49.8), mean birth weight (included: 2532, non-included: 2430) and proportion monozygotic (included: $43.5 \%$, non-included: $38 \%$ ).

Fifteen pairs were excluded from the analyses because of major congenital malformations (six pairs), implausible birth weight data (one pair) and missing birth weight and/or zygosity data (eight pairs).

\section{Measures}

Parents were asked to fill in the $\mathrm{CBCL}^{26}$. This questionnaire is developed to examine the extent to which chldren have behavioural and emotional problems as seen by the parents. Although the CBCL allows for the calculation of eight separate scores corresponding to several behavioural dimensions based on exploratory factor analysis, confirmatory factor analytic studies have shown inadequate empirical suppost for these syndromes and their differentiation ${ }^{27,28}$. Instead, a general problem behaviour factor appears to underlie CBCL data across different age groups ${ }^{27,28}$. We therefore examined the total amount of psychopathology, as measured by the total problem score, subjected to a square-root transformation to achieve normality.

Main effects on CBCL scores of the following obstetric variables were examined: mode of delivery, foetal presentation, artificial induction of ovulation and lower birth weight. In order for birth weight to reflect the true exposure of being small for gestational age (SGA), and to correct for the possible confounding influence of sex, analyses were conducted with birth weight corrected for sex and gestational age (see below). 
We constructed an a priori, but biologically meaningful, dichotomous classification of the following PBCs. For mode of delivery, spontaneous delivery was defined as nonexposed and all other kinds of delivery (vacuum extraction, forceps, sectio, Bracht-, Mauriceau-, Lövset- extraction, versie-extraction) as exposed. For foetal presentation, head position was defined as non-exposed and all other positions as exposed. Normal induction of ovulation was defined as non-exposed and artificial induction of ovulation as exposed. This exposed group included children bom after in-vitto-fertilisation (12 children) as well as children born after artificial induction of ovulation without in-witrofertilisation ( 116 children).

\section{Analysis}

Main effects of $\mathrm{PBCs}$ were assessed using regression analysis yielding regression coefficients (B) as a measure of effect size. Because the members of one twin pair cannot be considered independent statistically, a multilevel regression procedure was carried out using the XTREG procedure in STATA ${ }^{29}$, thus taking account of the fact that level-one units (level of individual twins) were clustered into level-two units (level of the pairs). This procedure gives more realistic estimates of standard errors that otherwise might be underestimated, giving rise to spuriously low $P$-values. All regression analyses were a priori adjusted for the child's age, sex and zygosity status, and whether a twin pair was same-sex or opposite-sex. In addition, for significant associations squared PBC variables were added to the equation in order to assess departure from linearity. Analyses were not adjusted for chorion type because in an earlier report on this sample no large or significant effects of chorion type on $\mathrm{CBCL}$ scores was found ${ }^{30}$. All PBCs were entered simultaneously in the model, so as to be able to assess their independent effects. In order to assess the effect of birth weight independent of gestational age, gestational age was also entered into the regression equation. As it is possible that no main effects are found for a PBC because of statistical interaction with significant effects in opposite directions for the values of a third variable (in this study the genetic factor), interactions were not only assessed for obstetric variables with significant main effects, but also for variables with no significant main effects.

For significant associations an explorative analysis was conducted to assess possible gene-PBC interaction using normal regression analysis. This was analysed not at the level of individual twins (one observation per individual twin) but at the level of twin pairs (ie one observation per twin pair). A model was assessed in which the amount of problem behaviour in twin 1 was regressed on the three-way interaction of the amount of problem behaviour in twin 2, zygosity ( $1=$ dizygotic and 2=monozygotic) and the $P B C$ value for twin 2 . Then, the two-way interaction effect of problem behaviour in twin 2 and zygosity was assessed stratified for low and high values of the PBC. These analyses were controlled for age, gestational age and the other PBCs. A positive twoway interaction is compatible with a genetic effect ( $M Z$ twins more alike than $\mathrm{DZ}$ twins). The three-way interaction is compatible with the genetic effect being different 
at different levels of the enwironmental exposure (gene-environment interaction). These exploratory findings were followed-up by more complex statistical analyses described below.

In order to assess possible interactions in more detail, structural equation modelling was used to fit models to the CBCL data ${ }^{31,32}$. Twin models of child psychopathology usually assume an effect of four latent variables on observed phenotypic variance: additive genetic effects (A), dominance genetic effects (D), effects of shared environment $(C)$ and effects of non-shared environment (E). Model fitting is used to estimate the contribution of these latent variables on the trait variance and to test the significance of these contributions. In an earlier report on this sample ${ }^{30}$, the ACE model was found to represent the best compromise between goodness of fit and parsimony (based on $x^{2}$-squared model statistics and Akaike Information Criterion ${ }^{31,33}$ ). The values for $\mathrm{A}, \mathrm{C}$ and $\mathrm{E}$ indicating the proportion of phenotypic variance explained according to the best fitting model were respectively $0.41,0.43$ and $0.17\left(\chi^{2}\right.$ model fit $=2.21, \mathrm{df}=3, \mathrm{p}=0.53$ ).

For dichotomously defined PBCs, six groups of twins were formed according to zygosity and $\mathrm{PBC}$ exposure status (MZ jointly exposed, $\mathrm{DZ}$ jointly exposed, $\mathrm{MZ}$ jointly non-exposed, $\mathrm{DZ}$ jointly non-exposed, $\mathrm{MZ}$ discordant for $\mathrm{PBC}$ exposure and $\mathrm{DZ}$ discordant for $\mathrm{PBC}$ exposure). However, for the variables artificial induction of ovulation, twins have obligatory sharing of exposure status, resulting in four groups rather than six. For all groups, the relationship between the latent $(A, C, E)$ variables and the observed data was examined. In order to examine gene-environment interaction, two ACE-models were compared. In the first model, the estimates for A, C and $\mathrm{E}$ were not constrained to be equal in exposed versus non-exposed groups. In the second model, the A factor was constrained to be equal in exposed and non-exposed groups. A better fit of the first model, which allows differential influence of genetic factors on the exposed and non-exposed groups, suggests the presence of gene-environment interaction, where the impact of at least some genes impacting on child psychopathology is modified by exposure to a PBC. Theoretically, a PBC could either amplify or attenuate variance due to the additive effect of genes: the analyses aimed to assess statistically whether a gene-environment interaction existed and to describe its direction and magnitude. $\mathrm{A}$ better fit of the second model suggests no interaction ${ }^{34}$.

For the continuous PBC, birth weight, a conceptually different approach was used ${ }^{35}$. A different explanatory model is invoked if the potential interaction variable is a continuous PBC rather than its dichotomised extreme, as the assumption now is that it is not an extreme value of a PBC that exerts an effect, but rather that there is a kind of additive, cumulative effect of the continuous PBC across the whole dimension. First, an analysis was conducted in which birth weight was regressed on gestational age and sex. In order to obtain a measure of birth weight corrected for gestational age and sex, 
standardised residuals of the above regression model were calculated for each twin and co-twin. The number of twin pairs with non-missing values on birth weight, gestational age and sex was 658 . Subsequently, missing values were substituted with the expected. value i.e. the mean score of all other birth weights. The adjusted measure of birth weight (range: - 5.0,3.6) was used in structural equation modelling as follows. Given a continuous moderator (interaction) variable $\mathrm{M}$ (i.e. being small for gestational age), we wish to examine its possible moderating effect on individual differences in problem behaviour, i.e., the degree to which it modifies the genetic effect on phenotypic variance. This question can be modelled in terms of redefining the partial regression coefficient of problem behaviour on the latent variable $A$, so that it includes the potential effect of moderation by the variable $M$ (figure 5.1). Thus, instead of the additive genetic path being simply $a$, it is now, for twin $1,\left(a+\beta_{A} M_{1}\right)$. That is, at the level of the path coefficient, additive genetic influence can be decomposed into a mean part $(a)$ and a moderator linked part $\left(\beta_{\mathrm{A}} \mathrm{M}_{1}\right)$. If the moderator has no effect, then $\beta_{\mathrm{A}}=0$. The $\beta_{M}$ in the means model $\left[\left(n+\beta_{M M l}\right)\left(m+\beta_{M} M 2\right)\right.$ in figure 5.1] represents the phenotypic regression of problem behaviour on $M$. Thus, a test of mediation involves setting $\beta_{M}$ to 0 .

A critical test of the GxE interaction model is that the data cannot be explained by heteroscedasticity (increasing error variance in twins who are smaller for gestational age). In order to account for this, the model used allowed the unique environmental parameter to differ as a function of being SGA (involving parameter $\beta_{\mathrm{E}}$ analogous to parameter $\beta_{\mathrm{A}}$ described above). The previously published finding of environmental influences on problem behaviour ${ }^{19}$ also underscores the need to assess the moderating effect of being SGA on the shared enwronmental variance. Therefore, the model also allowed for this parameter to be fitted. If there is genetic interaction while taking into account shared or nonshared enwironment interaction with being SGA, then genetic interaction cannot be explained just in terms of increased error variance or interaction with shared environment (involving parameter $\beta_{C}$ analogous to parameter $\beta_{\wedge}$ described above). Two models were therefore compared: one in which $\beta_{A}, \beta_{C}, \beta_{E}$ and $\beta_{M}$ were freed (full model) and one in which only $\beta_{C}, \beta_{E}$ and $\beta_{M}$ were freed and $\beta_{A}$ was set to zero (test of moderation). A full description of this model, including the implied covariance matrices, is available upon request.

If a moderating effect was apparent, we plotted out the variance component as a function of the moderator. In the plot, the $x$-axis represents the moderator variable (continuous measure of being small for gestational age) and the y-axis represents the components of variance, as functions of the moderator. For example, for the $j$ th value of $\mathrm{M}$ (small for gestational age) the genetic variance component was calculated as $(a+$ $\left.\beta_{s} M_{j}\right)^{2}$. The same was done for the shared environment variance component $(c+$ $\left.\beta_{C} M_{j}\right)^{2}$ and for the non-shared environment variance component $\left(e+\beta_{\mathbb{E}} M_{j}\right)^{2}$. Crosstwin cross-trait correlations were calculated to get a better insight in the genetic contribution of the effect of being SGA on psychopathology. 


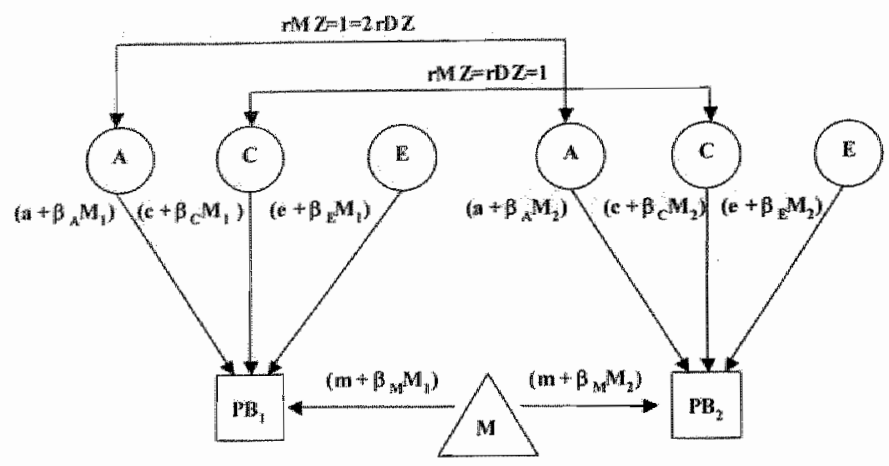

$P B=$ problem behaviour

Figure 5.1 Path diagram showing complete model for continuous moderator M (PB, problen behaviour).

\section{Results}

\section{Sample}

The mean age of the sample was 10.3 years ( $\mathrm{SD}=3.3$ ), and consisted of $539(72 \%)$ same-sex pairs, and $206(28 \%)$ opposite sex pairs. Of the same-sex pairs, 255 were male $(47 \%)$ and 284 female (53\%). The number of monozygotic pairs was $324(44 \%)$. The mean, square-root transformed, CBCL score was 3.91 ( $\mathrm{SD}=1.77$ ). The mean birth weight was 2533 gr. ( $S D=501$ ), and the mean gestational age was 37.0 weeks $(\mathrm{SD}=2.3)$. Table 5.1 shows numbers and percentages of $\mathrm{MZ}$ and $\mathrm{DZ}$ twin pairs jointly exposed, jointly non-exposed and discordant for the dichotomous PBC exposures.

"Table 5.1 Numbers and percentages of $\mathrm{MZ}$ and $\mathrm{DZ}$ twin pairs who were jointly exposed, jointly nonexposed or discofdant for the binary PBC exposures.

\begin{tabular}{|c|c|c|c|c|c|c|c|c|c|c|}
\hline \multirow[b]{2}{*}{ PBC expositrowas } & \multirow[b]{2}{*}{$N$} & \multicolumn{3}{|c|}{$\mathrm{MZ}$} & \multicolumn{3}{|c|}{$D Z$} & \multicolumn{3}{|c|}{ Total somple } \\
\hline & & Exisposent & Nomexposed & Diseordan: & Ixposed & Nolutuposed & Discoudan & Eappoged & Nonexposed & Discondant \\
\hline \multirow[t]{2}{*}{ Modite of delivery } & 735 & 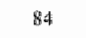 & 164 & 72 & H\$ & 187 & 77 & 235 & 351 & 1.49 \\
\hline & & $(1,4,0 \%)$ & $(22,30)$ & $(9.8 \%)$ & $00.5 \%$ & $(25,4 \%)$ & $(10,5 \%)$ & $(32,00)$ & $(47.8 \%)$ & $(20.90)$ \\
\hline \multirow[t]{2}{*}{ Fetal presenturiom } & 731 & 22 & 167 & 126 & 44 & 202 & 170 & 60 & 360 & 296 \\
\hline & & $(3.0 \mathrm{O})$ & $(22.8 \%)$ & $(17.16)$ & $\left(6.0^{\mathrm{m} / \mathrm{t}} \mathrm{0}\right)$ & $(27,610)$ & $(23.3 \%)$ & $(9.0 \%)$ & $(50.5 \%)$ & $(40.5 \%)$ \\
\hline Artithe int induscion & 712 & 10 & 300 & - & 118 & 284 & - & 128 & 584 & - \\
\hline of oxuldation" & & $(1.4 \%)$ & $(42.10)$ & & $16.6 \%$ & $(39.94 \%)$ & & $(18.0 \%)$ & $(82.0 \%)$ & \\
\hline
\end{tabular}

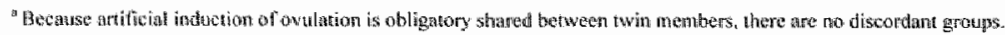




\section{Independent PBC main effects}

CBCL scores increased with decreasing birth weight $(B=0.0003, p=0.012)$, independent of gestational age and the other PBCs. No departure from linearity was found. No significant independent effects were found for mode of delivery $(B=-0.007$, $\mathrm{p}=0.95)$ gestational age $(\mathrm{B}=-0.021, \mathrm{p}=0.52)$, artificial induction of ovulation $(\mathrm{B}=0.10$, $p=0.57)$ and foetal presentation $(B=-0.15, p=0.060)$.

\section{Interactions between genes and PBCs.}

In the model of problem behaviour in twin 1, a three-way positive interaction between psychopathology of twin 2, zygosity and birth weight of twin 2 was found $(B=0.0001$, $p=0.000$ ). No three-way interactions were apparent for the other PBCs. Stratified for birth weight, no significant interaction between zygosity and psychopathology in twin 2 was found for children with a birth weight under $2000 \mathrm{~g}(\mathrm{~B}=0.1181, \mathrm{p}=0.440)$. However, for a birth weight of more than $2000 \mathrm{~g}$, the interaction was positive and significant $(\mathbb{B}=0.2318, p=0.000)$. Similar results were found when the same analyses were done regressing problem behaviour of twin 2 on that of twin 1 instead of the other way around.

Table 5.2 shows the fit statistics of the ACE models for the dichotomous exposure factors. The ACE model in which the additive genetic factor (A) was not alllowed to vary between exposed and non-exposed groups is called the A(same)CE model (i.e. A was constrained to be the same in exposed and non-exposed groups). For all dichotomous exposure factors, this model was a better compromise between goodness of fit and parsimony, as indicated by a lower AIC score, than the ACE model in which the additive genetic factor was allowed to vary.

Table 5.2 Fit statistics of ACE models for binary expostre factors.

\begin{tabular}{|c|c|c|c|c|c|c|c|c|c|c|}
\hline Modell & $A(\exp )^{i}$ & $C(\exp )^{\mathrm{a}}$ & $E(\exp )^{a}$ & A(nexp $)^{h}$ & Conexp) & $\mathrm{E}(\operatorname{nexp})^{19}$ & $x^{2}$ & $d f^{*}$ & $p$ & $A \mid C^{k}$ \\
\hline \multicolumn{11}{|c|}{ Mode of delivery } \\
\hline $\mathrm{ACE}$ & 0.666 & 0.626 & 0.405 & 0.627 & 0.666 & 0.404 & 15,622 & 12 & 0.2091 & -8.378 \\
\hline $\mathrm{A}(\mathrm{same}) \mathrm{CE}$ & 0.666 & 0.626 & 0.405 & 0.626 & 0.667 & 0.404 & 15.622 & 13 & 0.2701 & $.10 .37 \mathrm{~g}$ \\
\hline \multicolumn{11}{|c|}{ Fetal presentation } \\
\hline$A C E^{\text {il }}$ & 0.711 & 0.616 & 0.339 & 0.641 & 0.646 & 0.415 & 4.764 & 12 & 0.9654 & -19.236 \\
\hline$A($ same $) C E^{e}$ & 0.662 & 0.626 & 0.412 & 0.670 & 0.653 & 0.352 & 5.213 & 13 & 0.9702 & -20.787 \\
\hline \multicolumn{11}{|c|}{ Artificial induction of ovalation } \\
\hline$A C E^{\mathbb{U}}$ & 0.411 & 0.683 & 0.604 & 0.632 & 0.663 & 0.402 & 3.338 & 6 & 0.7653 & -8.662 \\
\hline Alsame ClF & 0.617 & 0.588 & 0.524 & 0.624 & 0.670 & 0.404 & 3.858 & 7 & 0.7960 & -10.142 \\
\hline
\end{tabular}

"parameter estimation of latent factor for exposed groups;" paraneter estimation of latent factor for non-exposed groups; " AlC is calculated as follows: $\chi^{2}$ - 2 df "Model assuming additive genetic ( $A$ ), shared (C) and nonshared (E) environmental inflicnces in which all estinates are allowed to vary between exposed and non-exposed groups; "Model assumimg addiive genetic (A), shared $(C)$ and nonshared (E) environmentall influences un which the additje genexic facior $(A)$ is not allowed to be different for exposed and non-exposed groups. 
For the continuous birth weight exposure adjusted for gestational age and sex, the test for moderation (interaction) was significant (table 5.3). Plotting out the variance component as a function of the moderator revealed that the influence of additive genetic factors on individual differences in problem behaviour decreased with being smaller for gestational age. Influences of shared and nonshared environment increased with being smaller for gestational age. (figure 5.2 ).

Cross-twin cross-trait correlations (table 5.4) revealed that correlations between birth weight of twin 1 and $C B C L$ score of twin 2 were similar for $\mathrm{DZ}(r=0.0950)$ and $\mathrm{MZ}$ $(r=0.1035)$ twins. Also, no differences were found between $D Z$ and $M Z$ twins for correlations between birth weight of twin 2 and CBCL score of twin $1(r=0.0295$ and $=-0.0369$ respectively).

Table 5.3 Model comparison for continuous birth weight exposure, corrected for gestational age and sex

\begin{tabular}{|c|c|c|c|}
\hline Model & -2 Log likelihood (d) & Model difference (df) & $p$ \\
\hline$A C E-\beta A-\beta C-\beta E A M$ (full model) & $5314.766(1479)$ & $-\cdots$ & - \\
\hline$A C E-\beta_{C} \beta E-B M($ test moderation of $A$ ) & $5325.252(1.480)$ & $10.49(1)$ & 0.001 \\
\hline$A C E-B_{A}-\beta E B M$ (test moderation of $\left.C\right)$ & $5327.417(1480)$ & $12.65(1)$ & $<0.001$ \\
\hline$A C E-\beta_{A} \beta C \cdot B M($ test moderation of $E)$ & $5333.422(1480)$ & $18.66(1)$ & $<0,001$ \\
\hline
\end{tabular}

* for explanation please see text

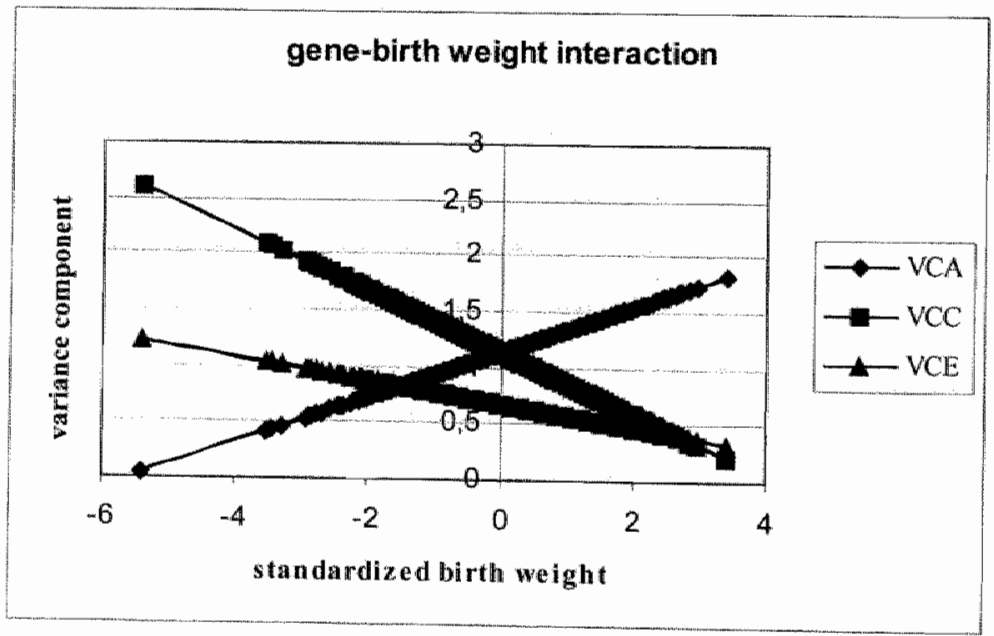

Figure 5.2 Plot of genetic (A), shared environmental (C) and unique environmental (E) variance components, VCA, VCC and VCE respectively, of the square root total CBCL score, as a function of the birth weight moderatort 
Table 5.4 Cross twin cross trait and cross twin within trait correlations (birth weiglat and child psychopathology) for $\mathrm{DZ}$ and $\mathrm{MZ}$ wins

\begin{tabular}{lccccc}
\hline & & \multicolumn{2}{c}{ Birth weight twin 1 } & \multicolumn{2}{c}{ CBCL score twin I } \\
& & $\mathrm{DZ}$ & $\mathrm{MZ}$ & $\mathrm{DZ}$ & $\mathrm{MZ}$ \\
\hline Birth weight twin 2 & $\mathrm{DZ}$ & 0.6503 & - & -0.0295 & - \\
& $\mathrm{MZ}$ & - & 0.7207 & - & -0.0369 \\
\multirow{2}{*}{ CBCL score twin 2 } & $\mathrm{DZ}$ & -0.0950 & - & 0.6409 & - \\
& $\mathrm{MZ}$ & - & -0.0295 & - & 0.8232 \\
\hline
\end{tabular}

\section{Discussion}

Confirming previous work, we found that lower birth weight adjusted for gestational age, or being SGA, was associated with greater child problem behaviour ${ }^{15-18}$. A main effect of being SGA is consistent with many previous studies reporting that children who are SGA are at increased risk for ADHD, depressive symptomatology and behavioural problems ${ }^{10,11,36-39}$.

Regression analyses stratified for birth weight showed a significant interaction between problem behaviour and zygosity only for children with a higher birth weight, taking into account gestational age, suggesting that genetic influence might be greater for children who are not SGA.

Furthermore, ACE models showed evidence for a differential influence of genetic factors on child problem behaviour as a function of being SGA. Thus, in as much as genes influence child psychopathology, their effect may be modified by being SGA, which is compatible with findings of previous research ${ }^{23}$. This differential influence of genetic factors suggests that child problem behaviour might be caused by being SGA or by high genetic vulnerability, suggesting that both causes "compete" for the same outcome.

As birth weight itself is subject to both genetic and environmental influences ${ }^{40}$, any explanation for the apparent association between being small for gestational age and childhood psychopathology should consider genetic and environmental mechanisms ${ }^{20}$, including the possibility that the observed relationship between being SGA and child problem behaviour is due to a shared environmental or genetic variable that influences both characteristics. For example, antisocial traits in the mother that are genetically transmitted to the offspring may affect both birth weight and antisocial behaviour in the child. However, the fact that the cross-twin cross-trait correlations were the same for $\mathrm{DZ}$ and $\mathrm{MZ}$ twins makes it unlikely that our results can be explained by genetic factors influencing both birth weight and child psychopathology. In addition, in a previous study in the same sample we showed, using a variation of the co-twin control method, that the effect of being SGA on childhood psychopathology was likely to be causal ${ }^{19}$. However, it is still possible that this causal effect is not direct but represents the effect of another, earlier environmental factor. For example, birth weight is influenced by a 
range of environmental factors such as gestational age, maternal age, parity, chorion type, placental proximity and presence or absence of vascular anastomoses; other factors that have been associated with LBW are number of previous LBW babies, premature rupture of membranes, multiple births, heavy smoking, early and late pregnancy bleeding, low maternal weight, short maternal height, older maternal age, pre-eclampsia, history of a previous stillbirth, primiparity, exposure to stressors and difficulties, chronic illness, fetal female sex and congenital anomalies ${ }^{4-49}$. All of these could theoretically be involved in the observed gene-birthweight interaction. However, there is considerable evidence that being SGA is an important independent factor in contributing to a range of adult health outcomes ${ }^{30-54}$, and it is interesting to speculate that part of these effects occur in competition with genetic factors.

If positive and/or negative gene-birth weight interaction is common in nature, it may explain the fact that heritability estimates derived from twin studies tend to be different from heritability estimates from non-twin samples such as extended family samples ${ }^{55}$, as twins on average have lower birth weights than singletons. In addition, problem behaviour discordance in $M Z$ twins, in which some degree of the transfusion syndrome is often present, may be attributable to the moderating effect of being SGA on genetic liability for this trait rather than a "pure" environmental effect.

Another interesting finding was the positive interaction between shared environmental factors and low birth weight, indicating that shared environmental factors and low birth weight work agonistically in bringing about postnatal mental health effects. Those with certain environmental backgrounds (shared by twins) are more sensitive to the effects of low birth weight on later problem behaviours. An alternative explanation for this finding, however, is the rater bias by which twins are rated more similar than they actually are. If this bias operates, it is likely to be greater in (more similar) MZ twins and since the $M Z$ twins in this sample had a lower birth weight ${ }^{19}$, the increased shared environmental influence with being SGA might be the result of such a differential rater bias. The interaction of non-shared environment with being small for gestational age is likely to reflect heteroscedasticity or increased error variance for children with lower birth weight.

A methodological drawback is the limited statistical resolution of the study, especially with regard to the lowest prevalence of the dichotomous PBCs. A further factor is the fact that some of the exposures, such as the Caesarean section, are heterogeneous in nature, with a substantial proportion representing elective rather than emergency procedures. As not much is known about the size of possible gene-environment interactions in childhood psychopathology, it is extremely difficult to give an exact estimate of the amount of statistical power of the current study ${ }^{56}$. It is quite possible, however, that if weaker interactions existed, they were not detected in the present study. 


\section{References}

1. Achenbach TM. Integrative guide for the $1991 \mathrm{CBCL} / 4-18, \mathrm{YSR}$, and TRF profiles. Burlington: University of Vermont, Department of Psychiatry, 1991.

2. Schmitz $S$, Fulker DW, Mrazek DA. Problem behavior in early and middle childhood: an initial behavior genetic anallysis. $J$ Child Psychol Psychiary 1995;36(8):1443-58.

3. Rutter $M$, Dunn $J$, Plomin $R$, et al. Integrating nature and nurture: implications of personenvironment correlations and interactions for developmental psychopathology. Dev Psychopathol 1997;9(2):335-64.

4. van Os J, Marcelis M. The ecogenetics of schizophrenia: a review. Schizophr Res $1998 ; 32(2): 127-35$.

5. van $O$ S J, Sham $P$. Gene-environment interactions. In: Murray RM, Jones PB, Susser E, wan Os $J$, Cannon $M$, eds. The epidemiology of schizophrenia. Cambridge: Cambridge University Press, 2001.

6. Botting N, Powls A, Cooke RW, Marlow N. Attention deficit hyperactivity disorders and other psychiatric outcomes in very low birthweight children at 12 years. J Child Psychol Psychiaty 1997;38(8):931-41.

7. Szatmari P, Saigal S, Rosenbaum P, Campbell D, King S. Psychiatric disorders at five years among children with birthweights less than $1000 \mathrm{~g}$ a a regional perspective. Dev Med Child Neurol 1990;32(11):954-62.

8. Cryan E, Byme $M$, O'Donovan A, O'Callaghan E. A case-control study of obstetric complications and later autistic disorder. $J$ Autism Dev Disord 1996;26(4):453-60.

9. Burd L, Severud R, Kerbeshian J, KJug MG. Prenatal and perinatal risk factors for autism. J Perimat Med 1999;27(6):441-50.

10. Frost AK, Reinherz HZ, Pakiz-Camras B, Giaconia RM, Lefkowitz ES. Risk factors for depressive symptoms in late adolescence: a longitudinal community study. Am $J$ Orthopsychiatry 1999;69(3):370-81.

11. Hoy EA, Sykes DH, Bill JM, Halliday HL, MoClure BG, Reid MM. The social competence of very-low-birthweight children: teacher, peer, and self-perceptions. I Abnowm Child Psychol 1992;20(2):123-50.

12. Buka SL, Tsuang MT, Lipsitt LP. Pregnancy/delivery complications and psychiatric diagnosis. A prospective study. Arch Gen Psychiany 1993;50(2):151-6.

13. Verdoux H, Bourgeois M. A comparative study of obstetric history in schizophrenics, bipolar patients and normal subjects. Schizophr Res 1993;9(1):67-9.

14. Geddes JR, Verdoux H, Takei $N$, et al. Schizophreniat and complications of pregnancy and labor: an individual patient data meta-analysis. Schizophr Bull 1999;25(3):413-23.

15. Cnattingius $\mathrm{S}$, Hultman $\mathrm{CM}$, Dahl $\mathrm{M}$, Sparen $\mathrm{P}$. Very preterm birth, birth trauma, and the risk of anorexia nervosa among girls. Arch Gen Psychiary 1999;56(7):634-8.

16. Pryor J, Silva PA, Brooke M. Growth, development and behaviour in adoleseents born small-for-gestational-age. I Paediatr Child Healih 1995;31(5):403-7.

17. Schothorst PF, van Engeland H. Long-term behavioral sequelae of prematurity. $d$ Am Acad Child Adolesc Psychiatry 1996;35(2):175-83.

18. Silva PA, McGee R, Williams S. A longitudinal study of the intelligence and behavior of preterm and small for gestational age children. I Dev Behav Pediatr 1984;5( 1 ):1-5.

19. van Os J, Wichers M, Danckaerts $M$, Van Gestel S, Derom C, Vlietinck R. A prospective twin study of birth weight discordance and child problem behavior. Biol Psychiatry 2001;50(8): 593-9.

20. Marcelis $\mathbf{M}$, van Os $\mathbf{J}$, Sham $\mathbf{P}$, et al. Obstetric complications and familial morbid risk of psychiatric disonders. Am $J$ Med Genet 1998;81(11):29-36. 
21. Camnon TD, Mednick SA, Pamas J, Schulsinger F, Praestholm J, Vestergaard A. Developmental brain abnormalities in the offspring of schizophrenic mothers. I. Contributions of genetic and perinatal factors. Arch Gen Psychiatry 1993;50(7):551-64.

22. Cantor-Graae E, MeNeil TF, Torrey EF, et al. Link between pregnancy complications and minor physical anomalies in monozygatic twins discordant for schizophrenia. An J Psychiatry 1994;151(8):1188-93.

23. Koeppen-Schomerus $G$, Eley TC, Wolke D, Gringras P, Plomin R. The interaction of prematurity with genetic and environmental influences on cognitive development in twins. $J$ Pediatr 2000;137(4):527-33.

24. Loos $R$, Derom $C$, Vlietinck $R$., Derom $R$. The East Flanders Prospective Twin Survey (Belgjum): a population-based register. Twin Res 1998; I(4):167-75.

25. Viletinck R. Determination of the zygosity of twins. Doctoral thesis: KU, 1986.

26. Verhulst FC, wan der Ende J, Koot HM. Handleiding voor de CBCL/4-18. Rotterdam: afdeling kinder- en jeugdpsychiatrie, Sophia Kinderziekenhuis/Academisch Ziekenhuis Rotterdam, Erasmus Universiteit Rotterdam, 1996.

27. Hartman CA, Hox J, Auerbach $J$, et al Syndrome dimensions of the child behavior checklist and the teacher report form: a critical empirical evaluation. $J$ Child Psychol Psychiary 1999;40(7):1095-116.

28. Greenbaum PE, Dedrick RF. Hierarchical confirmatory factor analysis of the Child Behavior Checklist/4-18. Psychological Assessment 1998;10(2):149-155.

29. StataCorp. STATA statistical software: Release 7.0.: Statacorp: College Station, TX, 2001.

30. Wichers MC, Danckaeris $M$, Van Gestel $S$, Derom $C$, Vlietink R, van Os J. Chorion type and twin similarily for child psychiatric symptoms. Arch Gen Psychiatry 2002;59(6):562-4.

31. Sham $P$. The analysis of continuous and quasi-contimuous characters. Statistics in human genetics. London: Arnold Applications of statistics, 1998.

32. Neale $\mathrm{MC}$, Heath $\mathrm{AC}$, Hewitt $\mathrm{JK}$, Eaves LJ, Fulker DW. Fitting genetic models with LISREL: hypothesis testing. Behow Genet 1989;19(1):37-49.

33. Akaike H. Factor analysis and AIC. Psychometrika 1987;52:317-332.

34. Neale MC, Cardon LR. Methodology for genetic studies of twins and families. Dordrecht: Kluwer academic publishers, 1992.

35. Purcell S. Moderating variables in twin model fitting. 2001 submitted manuscript.

36. McCormick MC, Gortmaker SL, Sobol AM. Very low birth weight children: behavior problems and school difficulty in a national sample. J Pediatr 1990;117(5):687-93.

37. Gjone H, Novik TS. Parental ratings of behaviour problems:" a twin and general population comparison. IChild Psychol Psychratry 1995;36(7):1213-24.

38. Sommerfelt $K$, Troland $K$, Ellertsen $B$, Markestad T. Behavioral problems in lowbirthweight preschoolers. Dev Med Child Newrol 1996;38(10):927 40.

39. Horwood LJ, Mogridge N, Darlow BA. Cognitive, educational, and behavioural outcomes at 7 to 8 years in a national very low birthweight cohort. Arch Dis Child Fetal Neonatal Ed $1998 ; 79(1): F 12=20$.

40. Vhetinck R, Derom R, Neale MC, et al. Genetic and environmental variation in the birth weight of wins. Behar Genet 1989;19(1):151-61.

41. Meis PJ, Michiehute R, Peters TJ, et al. Factors associated with term low birthweight in Cardiff, Wales. Paediary Perinat Epidemiol 1997;11(3):287-97.

42. Bjerre B, Bjerre 1. Significance of obstetric factors in prognosis of low birthweight children. Acta Paediatr Scand 1976;65(5):577-83.

43. Abdulrazzaq $\mathrm{YM}$, Bener A, Dawodu A, et al. Obstetric risk factors affecting incidence of low bith weight in live-born infants. Biol Neonate $1995 ; 67(3): 160-6$. 
44. Shu XO, Hatch MC, Mills J, Clemens J, Susser M. Matemal smoking, alcohol drinking, caffeine consumption, and fetal growth: results from a prospective study. Epidemology $1995 ; 6(2): 115-20$.

45. Herceg A, Simpson JM. Thompson JF. Risk factors and outcomes associated with low birthweight delivery in the Australian Capital Territory 1989-90. J Paediair Child Health $1994 ; 30(4): 33 \rrbracket-5$.

46. Orr ST, James SA, Miller CA, et al. Psychosocial stressors and low birthweight in an urban population. Am J Prev Med 1996;12(6):459-66.

47. Pritchard CW, Teo PY. Preterm birth, low birthweight and the stressfulness of the household role for pregnant women. Soc Sci Med 1994;38(1):89-96.

48. Wadhwa PD, Sandman CA, Porto M, Dunkel-Schetter C, Garite TJ. The association. between prenatal stress and infant birth weight and gestational age at birth: a prospective investigation. Am J Obstet Gynecol 1993;169(4):858-65.

49. Corey LA, Nance WE, Kang KW, Christian JC. Effects of type of placentation on birthweight and its variability in monozygotic and dizygotic twins. Acta Genet Med Gemellol 1979;28(1):47-50.

50. Cannon $\mathrm{M}$, Jones $\mathrm{P}$, Gilvarry $\mathrm{C}$, et al. Premorbid social functioning in sehizophrenia and. bipolar disorder: similarities and differences. Am J Psychiatry 1997;154(11):1544-50.

51. Jones PB, Rantakallio P, Hartikainen AL, Isohanni M, Sipila P. Schizophrenia as a longterm outcome of pregnancy, delivery, and perinatal complications: a 28 -year follow-up of the 1966 north Finland general population birth cohort. Am J Psychiatry 1998;155(3): $355-64$.

52. Rifkin L, Lewis S, Jones P, Toone B, Murray R. Low birth weight and schizophrenia. Br I Psychiatry 1994;165(3):357-62.

53. Barker DJ, Bull AR, Osmond C, Simmonds SI. Fetal and placental size and risk of hypertension in adult life. $B m j$ 1990;301(6746):259-62.

54. Valdez R, Athens MA, Thompson GH, Bradshaw BS, Stern MP. Birthweight and adult health outcomes in a biethnic population in the USA. Diabetologia 1994;37(6):624-31.

55. Khoury MJ, Beaty $\mathrm{TH}_{3}$ Cohen BH. Genetic epidemiology. Oxford: Oxford University Press, $₫ 993$.

56. Hwang SJ, Beaty TH, Liang KY, Coresh J, Khoury MJ. Minimum sample size estimation to detect gene-environment interaction in case-control designs. Am $J$ Epidemial 1994; 140(11): 1029-37. 


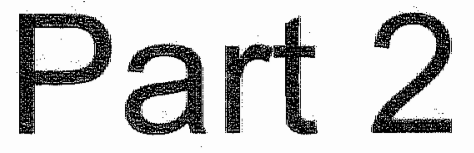

Role of immune activation in depression 


\section{Chapter}

\section{The psychoneuroimmuno-pathophysiology of cytokine-induced depression in humans}

Marieke Wichers, Michael Maes

International Joumal of Neuropsychopharmacology 2002,5:375-88 


\section{Abstract}

Administration of the cytokines interferon $\alpha$ and interleukm-2 is used for the treatment of various disorders, such as hepatitis $\mathrm{C}$ and various forms of cancer. The most serious side-effects are symptoms associated with depression, including fatigue, increased sleepiness, irritability, loss. of appetite as well as cognitive changes. However, great differences exist in the prevalence of the development of depressiwe symptoms across studies. Differences in doses and duration of therapy may be sources of variation as well as individual differences of patients, such as a history of psychiatric illness. In addition, sensitisation effects may contribute to differential responses of parients to the administration of cytokines. In aninals administration of pro-inflammatory cytokines induces a pattern of behavioural alterations called "sickness behaviour" which resembles the vegetative symptoms of depression in humans. Changes in serotonin (5-HT) receptors and in levels of 5-HT and its precursor tryptophan (TRP) in depressed people support a role for 5-HT in the development of depression. In addition, evidence exists for a dysregulation of the noradrenergic system and a hyperactive hypothalamic-pituitary-adrenal (HPA) axis in depression. Some mechanisms exist which make it possible for cytokines to cross the bloodbrain-barrier. Pro-inflammatory cytokines such as $I L-1 \beta$, IFN- $\alpha$, IFN- $\gamma$ and TNF- $\alpha$ affect the 5HT metabolism directly and/or indirectly by stimulating the enzyme indoleamine 2,3 dioxygenase which leads to a peripheral depletion of tryptophan. IL- I, IL-2 and TNF- $\alpha$. influence noradrenergic activity and $I L-1, I L-6$ and TNF- $\alpha$ are found to be potent stimulators of the HPA axis. Altogether, administration of cytokines may induce alterations in the brain resembling those found in depressed patients, which leads to the hypothesis that cy tokines induce depression by their influence on the 5-HT, noradrenaline (NE) and HPA system. 


\section{Cytokine therapy and neuropsychiatric side-effects}

Cytokine therapy is used for the treatment of various disorders. The cytokine 'interferon- $\alpha$ ' (IFN- $\alpha$ ) has been used as a therapeutic agent in humans since 1976. First, it was used for the treatment of chronic hepatitis B'. Over the years it was also found to be effective in various forms of cancer such as renal cell cancer ${ }^{2}$, metastatio melamoma ${ }^{3}$, chronic myelogenous leukaemia, AIDS related Karposi's sarcoma and other forms of cancer. In addition, it has been used as a therapy for HIV infected patients ${ }^{4}$. IFN- $\alpha$ is mainly used for the treatment of patients suffering from a malignant melanoma and for chronic hepatitis $\mathrm{C}$ patients.

IFN- $\alpha$ demonstrates major antiviral and immunomodulatory effects ${ }^{5}$. It increases the expression of major histocompatibility complex (MHC) class I molecules and cellular adhesion molecules which is thought to facilitate the recognition of virus-infected or tumor cells by cytolytic T-lymphocytes ${ }^{6,7}$. In addition it promotes the differentiation of macrophages, the production of pro-inflammatory cytokines such as IFN- $\gamma^{8}$, interleukin-6 (IL-6) ${ }^{9}, \mathrm{IL}-1$ and tumor necrosis factor alpha (TNF- $\alpha$ ) ${ }^{10}$ and it may induce a 2- to 5-fold increase in surface receptors for the constant immunoglobulin region (Fc receptors) ${ }^{10}$. These effects may result in increased macrophage function and an enhanced efficiency of antigen presentation'". IFN- $\alpha$ also augments the cytotoxic activity of natural killer (NK) cells by enhancing interleukin-2 (IL-2) dependent growth, cytokine production and antibody-dependent cellular cytotoxicity ${ }^{7}$. Finally, type I IFNs (IFN- $\alpha$, IFN- $\gamma$ and IFN- $\omega$ ) have variable effects on B-cell proliferation, differentiation, and antibody formation. Whether the effect is activation or inhibition depends upon the immunoglobulin isotype, the antigen dose, and the simultaneous secretion of other cytokines ${ }^{12,13}$.

In hepatitis $C$ the response rate of IFN- $\alpha$ monotherapy is only $10-15 \%$. However, a combination therapy of ribavirin together with IFN- $\alpha$ increases the overall response rate to $40 \%{ }^{4}$. In cancer, the response rate is around $20 \%$. A meta-analysis showed a mean overall response rate of $14 \%$ (range $4-33 \%$ ) for renal cell carcinoma and $24 \%$ (range 10-46\%) for metastatic melanoma.

Another cytokine, IL-2, has been used as a therapeutic agent for the treatment of various forms of cancer, since 1981. IL-2 is an autocrine and paracrine growth factor that is secreted by activated T lymphocytes and promotes T" cell proliferation. IL-2 stimulated $T$ cells exhibit enhanced cytotoxicity and produce lymphokines such as IFN$\gamma$, tumour necrosis factor (TNF)- $\beta$ and transforming growth factor (TGF)- $\beta$, $B$ cell growth factors such as IL-4 and IL-6 and hematopoletic growth factors such as IL-3, IL-5 and granulocyle-macrophage colony-stimulating factor (GM-CSF) In addition, IL-2 stimulates the cytolytic activity of NK cells and their secretion of several cytokines including IFN- $\gamma$, GM-CSF and TNF $-\alpha$, it enhances the proliferation and antibody secretion by normal $B$ cells and it stimulates the cytotoxic activities of activated macrophages and promotes their secretion of TNF- $\alpha$, IL-1 and IL-6. IL-2 therapy has been shown to produce partial remission in some patients with renal cell 
carcinoma or metastatic melanoma". In cancer therapy $I L-2$ is also used in combination with administration of IFN- $\alpha$ in order to increase the response rate.

\section{Neuropsychiatric side-effects of IFN- $\alpha$}

In almost all patients, administration of IFN- $\alpha$ induces an acute influenza-like syndrome 6 to $8 \mathrm{~h}$ after the initial injection. Symptoms include fever, chills, malaise, myalgias, arthralgias and tachycardia. These symptoms gradually diminish over the first 2 wk of treatment. Other side-effects are gastrointestinal symptoms, such as anorexia, dyspepsia, nausea, diarrhoea, abdominal pain; respiratory symptoms, such as cough, dyspnoea and pharyngitis; dermatological symptoms such as hair loss, itching and rash; and haematological symptoms, such as anaemia thrombocytopenia and granulocytopenia ${ }^{16}$. However, the most common reason for discontimuation of IFN- $\alpha$ based immunotherapy are neuropsychiatric symptoms.

The most common neuropsychiatric side-effects are symptoms associated with depression, such as fatigue, increased sleepiness and difficulty sleeping, irritability, loss of appetite, weight loss and low mood. A full blown depressive disorder is reported in up to $36 \%$ of cases ${ }^{14}$. Other neuropsychiatric symptoms are cognitive changes involving verbal memory, cognitive speed and executive function ${ }^{17}$. In rare cases IFN- $\alpha$ may cause psychosis, delirium ${ }^{18,19}$, persistent manic depressive illness ${ }^{20}$ recurrence of a post-traumatic stress disorder ${ }^{21}$ or suicidal behaviour ${ }^{22-25}$ "

Most studies which examine the effects of IFN- $\alpha$ only briefly mention the occurrence of neuropsychiatric side-effects in some patients, using subjective rapports. However, there are several studies which specifically examined the rate of depressive and cognitive symptoms during IFN- $\alpha$ therapy using instruments to measure these affective and cognitive changes (table 6.1-3). Almost all studies report an increase in depressive symptoms during IFN- $\alpha$ therapy ${ }^{8,17,26-29}$. One study measured depressive symptoms using the Beck Depression Inventory (BDI), but also performed photon emission tomography (PET) scans before and 3 months after starting IFN- $\alpha$ therapy ${ }^{30}$. Although they reported a non-significant increase in depressive symptoms, they found that hypometabolism in the prefrontal areas covaried strongly with the BDI score ( $p<0.001)$, suggesting that IFN- $\alpha$ changes the frontal lobe functioning. Another study ${ }^{2}$ reported an increase in the behavioural symptoms of depression, such as decreased energy, psychomotor slowing, hypersomnia, loss of interest and decreased appetite. Paradoxically and in contrast to most studies, they found a decline in the number of patients experiencing episodic depression, which they explained as reflecting the patients' state of emotional indifference, consistent with changes in frontal lobe functioning. Only two studies found no changes at all in depressive symptoms ${ }^{31,32}$.

More inconsistent results are found concerning the influence of IFN- $\alpha$ on symptoms of anxiety. Four studies, using the State-Trait Anxiety Inventory (STAI) ${ }^{33}$, the Hamilton Anxiety Rating Scale (HAM-A) ${ }^{34}$, the non-patient version of the Structured clinical interview for DSM-III-R (SCID-NP) ${ }^{28}$ or a mental status examination ${ }^{29}$ as assessment, showed an increase in level of anxiety. In three other studies $2,27,30$, however, levels of 
anxiety appeared to be decreased. Although in one study the decline was nonsignificant $^{30}$.

Table 6.1 Studies using depression/anxiety assessments and measurements for cognitive function

\begin{tabular}{|c|c|c|c|c|c|}
\hline Study & Year & $\mathrm{N}$ & Measure & Condition & Findings \\
\hline Pavol & 1995 & 25 & $\begin{array}{l}\text { subtests of WAIS-R, Verbal and } \\
\text { nonverbal selective reminding } \\
\text { test, grooved pegboard, subtest } \\
\text { of multilingual aptaasia } \\
\text { examination, } \\
\text { TMT-A en B, booklet caiegory } \\
\text { test, MMPI }\end{array}$ & $\begin{array}{l}1 F \mathrm{~N}-\mathrm{n}=25 \\
\text { Control } n=16\end{array}$ & 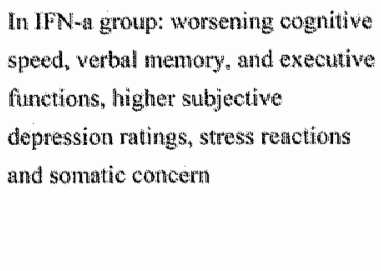 \\
\hline Caracani & 1998 & 67 & $\begin{array}{l}\text { UPDS, BPS, corsi cubes spatial } \\
\text { memory test, digit span, STAI, } \\
\text { TIC }\end{array}$ & $\begin{array}{l}15 \mathrm{~N} \cdots x=37 \\
\text { control } n=30\end{array}$ & $\begin{array}{l}\text { In IFV-a group: action tremor, brief } \\
\text { visual hallucinations, higher tevel of } \\
\text { anxiety, no charuges in cognitive } \\
\text { function. }\end{array}$ \\
\hline Juengling & 2000 & 11 & $\begin{array}{l}\text { PET scan, AVLT, verbal } \\
\text { fhency, } \\
\text { TMT-A, BDI, HADS and SCLm } \\
90\end{array}$ & IFN- $-x$ & $\begin{array}{l}\text { Non-significant raise in depression } \\
\text { and decline in anxiefy. Significan } \\
\text { worsening AVLT, fromal } \\
\text { lhypometabolism which corretated } \\
\text { strongly with BDI scores }\end{array}$ \\
\hline Mapou & 1996 & 18 & $\begin{array}{l}\text { complete neuropsychological } \\
\text { evaluation including thests of } \\
\text { attention, tesponse speed, motor } \\
\text { skills, language, visuospatial } \\
\text { skills, learning and memory. } \\
\text { BDD, STAl }\end{array}$ & IFN $-\alpha$ & No significant changes \\
\hline Adams & 1984 & 10 & $\begin{array}{l}\text { Clinical mental status } \\
\text { examination } \\
\text { Bender Gestat Test, TMT A } \\
\text { and B. Halstead Reitan Battery, } \\
3 \text { WAIS subtests }\end{array}$ & IFN- $\alpha$ & 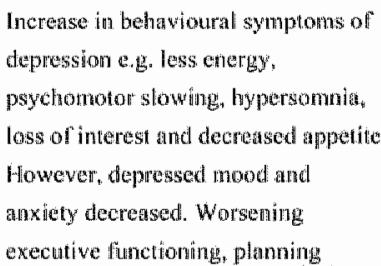 \\
\hline
\end{tabular}

TMT: trail making test; MMPU: Minnesota Multiphasic Personality Invertory; TIC: Therapy Impract Questionmatre; UPDS: Unified scalle for the evaluation of parkinsonism symptoms: BPS: Brief Psychiatric Saalle: A WT: Auditogy Vorball Leatring Test: BDI: Beck Depression Inventory; HADS: Hospital Anxiety and Depression Scale; SCL-90: Symptom Check List -90; STAI: Staie-Trait Anxiety Inventory; WAIS: Wechsler Adult Intelligence Scale. 
Table 62. Sudies using only assessments of depression/anxiety

\begin{tabular}{|c|c|c|c|c|c|}
\hline Study & Yalr & M & Weastre & 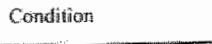 & Findingaps \\
\hline 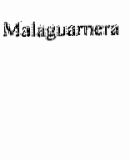 & 998 & 96 & $\operatorname{sins}$ & 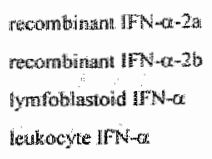 & 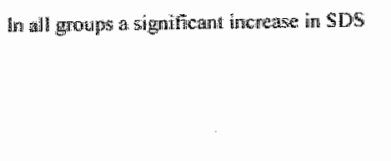 \\
\hline 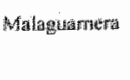 & $29 \mathrm{sin}$ & 96 (sime & $H A M-D$ & samie condicitonis & 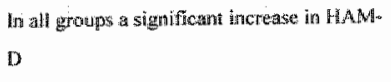 \\
\hline Bionliceorso & 2002 & 14 & MAWI-A and MADPS & $1+x-2 x-2$ & $\begin{array}{l}\text { Signifleant increatse in HAM-A and } \\
\text { MADRS } 50 \text { Ho sconed }>15 \text { an MADRS }\end{array}$ \\
\hline Plent? & 1037 & 36 & $1 \mathrm{ADS}, \mathrm{BDH}, \mathrm{SH}-36$ & $B P+D \times 2 b$ & 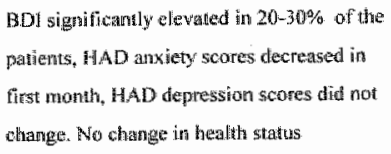 \\
\hline Meilder & 2000 & 63 & $\mathrm{SClD}, \mathrm{SCH} ; \mathrm{GH}$ & $\| F \mid N=\alpha$ & Wo changes in anxiety of depression scoures \\
\hline Pariantite & 1999 & 50 & $\mathrm{SCH}$ & 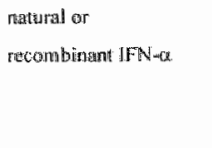 & 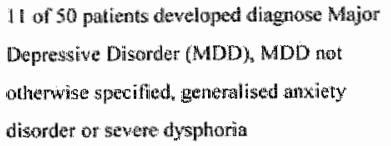 \\
\hline Remaulli & 1987 & 58 & 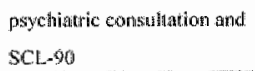 & IFW-O & 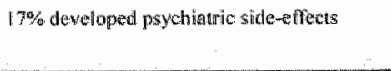 \\
\hline
\end{tabular}

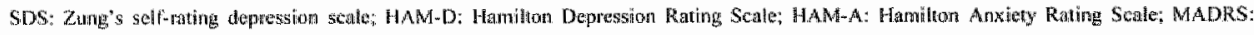

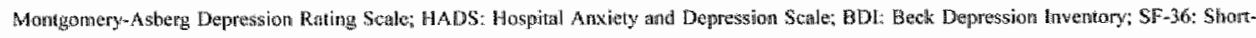

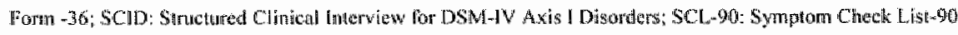

Table 6.3 Study using only assessment of zognitive function

\begin{tabular}{|c|c|c|c|c|c|}
\hline Situdy & Ycats & $N$ & Merssure & Condition & Finding \\
\hline Potabiainen & 1905 & 21 & 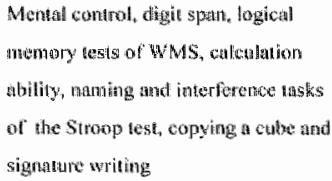 & 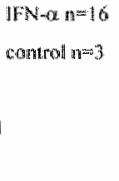 & 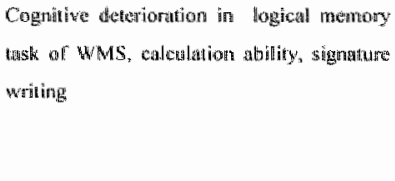 \\
\hline
\end{tabular}

\section{Neuropsychiatric side-effects of IL-2}

Most studies evaluating IL-2 treatment report neuropsychiatric side-effects such as loss of energy, fatigue, malaise and decreased food intake ${ }^{35-37}$.

Only few studies were carried out that examined the neuropsychiatric effects of $\mathbb{L L}-2$ using psychiatric and/or cognitive instruments. Denicoff ${ }^{38}$ studied 44 patients with 
metastatic cancer who received recombinant IL-2 alone, or IL-2 followed by treatment with combined autologous lymphokine-activated killer cells and IL-2. Cognitive tests and mood self-rating instruments were administered at the beginning and end of the [L-2 only and combined IL-2 and lymphokine-activated killer cell treatment phases, as well as before discharge. Of the 44 patients studied, 15 showed severe behavioural changes, such as severe agitation and combative behaviour that necessitated the use of neuroleptic agents in 12 patients, physical restraints in 12 , or emergency psychiatric consultation. In addition, 22 patients had severe cognitive changes, such as disorientation, delusions and hallucinations, and met the DSM-III criteria for delirium. Neuropsychological changes were mainly seen in the performance of the trail making test (part B), in which the mean reaction time was nearly doubled. The Beck Depression rating scores were increased at the end of the combined LL-2 and lymphokine-activated killer cell phase, but this test did not reach statistical significance when corrected for number of t-lests done. Only one patient eventually met the DSM-III criteria for depression. One other study ${ }^{39}$, in which neuropsychiatric toxicity was evaluated every treatment week, reports neuropsychiatric symptoms after highdose IL-2. Fourteen of 61 patients experienced neuropsychiatric symptoms. One patient died of brain stem ischemia, 1 complained about hallucinations. Computer tomography of the brain revealed brain metastases in 2 patients, one suffering from disorientation and depressive symptoms and one having headaches and concentration difficulties.

IL-2 therapy has also been combined with administration of IFN- $\alpha$. Fenner et al. ${ }^{40}$ conducted a study in which 101 patients were evaluated for neurotoxicity during treatment with a combination of IL-2 and IFN- $\alpha$. A total of 39 patients had minor or major concentration difficulties, 5 became disoriented, 37 suffered from mild paraesthesia, 4 patients had transient muscle weakness and 1 patient had hemiparesis. In addition, Capuron et al. ${ }^{41}$ evaluated the development of depression and anxiety in cancer patients receiving IL-2 (20 patients), IFN- $\alpha$ (8 patients) or a combination of IL-2 and IFN- $\alpha$ ( 6 patients), using the Montgomery Asberg Depression Rating Scale (MADRS) and the Covi Scale Anxiety, respectively. IL-2 treatment, but not IFN $-\alpha$ treatment, significantly raised the depression scores. Combined treatment of IL-2 and IFN- $\alpha$ produced much higher depression scores than IL-2 alone. Anxiety scores were raised significantly only after the combined treatment of IFN- $\alpha$ and IL-2. Addition of IFN- $\alpha$ to IL-2 treatment seemed to be acting synergistically in the development of anxiety and depressive symptoms and amplifies the neuropsychiatric elfect of $I L-2$.

\section{Interpretation of differences across studies}

Although many studies agree that depression and cognition scores worsen during immunotherapy, there are many differences in the prevalences of these side-effects, ranging from no significant differences in depressive symptoms ${ }^{32}$ to a prevalence of $45 \%$ of patients who suffer from a full blown depressive disorder after 12 wh of IFN- $\alpha$ treatment $^{42}$. Some explanations for this discrepancy may be postulated. In the first place, the neuropsychiatric side-effects appear to be dose-related ${ }^{43}$. Denicoff et al. ${ }^{38}$ 
found that patients who were receiving low doses were more likely to have only mild cognitive effects or no neuropsychiatric effects than were those receiving high doses $(68 \%$ compared with $29 \%)$. In addition, the duration of therapy may influence the occurrence of psychiatric symptoms. After 24 wk $25 \%$ of a total of 231 patients receiving IFN- $\alpha$ therapy showed depressive symptoms, while after 48 wh of treatment the percentage was $37 \%$ of a total of 225 patients $^{44}$. For anxiety, $9 \%$ and $13 \%$ of all patients experienced symptoms of anxiety after 24 and $48 \mathrm{wk}$, respectively. The incidence of irritability also increased as a function of duration of therapy, with $19 \%$ experiencing irritability after 24 week and $27 \%$ after 48 wk of therapy. Furthermore, in some studies patients receive additional medication that may affect the incidence of psychiatric side-effects. Another issue is the method used to measure the psychiatric symptoms. Most studies base their incidence rate on subjective reports, other studies, however, summarized in table 1 and 2 , use more reliable objective measurements to assess the amount of psychiatric problematic of patients. This of course may also be a source of variation in the percentage of patients reported that have experienced some kind of neuropsychiatric side effect.

\section{Predictors of psychiatric symptoms}

Others sources of variation are the individual differences between patients. In psychiatric risk groups, the incidence of neuropsychiatric side-effects may be higher and history of psychiatric illness is seen as a contraindication for treatment with IFN- $\alpha$. It is thought that patients with pre-existing psychiatric conditions have more risk to develop psychiatric side-effects. Ho et al. $^{45}$ found that $32 \%$ of patients with a psychiatric history and only $14 \%$ of patients without psychiatric history developed neuropsychiatric symptoms. In addition, delirium tended to occur in patients who had previous evidence of organic brain injury or dysfunction or previous drug and alcohol abuse $^{29}$. Furthermore, Hensley et al. ${ }^{46}$ found severe neuropsychiatric toxicity in 12 of $19(63 \%)$ patients with a pre-existing neurological or psychiatric diagnose compared to 10 of $72(14 \%)$ patients without diagnose. However, other studies showed no evidence of this increased risk for neuropsychiatric side-effects for at risk patients ${ }^{28,32}$.

There is also some evidence that biological measurements may function as a predictor for the risk of neuropsychiatric side-effects. Lowered activity of peptidases, such as prolylendopeptidase (PEP) and dipeptidyl peptidase IV (DPP IV) may occur in major depression. Patients who had a lowered PEP or DPP IV activity before starting IFN- $\alpha$ therapy had significantly higher MADRS and HAM-A scores both at baseline and during immunotherapy than patients with normal baseline PEP or DPP IV activity. Furthermore, patients with lowered serum DPP IV activity also had significantly higher increases in MADRS ratings following IFN- $\alpha$ therapy than those with normal serum DPP IV activity ${ }^{47}$. 


\section{Sensitisation and cross-sensitisation}

Other sources of variability across patients are time-dependent sensitisation (TDS) and cross-sensitisation. TDS is the phenomenon that a drug, administered once or twice, triggers a biological process which then progresses entirely as a function of the passage of time ${ }^{48}$. For example, an acute exposure to either the tricyclic antidepressant (TCA), imipramine, or one very brief electroconvulsive shock (ECS), followed by 7-10 days without treatment, induced a change in the responsivity of dopamine autoreceptors, which grew, i.e., sensitised or strengthened, with the passage of time, resulting in changes that were approximately $30 \%$ greater than those seen in control groups examined at the same time but exposed to daily drug or $\operatorname{ECS}^{49,50}$. A drug represents a foreign substance which is a potential threat to the organism. TDS is a non-specific process with adaptive value which ensures that if the organism survives the initial threatening episode it would have a sensitized defensive response, enabling it to react faster and/or more strongly, should it ever reencounter the same or a similar stimulus ${ }^{48}$. Because of the existence of this phenomenon it is possible that patients react differently on a specific drug, because of different earlier experiences. Furthermore, long-lasting cross-sensitization of behavioural responses has been described for drugs and stressors, i.e., the phenomenon that sensitisation may also lead to exaggerated responses to stimuli of a different nature ${ }^{51}$. For example, it has been found that single administration of IL-1 to adult rats not only enhanced adrenocorticotropin (ACTH) and corticosterone responses to $\mathrm{IL}-1$, but also to electric foot shocks ${ }^{52}$ and amphetamine ${ }^{53}$. Similarly, electric foot shocks induce long lasting sensitisation of the ACTH response to a novel environment ${ }^{54}$ and cross-sensitisation of the HPA response to amphetamine ${ }^{53}$. Thus, because of the fact that patients may differ in the extent to which they have experienced specific stressors, or intake of drugs or other foreign substances, they may differ in reaction to the administration of IFN- $\alpha$ or IL-2.

\section{Cytokine-induced sickness behaviour}

Peripheral or central administration of pro-inflammatory cytokines in rats, such as IL-1 $\beta$, IL-6 and TNF- $\alpha$, induces a behavioural pattern referred to as 'sickness behaviour $^{55}$. IL-1 $\beta$ and TNF- $\alpha$ provoke increased sleep ${ }^{56}$, reduced locomotor activity $^{57,58}$ and both IL-1 $\beta$ and TNF- $\alpha$ decrease consumption of chocolate milk in mice ${ }^{59}$. Furthermore, it was found that these two cytokines act synergistically in doing this ${ }^{59}$. In addition, decreased social exploration and decreased body weight was found in response to administration of IL-1 and TNF- $\alpha$. Pre-treatment with IL-1 receptor antagonist (IL-1 ra) antagonized the depressive effect of TNF- $\alpha$ on behaviour, but not on body weight. These results suggest that behavioural alterations of TNF- $\alpha$, but not metabolic changes, are mediated by $\mathrm{IL}-1$. Bluthe et al. ${ }^{61}$ did not find direct effects of IL-6 on social exploration, immobility or body weight and no effects of IL-6 were found on the consumption of chocolate milk ${ }^{59}$. However, when IL- 6 deficient mice 
(IL-6 - - were compared with IL $-6+1+$ mice, a weakened effect of lipopolysaccharide (LPS) and IL-1 on social interaction and body weight was found in the IL-6 deficient mice, suggesting a supporting, but not essential role for $\mathbb{L}-6$ in the development of sickness behaviour ${ }^{6 !}$.

These symptoms, induced by administration of pro-inflammatory cytokines, resemble the vegetative symptoms of depression in humans, such as anorexia, weight loss, psychomotor retardation, sleep disorders and anergy ${ }^{62}$. Charlton ${ }^{6.3}$ describes sickness behaviour as an evolutionary evolved physiological and psychological adaptation to acute infective and inflammatory illness in many mammalian species, which is nearly identical to major depressive disorder in humans. Charlton ${ }^{63}$ proposes that malaise, the symptoms of feeling ill, is the core emotion of depression and that low mood is the product of malaise.

\section{The serotonin (5-HT) hypothesis of depression}

Major evidence exists that disturbances in the serotonergic functioning play a causal role in the pathophysiology of depression. The serotonergic system evolved very early in evolution and is widely distributed throughout the brain. Output innervates virtually all regions of the central nervous system, particularly the cerebral cortex, limbic regions, basal ganglia and hypothalamus ${ }^{64}$. This extremely wide distribution probably explains why alterations in 5-HT function can modify so many behaviours, including motor output, learning, sleep, circadian pattern, food intake and sexual activity ${ }^{65}$.

Several neurochemical changes in the 5-HT system are seen in depressed people. Tryptophan (TRP), the precursor of 5-HT has to compete with other competing amino acids (CAA) for entrance through the blood brain barrier. Lower plasma TRP levels and a lower TRP/CAA ratio are found in depression ${ }^{66}$. This depletion of plasma comcentrations of TRP is likety to lead to a reduced synthesis of 5-HT in the brain since the latter depends on the plasma availability of TRP. Furthermore, studies have consistently found that acute TRP depletion, experimentally induced by giving a TRP. free amino acid diet, can transiently reverse the therapeutic effect of antidepressant medications $^{67}$ and that it produces a deterioration in mood in subjects who are at at greater risk for depression ${ }^{6 ?}$.

In addition, central changes in 5-HT metabolism have been shown. Changes are found in the 5-HT transporter (5-HTT) function. The 5-HT transporter is located on the presynaptic membrane 5 -HT cell bodies in the raphe nuclei where it regulates 5 -HT levels in the synaptic cleft by modulating the reuptake of 5-HT into the presynaptic cell $^{68}$. Evidence exists that 5-HT uptake is genetically controiled. Transcriptional activity of the human 5-HTT gene is modulated by a polymorphic repetitive element (5-HTTLPR). Having the long variant of the 5-HTTLPR genotype leads to more 5HTT mRNA, 5-HTT protein and 5-HT uptake than having the short variant ${ }^{69}$. Moreover, this polymorphism is associated with anxiety-depression-, and aggression- 


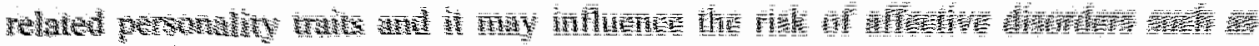
depressivitar:

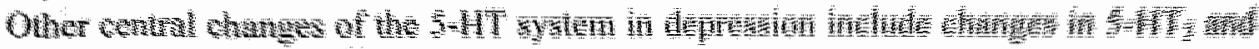

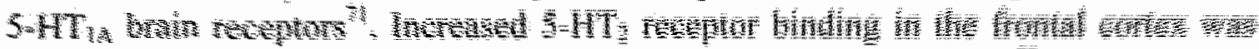

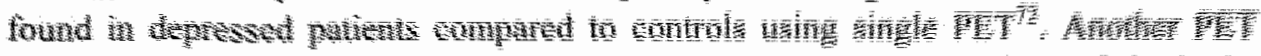

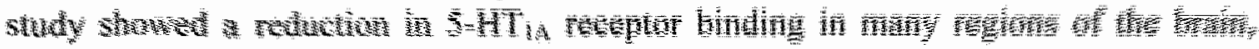

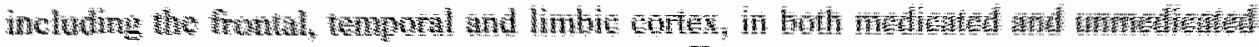

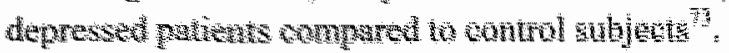

\section{The noradrenergic hypothesis of depression}

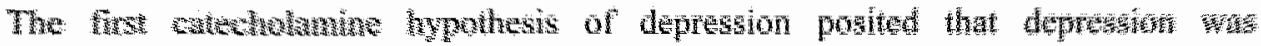

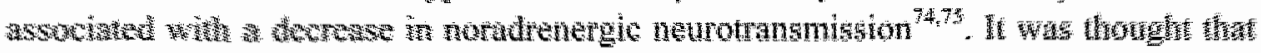

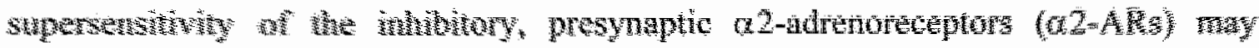

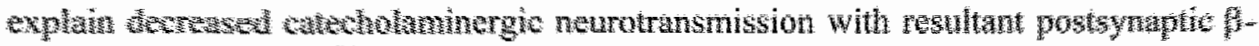

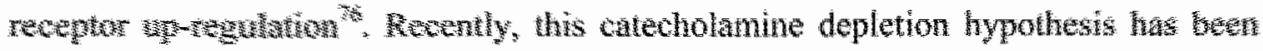
reformulated the the "dysregulation hypothesis" which proposes that an impared negarive fethos on the presynapic neuron causes an exaggerated noradrenaline (NE) releace. The fallwing findings support this hypothesis. First, depressed patients

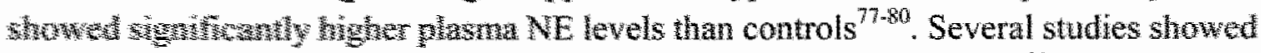

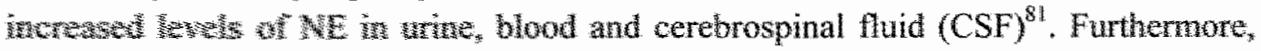

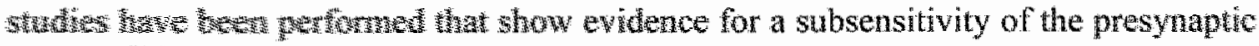

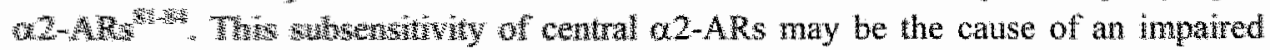

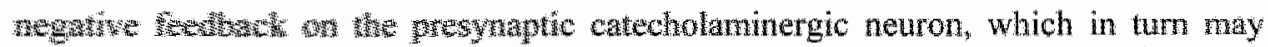

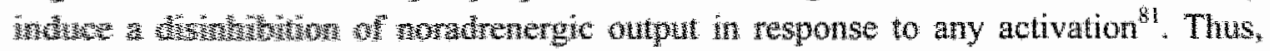

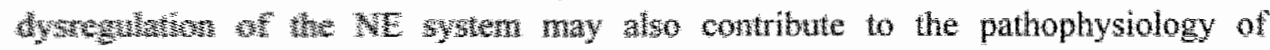
deprestion

\section{The HPA awe and depression}

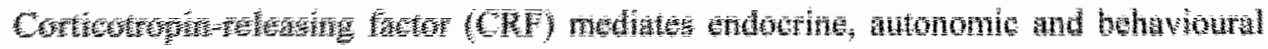
xeryont

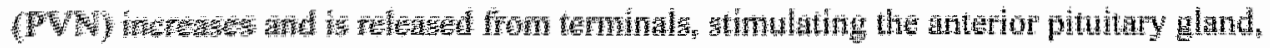

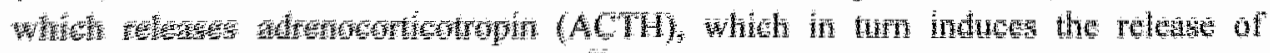

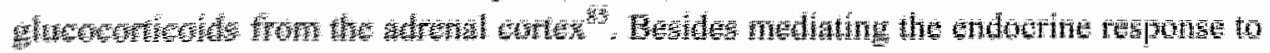

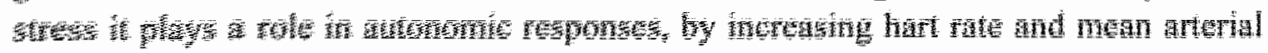

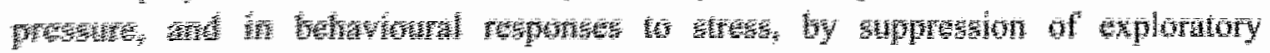
be

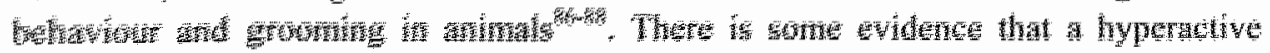

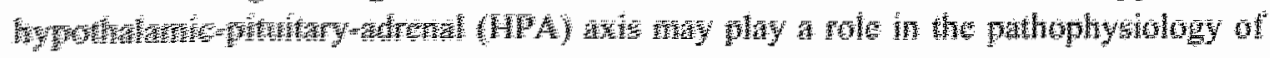


depression ${ }^{85}$. Elevated CSF CRF concentrations and plasma cortisol levels have been observed in drug-free patients with major depression compared with patients with other psychiatric disorders and healthy controls ${ }^{89}$. In addition, post-mortem studies revealed elevated CRF concentrations and CRF MRNA in the hypothalamic PVN of depressed patients ${ }^{90,91}$. Second, normalization of these levels occurs after successful antidepressant treatment with electroconvulsive therapy $(\mathrm{ECT})^{92}$ or with fluoxetine ${ }^{93}$. In addition to a hyperactive HPA axis, evidence exists for an impaired negative feedback control of the HPA axis exerted by corticosteroids. Endogenous glucocorticoids serve as potent negative regulators of the synthesis and release of CRF through binding to glucocorticoids receptors (GR) in the hypothalamus and hippocampus. An abnormality in this feedback function in depressed patients is supported by their abnormal responses to the dexamethasone suppression test (DST) ${ }^{94}$. Depressed patients demonstrate nonsuppression of cortisol secretion following administration of the synthetic glucocorticoid, dexamethasone ${ }^{95-97}$. A reduction in the number of GRs in depressed patients relative to healthy controls has been reported ${ }^{98-100}$. Furthermore, Gormley et al. ${ }^{98}$ and Lowy et al. ${ }^{101}$ reported that only depressed DST suppressors showed a decrease in GR binding after dexamethasone administration.

\section{Interactions between neurotransmitter systems and HPA axis with implications for depression}

There is a significant interconnectivity ${ }^{102}$ between the locus coeruleus (LC), where most cell bodies containing NE are found, and the raphe nuclei (RN), the primary location of serotonergic neurons. Their actions appear to be mutually inhibitory. The dorsal raphe nucleus (DRN) is able to mediate activation of the LC by its effect on the two principal neural inputs that modulate LC activity, the nucleus paragigiantocellularis (PGI) with an excitatory and the nucleus prepositus hypogloss (PrH) with an inhibitory influence on LC activity. The DRN inhibits LC activity by activating the $\mathrm{PrH}$ via $5-\mathrm{HT}_{2}$ receptors and by inhibiting the PGI via inhibitory $5-\mathrm{HT}_{1 \mathrm{~A}}$ receptors. In return, the LC exerts an inhibitory influence on the median raphe nucleus (MRN) via the inhibitory $\alpha_{2}$ receptors and both excitatory and inhibitory effects on the DRN via $\alpha_{1}$ and $\alpha_{2}$ receptors, respectively. In addition, inhibitory $\alpha_{2}$ receptors have been localized on 5-HT terminals and excitatory 5-HT3 receptors on NE terminals. This suggests a negative feedback loop in which increasing extracellular 5-HT concentrations lead to increased inhibition of 5-HT via the activation of the presynaptic $\alpha_{2}$ receptors of the noradrenergic system ${ }^{102,103}$.

Stress or activating stimuli cause an initial activation of the LC-NE system via the release of CRF from the amygdala in the limbic system and from the paraventricular nucleus (PVN) in the hypothalamus. This activation is opposed by the inhibition of these circuits by 5 -HT release which promotes tolerance to aversion and decreases the
stress response 102,103 
In depression, as described before, the interaction between NE and 5-HT may be out of balance: the NE system is hyperactive causing an enhanced response to stress/fear related stimuli, while the 5 -HT system has been found to be hypoactive and thus causing decreased inhibition of stress reactivity and decreased tolerance to aversion. These neurotransmitter alterations here by contribute to an abnormally activated amygdala which leads to increased release of CRF and adrenal steroids, which in turn further activate vigilance and stress/fear responsiveness ${ }^{103}$.

\section{Influence of cytokines on depression modulating systems}

\section{Cytokines and Blood-brain-barrier}

The presence of a blood-brain barrier (BBB) effectively restricts the free exchange of most solutes between plasma and the extracellular fluid of the brain. Nevertheless, peripherally circulating cytokines are able to affect central brain function. Passive transport across the blood brain barrier is not likely, because cytokines are relatively large protein molecules and their hydrophilic nature does not allow them to cross the blood-brain barrier ${ }^{104}$. However, four possible ways have been proposed for cytokines to communicate with the brain. First, cytokines may be transported into the brain by specific active transport mechanisms ${ }^{104}$. Specific uptake mechanisms for various peptides, including IL-1 $\alpha$ and IL-1 $\beta$, have been demonstrated at the luminal surface of the $\mathrm{BBB}^{105,106}$. In addition, cytokines may enter the brain at the sites where the blood brain barrier is deficient, for example at the organum vasculosum of the lamina terminalis (OVLT), with consequent stimulation of other messengers, such as prostaglandins in this location, which can diffuse to neighboring regions ${ }^{107,108}$. Third, cytokines may affect the BBB by the induction of adhesion molecules, such as ICAM-1 and VCAM-1 in the brain endothelium, which increases the potential for circulating T lymphocytes, especially $\mathrm{CD} 4+\mathrm{T}$ lymphocytes, to cross the BBB ${ }^{109}$. Fourth, cytokines may be able to activate ascendent peripheral nerves. The vagus nerve innervates regions of the body in which immune responses occur (the gut, spleen, thymus, lymph nodes etc.) and provides afferent input to the brain from these regions. IL-1 receptors are found on structures that surround vagal terminals called paraganglia. These paraganglia synapse onto the vagal fibers where they release a number of different neurotransmitters. Thus, IL-] released by activated immune cells binds to IL-1 receptors, which causes the paraganglia to release a transmitter onto the vagal terminals, thereby activating afferent vagal fibers. These fibers terminate in the nucleus tractus solitarius (NTS) and the area postrema. The NTS projects to the hippocampus and the hypothalamus, acting on central IL-1 receptors. This allows peripheral IL-1 to induce central IL-1 production ${ }^{104,110}$. Thus, although passing the BBB is difficult for cytokines, they do have the potential to influence brain function. 


\section{Influence of cytokines on 5-HT}

Several cytokines have profound effects on the serotonergic systems in the brain and in the periphery. Peripheral and central administration of $I L-1 \beta, \mathbb{F N}-\gamma$, and TNF- $\alpha$ significantly increase extracellular 5-HT concentrations in rats in several brain areas such as the hypothalamus, the hippocampus and the cortex ${ }^{11}$. Intraperitoneal injection of LPS and L-1 increased mouse brain concentrations of the 5-HT catabolite, 5 -hydroxyindoleacetic acid (5-HIAA), and TRP in all brain areas examined ${ }^{112}$. No changes were found after IL-6 injection. However, Zalcman et al. ${ }^{13}$ also reported elevated 5-HIAA levels in hippocampus and prefrontal cortex after intraperitoneal injection with IL-6 into mice.

Cytokines, such as IL-1, IFN- $\gamma$ and TNF- $\alpha$ not only acutely stimulate 5-HT neurotransmission, but also reduce the production of 5-HT by stimulating an enzyme called indoleamine 2,3 dioxygenase (IDO), which converts TRP, the precursor of 5$\mathrm{HT}$, into kynurenine. Overstimulation of IDO leads to depletion of plasma concentrations of TRP and therefore to reduced synthesis of 5-HT in the brain ${ }^{114}$.

Furthermore, the pro-inflammatory cytokines IL-1, IFN- $\alpha$, IFN- $y$ and TNF- $\alpha$ also have been shown to upregulate the 5-HTT, causing a depletion of extracellular 5-HT ${ }^{115-11}$, while the anti-inflammatory cytokine $\mathrm{IL}-4$ was shown to induce a reduction of 5 - $\mathrm{HT}$ uptake $^{118}$.

Finally, evidence exists for modulation of $5-\mathrm{HT}_{\mathbb{U}}{ }^{110}$ and $5-\mathrm{HT}_{2}{ }^{120}$ receptors by IFN- $\alpha$.

\section{Influence of cytokines on NE}

Effects of cytokines on the noradrenergic system have also been described. IL-1 has been shown to stimulate hypothalamic and preoptic noradrenergic neurotransmission in rats $^{121}$ and mice ${ }^{122}$. In addition, Zalcman et al. ${ }^{133}$ also observed 14 - 1 -induced increases in the MHPG/NE ratio in the prefrontal contex and hippocampus in mice. All these effects of IL-1 are characteristic of various forms of IL-1 administered by various routes $^{123}$.

Other cytokines also show some influence on NE. Intraperitoneal injection of IL-2 in mice increased MHPG concentrations and the MHPG/NE ratio in the hypothalamus ${ }^{113}$. For TNF- $\alpha$ inconsistent results have been found. It has been reported to increase brain MHPG, but only at the higher doses ( $1 \mu \mathrm{g}$ or more) ${ }^{12.4}$. In contrast, other studies reported that TNF- $\alpha$ inhibited NE release from the median eminence ${ }^{125}$ and from the myenteric plexus ${ }^{126}$.

\section{Influence of cytokines on HPA axis}

IL- 1 has been shown to be a potent stimulator of the HPA axis ${ }^{127}$. IL- 1 administration to mice markedly increased HPA activation, indicated by elevation of plasma corticosterone, in parallel with its effect on $\mathrm{NE}^{128}$. In addition, many researchers have reported that IL-6 administration activates the HPA axis as indicated by elevations of ACTH and corticosterone. Wang ${ }^{129}$ and Dunn ${ }^{130}$ found that injection of murine IL-6, 
injected either intravenously or intraperitoneally, elicted modest increases in plasma ACTH and corticosterone. However, maximal concentrations were much lower than observed with IL-1 ${ }^{129}$. TNF- $\alpha$ also enhances HPA activation, but was found to be significantly less potent than $\mathrm{IL}-1^{130-132}$.

Furthermore, pro-inflammatory cytokines may induce a mechanism which leads to the generation of glucocorticoid resistance. The human glucocorticoid receptor (hGR) gene encodes two protein isoforms: GR $\alpha$ which binds hormone, translocates to the nucleus, and regulates gene transcription, and GRB which does not bind known ligands and attenuates GR $\alpha$ action. TNF- $\alpha$ and IL-1 $\beta$ induce a disproportionate increase in GR $\beta$ over GR $\alpha$. By causing this accumulation of GR $\beta$ isoform levels, which leads to increased inhibition of GR $\alpha$ action, pro-inflammatory cytokines may trigger glucocorticoid resistance ${ }^{1.33}$.

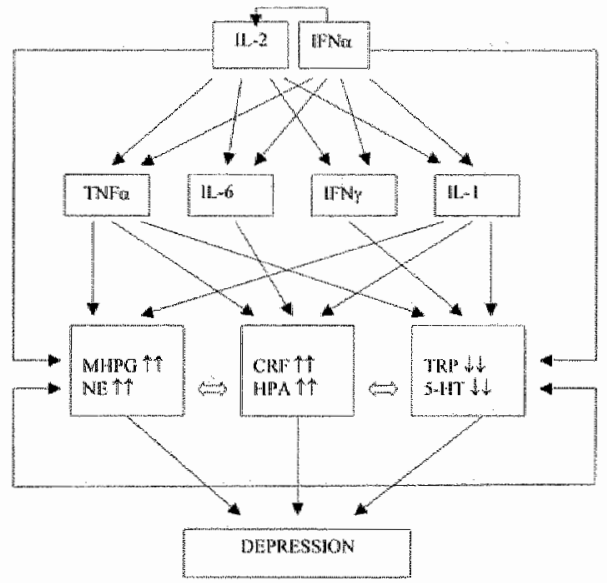

Fugure 6.1 Possible ways for pro-inflammatory cytokines to induce depression.

\section{Hypothesis of the mechanism of cytokine-induced depression}

In short, IFN- $\alpha$ and IL-2 have been shown to cause several depressive and other neuropsychiatric symptoms in a high percentage of patients. Mechanisms by which these symptoms are produced are unknown, however, a possible model of the way in which pro-inflammatory cytokines may induce depression may be proposed (figure 6.1). IFN- $\alpha$ stimulates the production of pro-inflammatory cytokines. The latter, in turn, affect the central NE and 5-HT neurotransmitter systems and the activity of the HPA axis. Also, these systems themselves show extensive interconnectivity, allowing for mutual interactions between them. Therefore, we may postulate that a disturbance in one these systems also affects the other systems. Changes in these systems, such as increased NE activity, increased HPA activity and decreased 5-HT brain availability, caused by pro-inflammatory cytokines, are exactly the changes also seen in patients with depression, suggesting that cytokines may induce depression by their effect on the 5-HT system, NE system, and the HPA axis. 


\section{References}

1. Anonymous. Interferon therapy in chronic hepatitis B. Lancet 1976;2(7995):1122-3.

2. Adams $\mathbb{F}^{*}$, Quesada JR, Gutterman JU. Neuropsychiatric manifestations of human leukocyte interferon therapy in patients with cancer. Jama 1984;252(7):938-41.

3. Borgstrom $S$, von Eyben FE, Flodgren P, Axelsson B, Sjogren HO. Human leukacyte interferon and cimetidine for metastatic melanoma. $N$ Engl $I$ Med 1982;307(17):1080-1.

4. Lane HC. The tole of alpha-interferon in patients with human immunodeficiency virus infection. Semin Oncol 1991;18(5 Suppl 7):46-52.

5. Dumoulin FL, Leifeld L, Sauerbruch T, Spengler U. Autoimmunity induced by interferonalpha therapy for chronic viral hepatitis. Biomed Pharmacother 1999;53(5-6):242-54.

6. Pfeffer LM, Dinarello CA, Herberman RB, et al. Biological properties of recombinant alpha-interferons: 40th anniversary of the discovery of interferons. Cancer Res 1998;58(12): 2489-99.

7. Herberman RB. Effect of alpha-interferons on immune function. Semin Oncol 1997;24(3 Suppl 9):S9-78-S9-80.

8. Bonaccorso S, Meltzer $\mathrm{H}$, Maes M. Psychological and behavioural effects of interferonalpha, Cur Opinion 2000;13:673-677.

9. Corssmit EP, Heijligenberg R, Hack CE, Endert E, Sauerwein HP, Romijn JA. Effects of interferon-alpha (IFN-alpha) administration on leucocytes in healthy humans. Chin Exp Immunol 1997;107(2):359-63.

10. Yoshie O, Mellman IS, Broeze RJ, Garcia-Blanco M, Lengyel P. Interferon action: effects of mouse alpha and beta interferons on rosette formation, phagocylosis, and surface-antigen expression of cells of the macrophage-type line RAW 309Cr.1. Cell Immunol 1982;73(1): 128-40.

11. Rhodes J, Ivanyi J, Cozens P. Antigen presentation by human monocytes: effects of modifying major histocompatibility complex class II antigen expression and interleukin I production by using recombinant interferons and corticosteroids. Eur $J$ Immunol $1986 ; 16(4): 370-5$.

12. Meurs E, Hovanessian AG. Alpha-interferon inhibits the expression of heavy chain mu messenger RNA in Daudi cells. Embo J 1988;7(6):1689-96.

13. Peters M, Ambrus JL, Zheleznyak A, Walling D, Hoofnagle JH. Effect of interferon-alpha on immunoglobulin synthesis by human B cells. I Immumol 1986;137(10):3153-7.

14. Collier $\mathbf{J}$, Chapman $\mathrm{R}$. Combination therapy with interferon-alpha and ribavirin for hepatitis C: practical treatment issues. BioDrugs 2001;15(4):225-38.

15. Oppenheim JJ, Ruscetti FW, Faltynek C. Cytokines. In: Stites DP, Terr AI, Parslow T, eds. Basis \& clinical immunology. Stamford, Connecticut: Appleton \& Lange, 1994: 870.

16. Dieperink E, Willenbring M, Ho SB. Neuropsychiatric symptoms associated with hepatitis $C$ and interferon alpha: A review. Am J Psychiary 2000; 157(6):867-76.

17. Pavol MA, Meyers CA, Rexer JL, Valentine AD, Mattis PJ, Talpaz M. Pattern of neurobehavioral deficits associated with interferon alfa therapy for leukemia. Neurology $1995 ; 45(5): 947-50$

18. Nozaki O, Takagi C, Takaoka K, Takata T, Yoshida M. Psychiatric manifestations accompanying interferon therapy for patients with chronic hepatitis $\mathrm{C}$ : an overview of cases in Japan. Psychiary: Clin Newrosci 1997;51(4):175-80.

19. Heeringa $M$, Honkoop P, de Man RA, Feenstra J, Smits CM. [Major psychiatric side effects of interferon alpha-2b1. Ned Tijdsch Geneeskd 1998;142(28):1618-21.

20. Monji A, Yoshida I, Tashiro $\mathrm{K}$, Hayashi $\mathrm{Y}$, Tashiro N. A case of persistent manic depressive illness induced by interferon- alfa in the treatment of chronic hepatitis $C$. Pychosomatics 1998;39(6):562-4. 
21. Maunder RG, Hunter JJ, Feinman SV. Interferon treatment of hepatits $\mathrm{C}$ associated with symptoms of PTSD. Psychosomatics 1998;39(5):461-4.

22. Fukunishi $\mathrm{K}$, Tanaka $\mathrm{H}$, Maruyama $\mathrm{J}$, et al. Burns in a suicide attempt related to psychiatric side effects of interferon. Burns 1998;24(6):581-3.

23. Janssen HL, Brouwer JT, van der Mast RC, Schalm SW. Suicide associated with alfainterferon therapy for chronic viral hepatitis. J Hepatol 1994;21(2):241-3.

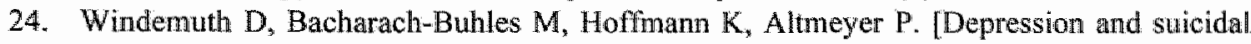
intentions as a side effect of high dosage interferon-alpha therapy--fwo cases]. Houtarzt $1999 ; 50(4) ; 266-9$.

25. Schafer M, Messer T, Wegner U, Schmid-Wendtner MH, Volkenandt M. [Psychiatric side effects during adjuvant therapy with interferon- alpha in patients with malignant melanoma. Clinical evaluation as well as diagnostic and therapeutic possibilities]. Hautart 1999;50(9):654-8.

26. Malaguarnera M, Di Fazio $\mathbb{1}$, Restuccia S, Pistone G, Ferlito L, Rampello L. Interferon alpha-induced depression in chronic hepatitis $\mathrm{C}$ patients: comparison between different types of interferon alpha. Neuropsychobiology 1998;37(2):93-7.

27. Hunt CM, Dominitz JA, Bute BP, Waters B, Blasi U, Williams DM. Effect of interferonalpha treatment of chronic hepatitis $\mathrm{C}$ on health- related quality of life. Dig Dis Sci $1997 ; 42(12): 2482-6$

28. Pariante CM, Orru MG, Baita A, Farci MG, Carpiniello B. Treatment with interferon-alpha in patients with chronic hepatitis and mood or anxiety disorders. Lancet $1999 ; 354(9173): 131-2$.

29. Renault PF, Hoofnagle JH, Park Y, et al. Psychiatric complications of long-term interferon alfa therapy. Arch Intern Med 1987;147(9):1577-80.

30. Juengling FD, Ebert D, Gut $\mathrm{O}$, et al. Prefrontal cortical hypometabolism during low-dose interferon alpha treatmernt. Psychopharmacology (Berl) 2000;152(4);383-9.

31. Mapou RL, Law WA, Wagner K, Malone IL, Skillman DR. Neuropsychological effects of Interferon Alfa-n3 treatment in asymptomatic human immunodeficiency virus-1-infected individuals. JNeuropsychiatry Clin Neurosci 1996;8(1):74-81.

32. Mulder RT, Ang $M$, Chapman B, Ross A, Stevens IF, Edgar C. Interferon treatment is not associated with a worsening of psychiatric symptoms in patients with hepatitis $\mathrm{C} . J$ Gastroenterol Hepatal 2000;15(3):300-3.

33. Caraceni $A$, Gangeri $L$, Martini $C$, et al. Neurotoxicity of interferon-alpha in melanoma therapy: results from a randomized controlled trial. Cancer 1998;83(3):482-9.

34. Bonaccorso $\mathrm{S}$, Marino $\mathrm{V}$, Puzella $\mathrm{A}$, et al. Increased depressive ratings in patients with hepatitis $C$ receiving interferon-alpha-based immunotherapy are related to interferon-alphainduced changes in the serotonergic system. J Clin Psychopharmacol 2002;22(1):86-90.

35. Krigel RL, Padavic-Shaller KA, Rudolph AR, Konrad M, Bradley EC, Comis RL. Renal cell carcinoma: treatment with recombinant interleukin-2 plus beta-interferon. $J$ Clin Oncol 1990;8(3):460-7.

36. Hersch EM. Phase I study of cancer therapy with recombinant interleukin-2 administered by intravenous bolus injection. biotherapy 1989;1:215-226.

37. Pardo N, Marti F, Fraga G, et al. High-dose systemic interleukin-2 therapy in stage IV neuroblastoma for one year after autologous bone marrow transplantation: pilot study. Med Pediatr Oncol 1996;27(6):534-9.

38. Denicoff $K D$, Rubinow DR, Papa $M Z$, et al. The neuropsychiatric effects of treatment with interleukin-2 and lymphokine-activated killer cells. Ann Intern Med 1987;107(3):293-300.

39. Buter J, de Vries EG, Sleijfer DT, Willemse PH, Mulder NH. Neuropsychiatric symptoms during treatment with interleukin-2. Lancet $1993 ; 341(8845): 628$. 
40. Fenner MH, Hanninen EL, Kirchner $\mathrm{HH}$, Poliwoda $\mathrm{H}$, Atzpodien J. Neuropsychiatric symptons during treatment with interleukin-2 and interferon-alpha. Lancet $1993 ; 341(8841) ; 72$.

41. Capuron L, Ravaud A, Dantzer R. Early depressive symptoms in cancer patients receiving interlleukin 2 and/or interferon alfa-2b therapy. J Clin Oncol 2000;18(10):2143-51.

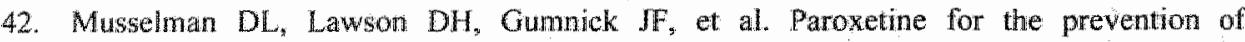
depression induced by high-dose interferon alfa. N Engl I Med 200 1;344(13):961-6.

43. Dusheiko $\mathrm{G}$. Side effects of alpha interferon in chronic hepatitis C. Hepatology $1997 ; 26(3$ Suppl 1):112S-121S.

44. McHulchison JG, Gordon $\mathrm{SC}$, Schiff ER, et al. Interferon alfa-2b alone or in combination with ribavirin as initial treatment for chronic hepatitis $C$. Hepatitis Interventional Therapy Group. N Engl J Med 1998;339(21):1485-92.

45. Ho SB, Nguyen $H_{3}$ Tetrick LL, Opitz GA, Basara ML, Dieperink E. Influence of psychiatric diagnoses on interferon-alpha treatment for chronic hepatitis $\mathrm{C}$ in a veteran population. Am J Gastroenterol 2001;96(1):157-64.

46. Hensley ML, Peterson B, Silver RT, Larson RA, Schiffer CA, Szatrowski TP. Risk factors for severe neuropsychiatric toxicity in patients receiving interferon alfa- $2 b$ and low-dose cytarabine for chronic myelogenous leukemia: analysis of Cancer and Leukemia Group B 9013. J Clin Oncol 2000;18(6):1301-8.

47. Maes $M$, Bonaccorso $S$. Lower activities of serum peptidases predict depressive and anxiety levels following interferon-alpha-baseddd immunotherapy with hepatitis $\mathrm{C}$. Acra Psychiar Scand 2004; 109(2):126-31.

48. Antelman SM, Levine J, Gershon 5. Time-dependent sensitization: the odyssey of a scientific heresy from the laboratory to the door of the clinic. Mol Psychiany $2000 ; 5(4): 350-6$.

49. Chiodo LA, Antelman SM. Electroconvulsive shock: progressive dopamine autoreceptor subsensitivity independent of repeated treatment. Science 1980;210(4471):799-801.

50. Chiodo LA, Antelman SM. Repeated tricyclics induce a progressive dopamine autoreceptor subsensitivity independent of daily drug treatment. Nature 1980;287(5781):451-4.

51. Antelman SM, Eichler AJ, Black CA, Kocan D. Interchangeability of stress and amphetamine in sensitization. Science 1980;207(4428):329-31.

52. Schmidt ED, Janszen AW, Wouterlood FG, Tilders FJ. Interleukin-1-induced long-lasting

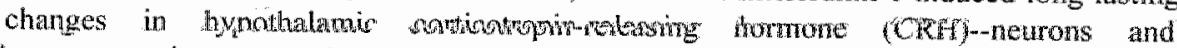
hyperresponsiveness of the hypothalamus-pitutary-adrenal axis. I Netrosci 1995;15(11):7417-26.

53. Schmidt ED, Tilders FI, Binnekade R, Scholfelmeer ANM, De Vries TI. Stressor or drug induced hupersectetion of corticosterone is not critically involved in the expression of longtem behavioral sensitization to amphetamine. Neuroscience in press.

54. van Digken HH, de Gowij DC, Sutanto W, Mos J, de Kloet ER, Thlers FJ. Short inescapable stress produces long-lasting changes in the brain-pituitary-adrenal axis of adult male tats. Newroendocrinology 1993;58(1):57-64.

55. Kent S, Bluthe RM, Kelley KW, Dantzer R. Sickness behavior as a new target for drug development. Trends Phamacol Sci 1992;13(1):24-8.

56. Krueger MM, Takahashi $S$. Kapas L, et al. Cytokines in sleep regulation. Ad Newroimmunol $1995 ; 5(2): 171-88$.

57. Lacosta $S$, Merali $Z$, Anisman H. Influence of interleukin-1 beta on exploratory behaviors, plasma ACTH, corticosterone, and central biogenic amines in mice Psychopharmacology (Berl) 1998:137(4):351-61. 


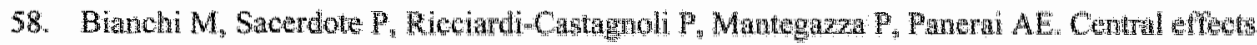
of tumor necrosis factor aha and inter a

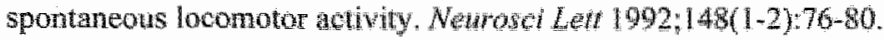

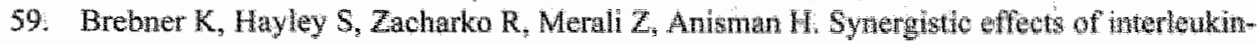
1 beta, interleukin-6, and tumor necosis factoralsha: central monowne, corticosteront and behavioral variations. Newopsychophamacology $2000,22(6), 566-80$.

60. Bluthe RM, Pawlowski $\mathrm{M}$, Suarez $\mathrm{S}$, et al. Synergy between tumor necrosis fictor alphat and interleukin-1 in the induction of sickness behavior in mice. Pyehomewrondocthology $1994 ; 19(2): 197-207$.

61. Bluthe RM, Michaud B, Poli $V$, Dantzar R. Role of IL=6 in cytokmeinduced sickness behavior: a study with IL-6 deficient mice. Physiol Behav 2000;70(3-4):367-73.

62. Maes M. A review on the acute phase response in major depression. Rev Nourosct $1993 ; 4(4): 407-16$.

63. Chartion BO. The malaise theory of depression: major depressive disorder is sickness behavior and antidepressants are analgesic. Med Hypotheses $2000 ; 54(1): 126-30$.

64. Tork 1. Anatomy of the serotonergic system. Amn N Y Acad Sci 1990,600:9-34.

65. Smith KA, Cowen PJ. Serotonin and depression. In: Honig A, van Prag HM, eds. Depression: neurobiological, psychopathological and therapeutic advances. Chichester: John Wiley \& Sons, 1997.

66. Maes M, Mettzer HY, Scharpe S, et al. Relationships between lower plasma L-tryptophan levels and immune- inflammatory variables in depression. Psychiary Res 1993;49(2):15165.

67. Dursun SM, Blackbum JR, Kutcher SP. An exploratory approach to the serotonergic hypothesis of depression: bridging the synaptic gap. Med Hypotheses $2001 ; 56(2): 235-43$.

68. Stalley IK, Malison RT, Inmis RB. Imaging of the serotonergic system: interactions of netroanatomical and functional abnormalities of depression. Biol Psychiamy 1998;44(7): 534-49.

69. Lesch KP, Bengel D, Heils A, et al. Association of anxiety-related traits with a polymorphism in the serotonin transporter gene regulatory region. Science 1996:274(5292):1527-31.

70. Lesch KP, Mossner R. Genetically driven variation in serotonin uptake: is there a link to affective spectrum, neurodevelopmental, and neurodegenerative disorders? Biol Psychiatry $1998: 44(3): 179-92$

71. Maes M, Meltzer H. The serotonin hypothesis of major depression. In: Bloom F. Kupfer D, eds. Psychopharmacology. New York: Raven Press, 1995: 933-944.

72. Mendelson SD. The current status of the platelet 5-HT(2A) receptor in depression. $f$ Affect Disord 2000;57(1-3):13-24.

73. Sargent PA, Kjaer $\mathrm{KH}$, Bench $\mathrm{CJ}$, et al. Brain serotonin $1 \mathrm{~A}$ receptor binding measured by positron emission tomography with [11C]WAY-100635; effects of depression and antidepressant treatment. Arch Gen Psychiary 2000;57(2):174-80.

74. Schildkraut JI. The catecholamine hypothesis of affective disorders: a review of supporting evidence. Am I Psychiary 1965;122(5):509-22.

75. Burney WE, Jr., Davis JM. Norepinephrine in depressive reactions. A review. Arch Gen Psychiaty 1965;13(6):483-94.

76. Garcia-Sevilla JA, Zis AP, Hollingsworth PJ, Greden JF, Smith CB. Platelet alpha 2adrenergic receptors in major depressive disorder. Binding of tritiated clonidine before and after tricyclic antidepressant drug treatment. Arch Gen Psychiary 1981;38(12):1327-33.

77. Roy A, Pickar D, De Jong J, Karoum F, Linnoilla M. Norepinephrine and its metabolites in cerebrospinal fluid, plasma, and urine. Relationship to hypothalamic-pituitary-adrenal axis function in depression. Arch Gem Psychiany 1988;45(9):849.57. 
78. Maes M, Vandewoude M, Schotte C, Martin M, Blockx P. Positiwe relationship between the catecholaminergic turnover and the DST results in depression. Psychol Med 1990;20(3): 493-9.

79. Maes $M$, Minmer $\mathbb{B}$, Suy $\mathbb{E}_{\text {, Vandervorst }} \mathrm{C}$, Raus J. Coexisting dysregulations of both the sympathoadrenal system and hypothalamic-pituitary-adrenal-axis in melancholia. $J$ Newral Transm Gen Sect 1991;85(3):195-210.

80. Potter WZ, Scheinin M, Golden RN, et al. Selective antidepressants and cerebrospinal fluid. Lack of specificity on norepinephrine and serotonin metabolites. Arch Gen Psychiatry $1985 ; 42(12): 1171-7$

81. Maes M, Van Gastell A, Delmeire L, Meltzer HY. Decreased platelet alpha-2 adrenoceptor density in major depression: effects of tricyclic antidepressants and fluoxetine. Biol Psychiatry 1999:45(3):278-84.

82. Mitrius JC, Micini M, Arora RC, Meltzer HY, UPrichard DC. responsiveness of alpha2receptors is decreased in platelets from depressed patients. Soc Neurosci Abstr 1983;9:990.

83. Kafka MS, Paul SM. Platelet alpha 2-adrenergic receptors in depression. Arch Gen Psychiairy 1986;43(1):91-5.

84. Roy A, Katka MS. Platelet adrenoceptors and prostaglandin responses in depressed patients. Psychiatry Res $1989 ; 30(2): 181-9$.

85. Arborelius L, Owens MJ, Plotsky PM, Nemeroff CB. The role of corticotropin-relleasing factor in depression and anxiety disorders. J Endacrinol 1999;160(1):1-12.

86. Dunn AJ, Berridge CW. Physiological and behavioral responses to corticotropin-releasing factor administration: is CRF a mediator of anxiety or stress responses? Brain Res Brain Res Rev 1990;15(2):71-100.

87. Owens MJ, Nemerofi CB. Physiology and pharmacology of corticotropin-releasing factor. Pharmacol Rev 1991:43(4):425-73.

88. Koob GF, Heinrichs SC, Pich EM, et al. The role of corticotropin-releasing factor in behavioural responses to stress. Ciba Found Symp 1993;172:277-89.

89. Nemeroff CB, Widerlov E, Bissette G, et al. Elevated concentrations of CSF corticotropinreleasing factor-like immunoreactivity in depressed patients. Science 1984;226(4680):13424.

90. Raadsheer FC, Hoogendijk WJ, Stam FC, Tilders FJ, Swaab DF. Increased numbers of corticotropin-releasing hormone expressing neurons in the hypothalamic paraventricular nucleus of depressed patients. Neuroendocrinology 1994;60(4):436-44.

91. Raadsheer FC, van Heerikhuize JJ, Lucassen PJ, Hoogendijk WJ, Tilders FJ, Swaab DF. Conticotropin-releasing hormone mRNA levels in the paraventricular nucleus of patients with Alzheimer's disease and depression. Am J Psychiatry 1995;152(9):1372-6.

92. Nemeroff $C B$, Bissette $G$, Akil $H$, Fink $M$. Neturopeptide concentrations in the cerebrospinal fluid of depressed patients treated with electroconvulsive therapy. Corticotrophin- releasing factor, beta-endorphin and somatostatin. Br I Psychiaty
$1991 ; 158: 59-63$.

93. De Bellis MD, Gold PW, Geracioti TD, Listwak S, Kling MA. Fluoxetine significantly reduces CSF CFH and AVP concentrations in patients with major depression. $A m J$ Psychiany 1993;150:656-657.

94. Carroll BJ, Curtis GC, Mendels J. Neuroendocrine regulation in depression. I. Limbic system- adrenocortical dysfunction. Arch Gen Psychiatry 1976;33(9):1039-44.

95. Gold PW, Goodwin FK, Chrousos GP. Clinical and biochemical manifestations of depression. Relation to the neurobiology of stress (1). $N$ Engl J Med 1988;319(6):348-53.

96. Nemeroff CB. The corticotropin-releasing factor (CRF) hypothesis of depression: new findings and new directions. Mol Psychiary 1996;1(4):336-42. 
97. Owens MJ, Nemeroff CB. The role of corticotropin-releasing factor in the pathophysiology of affective and anxiety disorders: laboratory and clinical studies. Ciba Found Symp $1993 ; 172: 296-308$.

98. Gormley GJ, Lowy MT, Reder AT, Hospelhom VD, Antel JP, Meltzer HY. Glucocorticoid receptors in depression: relationship to the dexamethasone suppression test. $A m J$ Psychiamy 1985;142(11):1278-84.

99. Sallee FR, Nesbitt L, Dougherty D, Hilal R, Nandagopal VS, Sethuraman G. Lymphocyte glucocorticoid receptor: predictor of sertraline response in adolescent major depressive disorder (MDD). Psychopharmacol Bull 1995;31(2):339-45.

100. Whalley LJ, Borthwick N, Copolov D, Dick H, Christie JE, Fink G. Glucocorticoid receptors and depression. Br Med J (Clin Res Ed) 1986;292(6524):859-61.

101. Lowy MT, Reder AT, Gormley GJ, Meltzer HY. Comparison of in viwo and in vitro glucocorticoid sensitivity in depression: relationship to the dexamethasone suppression test. Biol Psychiary 1988;24(6):619-30.

102. Mongeau $R$, Blier $P$, de Montigny $C$. The serotonergic and noradrenergic systems of the hippocampus: their interactions and the effects of antidepressant treatments. Brain Res Brain Res Rev 1997;23(3):145-95.

103. Ressler KJ, Nemeroff CB. Role of serotonergic and noradrenergic systems in the pathophysiology of depression and anxiety disorders. Depress Anxiety 2000;12(Suppl 1): 2-19.

104. Maier SF, Watkins LR. Cytokines for psychologists: implications of bidirectional immuneto- brain communication for understanding behavior, mood, and cognition. Psychol Rey 1998;105(1):83-107.

105. Ermisch A, Brust P, Kretzschmar R, Ruhle HJ. Peptides and blood-brain barrier transport. Physial Rew 1993;73(3):489-527.

106. Begley DJ. Peptides and the blood-brain barrier. In: Bradbury MWB, ed. Handbook of experimental pharmacology: physiology and pharmacology of the blood-brain barrier. Berlin: Springer, 1992: 151-203.

107. Blatteis CM. Neuromodulative actions of cytokines. Yale J Biol Med 1990;63(2):133-46.

108. Stitt JT. Prostaglandins, the OVLT and fever. Oxford: Pergamon, 1992.

109. Brown KA. Factors modifying the migration of lymphocytes across the blood-brain barrier. Int Immunopharmacol $2001 ; 1(12): 2043-62$.

110. Ek $M$, Kurosawa $M$, Lundeberg T, Ericsson A. Activation of vagal afferents after intravenous injection of interleukin-I beta: role of endogenous prostaglandins. I Neurosi $i$ 1998; 18(22): $9471-9$.

11. Clement HW, Buschmann J, Rex S, et al. Effects of interferon-gamma, interleukinm I beta, and tumor necrosis factor-alpha on the serotonin metabolism in the nucleus raphe dorsalis of the rat. $J$ Newal Transm 1997;104(10):981-9!.

112. Dumn AJ. Endotoxin-induced activation of cerebrall catecholamine and serotonin metabolism: comparison with interleukin-1. I Pharmacol Exp Ther 1992;261(3):964-9.

113. Zalcman S, Green-Johnson JM, Murray L, et al. Cytokine-specific central monoamine alterations induced by interleukin- $1,-2$ and -6 . Brain Res 1994;643(1-2):40-9

114. Heyes MP, Saito K, Crowley JS, et al. Quinolinic acid and kynurenine pathway metabolism in inflammatory and non-intlammatory neurological disease. Brain 1992; 115(Pt 5):124973.

115. Ramamoorthy S, Ramamoorthy JD, Prasad PD, et al. Regulation of the human serotonin transporter by interleukin- $I$ beta. Biochem Biophys Res Commw 1995;216(2):560 7.

116. Mossner R, Heils A, Stober G, Okladnova O, Daniel S, Lesch KP. Enhancement of serotonin transporter function by tumor necrosis factor alpha but not by interleukin-6. Neurochem Int 1998;33(3):251-4. 
117. Morikawa O, Sakai N, Obara H, Saito N. Effects of interferon-alpha, interferon-gamma and CAMP on the transcriptional regulation of the seratonin transporter. Eur $J$ Pharmacol $1998 ; 349(2-3) ; 317-24$

118. Mossner R, Daniel S, Schmitt A, Albert D, Lesch KP. Modulation of serotonin transporter function by interleukin-4. Life Sci 2001;68(8):873-80.

119. Abe $S$, Hori $T$, Suzuki $T$, Baba A, Shiraishi $H$, Yamamoto T. Effects of chronic administration of interferon alpha $\mathrm{AD}$ on serotonergic receptors in rat brain. Newrochem Res $1999 ; 24(3): 359 m 63$.

120. Kugaya A, Kagaya A, Uchitomi Y, Yokota N, Yamawaki S. Effect of interferon-alpha on DOI-induced wet-dog shakes in rats. INewral Transm 1996;103(8-9):947-55.

121. Kabiersch $A$, del Rey $A$, Honegger $C G$, Besedovsky HO. Interleukin-1 induces changes in norepinephrine metabolism in the rat brain. Brain Behav Imwan 1988;2(3):267-74.

122. Dumn AJ. Systemic interleukin-1 administration stimulates hypothalamic norepinephrine metabolism parallelling the increased plasma corticosterone. Life Sci 1988;43(5):429-35.

123. Dunn AJ, Wang J, Ando T. Effects of cytokines on cerebral neurotransmission. In: Dantzer $\mathrm{R}$, Wollman EE, Yirmiya $\mathrm{R}$, eds. Cytokines, stress and depression. New York: Kluwer Academic/ Plenum Publishers, 1999.

124. Ando T, Dunn Al. Mouse tumor necrosis factor-alpha increases brain tryptophan concentrations and norepinephrine metabolism while activating the HPA axis in mice. Newroinmumomodulation 1999;6(5):319-29.

125. Elenkov $1 J$, Kovacs K, Duda E, Stark E, Vizi ES. Presynaptic inhibitory effect of TNFalpha on the release of noradrenaline in isolated median eminence. I Neuroimmunol 1992;41(1): 117-20.

126. Hurst SM, Collins SM. Mechanism underlying tumor necrosis factor-alpha suppression of norepinephrine release from rat myenteric plexus. Am J Physiol 1994;266(6 Pt 1):G1 123-9.

127. Besedovsky H, del Rey A, Sorkin E, Dinarello CA. Immunoregulatory feedback between interleukin-I and glucacorticoid hormones. Science 1986;233(4764):652-4.

128. Dunn A.J, Swiergiel AH. The role of cytokines in infection-related behavior. Ann $N$ Y Acad Sci $1998 ; 840: 577-85$.

129. Wang $J_{y}$ Dumn AJ. Mouse interleukin-6 stimulates the HPA axis and increases brain tryptophan and serotonin metabolism. Neurochem Int 1998;33(2):143-54.

130. Dunn AJ. The role of interleukin-1 and tumor necrosis factor alpha in the neurochemical and neuroendocrine responses to endotoxin. Brain Res Bull 1992;29(6):807-12.

131. Besedovsky HO, del Rey A, Klusman I, Furukawa H, Monge Arditi G, Kabiersch A. Cylokines as modulators of the hypothalamus-pituitary-adrenal axis. J Steroid Blochem Mol Biol 199\|:40(4-6):613-8.

132. Del Rey $A_{n}$ Besedovsky HO. Metabolic and neuroendocrine effects of pro-inflammatory cytokines. Eur J Clin Imest 1992;22 Suppl 1:10-5.

133. Webster JC. Oakley RH, Jewell CM, Cidlowski JA. Proinflammatory cytokines regulate human glucocorticoid receptor gene expression and lead to the accumulation of the dominant negative beta isoform: a mechanism for the generation of glucocorticoid resistance. Proc Natl Acad Sci U S A 2001;98(12):6865-70. 


\section{Chapter 7}

The role of indoleamine 2,3 dioxygenase (IDO) in the pathophysiology of interferon- $\alpha$-induced depression

Marieke Wichers, Michael Maes

Journal of Psychiatry and Neuroscience 2004;29:11-17 


\section{Abstract}

The mechanisms by which administration of interferon- $\alpha$ induces neuropsychiatric side effects, such as depressive symptoms and changes in cognitive function, are not clear as yet. Direct influence on serotonergic neurotransmission may contribute to these side effects. In addition, the enzyme indoleamine 2,3 dioxygenase (IDO), which converts tryptophan into kynurenine, may play an important role, first, because IDO activation leads to reduced levels of tryptophan, the precursor of serotonin (5-HT), and thus to reduced central 5-HT synthesis. Second, kynurenine metabolites such as 3-hydroxy-kynurenine (3-OH-KYN) and quinolinic acid (QA), have toxic effects on brain function. $3-\mathrm{OH}-\mathrm{KYN}$ is able to produce oxidative stress by increasing the production of reactive oxygen species (ROS) and QA may produce overstimulation of hippocampal $N$-methyl-D-aspartate (NMDA) receptors which leads to apoptosis and hippocampal atrophy. Both ROS overproduction and hippocampal atrophy caused by NMDA overstimulation have been associated with depression. 


\section{Introduction}

The pro-inflammatory cytokine interferon (IFN)- $\alpha$ is commonly used in the treatment of patients with hepatitis $\mathrm{C}$ and cancer, but its administration induces neuropsychiatric side effects ${ }^{1,2}$. Symptoms frequently associated with IFN- $\alpha$ treatment are fatigue, both increased sleepiness and difficulty sleeping, irritability, loss of appetite, weight loss and low mood. A full blown depressive disorder is reported in up to $36 \%$ of cases ${ }^{3}$. Cognitive changes involving verbal memory, cognitive speed and executive function are also reported ${ }^{4-6}$.

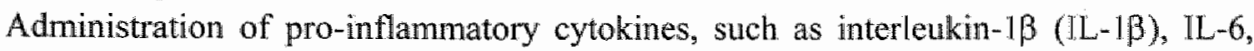
IFN- $\alpha$ and tumour necrosis factor (TNF)- $\alpha$, in rats or mice, induce a behavioural pattern referred to as 'sickness behaviour" ${ }^{\text {? }}$ which includes increased sleep ${ }^{8}$, reduced locomotor activity ${ }^{910}$, decreased sucrose consumption ( as a measure for anhedonia" ${ }^{11}$ ), weight loss and decreased social exploration ${ }^{12}$. These symptoms resemble the vegetative symptoms of depression in humans $\mathrm{s}^{2,13}$.

The development of sickness behaviour ${ }^{14}$ and depression ${ }^{15,16}$ is linked to dysregulation of the neurotransmitter serotonin $(5-\mathrm{HT})$. Several neurochemical changes in both the peripheral and central 5-HT system are seen in depressed patients, such as lower levels of peripheral tryptophan (TRP), the precursor of $5-\mathrm{HT}^{17}$, changes in central $5-\mathrm{HT}$ transporter (5-HTT) function ${ }^{18}$ and changes in $5-\mathrm{HT} 1_{\mathrm{A}}{ }^{19}$ and $5-\mathrm{HT} 2_{\mathrm{A}}$ brain receptors ${ }^{20}$. Therefore, one way in which IFN- $\alpha$ may induce depressive symptoms is by affecting the serotonergic system.

\section{IFN- $\alpha$ and central 5-HT neurotransmission}

IFN- $\alpha$ exerts direct influence on 5-HT brain neurotransmission. IFN- $\alpha$, and also other pro-inflammatory cytokines, such as IFN- $\gamma$, TNF- $\alpha$ and IL-1, have been shown to upregulate 5-HTT, causing a decrease of extracellular $5-\mathrm{HT}^{2 \mathrm{i}-23}$. IFN- $\alpha$ may also indirectly influence 5 -HTT activity by increasing the production of IFN- $\gamma$, TNF- $\alpha$ and IL-1. In addition, IFN- $\alpha$ modulates the $5-\mathrm{HTIA}^{24}$ and $5-\mathrm{HT}^{25}$ brain receptors.

\section{IDO activity causes TRP depletion}

A second pathway by which IFN- $\alpha$ modulates the 5 -HT system is by induction of the enzyme indoleamine 2,3 dioxygenase (IDO). IDO is the rate-limiting enzyme in the $\mathrm{L}$ TRP-kynurenine pathway that converts L-TRP, the precursor of 5-HT, to Nformylkynurenine, resulting in a diminished synthesis of central 5-HT. IDO is widely distributed in various tissues, including the brain, lung, heart, kidney, and intestine ${ }^{26}$. Cytokines, such as IFN- $\alpha$, IFN- $\beta$, TNF- $\alpha$ and IFN- $\gamma$ have been shown to upregulate IDO expression ${ }^{26-34}$. IFN- $\alpha$ has a weak direct effect on IDO induction and an indirect 
effect through a $15 \mathrm{kD}$ protein, which is a product of IF $\mathrm{N}$ - $\alpha$-stimulated monocytes and lymphocytes and which stimulates IDO and IFN- $\gamma$ production ${ }^{32}$.

IFN- $\alpha$ therapy in hepatitis $C$ patients causes a decrease in TRP (4-6 months after starting therapy) and an increase in kynurenine plasma levels seen at 2 weeks after starting therapy, with kynurenine plasma levels remaining the same as at 2 weeks when measured at week 4,16 and 24 , indicating higher $\mathrm{IDO}$ activity ${ }^{33}$. In addition. IDO induction is also mediated by an IFN-n-independent mechanism involving the proinflammatory cytokine TNF- $\alpha^{26}$. Anti-inflammatory cytokines, such as IL-4 and IL-10 diminish TRP metabolism ${ }^{34}$.

Overstimulation of IDO leads to depletion of plasma concentrations of TRP and, therefore, to reduced synthesis of 5-HT in the brain ${ }^{35}$, which may play a role in the development of depressive symptoms. In addition, not only TRP but also 5 hydroxytryptophan (5-HTP) and 5-HT itself can be substrates for IDO ${ }^{36}$. Therefore, it can be postulated that in addition to lowering peripheral levels of TRP, 5-HT synthesis in the brain can also be reduced by central degradation of 5-HT by IDO. However, there is another possible way in which IFN- $\alpha$-induced overstimulation of IDO may produce depressive symptoms. By upregulating IDO expression IFN- $\alpha$ can initiate the kynurenine pathway lleading to the production of a variety of neuroactive metabolites. These kynurenine metabolites themselves may play a causative role because the ratio of kynurenine to TRP is positively associated with depression and anxiety scores ${ }^{33,37}$.

\section{Neurotoxic metabolites of the kynurenine pathway}

Several metabolites formed along the kynurenine pathway are found to have neurotoxic effects, such as 3-hydroxy-kynurenine ( $3 \mathrm{OH}-\mathrm{KYN})$, a direct metabolite of kynurenine, and Quinolinic Acid (QA) which is formed later in the kynurenine pathway ${ }^{38-42}$. Peripheral kynurenine is transported through the blood-brain barrier by a large neutral amino acid carrier and thus may easily reach the central nervous system. In the brain it is taken up by glia cells by which it is further metabolised ${ }^{43,44}$. In this way neurotoxic metabolites are formed in the brain that can cause neurodegeneration.

The neurotoxicity of these kynurenine metabolites has been demonstrated in animals ${ }^{45-}$ 50 and in vitro ${ }^{41}$, whereas data from humans show elevated levels in several neurodegenerative disorders. Increased production of $3 \mathrm{OH}-\mathrm{KYN}$ or $\mathrm{QA}$ or both, is found in certain neurodegenerative conditions in humans ${ }^{38}$, such as in Huntington's Disease $^{51,52}$, Parkinson's Disease ${ }^{53}$ and in the AIDS-dementia complex ${ }^{54,55}$. In the last condition, QA levels are increased in the cerebrospinal fluid up to 20 -fold and are correlated with the severity of cognitive and motor dysfunctions. Increased production of $3 \mathrm{OH}-\mathrm{KYN}$ and QA may also contribute to neuronal damage in cognitive decline of aging $^{56}$, infections of the central nerwous system ${ }^{57}$, malaria ${ }^{58}$, ischemia ${ }^{59}$, hypoxia at birth $^{61}$, traumatic injury ${ }^{6 !}$ and epilepsy ${ }^{62}$. In addition, they may play a role in the 
development of psychiatric diseases such as anxiety ${ }^{63}$, depression ${ }^{64}$ and schizophrenia ${ }^{65}$.

The following mechanisms may account for the effect of $3-\mathrm{OH}-\mathrm{KYN}$ and $\mathrm{QA}$ on neurodegenerative diseases and depressive symptoms (figure 7.1). Even relatively low levels of $3 \mathrm{OH}-\mathrm{KYN}$ may cause neurotoxicity by inducing oxidative stress and neuronal apoptosis $^{40,41}$. 3-OH-KYN is transferred into cells by neutral amino acid transporters. Only after interaction with cellular xanthine oxidase, 3-OH-KYN is capable of producing sufficient amounts of reactive oxygen species (ROS), such as superoxide radical, hydrogen peroxide and hydroxyl radical, to induce internucleosomal DNA cleavage leading to apoptosis. Various antioxidative agents prevent cell death induced by $3-\mathrm{OH}-\mathrm{KYN}$. The cortex and the striatum are most sensitive to $3-\mathrm{OH}-\mathrm{KYN}$ insults. Differences in vulnerability to $3-\mathrm{OH}-\mathrm{KYN}$ for different brain regions are likely to result from differences in ability to take up large neutral amino acids ${ }^{41}$. Overproduction of ROS has been associated with depression. An association between overproduction of ROS and increased monoamine oxidase (MAO) activity has been suggested "In addition, polyunsaturated fatty acids (PUFAs) are vulnerable to oxidation. Overproduction of ROS might result in destruction of phospholipids and reduce viscosity of cell membranes ${ }^{67}$ Alterations in membrane viscosity may influence receptor density or function of serotonergic or catecholaminergic receptors ${ }^{6 .}$, Overproduction of proinflammatory cytokines, increased MAO activity and, thus, lower levels of catecholamines, disturbances in PUFAs structures and ratios, and the decrement of serotonergic and catecholamineric receptor densities and functioning are all associated with depression ${ }^{2,69,70}$. Furthermore, selective serotonin reuptake inhibitors have antioxidant properties and reverse the overproduction of $\operatorname{ROS}^{71}$.

$\mathrm{QA}$ is a potent $\mathrm{N}$-methyl-D-aspartate (NMDA) receptor agonist. Overstimulation of NMDA receptors increases calcium influx into the target neurons, which will lead to neuronal damage ${ }^{47,72}$. In addition, QA can contribute to the formation of free radicals, first because the influx of calcium ions into neurons after activation of glutamate receptors may lead to the generation of $\operatorname{ROS}^{73,74}$. Furthermore, with the generation of free radicals, QA induces lipid peroxidation in membrane lipids and proteins, leading to changes in neuronal membrane fluidity, receptor function and ion permeability ${ }^{75}$. Finally, QA and 3-OH-KYN act synergistically in the production of tree radicals, so that even low doses of QA potentiate the excitotoxicity of 3-OH-KYN ${ }^{76,77}$.

Intrahippocampal injection of QA in rats causes substantial loss of hippocampal neurons ${ }^{45,48,75}$. QA-induced neurotoxicity can be significantly reduced by pharmacological blockade of kynurenine 3-hydroxylase, the enzyme responsible for the formation of 3-OH-KYN from L-KYN or by administration of Kynurenate (KYNA), another metabolite of the kynurenine pathway, which inhibits NMDA receptor function and thus protects against excitotoxic insults 48 . 


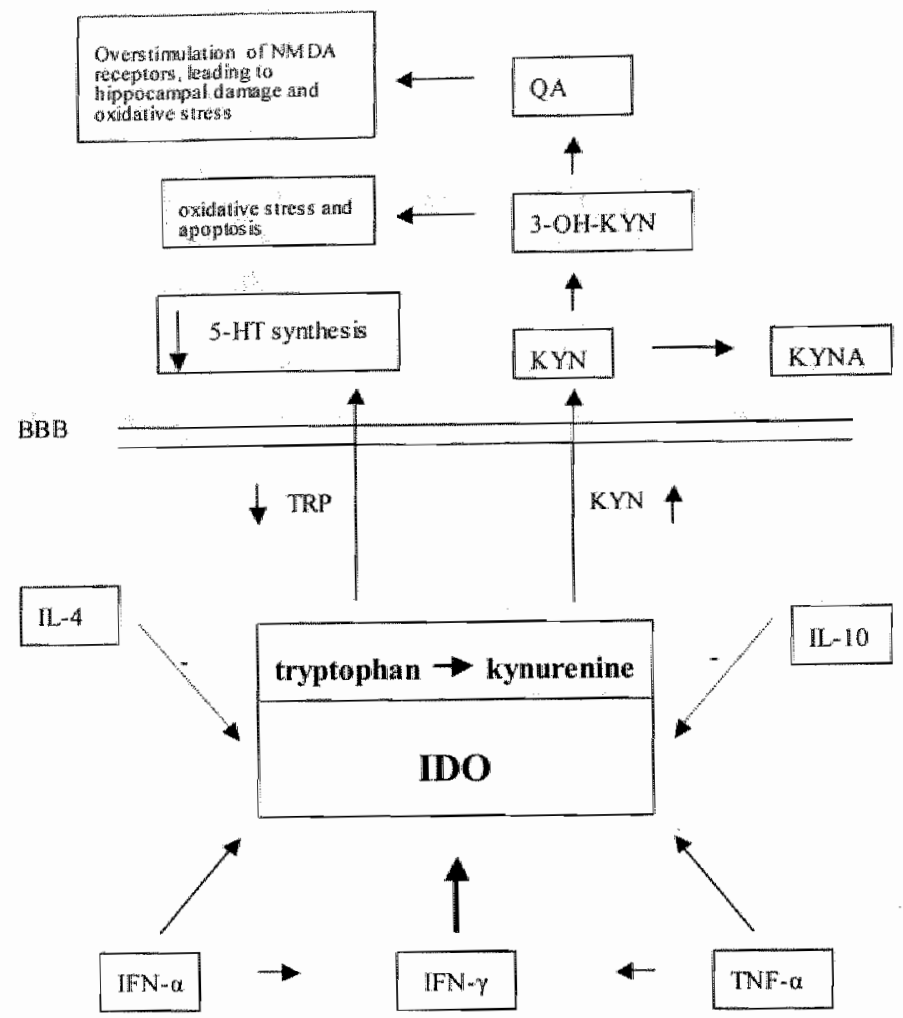

Figure 7.1 The role of indoleamine 2,3-dioxygenase (IDO) in cytokine-ind uced lowered tryptophan (TRP) levels and production of neuroloxic metabolites. The dotted arrows indicate that IL-4 and IL-10 diminish IDO activity. The diagonal arrows leading from IFN- $\alpha$ and TNF- $\alpha$ to IDO indicate that these cytokines increase IDO activity and, thus, cause increased metabolism of TRP, resulting in decreased availability of TRP that crosses the BBB to synthesize 5-HT. The horizontal arrows between IFN- $\alpha$ and IFN- $\gamma$ and between TNE- $\alpha$ and IFN- $\gamma$ refer to the fact that IFN- $\alpha$ and TNF-a increase production of IFN- $y$, which exerts a powerful stimulating effect (thick vertical arrow) on $\mathrm{DDO}$ activity. $\mathrm{NMDA}=\mathrm{N}$-methyl-D-aspartate, $\mathrm{QA}=$ quinolinic acid, 3-OH-KYN = 3-hydroxy-kynurenine, $5-H T=$ serotonin, $\mathrm{KYN}=$ kynurenine, $\mathrm{KYNA}=$ kynurenate, $\mathrm{BBB}=$ bload-brain-barrier, $\| L-4=$ interleukin- $4, \| \mathrm{NN}-\alpha=$ interferon- $\alpha, \mathrm{TNF}-\alpha=$ tumour necrosis factor- $\alpha$. 


\section{Hippocampal neurodegeneration and depression}

Major depression is associated with hippocampal volume $105 s^{78.79}$. Hypothalamicpituitary-adrenal (HPA) axis inhibition appears to be mediated by negative feedback from circulating glucocorticoids ${ }^{80}$. Destruction of the hippocampus attenuates the negative feedback via loss of glucocorticoid receptors, which will increase HPA activity. Loss of the normal glucocorticoid feedback has been reported in humans with depression and animals in chronic stress paradigms ${ }^{81-83}$. Hippocampal atrophy results from an excess of excitatory amino acid neurotransmitters, such as glutamate that acts on the NMDA receptor, which can be produced by glucocorticoid overexposure ${ }^{84-86}$. However, Magariños and $\mathrm{McEwen}^{87}$ found a dissociation between parameters indicating the glucocorticoid stress response and hippocampal atrophy in rats. Dendritic atrophy occurred in spite of the habituation of the glucocorticoid stress response after days of repeated stress. In addition, hypercortisolism occurs in approximately half of the patients with depression, while atrophy seems to be demonstrable in a far higher percentage of individuals ${ }^{86}$. This suggests that besides glucocorticoids, other factors contribute to neurodegeration, for example. the neurotoxic metabolites of kymurenine, whose levels are raised in depression. Therefore, we hypothesize a second mechanism in which kynurenine metabolites, such as QA, cause NMDA receptor overstimulation leading to hippocampal atrophy and subsequent interference with the normal negative feedback function of HPA axis activity.

\section{Conclusion}

Administration of IFN- $\alpha$ causes the development of depressive symptoms in a high percentage of patients. This may be caused by direct influence of IFN- $\alpha$ on central 5 HT transmission, or indirectly via induction of the enzyme IDO. The latter may play an important rolle in the pathophysiology of IFN- $\alpha$-induced depression through its effect on brain TRP availability that is crucial to the formation of central 5-HT. Furthermore, IDO is the rate-limiting step in the brain kymurenine pathway that leads to the formation of some neurotoxic substances, such as 3-OH-KYN and QA, which cause neuro-degeneration that may contribute to the development of depression. 


\section{References}

1. Bonaccorso $\mathrm{S}$, Marino V, Biondi M, Grimaldi F, Ippoliti F, Maes M. Major depression induced by interferon-alpha in patients affected by hepatitis $\mathrm{C}$ virus. $I$ Affect Disord $2002 ; 72(3) ; 237-41$.

2. Maes M. Evidence for an immune response in major depression: a review and hypothesis. Prog Newropsychophamacol Biol Psychiarny 1995;19(1):11-38.

3. Collier J, Chapman $\mathrm{R}$. Combination therapy with interferon-alpha and ribavirin for hepatitis C: practical treatment issues. BioDrugs $2001 ; 15(4): 225-38$.

4. Juengling $\mathrm{FD}$, Ebert $\mathrm{D}_{3}$ Gut $\mathrm{O}$, et al. Prefrontal cortical hypometabolism during low-dose interferon alpha treatment. Psychopharmacology (Berl) 2000;152(4):383-9.

5. Pavol MA, Meyers CA, Rexer JL, Valentine $\mathrm{AD}_{\text {, }}$ Mattis PJ, Talpaz M. Pattern of neurobehavioral deficits associated with interferon alfa therapy for leukemia. Neurology $1995 ; 45(5): 947-50$.

6. Adams F, Quesada JR, Gutterman JU. Neuropsychiatric manifestations of human leukocyte interferon therapy in patients with cancer. Jama 1984;252(7):938-41.

7. Kent S, Bluthe RM, Kelley KW, Dantzer R. Sickness behavior as a new target for drug development. Trends Pharmacol Sci 1992;13(1):24-8.

8. Krueger JM, Takahashi $\mathrm{S}$, Kapas $\mathrm{L}$, et all. Cytokines in sleep regulation. Adv Neuroimmumol $1995 ; 5(2): 171-88$.

9. Lacosta S, Merali Z, Anisman $\mathrm{H}$. Influence of interleukin- Ibeta on exploratory behaviors, plasma ACTH, conticosterone, and central bjogenic amines in mice. Psychopharmacology (Berl) 1998;137(4):351-61.

10. Bianchi M, Sacerdote P, Ricciardi-Castagnoli P, Mantegazza P, Panerai AE. Central effects of tumor necrosis factor alpha and interleukin-1 alpha on nociceptive thresholds and spontaneous locomotor activity. Neurosci Lett 1992; $148(1-2): 76-80$.

11. Sammut $S$, Goodall $G$, Muscat $R$. Acute interferon-alpha administration modulates sucrose consumption in the rat. Psychonewroendocrinology 2001;26(3):261-72.

12. Bluthe RM, Pawlowski $M$, Suarez $S$, et al. Synergy between tumor necrosis factor alpha and interleukin-1 in the induction of sickness behavior in mice. Psychoneuroendocrinology 1994; $9(2): 197-207$.

13. Chartion BG. The malaise theory of depression: major depressive disorder is sickness behavior and antidepressants are analgesic. Med Hypotheses 2000;54(1):126-30.

14. Linthorst AC. Reul IM. Brain neurotransmission during peripheral inflammation. Awn $N$ Y Acad $5 c i 1998 ; 840: 139-52$.

15. Dursun SM, Blackburn JR, Kutcher SP. An exploratory approach to the serotonergic hypothesis of depression: bridging the synaptic gap. Med Hypotheses 2001;56(2):235-43.

16. Graeff FG, Gumaraes FS, De Andrade TG, Deakin JF. Role of 5-HT in stress, anxiety, and depression. Pharmacol Biochem Behav 1996;54(1):129-41.

17. Maes M, Meltzer HY, Scharpe S, et al. Relationships between lower plasma L-tryptophan levels and immune- innammatory variables in depression. Psychiatry Res 1993;49(2): 151-65.

18. Lesch KP. Mossner R. Genetically driven variation in serotonin uptake: is there a link to affective spectrum, neurodevelopmental, and neurodegenerative disorders? Biol Psychiary 1998;44(3): 179-92.

19. Sargent PA, Kjaer $\mathrm{KH}$, Bench $\mathrm{CJ}$, er al. Brain serotonin $1 \mathrm{~A}$ receptor binding measured by positron emission tomography with [1IC]WAY-100635: effects of depression and antidepressant treatment. Arch Gen PSychiatry 2000;57(2):174-80.

20. Yatham LN, Liddle PF, Shiah IS, et al. Brain serotonin2 receptors in major depression: a positron emission tomography study. Arch Gen Psychiatry 2000;57(9):850-8. 
21. Ramamoorthy S, Ramamoorthy JD, Prasad PD, et al. Regulation of the human serotonin transporter by interleukin-1 beta. Biochem Biophys Res Commun 1995,216(2):560-7.

22. Mossner R, Heils A, Stober G, Okladnova O, Daniel $S$, Lesch KP. Enhancement of serotonin transporter function by tumor necrosis factor alpha but not by interleukin-6. Neurochem Int 1998;33(3):251-4.

23. Morikawa O, Sakai N, Obara H, Saito N. Effects of interferon-alpha, interferon-gamma and CAMP on the transcriptional regulation of the serotonin transporter. Eur $J$ Pharmacol $1998 ; 349(2-3): 317-24$.

24. Abe S, Hori T, Suzuki T, Baba A, Shiraishi H, Yamamoto T. Effects of chronic administration of interferon alpha $A / D$ on serotonergic receptors in rat brain. Neurochem $\operatorname{Res} 1999 ; 24(3): 359-63$.

25. Kugaya A, Kagaya A, Uchitomi $Y$, Yokota $N$, Yamawaki S. Effect of interferon-alpha on DOI-induced wet-dog shakes in rats. $J$ Neural Transm 1996; 103(8-9):947-55.

26. Fujigaki S, Saito K, Sekikawa K, et al. Lipopolysaccharide induction of indoleamine 2,3dioxygenase is mediated dominantly by an IFN-gamna-independent mechanism. Eur $J$ Immunol 2001;31(8):2313-8.

27. Takikawa $O$, Kuroiwa $T$, Yamazaki $F$, Kido R. Mechanism of interferon-gamma action. Characterization of indoleamine 2,3-dioxygenase in cultured human cells induced by interferon-gamma and evaluation of the enzyme-mediated tryptophan degradation in its anticellular activity. $J$ Biol Chem 1988;263(4):2041-8.

28. Pemberton LA, Kerr SJ, Smythe G, Brew BJ. Quinolinic acid production by macrophages stimulated with $\llbracket \mathrm{FN}$-gamma, TNF-alpha, and IFN-alpha. J Interferon Cyrokine Res 1997; 17(10):589-95.

29. Jansen $\mathrm{M}$, Reinhard JF, Jr. Interferon response heterogeneity: activation of a proinflammatory response by interferon alpha and beta. A possible basis for cliverse responses to interferon beta in MS. J Leukoc Biol 1999;65(4):439-43.

30. Taylor MW, Feng GS. Relationship between interferon-gamma, indoleamine 2,3dioxygenase, and tryptophan catabolism. Faseb J 1991;5(11):2516-22.

31. Guillemin GJ, Kerr SJ, Pemberton LA, et al. IFN-betalb induces kynurenine pathway metabolism in human macrophages: potential implications for multiple sclerosis treatment. IInterferon Cytakine Res 2001;21(12): 1097-101.

32. Recht $\mathrm{M}$, Borden $\mathrm{EC}$, Knight $\mathrm{E}, \mathrm{J}_{\mathrm{r}}$. A human $15-\mathrm{kDa} \mathrm{IFN}$-induced protein induces the secretion of JFN-gamma. J Imwnwo/ 1991;147(8):2617-23.

33. Bonaccorso $\mathrm{S}$, Marino $\mathrm{V}$, Puzella $\mathrm{A}$, et al. Increased depressive ratings in patients with hepatitis $C$ receiving interferon-alpha-based immunotherapy are related to interferon-alpliainduced changes in the serotonergic system. J Clin Psychopharmacol 2002;22(1) "86-90.

34. Chiarugi $A$, Calvani $M$, Meli E, Traggiai $E$, Moroni F. Synthesis and release of neurotoxic kynurenine metabolites by human monocyte-derived macrophages. I Neuroimmunol $2001 ; 120(1-2): 190-8$.

35. Heyes MP, Saito K, Crowley JS, et al. Quinolinic acid and kynurenine pathway metabolism in inflammatory and non-inflammatory neurological disease. Brain 1992;115(Pt5): $1249-73$.

36. Stone TW, Darlington LG. Endogenous kynurenines as targets for drug discovery and development. Nat Rev Drug Discov 2002; 1 (8) $6009-20$.

37. Maes M, Verkerk R, Bonaccorso S, Ombelet W, Bosmans E, Scharpe S. Depressive and anxiety symptoms in the early puerperium are related to increased degradation of tryptophan into kynurenine, a phenomenon which is related to immune activation. Life $5 \mathrm{ci}$ $2002 ; 71(16): 1837$.

38. Stone TW. Kynurenines in the CNS: from endogenous obscurity to therapeutic importance. Prog Neurobiol 2001;64(2):185-218. 
39. Dang $Y$, Dale $W E_{*}$ Brown OR. Comparative effects of oxygen on indoleamine 2,3. dioxygenase and tryptophan 2,3-dioxygenase of the kynurenine pathway. Free Radic Bial Med 2000;28(4):615-24.

40. Moroni $\mathbb{F}$. Tryptophan metabolism and brain function: focus on kymurenine and other indole metabolites. Eur J Pharmacol 1999;375(1-3):87-100.

41. Okuda S, Nishiyama $N$, Saito $H$, Katsuki $H$. 3-Hydroxykynurenine, an endogenous oxidative stress generator, causes neuronal cell death with apoptotic features and region selectivity. $J$ Neurochem 1998; $70(1): 299-307$.

42. Guillemin GJ, Kerr SJ, Smythe GA, et al. Kynurenine pathway metabolism in human astrocytes: a paradox for neuronal protection. J Neurochem $2001 ; 78(4): 842-53$.

43. Speciale $\mathrm{C}$, Hares $\mathrm{K}$, Schwarcz R, Brookes $\mathrm{N}$. High-affinity uptake of L-kynurenine by a Nat-independent transporter of neutral amino acids in astrocytes. I Neurosci $1989 ; 9(6): 2066-72$.

44. Fukui S, Schwarcz $\mathbb{R}$, Rapoport SI, Takada Y, Smith QR. Blood-brain barrier transport of kynurenines: implications for brain synthesis and metabolism. I Neurachem $1991 ; 56(6): 2007-17$.

45. Behan WM, McDonald $M$, Darlington $\mathrm{LG}$, Stone TW. Oxidative stress as a mechanism for quinolinic acid-induced hippocampal damage: protection by melatonin and deprenyl. $B r J$ Pharmacol 1999;128(8):1754-60.

46. Qin $Z \mathrm{H}$, Wang $\mathrm{Y}$, Chase TN. Stimulation of $\mathrm{N}$-methyl-D-aspartate receptors induces apoptosis in rat brain. Brain Res 1996;725(2):166-76.

47. Schwarez R, Whetsell WO, Jr., Mangano RM. Quinolinic acid: an endogenous metabolite that produces axon-sparing lesions in rat brain. Science 1983;219(4582):316-8.

48. Wu $\mathrm{HQ}$, Guidetti $\mathrm{P}$, Goodman $\mathrm{JH}$, et al. Kynurenergic manipulations influence excitatory synaptic function and excitotoxic vulnerability in the rat hippocampus in vivo. Neuroscience 2000;97(2):243-51.

49. Guidetti P, Schwarcz R. 3-Hydroxykynurenine potentiates quinolinate but not NMDA toxicity in the rat striatum. Eur J Neurosici 1999;11(11):3857-63.

50. Heyes MP, Jordan EK, Lee K, et al. Relationship of neurologie status in macaques infected with the simian immunodeficiency virus to cerebrospinal fluid quinolinic acid and kymurenic acid. Brain Res 1992;570(1-2):237-50.

51. Reynolds GP, Pearson SJ. Increased brain 3-hydroxykynurenine in Huntington's disease.

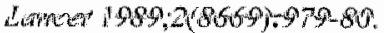

52. Reynolds GP, Pearson SI, Haiket J, Sandler M. Brain quinolinic acid in Huntington's disease. INeurochem $1988 ; 50(6): 1959-60$.

53. Ogawa $T$, Matson $W R$, Beal MF, et al. Kynurenine pathway abnormalities in Parkinson's disease. Neurology 1992;42(9):1702-6.

54. Heyes MP, Saito K, Lackner A, Wiley CA, Achim CL, Markey SP. Sources of the neurotoxin quinolinic acid in the brain of HIV-1- infected patients and retrovirus-infected macaques. Faseb J 1998;12(10):88 1-96.

55. Chao CC, Mu S, Gekker G, Lokensgard JR, Heyes MP, Peterson PK. U50,488 protection against HIV-I-related neurotoxicity: involvement of quinolinic acid suppression. Netropharmacology 2000;39(1):150-60.

56. Moroni F, Lombardi G, Moneti G, Aldinio C. The excitotoxin quinolinic acid is present in the brain of several mammals and its cortical content increases during the aging process. Neurosci Lett 1984;47(1):51-5.

57. Heyes MP, Saito K, Milstien S, Schiff SI. Quinolinic acid in tumors, hemorrhage and bacterial infections of the central nervous system in children. $J$ Neurol Sci 1995; 133(1-2): $112-8$. 
58. Sanni $\mathrm{LA}$, Thomas $\mathrm{SR}$, Tattam $\mathrm{BN}$, et al. Dramatic changes in oxidative tryptophan metabolism along the kymurenine pathway in experimental cerebral and noncerebral malaria. Am o Pathol 1998;1.52(2):611-9.

59. Saito K, Nowak TS, Jr, Markey SP, Heyes MP. Mechanism of delayed increases in kymurenine pathway metabolism in damaged brain regions following transient cerebral ischemia. I Newrochem 1993;60(1): 180-92.

60. Kazda H, Taylor N, Healy D, Walker D. Maternal, umbilical, and amniotic fluid concentrations of tryptophan and kynurenine after labor or cesarean section. Pediatr Res 1998;44(3):368-73.

61. Sinz EH, Kochanek PM, Heyes MP, et al. Quinolinic acid is increased in CSF and associated with mortality after traumatic brain injury in humans. $J$ Cereb Blood Flow Metab 1998;18(6):610-5.

62. Heyes MP, Wyler AR, Devinsky O, Yergey JA, Markey SP, Nadi NS. Quinolinic acid concentrations in brain and cerebrospinal fluid of patients with intractable complex partial seizures. Epilepsia 1990;31(2):172-7.

63. Orlikov AB, Prakhye IB, Ryzov IV. Kynurenine in blood plasma and DST in patients with endogenous anxiety and endogenous depression. Biol Psychiarry 1994;36(2):97-102.

64. Mangoni A. The "kymurenine shunt" and depression. Adv Biochem Psychopharmacol $1974 ; 11(0): 293-8$.

65. Issa $F$, Kirch $D G$, Gerhardt GA, et al. A multidimensional approach to analysis of cerebrospinal fluid biogenic amines in schizophrenia: II. Correlations with psychopathology. Psychiary Res 1994;52(3):251-8.

66. Gutteridge JM. Lipid peroxidation and antioxidants as biomarkers of tissue damage. $\mathrm{Clm}$ Chem 1995;41(12 Pt 2):1819-28.

67. McIntyre N. Familial LCAT deficiency and fish-eye disease. J Intherir Metab Dis $1988 ; 1$ (Suppl 1):45-56.

68. Van der Vliet A, Bast A. Effect of oxidative stress on receptors and signal transmission. Chem Biol Interact 1992;85(2-3):95-116.

69. Maes M, Meltzer H. The serotonin hypothesis of major depression. In: Bloom F, Kupfer D, eds. Psychopharmacology. New York: Raven Press, 1995: p. 933-944.

70. Maes M, Smith R, Christophe A, Cosyns P, Desnyder R, Meltzer H. Fatty acid composition in major depression: decreased omega 3 fractions in chollesteryl esters and increased C20:4 omega 6/C20:5 omega 3 ratio in cholesteryl esters and phospholipids. I Affect Disord $1996 ; 38(1): 35-46$.

71. Blici M, Efe H, Koroglu MA, Uydu HA, Bekarogh M, Deger O. Antokdative enzyme activities and lipid peroxidation in major depression: alterations by antidepressant treatments. I Affect Disord 2001;64(1):43-51.

72. Perkins MN, Stone TW. An tontophoretic investigation of the actions of convalsant kynurenines and their interaction with the endogenous excitant quinolinic acid. Brain Res $1982: 247(1): 184-7$.

73. Hartley DM, Kurth MC, Bjerkness L, Weiss MH, Choi DW. Ghutamate receptot-indaced $45 \mathrm{Ca} 2+$ accumulation in cortical cell culture cortelates with subsequent neturonal degeneration. I Newrosci $1993 ; 13(5): 1993-2000$.

74. Adante $A$, Gagliardi S, Minerwini GM, Chotti MT, Marra E, Calissano P. Gutanate neurotoxicity in rat cerebellar granule cells: a major role for xanthine oxidase in oxygen radical fomation. J Newrochem 1997;68(5):2038-45.

75. Santamaria A, Galwan-Arzate S, Lisy V, et al. Quinolinic acid induces oxidative stress in rat brain synaptosomes. Nemoreport $2001 ; 12(4): 871-4$.

76. Guillemin GJ, Brew BJ. Implications of the kymurenine pathway and quinolinic acid in Alzheimer's disense. Redox Rep 2002;7(4):199-206. 
77. Nakagami $Y$, Saito $H_{6}$ Katsuki H. 3-Hydroxykymurenine toxicity on the rat striatum in vivo. Jpn J Pharmacol 1996,7 I(2):183-6.

78. Sheline YI, Sanghavi M. Mintun MA, Gado MH. Depression duration but not age predicts hippocampal volume loss in medically healthy women with recurrent major depression. $J$ Neurosci $1999 ; 19(12): 5034-43$.

79. Bremner JD, Narayan M, Anderson ER, Staib LH, Miller HL, Charney DS. Hippocampal volume reduction in major depression. Am J Psychiatry 2000;157(1):1 15-8.

80. Sapolsky RM, Meaney MJ, McEwen BS. The development of the glucocorticoid receptor system in the rat limbic brain. HI. Negatiwe-feedback regulation. Brain Res 1985;350(1-2): 169-73.

81. Sapolsky RM, Krey LC, McEwen BS. The adrenocortical axis in the aged rat: impaired sensitivity to both fast and delayed feedback inhibition. Neurobial Aging 1986;7(5):331-5.

82. Liberzon I, Krstov M, Young EA. Stress-restress: effects on ACTH and fast feedback. Psychoneuroendoctinology 1997;22(6):443-53.

83. Young EA, Haskett RF, Murphy-Weinberg V, Watson SJ, Akil H. Loss of glucocorticoid fast feedback in depression. Arch Gen Psychiatry 1991;48(8):693-9.

84. McEwen BS. Effects of adverse experiences for brain structure and function. Biol Psychiatry 2000;48(8):721-31.

85. McEwen BS. Possible mechanisms for atrophy of the human hippocampus. Molecular psychiary 1997;2(3):255-62.

86. Sepolsky RM. Glucocorticoids and hippocampal atrophy in neuropsychiatric disorders. Arch Gen Psychiatry 2000;57:925-35.

87. Magarinos AM, McEwen BS. Stress-induced atrophy of apical dendrites of hippocampal CA3c neurons: comparison of stressors. Neuroscience 1995;69(1):83-8. 


\section{Chapter 8}

\section{Early increase in vegetative symptoms predicts interferon-alpha-induced cognitive-depressive changes}

Marieke Wichers, Ger Koek, Geert Robaeys, Bert Praamstra, Michael Mares Psychological Medicine 2005;35:433-41 


\section{Abstract}

\section{Background}

The vegetatye symptoms of depression resemble the symptoms of malaise associated wh activation of the infammatory response system (IRS), and can be regarded as an expression of a centrat motivational state that resets the organism's priorties to promote recovery from infection. Early vegetative symptoms, however, nay also contribute to the high rates of depression seen later in the course of immune activation. We hypothesised that the onset of vegetative-depressive symptoms early in the treatment whth the pro-inflammatory cytokine interferon-alpha (IFN-a) in Chronic Hepatitis $\mathrm{C}$ patents would increase the risk for subsequent depressive cognitions.

\section{Methods}

16 patients eligible for IFN-a treatment free of psychiatric disorders were recruited. The DSMIV, the Multidimensional Fatigue Inventory, and the Montgomery Depression Rating Scale (MADRS) were administered at baseline and 1,2, 4, 8, 12 and 24 weeks after treatment was initiated. Cognitive-depressive and vegetative-depressive symptom clusters were constructed.

\section{Results}

Fatigue and depression scores increased significantly during IFN-a treatment. Depression scores were highest at week 8 of treatment. First week increase in vegetative-depressive symptom score predicted cognitive-depressive symptom score at week 8 and at week 24 .

\section{Conclusions}

During IFNa treatment, vegetative symptoms of depression appear earlier than, and are predictive of, their cognitive counterparts. This finding suggests that low mood state may in part be driven by the increase in early vegetative-depressive symptoms in the course of IFN- $\alpha$ induced immune activation. 


\section{Introduction}

Administration of interferon-alpha (IFN- $\alpha$ ), a cytokine demonstrating major antiviral and immunomodulatory effects, has been used effectively as treatment for a variety of chronic viral infections and malignant disorders, including chronic hepatitis $C$. Despite its potential therapeutic benefits, administration of IFN- $\alpha$ frequently induces psychiatric pathology such as severe fatigue and depressive symptoms. Recent clinical studies have shown that approximately 16 to $45 \%$ of patients treated with IFN- $\alpha$ developed depressive symptoms during the course of therapy ${ }^{1-4}$. Prevalences of neuropsychiatric side effects due to IFN- $\alpha$ treatment differ greatly between studies, but most variation may be explained by differences in the methodology used. Thus, neuropsychiatric side effects appear to be dose-related, duration of therapy varies between studies, different assessment scales were used and sometimes prevalences were based only on subjective patient reports ${ }^{5.6}$. Finally, co-administration of IFN- $\alpha$ with ribavirin or administration of IFN- $\alpha$ in pegylated (PEG) form are associated with different prevalences of neuropsychiatric side effects than standard IFN $-\alpha$ administration ${ }^{7}$. However, most studies agree on the fact that fatigue, irritability and depression are very troublesome side effects of IFN- $\alpha$ treatment which may require dose-reduction or even discontinuation ${ }^{8-10}$.

The link between immune activation and depressive symptoms has been documented extensively. Major depression is accompanied by an activation of the inflammatory response system ${ }^{11}$. Furthermore, acute infectious illness ${ }^{12}$ and upper respiratory tract infections $^{13}$, as well as chronic inflammatory diseases ${ }^{14-18}$, have been associated with depressive symptoms. Furthermore, cytokines can enter the brain by crossing the blood-brain-barrier (BBB) via transport mechanisms, through areas where the BBB is lacking and they can transmit signals to the brain via the vagus nerve. Also, they can activate the brain vasculature to cause release of signalling molecules within the brain parenchyma ${ }^{19}$. The fact that cytokines are able to communicate with the central nervous system (CNS) to influence behaviour ${ }^{20}$, supports the possibility of their role as contributors to psychopathology, including mood disorders.

Cytokines produced in response to infection endogenously produce behavioural changes similar to those produced by the exogenous administration of IFN- $\alpha$. These behavioural changes include fever, experience of weakness, fatigue, hypersomnia, depressed activity, decreased appetite and loss of interest in social activities, and result in a state of general malaise. Instead of regarding these behaviours as the result of the debilitation process that occurs during infection, it has been argued that they are actually part of a natural homeostatic reaction the body uses to fight infection. Sickness behaviour ${ }^{21,22}$ can be regarded as an expression of a central motivational state that resets the organism's priorities to promote recovery from infection ${ }^{23}$. This behavioural response to infection is triggered by the pro-inflammatory cytokines that are produced by activated immune cells (mainly interleukin (IL)-1, IL-6 and tumour necrosis factor (TNF)- $\alpha$ ). 


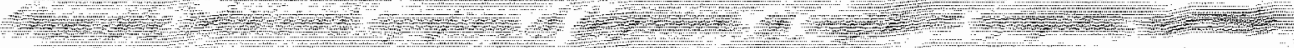
It

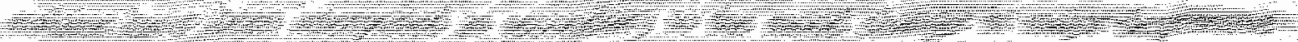

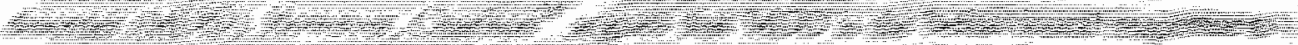

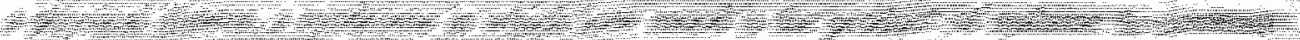

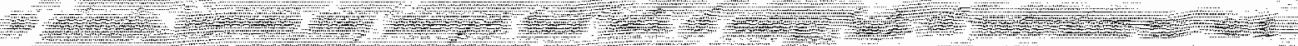

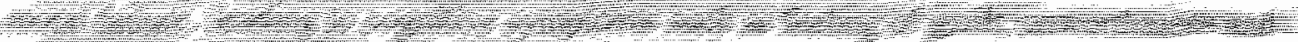

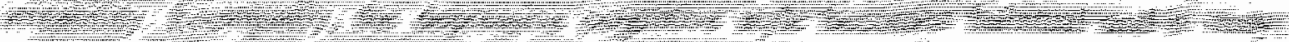

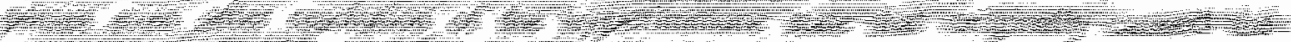

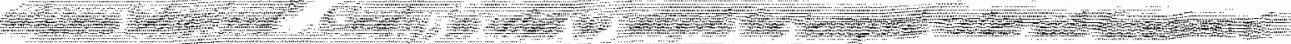

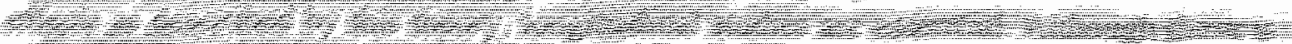

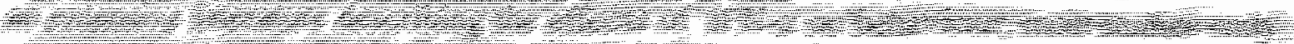

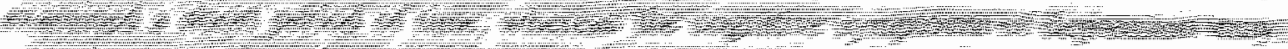

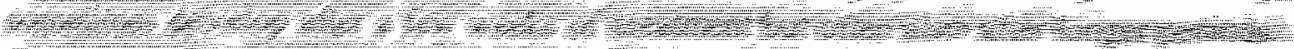

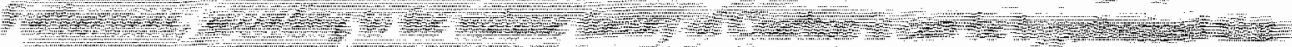

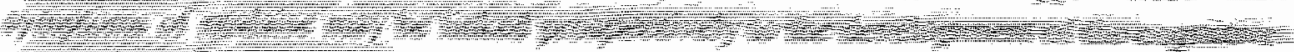

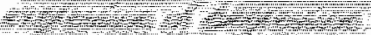

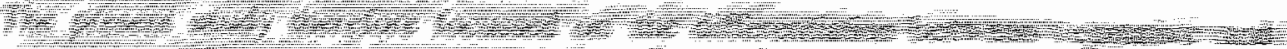

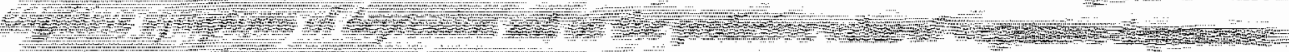

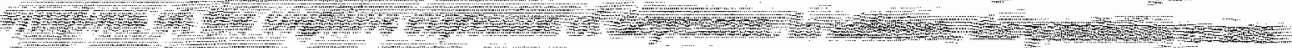

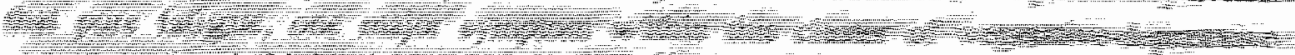

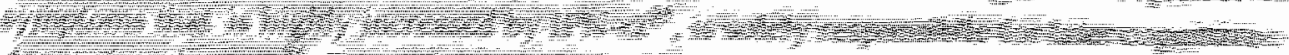

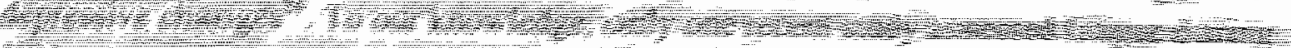

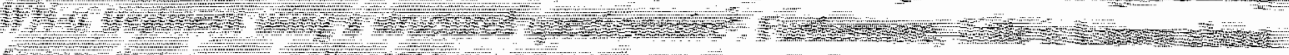

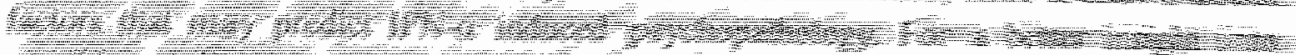

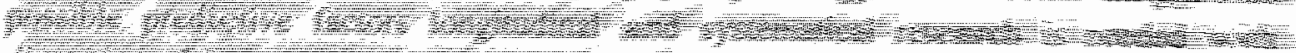

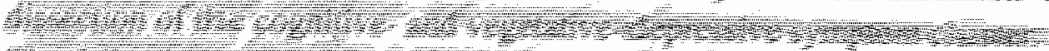

IFNa treatment. We hypoth time during treatment; ii) that vegetat: i) symptoms of depression would increase over would be predictive of, cognitive-depressive symptoms.

\section{Methods}

\section{Subjects} eligible for IFN- $\alpha$ treatment, were recruited. Chronic hepatitus $C$ was defined as: antibodies to hepatitis $\mathrm{C}$ virus (HCV) positive, HCV-RNA positive and elevated transaminases at least once in the previous 6 months.

Patients had a complete medicat history 6 months.

check betore study entry. In addition, physical examination and laboratory blood 


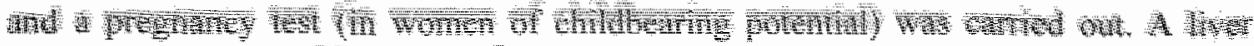

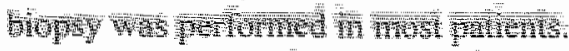

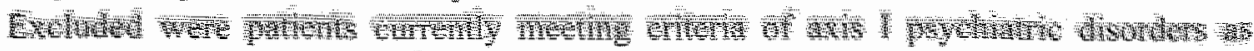

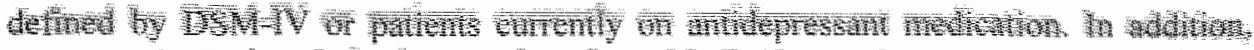

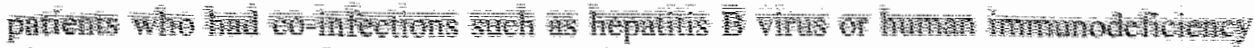

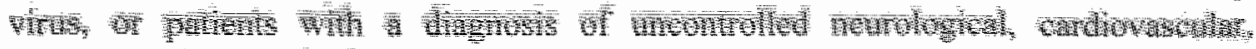

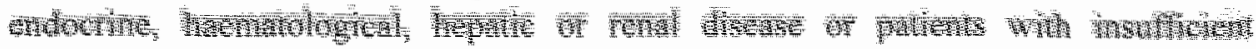

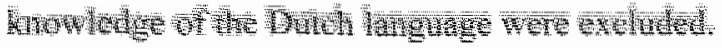

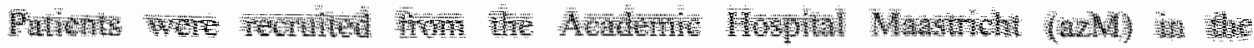

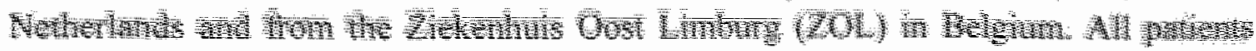
masen mumprom

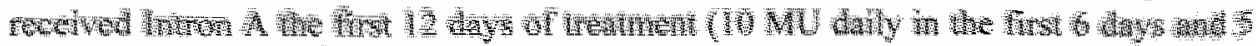

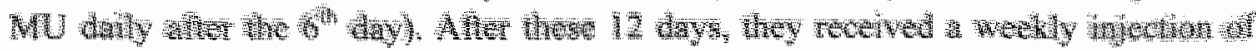

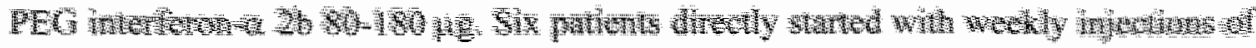

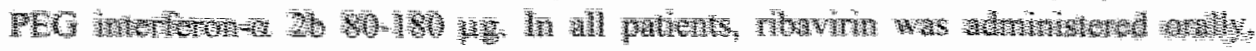

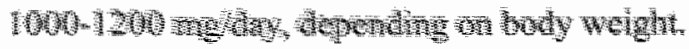

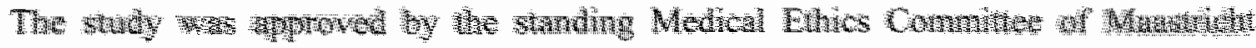

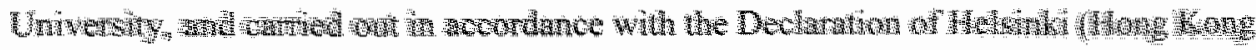

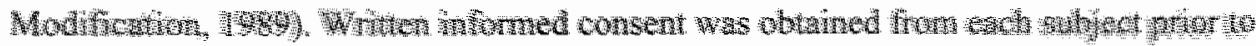

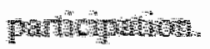

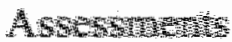

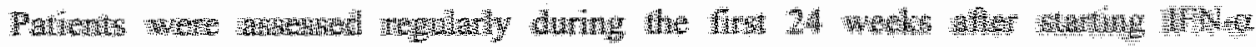

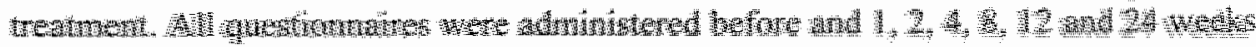

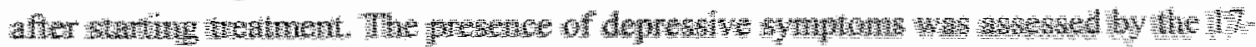

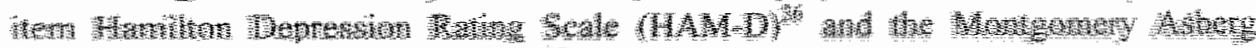
Depression Rating Scale (MADRS) ${ }^{27}$. Fatigue was assessed by the Multidimensional Fatigue Inventory (MFI), which is a self-report instrument consisting of five soales measuring general fatigue, physical fatigue, reduced activity, reduced motivation and mental fatigue ${ }^{2}$. To detemine the presence of any axis I psychiatric disorder, the Structured Chnical Interview for DSM-IV axis I Disorders Version 5.0 was administered. In addition, at each assessment patients were first asked to describe what: side-effects they had experienced since the last visit.

\section{Statistical analysis}

Two separate dimensilons of depressive symptoms, one representing cognitivedepressive and one representing vegetative-depressive symptoms were constructed out of both the HAM-D and the MADRS questionnaires. The cognitivedapressive Symptom cluster was constructed by calculating the sum of the HAM-D item scores concerning depressed mood, feelings of guil, suicidal thoughts and tension/worry. In addition, the sum was obtained from the HAM-D item scores conceming diffouty 
with falling asleep, sleeping during the night, early awakening, reduced motivation, psychomotor retardation, reduced appetite and decreased energy and libido, to construct the vegetative-depressive symptom cluster. For the MADRS, the same procedure was followed. Scores of the items concerning reported sadness, tension/irritability, feelings of guilt/inferiority and suicidal thoughts were summed to construct the cognitive-depressive symptom cluster and scores of the items concerning

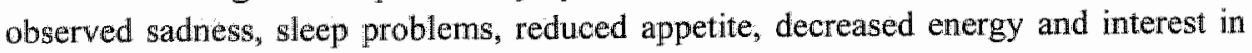
social activities were summed together to construct the vegetative-depressive symptom cluster. Furthermore, the 5 dimensions of the MFI fatigue were highly and significantly correlated with each other. Therefore, the sum of all 5 MFI fatigue dimensions was used in further analyses.

The data were analysed with the STATA computer program, version 7 (STATA, 2001). Since the two depression rating scales were highly correlated $(r=0.72)$ only results of the MADRS are shown, with the exception, for methodological reasons, of some analyses (see below). The MADRS was chosen as the main outcome because it has been used frequently to assess IFN- $\alpha$ induced depressive symptoms and therefore allows comparison with earlier studies in which this scale was used.

Because repeated measurements within the same person were used, the observations cannot be considered independent statistically. Therefore, multilevel random regression models were fitted, using the XTREG procedure in STATA (Statacorp, 2001). This takes into account the fact that level-one units (level of individual observations) were clustered into level-two units (levels of the subjects). Effect sizes of explanatory variables were expressed as regression coefficients $(\beta)$ from the multilevel models. All analyses were corrected for the following a priori hypothesised confounders: age, sex, smoking, hospital centre, use of benzodiazepine medication, use of marijuana during the study and mode of acquisition of infection.

Multilevel regression models were then used to assess the effect of time on the total MADRS score, the MADRS vegetative-depressive symptom score, the MADRS cognitive-depressive symptom score and the total MFI score. The effects of increase in fatigue and vegetative-depressive symptoms within the first week of treatment on cognitive-depressive symptoms at week 8 and 24 were assessed using standard (unilevel) regression analysis. These analyses were corrected for baseline cognitivedepressive symptoms score. In order to prevent bias due to inter-item correlations between items of the same scale, HAM-D cognitive-depressive symptoms were regressed on MADRS vegetative-depressive symptoms.

All regression analyses were performed again without subjects whose IFN- $\alpha$ dose had been reduced during the course of treatment, in order to examine if the magnitude of depression scores was biased by any reduction in dose. 


\section{Results}

\section{Subject characteristics}

Twenty-one patients were included in the study. Four patients dropped out during the study period due to problems unrelated to psychiatric side-effects. In addition, I patient was left out of the analyses because of insufficient data. The final study sample consisted of 16 patients, 12 men and 4 women. Their mean age was $42 \pm 7.7$ years. In 7 of 16 patients, a temporary dose-reduction or discontinuation of treatment was necessary due to severe side effects. Eleven patients $(68 \%)$ reported lifetime drug dependence - these were patients who had acquired the virus by intravenous drug use (IVDU). Seven of the 16 patients (44\%) received low-dosage benzodiazepines (varying between 10 and $40 \mathrm{mg}$ a day) during the study and 7 out of 16 patients were using some form of drugs: 5 were regular users of marijuana. Of these 5 individuals 1 used heroin on a regular basis. Two other individuals were on methadone-substitution. Their drug habit was stable throughout the study period. Five out of $16(31 \%)$ patients, 4 men and 1 woman, fulfilled the criteria for MDD at some point during the studied period. One of the patients developed a panic disorder after 2 weeks of treatment. There were no large or statistically significant differences between patients who did and did not develop MDD with respect to age ( $T=0.7, p=0.49$ ), history of suicide attempts $\left(\chi^{2}=0.26, p=0.6\right)$, family history of psychiatric disorders $\left(\chi^{2}=0.37, p=0.5\right)$ past diagnosis of a psychiatric disorder $\left(\chi^{2}=0.87, p=0.4\right)$, acquiring the virus by intravenous drugs use $\left(\chi^{2}=0.26, p=0.6\right)$, continuing drug habit $\left(\chi^{2}=0.78, p=0.4\right)$ during the study. Similarly, none of the scores on fatigue, depression or irritability differed between the MDD and the non-MDD group at baseline (for means and proportions see table 8.1).

\section{Self-reported side-effects}

All but one patient experienced flu-like symptoms at some point during the study period, and all but one reported fatigue. High percentages of reported 'irritability' and 'depressive feeling' were found: $75 \%$ and $63 \%$, respectively. Depressed appetite was reported in $63 \%$, problems with concentrating in $50 \%$ and symptoms of panic/anxiety (as defined by at least one of the following: feeling of fainting, dizziness, chest ache, palpitations) in $25 \%$. Flu-like symptoms (figure 8.1 ) were mostly reported in the first weeks of treatment, while the highest frequency of patients reporting a depressed feeling was at week 12. Fatigue symptoms tended to be reported during the whole study period with a peak at 4 weeks after initiating treatment. 
Table 8.1 Clinical characteristics of Hepatitis C patients unidergoing interferon-a therapy.

\begin{tabular}{|c|c|c|c|}
\hline & Total $(n=16)$ & MDD $(n=5)$ & Non-MDD $(n=11)$ \\
\hline Age $(S D)$ & $42(7.7)$ & $44(5.2)$ & $41(8.6)$ \\
\hline Gender female & 4 & 1 & 3 \\
\hline male & 12 & 4 & 8 \\
\hline Cigatetu smoking $(\%)$ & $7(44 \%)$ & $3(60 \%)$ & $4(36 \%)$ \\
\hline \multicolumn{4}{|l|}{ Aquisilition virus } \\
\hline Blood transfusion & 2 & 0 & 2 \\
\hline IVDU & $\|$ & 3 & 8 \\
\hline Unknown & 3 & 2 & 1 \\
\hline \multicolumn{4}{|l|}{ Subsitance use during study $(\%)$} \\
\hline No substance use & $9(56 \%)$ & $2(40 \%)$ & $7(64 \%)$ \\
\hline Marijuana smoking & $4(25 \%)$ & $1(20 \%)$ & $3(27 \%)$ \\
\hline Methadone & $2(13 \%)$ & $1(20 \%)$ & $1(9 \%)$ \\
\hline Heroin (and marijuana) & $1(6 \%)$ & $1(20 \%)$ & $0(0 \%)$ \\
\hline Benzodiazepine medication during study $(\%)$ & $4(25 \%)$ & $1(20 \%)$ & $3(22 \%)$ \\
\hline Family history of psychiatric illness $(\%)$ & $2(13 \%)$ & $1(20 \%)$ & $1(9 \%)$ \\
\hline Diagnose in past of psychiatric illness $(\%)$ & $3(19 \%)$ & $1(20 \%)$ & $2(18 \%)$ \\
\hline Past suicide atternpt $(\%)$ & $4(25 \%)$ & $2(40 \%)$ & $2(18 \%)$ \\
\hline Past use of antidepressants $(\%)$ & $3(19 \%)$ & $1(20 \%)$ & $2(18 \%)$ \\
\hline
\end{tabular}

MDD, Major depressiwe disorder; IVDU, intravenous drug use

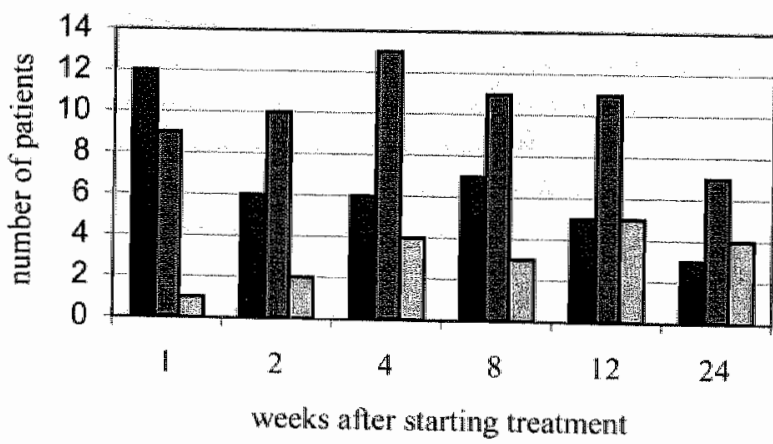

flu-like symptoms
fatigue
圆 depressive feeling

Figure 8.1 Number of patients reporting th-like symptoms, fatigue and/or a depressive feeling, for each time point after starting treatment.

\section{Total depression score during IFN- $\alpha$ treatment}

The MADRS depression score showed a significant increase during IFN- $\alpha$ treatment (effect time: $\beta=0.32, p=0.000$ ), with an immediate sharp increase in depressive symptoms until week 8 , followed by a flattening of the line and a small but nonsignificant decline in score at week 12 and 24 (figure 8.2; table 8.2). However, the analysis performed without subjects with dose reductions showed that the highest 
difference with baseline occurred at week $24(\beta=14.7, p=0.000)$ and not at week 8 $(\beta=14.0, p=0.000)$ and effect sizes were increased. Marijuana use showed no significant effect on MADRS score nor did difference in IFN- $\alpha$ treatment (intron A followed by PEG IFN- $\alpha$ compared to immediate PEG IFN- $\alpha$ treatment), although the group starting with intron A showed slightly lower depression scores.

Table 8.2 Multilevel regression anaiyses indicating differences on each dimension for each time point, compared to baseline, using the regression coefficient $(\beta)$.

\begin{tabular}{|c|c|c|c|c|c|c|}
\hline Weeks & 1 & 2 & 4 & 8 & 12 & 24 \\
\hline Dimension & $\beta$ & $\beta$ & $\beta$ & $\beta$ & $\beta$ & $\beta$ \\
\hline total MFI seore & $14.5^{6}$ & $21.6^{*}$ & $19.2^{\circ}$ & $21.0^{\circ}$ & $16.4^{\circ}$ & $15.0^{\circ}$ \\
\hline total MADRS score & $6.97^{\mathrm{n}}$ & $10.5^{\circ}$ & $11.2^{\mathrm{e}}$ & $13.8^{\circ}$ & $12.8^{\circ}$ & $12.33^{*}$ \\
\hline wegetative-depressive symptom seore & $5.22^{\mathrm{c}}$ & $6.58^{\circ}$ & $6.81^{\circ}$ & $8.63^{\mathrm{c}}$ & $8.87^{\circ}$ & $7.91^{\circ}$ \\
\hline cognitive- depressive symptom score & 0.17 & 0.94 & $1.44^{\mathrm{a}}$ & $1.38^{\mathrm{a}}$ & 1.04 & $1.38^{\mathrm{1}}$ \\
\hline
\end{tabular}

MFI, Multidimensional Fatigue Inventory; MADRS, Montgomery-Asberg Depression Rating Scale ${ }^{3 i} \mathrm{p}<0.05 ;{ }^{\mathrm{b}} \mathrm{p}<0.01 ;{ }^{\mathrm{c}} \mathrm{p}<0.001$

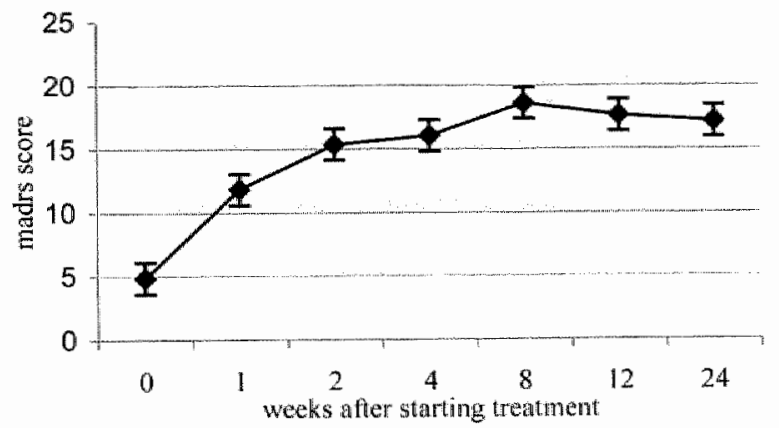

Figure 8.2 MADRS scores from baseline until the $24^{\text {th }}$ week of IF $\mathrm{N}-\alpha$ treatment

Vegetative-depressive and cognitive-depressive symptom score during IFN- $\alpha$ treatment

Fatigue score and vegetative-depressive symptom score were significantly increased at all time points during IFN- $\alpha$ treatment, compared to baseline (table 8.2). Vegetativedepressive symptoms increased rapidly. After one week of treatment 3 patients showed increases in scores between 50 and $100 \%$. Another 3 patients showed increases between 100 and $300 \%$ and scores of 6 patients were increased more than $300 \%$. Only 4 patients showed no increase in vegetative-depressive symptoms in the first week. 
Cognitive-depressive symptoms were only significantly increased compared with baseline at week 4,8 and 24 (table 8.2). At week 12 , difference with baseline was of comparable effect size but did not reach statistical significance according to conventional alpha $(\beta=1.04, p=0.07)$. However, when subjects with dose-reductions were excluded from the analyses, increase at week 12 was significant and effect sizes for week 8,12 and 24 were increased $(\beta=1.4, p=0.05 ; \beta=1.7, p=0.03 ; \beta=1.7, p=0.03$, respectively).

Impact of early increase in physical fatigue and vegetative-depressive symptoms on later cognitive-depressive symptoms

A first-week increase in fatigue score had no impact on cognitive-depressive symptoms at week 8 or 24. However, a first-week increase in MADRS vegetative-depressive symptoms, corrected for baseline HAM-D cognitive-depressive symptoms, displayed a strong impact on HAM-D cognitive-depressive symptoms at week $8(\beta=0.46, p=0.02)$ and week $24(\beta=0.43, p=0.005)$. Analyses were similarly significant when using, inversely, MADRS cognitive-depressive symptom score and HAM-D vegetativedepressive symptom score (results not shown).

Furthermore, when subjects were differentiated into those having a low or high increase in MADRS vegetative-depressive symptom score in the first week according to medium split of the distribution, a significant interaction was found between "time" and 'high or low increase in first week vegetative-depressive symptoms' in the model of cognitive-depressive symptoms $(\beta=3.34, \mathrm{p}=0.003)$, indicating that subjects with a high first week increase in vegetative-depressive symptoms had a significantly higher increase in cognitive-depressive symptom score from baseline to week 8 , compared to subjects with a low first week vegetative-depressive symptom increase (figure 8.3).

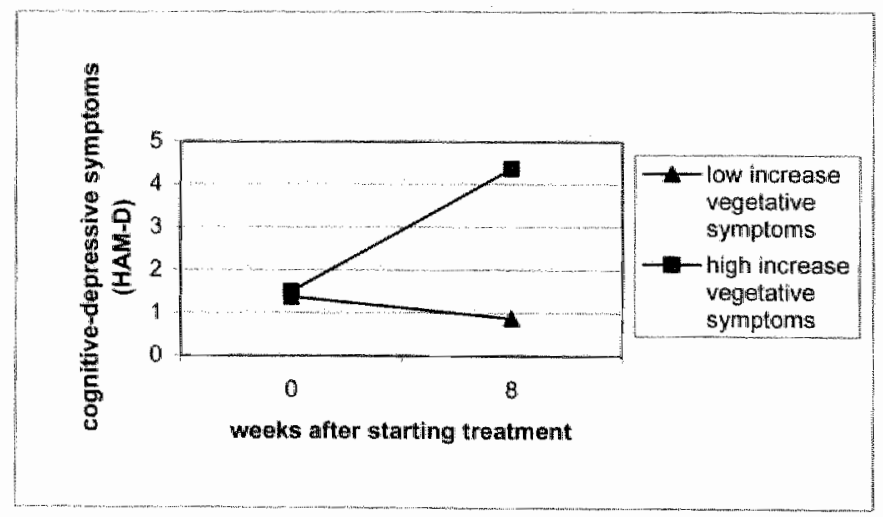

Figure 8.3 Increase in cognitive-depressive symptoms (HAM-D) during IFN-o treatment for low and high first week increase in vegetative depressive symptoms (MADRS) 


\section{Discussion}

IFN- $\alpha$ treatment significantly increased symptoms of fatigue, vegetative and cognitive symptoms of depression. Thirty-one percent of the patients fulfilled at least once during the studied period the criteria for MDD. Depression scores showed a first sharp increase that attenuated approximately after 8 weeks of treatment. Furthermore, first week increase in vegetative-depressive symptoms was predictive of cognitivedepressive symptoms at week 8 and week 24 .

The percentage of patients developing an MDD during IFN- $\alpha$ treatment in our sample and the finding that after 8 weeks most depressive symptoms have come to expression is comparable to results found in other recent studies ${ }^{2,3,29-31}$. Similar to our findings, Capuron $^{29}$, who also distinguished vegetative-depressive symptoms (labelled "neurovegetative symptoms') from cognitive-depressive symptoms (labelled as "depressive symptoms'), also found an immediate and lasting increase in neurovegetative symptoms compared to baseline, while the cognitive-depressive symptoms were not significantly different from baseline until the $8^{\text {th }}$ week of treatment. Our study contrasts with the study of Dieperink et al. ${ }^{2}$ in which an association was reported between baseline and IFN- $\alpha$-induced depressive symptoms.

In the present study, based on a longitudinal design and dimensional analyses, different time patterns among emerging symptoms could be distinguished. The whole cluster of vegetative-depressive symptoms emerging in the first week of treatment, i.e. reductions in sleep, motivation, appetite, energy, libido, social interest and slowness of movement and speech, appeared to be important in predicting cognitive-depressive symptoms at week 8 and 24 . This finding supports Charlton's theory that cognitive symptoms of depression follow from a feeling of malaise, which arises in response to infection to reset the organism's priorities and is triggered by a set of pro-inflammatory cytokines.

According to this theory, increase in pro-inflammatory cytokines causes a behavioural state of malaise which itself induces cognitive complaints and mood change. However, our results may also be consistent with the idea that the pro-inflammatory cytokines that produce the vegetative-depressive symptoms, also affect other biological systems, in a dose-dependent manner, which then may result in a state of increased vulnerability to depressed mood. As pro-inflammatory cytokines, mainly IL-1 and IL-6 $6^{32}$, are potent activators of the HPA axis, it is not unlikely to assume that they are involved in the HPA axis hyperactivity that is associated with $\mathrm{MDD}^{33}$. In addition, other possible mechanisms by which cytokines may induce MDD may be considered. The proinflammatory cytokine IFN- $\gamma$ induces the kynuremine pathway by induction of the enzyme indoleamine 2,3 dioxygenase (IDO), which converts tryptophan (TRP), the precursor of serotonin $(5-\mathrm{HT})$, to kynurenine and other metabolites, some of which have neurotoxic properties ${ }^{34}$. Depletion of peripheral TRP, which lowers the availability of TRP to the brain, leads to decreased central 5-HT synthesis, a neurotransmitter that is considered important in the aetiology of depression ${ }^{35}$. 
Moreover, the production of neurotoxic substances along the kynurenine pathway may be inwolved in the development of neuropsychiatric disorders ${ }^{36}$.

This study has some limitations. No control group was used in this study. As mentioned in the introduction, inclusion of a control group in these kinds of studies, such as untreated hepatitis $C$ patients, is a major challenge. First, it implies asking patients to postpone the start of their treatment that is ethically not justifiable. Second, a double-blind research design would be impossible to implement, since effects of IFNa compared to placebo treatment would be so obvious that patients and interviewers would be unblinded from the start. However, in a within-subject design a control group is not strictly necessary, because subjects function as their own controls using their baseline measurements.

Another limitation is the relatively small sample size and the inclusion of patients having experienced past drug addiction. This may limit the extrapolation to other populations than Hepatitis $C$ patients. Furthermore, occurrence of depressive symptoms may have been influenced by differences in form of IFN- $\alpha$ treatment and current drug use. The rate of drug use during the study was $60 \%$ in patients who developed MDD, compared to only $36 \%$ in patients who remained free of MDD (table 8.1). Although not significant, this finding suggests that current drug use may function as a risk factor. Further studies should examine the effects of treatment form and drug use on depressive symptoms.

\section{Acknowledgements}

We thank Jim van Os for reviewing the manuscript. 


\section{References}

1. Dieperink E, Ho SB, Thuras P. Willenbring ML. A prospective study of neuropsychiatric symptoms associated with interferon-alpha- $2 b$ and ribavirin therapy for patients with chromic hepatitis C. Psychosomarios 2003;44 (2), 104-12.

2. Bonaccorso $S$, Marino $V$, Puzella A, Pasquini $M$, Biondi $M$, Artini $M$, Almerighi $C$, Verkerk R, Meltzer H, Maes M. Increased depressive ratings in patients with hepatitis $C$ receiving interferon-alpha-based immunotherapy are related to interferon-alpha- induced changes in the serotonergic system. Joumal of Clinical Psychophamacology 2002;22 (1),86-90.

3. Hauser P, Khosla J, Aurora H, Laurin J, Kling MA* Hill J, Gulati M, Thornton AJ, Schultz RL, Valentine AD, Meyers CA. Howell CD. A prospective study of the incidence and open-label treatment of interferon-induced major depressive disorder in patients with hepatitis C. Molecular Psychiatry 2002;7 (9),942-7,

4. Musselman DL, Lawson DH, Gumnick JF, Manatunga AK, Penna S, Goodkin RS, Greiner $\mathrm{K}$, Nemeroff $\mathrm{CB}$, Miller AH. Paroxetine for the prevention of depression induced by highdose interferon alfa. New England Joumal of Medicine 2001;344 (13),961-6.

5. Schaefer M, Engelbrecht MA, Gut O, Fiebich BL, Bauer J, Schmidt F, Grunze H, Lieb K. Interferon alpha (IFNalpha) and psychiatric syndromes: a review. Progress in Neuropsychopharmacology and Biological Psychiatry 2002;26 (4), 731-46.

6. Van Gool AR, Kruit WH, Engels FK, Stoter G, Bannink M, Eggermont AM. Neuropsychiatric side effects of interferon-alfa therapy. Phamacy World and Science $2003 ; 25(1), 11-20$.

7. Keating GM, Curran MP. Peginterferon-alpha-2a (40kD) plus ribawin: a review of its use in the management of chronic hepatitis C. Drugs 2003;63 (7),701-30.

8 Dalakas MC, Mock V. Hawkins MJ. Fatigue: definitions, mechanisms, and paradigms for study. Seminars in Oncology 1998;25 (1 Suppl 1),48-53.

9. Licinio J, Kling MA, Hauser P. Cytokines and brain function: relevance to interferon-alphainduced mood and cognitive changes. Seminars in Oncology 1998;25 (1 Suppl 1),30-8.

10. Dusheiko, G. (1997) Side effects of alpha interferon in chronic hepatitis C. Hepatology 26 (3 Suppl 1), 112S-121S.

11. Maes M. Evidence for an immune response in major depression: a review and hypothesis. Progress in Neuropsychopharmacology and Biological Psychiatry 1995; 19 (1),11-38.

12. Meijer A, Zakay-Rones $Z$, Morag A. (1988) Post-influenzal psychatric disorder in adolescents. Acia Psychiatrica Scandinavica 1988;78 (2),176-81.

13. Hall S, Smith A. Inwestigation of the effects and aftereffects of naturally occurring upper respiratory tract illnesses on mood and performance. Physiology and Behavior 1996;59 (3), $569-77$.

14. Foley FW, Traugott U, LaRocca NG, Smith CR, Perlman KR, Caruso LS, Scheinberg LC. A prospective study of depression and immune dysregulation in multiple selerosils. Archives of Neurology 1992;49 (3),238-44.

15. Minden SL, Schiffer RB. Affective disorders in multiple sclerosis. Revisw and recommendations for clinical rescarch. Archives of Neurology 1990;47 (1),98-104.

16. EIsehety A, Bertorini TE. Neurologic and neuropsychiatric complications of Crohn's disease. Southern Medical Journal 1997,90 (6),606-10.

17. Parker J, Smarr K, Anderson S, Hewett J, Walker S, Bridges A, Caldwell W. Relationship of changes in helplessness and depression to disease activity in rheumatoid arthritis. Journar of Rhew watology 1992;19(12), 1901-5.

18. Pincus $T$, Griffith J, Pearce $S$, Isenberg D. Prevalence of self-reported depression in patients with rheumatoid arthritis. British Joumal of Rheumatology 1996;35 (9), 879-83. 
19. Blatteis CM. The afferent signalling of fever. Joumal of Physiology $2000 ; 526$ Pt 3,470 .

20. Besedovsky HO, del Rey A. Immune-neuro-endocrine interactions: facts and hypotheses. Endocrine Rexiews 1996;17 (1), 64-102.

21. Dunn AJ, Swiergiel AH. The role of cytokines in infection-related behavior. Annals of the New York Academy of Science 1998:840, 577-85.

22. Kelley KW, Bluthe RM, Dantzer $\mathbb{R}$, Zhou JH, Shen WH, Johnson $\mathbb{R W}$, Broussard SR. Cytokine-induced sickness behavior. Brän Behavior and Immunity 2003;17 (1 Suppl), 112 8.

23. Hart BL. Biological basis of the behavior of sick animals. Neuroscience and Biobehavioral Reviews 1988;12 (2),123-37

24. Charlion BG. The malaise theory of depression: major depressive disorder is sickness behavior and antidepressants are analgesic. Medical Hypotheses 2000;54 (1), 126-30.

25. Bonaccorso $\mathrm{S}$, Marino $\mathrm{V}$, Biondi $\mathrm{M}$, Grimaldi $\mathrm{F}$, Ippoliti $\mathrm{F}$, Maes $\mathrm{M}$. Depression induced by treatment with interferon-alpha in patients affected by hepatitis $\mathrm{C}$ virus. Joumal of Affective Disorders 2002;72 (3),237-41.

26. Hamilton M. Development of a rating scale for primary depressive illness. British Joumal of Social and Clinical Psychology 1967,6 (4),278-96.

27. Montgomery SA, Asberg M. A new depression scale designed to be sensitive to change. British Journal of Psychiatry 1979;134, 382-9.

28. Smets EM, Garssen B, Bonke $B$, De Haes $J C$. The Multidimensional Fatigue Inventory (MFI) psychometric qualities of an instrument to assess fatigue. Joumal of Psychosomatic Research 1995;39 (3),315-25.

29. Schaefer M, Schmidt F, Folwaczny C, Lorenz R, Martin G, Schindlbeck N, Heldwein W, Soyka M, Grunze H, Koenig A, Loeschke K. Adherence and mental side effects during hepatitis $C$ treatment with interferon alfa and ribavirin in psychiatric risk groups. Hepatology 2003;37 (2), 443-51.

30. Capuron L, Gumnick JF, Musselman DL, Lawson DH, Reemsnyder A, Nemeroff CB, Miller AH. Neurobehavioral Effects of Interferon-alpha in Cancer Patients. Phenomenology and Paroxetine Responsiveness of Symptom Dimensions. Neuropsychopharmacology $2002 ; 26(5), 643-52$.

31. Horikawa $N$, Yamazaki $T$, Izumi $N_{x}$ Uchihara $M$. Incidence and clinical course of major depression in patients with chronic hepatitis type $\mathrm{C}$ undlergoing interferon-alpha therapy: a prospective study. General Hospital Psychiatry 2003;25 (1),34-8.

32. John CD, Buckingham JC. Cytokines: regulation of the hypothalamo-pituitaryadrenocortical axis. Current Opinion in Phormacology 2003;3 (1),78-84.

33. Checkley $S$. The netroendocrinology of depression and chronic stress. British Medical Bullerin 1996;52 (3),597-617.

34. Wirleitner B, Neurauter G, Schrocksnadel K, Frick B, Fuchs D. Interferon-gamma-induced conversion of tryptophan: immunologic and neuropsychiatric aspects. Current Medicimal Chenistry $2003 ; 10(16), 1581-91$.

35. Graeff FG, Guimaraes FS, De Andrade TG, Deakin JF. Role of 5-HT in stress, anxiety, and depression. Pharmacology Blochemistry and Behavior 1996;54 (1),129-41.

36. Stone TW. Endogenous neurotoxins from tryptophan. Toxicon 2001;39 (1),61-73. 


\section{Chapter}

\section{Interferon- $\alpha$-induced depressive symptoms are related to changes in the cytokine network but not to cortisol}

Marieke Wichers, Gunter Kenis, Ger Koek, Geert Robaeys, Nancy Nicolson, Michael Maes

Submitted 


\section{Abstract}

\section{Background}

Administration of interferon- $\alpha$ (IFN- $\alpha$ ) has been observed to induce depressive symptoms. Since pro-inflammatory cytokines have the potential to activate the hypothalamo-pituitaryadrenocortical (HPA) axis and HPA axis hyperactivity is also encountered in depressive patients. the induction of depressive symptoms by IFN- $\alpha$ may be mediated by changes in the cytokine network and the HPA axis.

\section{Methods}

In 17 patients undergoing IFN- $\alpha$ treatment, depressive symptoms were measured using the Montgomery Depression Rating Scale (MADRS). In addition, serum IL-1RA, sIL-2R, IL-6, sIL$6 R, \mathbb{L}-8, \pi L-10$ and TNF- $\alpha$ concentrations were measured. Saliva was collected five times over the course of a day in order to assess Daily Average Cortisol (DAC) and awakening response. Assessments were carried out at baseline and at $1,2,4,8,12$ and 24 weeks after starting treatment.

\section{Results}

During treatment, the increases in the MADRS score and cytokine concentrations were interrelated. sIL-2R, TNF $\alpha$ and IL-6 co-varied significantly over time with the MADRS score. DAC was increased at week 8 only; the cortisol awakening response was decreased at week 8 compared with baseline. No associations between DAC or cortisol awakening response with the MADRS score were found nor did either of the cortisol measures mediate the associations between cytokines and the MADRS score.

\section{Conclusions}

Changes in IFN- $\alpha$-induced depressive symptoms are accompanied by cytokine changes. However, the cortisol response to administration of IFN- $\alpha$ does not play a mediating role in the induction of depressive symptoms during treatment. The clear connection between cytokine concentrations and depressive symptoms should stimulate further research to examine the mechanisms by which imnune activation affects mood. 


\section{Introduction}

Administration of interferon- $\alpha$ (IFN- $\alpha$ ), a cytokine demonstrating major antiviral and immunomodulatory effects, has been used effectively as treatment for a variety of chronic viral infections and malignant disorders, including chronic hepatitis $\mathrm{C}$. Despite its potential therapeutic benefits, administration of $\mathrm{IFN}-\alpha$ frequently induces psychiatric pathology such as severe fatigue and depressive symptoms. Recent clinical studies have shown that approximately 16 to $45 \%$ of patients treated with IFN- $\alpha$ developed depressive symptoms during the course of therapy ${ }^{1-4}$.

IFN- $\alpha$ is a pro-inflammatory cytokine that is known to increase serum concentrations of cytokines such as interleukin (IL)-1, IL-6, tumour necrosis factor (TNF)- $\alpha, \mathrm{IL}-2$ and IFN- $\gamma^{5}$, shifting the $\mathbb{T}$-helper $(\mathrm{Th}) 1 / \mathrm{Th} 2$ balance towards a Th1 type response. Major depression has also been associated with increased Thl activation and inflammatory response $^{6}$, as increased concentrations of pro-inflammatory cytokines and several other indicators of an inflammatory response, including neopterin, prostaglandin E2, increased concentrations of complement proteins and positive acute phase proteins (APPs), are encountered in depression ${ }^{7.9}$.

Although the pathway by which increased Th1 immune activation may cause depressive symptoms remains to be elucidated, activation of the hypothalamo-pituitaryadrenocortical (HPA) axis may constitute one possible link. The pro-inflammatory cytokines IL-1, IL-6 and TNF- $\alpha$ have the ability to trigger activation of the HPA axis by provoking the release of corticotropin-releasing hormone $(\mathrm{CRH})$ and arginine vasopressin (AVP) ${ }^{10,11}$. This activation results in the release of glucocorticoids, which in turn exert a negative feedback on both the immune response and $\mathrm{CRH}$ release ${ }^{10,12}$. In addition, studies have shown that acute administration of IFN- $\alpha$ in humans activates the HPA axis, as reflected by an increase in adrenocorticotropin hormone (ACTH) and cortisol concentrations ${ }^{13-16}$.

Hyperactivity of the H.PA axis is also implicated in the pathophysiology of depression. Depressed patients exhibit elevated cerebrospinal fluid (CSF) CRH concentrations ${ }^{17}$, a blunted ACTH response after intravenous administration of $\mathrm{CRH}^{18,19}$. In addition, depressed patients show elevated cortisol levels ${ }^{20,21}$ and the diurnal cortisol pattern deviates from healthy subjects in that they exhibit a steeper increase in awakening response $\mathrm{e}^{22,23}$. Furthermore, depressed patients show incomplete suppression of cortisol by dexamethasone, which indicates impaired negative feedback function most likely due to impaired corticosteroid receptor signalling ${ }^{24,25}$, a deficit that may be induced by the pro-inflammatory cytokine $1 \mathrm{~L}-\mathrm{1}^{26}$. Treatment with antidepressants appears to restore negative feedback deficits by increasing corticoid receptor sensitivity ${ }^{27}$. HPA axis activation could thus play a role in mediating the depressive response following increased immune activation. This means that immune activation may increase depressive symptoms through its effect on HPA axis functioning.

A previous report from our group, based on the same sample of patients, replicated other studies in finding a large increase in depressive symptoms during IFN- $\alpha$ 
treatment ${ }^{2 \%}$. The goal of the current study was to clarify the role of the cytokine network and the HPA axis in the development of depressive symptoms. We bypothesized that, in a longitudinal observation frame, 1) IFN- $\alpha$ treatment results in increased activation of the cytokine network; 2) cytokine levels are associated with depressive symptoms; 3) HPA axis activity (as measured by daily average cortisol secretion and cortisol awakening response) increases during treatment in parallel with activation of the cytokine network, and 4) HPA axis activation mediates the association between cytokine levels and depressive symptoms.

\section{Methods}

\section{Subjects}

Twenty-one patients with chronic active hepatitis $C$ infection, aged 25-57 years and eligible for IFN- $\alpha$ treatment, were recruited. Chronic hepatitis $C$ was defined as: antibodies to HCV positive, HCV-RNA positive, and elevated transaminases at least once in the previous 6 months.

Patients underwent a complete medical history, physical examination and laboratory blood check before study entry. An ultrasound of the upper abdomen, an ECG, and a pregnancy test (in women of childbearing potential) were also carried out. In addition, a liver biopsy was performed in most patients.

Excluded were patients currently meeting criteria of axis 1 psychiatric disorders as defined by DSM-IV or patients currently on antidepressant medication. In addition, patients who had co-infections such as hepatitis B virus or human immunodeficiency virus, or patients with a diagnosis of uncontrolled neurological, cardiovascular, endocrine, haematological, hepatic or renal disease, or patients with insufficient knowledge of the Dutch language were excluded.

Patients were recruited from the Academic Hospital Maastrich (azM) in the Netherlands and from the Hospital East Limburg (ZOL) in Belgium. All patients received some form of interferon-alpha treatment and ribavirin. One patient received IFN- $\alpha 2$ b (Intron A), $3 \times 3$ MU weeklly throughout the study period. Nine patients received Intron A the first 12 days of treatment $(10 \mathrm{MU}$ daily in the first 6 days and 5 MU daily after the $6^{\text {th }}$ day). After these 12 days, they received a weekly injection of 80 $180 \mu \mathrm{g}$ of PEG IFN- $\alpha 2 b$. Six patients directly started with weekly injections of $80-180$ $\mu \mathrm{g}$ of $\mathrm{PEG} \| \mathrm{FN}-\alpha 2 \mathrm{~b}$. In all patients, ribavirin was administered orally, $1000-1200$ mig/day, depending on body weight.

The study was approved by the standing Medical Ethics Committee of Maastricht University and carried out in accordance with the Declaration of Helsinki (Hong Kong Modification, 1989). Written informed consent was obtained from each subject prior to participation. 


\section{Assessment of depressive symptoms and psychiatric disorder}

Patients were assessed regularly during the first 24 weeks after starting IFN- $\alpha$ treatment. The 17-item Hamilton Depression Rating Scale (HAM-D) ${ }^{29}$ and the Montgomery Asberg Depression Rating Scale (MADRS) were administered before and $1,2,4,8,12$ and 24 weeks after starting treatment. To determine the presence of any axis I psychiatric disorder, the Structured Clinical Interview for DSM-IV axis I Disorders Version 5.0 was administered. Since the two depression rating scales correlated highly $(r-0.8)$, only the results of the MADRS are shown. The MADRS was chosen because it has been used frequently to assess IFN-a induced depressive symptoms and therefore allows comparison with these earlier studies.

\section{Serum cytokine measures}

Blood samples were taken after an overnight fast. After cloting at room temperature, samples were centrifuged, serum collected and stored at $-80^{\circ} \mathrm{C}$ until determination of cytokines. Cytokines in serum were measured using commercially available enzyme linked immunosorbent assays (ELISAs). Reagents for IL-6, IL-8, IL-10 and IL-1 receptor antagonist (IL-IRA) were purchased from BD-Biosciences (Erembodegem, Belgium); those for TNF- $\alpha$, soluble interleukin (sLL)-6R and sIL-2R were obtained from DiaMed-Eurogen (Turnhout, Belgium). Determinations were performed in a single assay run by the same operator. Detection limits were: $1 \mathrm{pg} / \mathrm{ml}$ (IL-6, IL-8 and TNF- $\alpha$ ), $1.5 \mathrm{pg} / \mathrm{ml}$ (IL-10), $5 \mathrm{pg} / \mathrm{ml}$ (IL-1RA), $0.2 \mathrm{ng} / \mathrm{ml}$ (sIL-6R), $50 \mathrm{U} / \mathrm{ml}$ (sIL-2R).

\section{Salivary cortisol measures}

Diumal cortisol levels were determined in saliva, collected with a cotton Salivette (Sarstedt, Etten-Leur, the Netherlands). Patients collected 5 saliva samples during a single day, with repeated sampling the day prior to each of the 7 assessment points of the longitudinal study (baseline, $1,2,4,8,12$ and 24 weeks after starting IFN- $\alpha$ treatment). Subjects took saliva samples at the moment of awakening, 30 minutes after awakening, and at 11.00, 16.00 and 21.00 h. Patients were instructed not to brush their teeth, eat or smoke for at least half an hour before taking a saliva sample. Since patients may forget to take the sample at the right moment, they were asked to write down the exact time that they had taken the sample on the tube. Patients kept their samples im their own refrigerators and brought them to the hospital when they came for the appointment the next day. Uncentrifuged saliva samples were frozen at $-20^{\circ} \mathrm{C}$. Cortisol levels were determined in duplicate by direct radioimmunoassay, using ${ }^{125}$ iodohistamine-cortisol and anti-cortisol serum made against the 3-CMO-BSA conjugate (Dr. J. Sullon, University of Liège, Belgium). After overnight incubation at 4 ${ }^{\circ} \mathrm{C}$, separation of free and antibody-bound ${ }^{125}$ I-cortisol was performed by a conventional 'second antibody' method. Mean intra- and interassay coefficients of variation were less than $13 \%$. 


\section{Statistical analysis}

The data were analysed with the STATA computer program, version 8 (STATA, 2002 [StataCorp. STATA Statistical Sofmare: Release 8.0. Texas: College Station, 2002]). Cytokine (with the exception of sIL-6R) and cortisol values were In-transformed to improve normality. Values with a $z$-score $>3$ were considered outliers and excluded from further analyses. The first two saliva samples taken in the morning were supposed to be taken 30 minutes apart. Values of saliva samples that deviated more than 15 minutes from this time interval were excluded. Values of saliva samples at the other three time points during the day were excluded if the collection time deviated more than one hour from the target time. In total, 15 samples were excluded because of too much deviation from the target time.

Daily average cortisol (DAC) ${ }^{31}$ was calculated. For baseline, this was done by first standardizing cortisol measures over all subjects at each of the diurnal sampling times and then averaging the $z$-scores, resulting in one DAC value for each subject. The average was taken over four of the five diurnal sampling times, namely at awakening, $11: 00,16: 00$, and $21: 00 \mathrm{~h}$. The second cortisol measure, 30 minutes after awakening, was not included in the $\mathrm{DAC}$, because the cortisol response to awakening is largely independent of basal levels ${ }^{32,33}$. For measurements at $1,2,4,8,12$ and 24 weeks after starting treatment, cortisol values were standardized in a similar fashion, but with the pre-treatment baseline means and SD's for the four diumal sampling times used to calculate the $\mathrm{z}$-scores to allow assessment of treatment-related changes in DAC. The advantage of the DAC measure compared to the 'area under the curve' (ALC) is that morning values, when cortisol levels are typically high, do not exert undue influence. $\mathrm{DAC}$ was not calculated if more than one of the four cortisol measurements over the day was missing. In addition, the cortisol response to awakening, defined as the change in cortisol levels during the first 30 minutes after awakening, was calculated for each subject at each of the 7 assessment points.

Multilevel random regression models were fitted, using the XTREG procedure in STATA (Statacorp, 2002). This multilevel model takes into account the fact that levelone units (individual observations) were clustered into level-two units (subjects). Effect sizes of explanatory variables were expressed as regression coefficients (B) from the multilevel models. All analyses were corrected for the following a priori hypothesized confounders: age, sex, smoking, hospital centre, benzodiazepine medication, use of marijuana during the study, mode of acquisition of infection and difference in IFN-a medication (intron A treatment in the first two week followed by PEG-intron or immediate PEG-intron medication). Analyses were performed to assess the increase in cytokine levels during IFN- $\alpha$ treatment. Second, total MADRS score was regressed on measurements of cytokine levels in order to examine cytokine associations with depressive symptoms. Subsequently, changes in DAC and awakening response during treatment were assessed. Since the changes in cytokine and cortisol concentrations during IFN- $\alpha$ treatment are not necessarily hypothesized to show a linear increase, effects at each separate time point were assessed. First, the DAC and awakening 
response were regressed on cytokine concentrations, in order to examine cytokine associations with cortisol measures. Second, the total MADRS score was regressed on DAC and the awakening response. Finally, in order to examine whether DAC or awakening response mediated any significant associations between increases in cytokine levels and MADRS score, the effect of adding DAC and awakening response to regression models of cytokines and MADRS score was assessed.

\section{Results}

\section{Subject characteristics}

Twenty-one patients were included in the study. Four patients dropped out due to problems unrelated to psychiatric side-effects. The final study sample consisted of 17 patients, 13 men and 4 women. The mean age of the sample was $42 \pm 7.3$ years. Two subjects had partial missing data (one with missing data on depressive symptoms and one with missing cortisol measurements). In 7 of 17 patients ( $41 \%$ ), a temporary dosereduction or discontinuation of therapy was necessary due to severe side effects. Ten patients (59\%) reported lifetime drug dependence and had acquired the virus by intravenous drug use (IVDU). Six of the 17 patients (35\%) received low-dosage benzodiazepines during the study and 7 out of 17 patients were currently using some form of drugs, of which 5 were regular users of marijuana. Of these 5 individuals, 1 additionally used heroine on a regular basis. The other 2 individuals were on methadone-substitution. Their drug habit was stable throughout the studied period. Five out of 16 patients ( $31 \%$ ) fulfilled DSM-IV criteria for MDD at some point during the study period.

\section{Cytokines and depressive symptoms}

The total MADRS score significantly increased during treatment $(B=0.34, p<0.001)$, with the highest score at 8 weeks after starting treatment, as we reported in a previous study $^{28}$. sIL-2R and TNF- $\alpha$ concentrations were strongly and significantly increased at all time points during treatment compared to baseline (tables 9.1 and 9.2). The IL-IRA was increased at 1, 2, 4 and 8 weeks after starting treatment. IL-8 and IL-10 showed an increase at week 1, and IL- 6 at week 4 and 8 after starting treatment. The soluble IL-6 receptor showed no significant changes. Regression analyses showed significant associations over time between $\operatorname{sIL}-2 \mathrm{R}(\mathrm{B}=14.3, \mathrm{p}<0.001)$, TNF $-\mathrm{D}(\mathrm{B}=16.7, \mathrm{p}<0.001)$ and IL-6 $(B=8.5, p<0.001)$, on the one hand, and the total MADRS score on the other. 
Table 9.1 Cytokine concentrations all week $1,2,4,8,12$ and 24 during WW $\alpha$ treament.

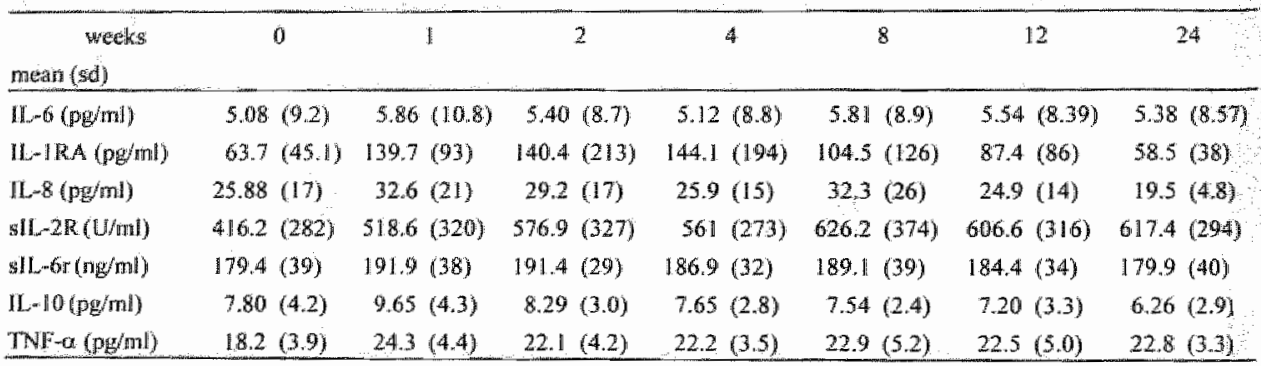

Table 9.2 Multilewel regression analyses indicating differences compared to baseline for each cytokine at week $1,2,4,8,12$ and 24 , with ' $\beta$ ' indicating the regression coefficient and ' $P$ ' the level of significance.

\begin{tabular}{|c|c|c|c|c|c|c|c|c|c|c|c|c|}
\hline \multirow[t]{2}{*}{ weeks } & \multicolumn{2}{|c|}{1} & \multicolumn{2}{|c|}{2} & \multicolumn{2}{|c|}{4} & \multicolumn{2}{|c|}{8} & \multicolumn{2}{|c|}{12} & \multicolumn{2}{|c|}{24} \\
\hline & $\beta$ & $p$ & $\beta$ & p & $\beta$ & $p$ & $\beta$ & $p$ & $\beta$ & $p$ & $\beta$ & $p$ \\
\hline Lll $-6^{9}(\mathrm{pg} / \mathrm{m})$ & 0.16 & 0.2 & 0.09 & 0.4 & 0.09 & 0.5 & 0.26 & $0.04^{5}$ & 0.20 & 0.1 & 0.08 & 0.5 \\
\hline $\mathrm{HL}-\mathrm{HRA}{ }^{a}(\mathrm{pg} / \mathrm{mll})$ & 0.69 & $0.000^{\text {tin }}$ & 0.51 & $0.001^{b}$ & 0.45 & $0.00 \|^{b}$ & 0.28 & $0.047^{\circ}$ & 0.10 & 0.5 & -0.03 & 0.8 \\
\hline$I L-8^{\prime}(\mathrm{pg} / \mathrm{m})$ & 0.31 & $0.000^{\mathrm{b}}$ & 0.11 & $0 . \|$ & 0.0004 & 0.9 & 0.13 & 0.07 & -0.02 & 0.8 & -0.11 & 0.1 \\
\hline$s 1 \mathrm{~L}-2 \mathrm{R}^{4}(\mathrm{U} / \mathrm{mL})$ & 0.32 & $0,000^{\mathrm{h}}$ & 0.40 & $0.000^{\circ}$ & 0.40 & $0,000^{\mathrm{b}}$ & 0.49 & $0.0000^{t o}$ & 0.47 & $0.000^{b}$ & 0.43 & $0.0000^{\mathrm{th}}$ \\
\hline $\mathrm{sL}-\mathrm{hr}$ (ng/mi) & 10.0 & 0.1 & 9.91 & 0.1 & 7.5 & 0.2 & 10.9 & 0.08 & 3.10 & 0.6 & -4.83 & 0.5 \\
\hline $1 \mathrm{~L}-10^{a}(\mathrm{pg} / \mathrm{ml})$ & 0.29 & $0.000^{\mathrm{b}}$ & 0.14 & 0.08 & 0.05 & 0.5 & 0.05 & 0.6 & -0.03 & 0.97 & -0.13 & 0 \\
\hline TNF $\alpha \alpha^{\prime \prime}(\mathrm{gg} / \mathrm{ml})$ & 0.29 & $0.000^{13}$ & 0.20 & $0.0000^{b}$ & 0.21 & $0.000^{\mathrm{b}}$ & 0.23 & $0.000^{b}$ & 0.21 & $0.000^{\mathrm{th}}$ & 0.21 & $0.000^{\circ}$ \\
\hline
\end{tabular}

In transformed; $p<0.05$

\section{Cortisol}

DAC values tended to increase over the course of treatment, but were only significantly increased at week 8 after starting treatment compared to baseline $(\mathrm{B}=0.68, \mathrm{p}=0.00 \| \mathrm{l})$ (figure 9.1). The awakening response declined during treatment. This decline was not apparent until week 8 after start of treatment $(B=-0.48, p=0.004)$ (figure 9.1).

\section{Cortisol and cytokines}

IL-8 was significantly and negatively associated with DAC over time $(B=-0.93$, $p<0.001)$. slL2R $(B=0.32, p=0.013), I L-6(B=0.37, p=0.001), I L-8(B=0.39, p=0.043)$ and $I \mathbb{L}-10(B=0.57, p=0.005)$ were positively associated with the awakening response.

\section{Cytokines, cortisol and depressive symptoms}

There was no significant relationship over time between the total MADRS score and $\mathrm{DAC}(\mathrm{B}=2.23, \mathrm{p}=0.09)$ or cortisol awakening response $(B=0.80, p=0.6)$. For the three cytokines with a significant association over time with the MADRS score, analyses were repeated, first correcting for DAC and then correcting for awakening response. 
Effects of cytokines on the MADRS score remained as significant as before with little drop in effect size. For DAC the beta-coefficient of sIL2R dropped from 14.3 to 14.2. For the awakening response it dropped from 14.3 to 13.2 for sL $2 \mathrm{R}$, and from 16.7 to 14.1 for TNF- $\alpha$. Other beta-coefficients increased.

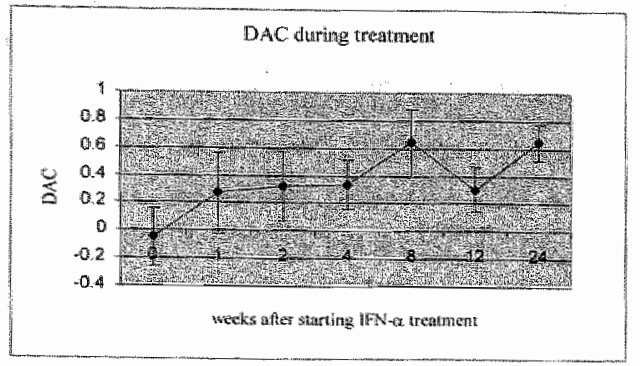

Change in daily aperage cortisol (DAC) over the course of treatment. DAC is calculated. from Ir-transformed cortisol values (ng/dil). First contisol measures were standardized over all subjects at each of the diumal sampling times and then 2 -scores were averaged, resulting in one $D A C$ value for each subject.

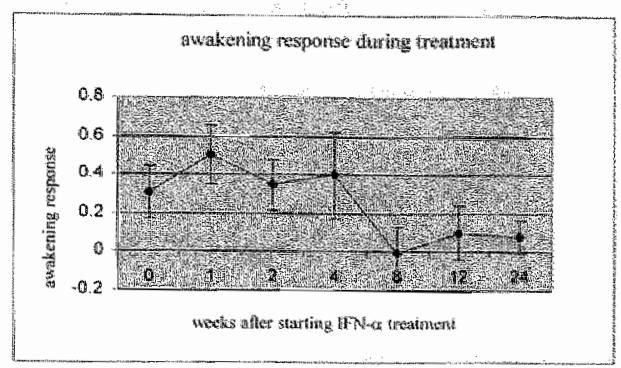

Change in awakening response over the cowse of treatment.

Awakening response is calculated from transformed cortisol values (ng/dL) as the increase in cortisol trom the frst to the second sample taken during the day far awakening and 30 mimutes afler awakening)

Figure 9.1 Changes in DAC (left) and awakening response (right) during IFN-a treatment.

\section{Discussion}

The main findings of this study are the following: 1) the pro-inflammatory cytokines sIL-2R, TNF- $\alpha$ and IL-6 were positively associated with depressive sympcoms during IFN- $\alpha$ treatment; 2) cortisol showed no significant association with depressive symptoms during IFN- $\alpha$ treatment; 3) no evidence was found that corlisol mediated the association between immune activation and depressive symptoms during IFN- $\alpha$ treatment.

\section{Cytokines and depression}

The results are in accordance with the study of Bonaccorso et al. ${ }^{34}$, who also found increased levels of $1 \mathrm{~L}-6, \mathrm{IL}-8$ and $\mathrm{IL}-10$, but no change in $\mathrm{sIL}-6 \mathrm{R}$ during $1 \mathrm{FN}-\alpha$ treatment. In that study, only $\| L-6$ correlated with the MADRS score over time; sIL2R and TNF- $\alpha$ were not measured. In the current study, sIL-2R, which is an important indicator of $\mathrm{T}$ cell activation ${ }^{3.5}$, showed the strongest association with depressive symptoms. The reported relationships between sIL-2R, TNF- $\alpha$ and IL-6 with depressive symptoms add to the existing evidence that pro-inflammatory cytokines play an important role in the pathophysiology of depression. 


\section{Cortisol and IFN- $\alpha$ treatment}

To our knowledge, studies concerning the effect of IFN- $\alpha$ on HPA axis activation have only examined HPA axis activity after acute injection of IFN- $\alpha^{13,14,16,36,37}$. All these studies report an immediate IFN-a-induced increase in cortisol and ACTH a few hours after injection of IFN- $\alpha$. During the course of treatment this acute response diminishes. Gisslinger et al. ${ }^{13}$ measured HPA axis response to acute IFN- $\alpha$ administration again 3 weeks after starting IFN- $\alpha$ treatment and found that $\mathrm{ACTH}$ and cortisol responses were only slightly and not significantly elevated, in contrast to the response after initial injection. In addition, Capuron et al. ${ }^{36}$ showed that, 8 weeks after starting IFN- $\alpha$ treatment, increase in ACTH and cortisol after acute IFN- $\alpha$ injection had completely disappeared. In this study, we did not measure immediate response of cortisol to IFN$a$, but the change in cortisol concentrations over the day resulting from chronic treatment, with the first measurement one week after starting IFN- $\alpha$ treatment. Therefore, this study adds new information to the knowledge about the course of HPA axis activation during IFN- $\alpha$ treatment. Daily average cortisol secretion did not show an immediate sharp increase over time and was significantly increased compared to baseline at week 8 only. Furthermore, the changes in cortisol awakening response during treatment were measured. Awakening response declined during the course of treatment. This finding contradicted our expectations, as studies report that depressive symptoms are associated with an increased cortisol response to awakening ${ }^{22,23}$. The observed blunting in awakening response over the course of treatment shows a greater resemblance to the response seen in patients with chronic fatigue syndrome, who show decreased cortisol responses to awakening ${ }^{38}$. Considering the fact that fatigue may have different effects on HPA axis activity than stress or depression, and that IFN- $\alpha$ is a potent inducer of fatigue symptoms, it is possible that changes in awakening response correlate stronger with IFN- $\alpha$-induced fatigue than depressive symptoms. However, mixed results have been found concerning awakening response and fatigue. Another study lound an increased cortisol awakening response in patients with vital exhaustion compared to control subjects ${ }^{3.9}$.

\section{Absence of cortisol mediation of IFN- $\alpha$ treatment induced depression}

Although HPA axis function changed during chronic IFN- $\alpha$ treatment, we found no evidence that cortisol secretion was related to the development of depressive symptoms over time. Nor was the assocuation between cytokines and depressive symptoms mediated by cortisol. Thus, cortisol changes during IFN- $\alpha$ treatment do not seem to be causal for the development of depressive symptoms. An explanation for this finding could be that only chronic HPA axis overactivation, for example in the case of chronic stress, causes changes, such as corticosteroid receptor desensitization, that are causally related to depressive symptoms, but not the sub-acute HPA axis stimulation seen. during IFN- $\alpha$ treatment. 


\section{Methodologic issues}

A limitation is the relatively small sample size and the inclusion of patients with past drug addiction. This may limit the generalisability to other populations than hepatitis $\mathrm{C}$ patients. Furthermore, differences in form of IFN- $\alpha$ treatment and current drug use, although controlled for, may have influenced the occurrence of depressive symptoms. Also, it is known that ribavirin induces a shift from Th2 to Th1-mediated immune response ${ }^{40}$. Therefore, ribavirin may contribute to cytokine-induced depressive symptoms. To our knowledge, no previous studies have examined the effect of ribavirin on cortisol. Drug use may have confounded cortisol response during IFN- $\alpha$ treatment, although this is not likely since drug use was stable over the course of treatment.

In addition, results of cortisol measurements should be interpreted cautiously, because sample collection was unsupervised. We excluded samples reportedly taken outside an acceptable time interval around the target time, with stricter criteria for the awakening response interval; this procedure improves the quality of the data obtained ${ }^{41}$.

\section{Conclusion}

Increases in cytokine concentrations are associated with the development of depressive symptoms during IFN- $\alpha$ treatment. However, the HPA axis response to administration of IFN- $\alpha$ does not appear to play a role in causing depressive symptoms during treatment. As there is a clear connection between cytokines and depressive symptoms, further research should focus on the mechanisms by which cytokines affect mood. Furthermore, trait characteristics that may predispose subjects to IFN- $\alpha$-induced mood disorder should be examined. 


\section{References}

1. Dieperink E, Ho SB, Thuras P, Willenbring ML. A prospective study of neuropsychiatric symptoms associated with interferon-alpha-2b and ribavirin therapy for patients with chronic hepatitis C. Psychosonatics 2003;44(2):104-12.

2. Bonaccorso $\mathrm{S}$, Marino $\mathrm{V}$, Puzella $\mathrm{A}$, et al. Increased depressive ratings in patients wih hepatitis $\mathrm{C}$ receiving interferon-alpha-based immunotherapy are related to interferon-alphainduced changes in the serotonergic system. J Clin Psychopharmacol 2002;22(1):86-90.

3. Hauser $\mathrm{P}$, Khosla J, Aurora $\mathrm{H}$, et al. A prospective study of the incidence and open-label treatment of interferon-induced major depressive disorder in patients with hepatitis $C$. Mol Psychiatry $2002 ; 7(9): 942-7$.

4. Musselman DL, Lawson DH, Gumnick JF, et al. Paroxetine for the prevention of depression induced by high-dose interferon alfa. N Engl J Med 2001;344(13):961-6.

5. Taylor $\mathrm{L}$, Grossberg SE. The effects of interferon-alpha on the production and action of other cytokines. Semin Oncol 1998;25(1 Suppl 1):23-9.

6. Maes M. Evidence for an immune response in major depression: a review and hypothesis. Prog Neuropsychopharmacol Biol Psychiatry 1995;19(1):11-38.

7. Sluzewska $A$, Rybakowski $J$, Bosmans $E$, et al. Indicators of immune activation in major depression. Psychiatry Res 1996;64(3):161-7.

8. Mikova $O$, Yakimova $R$, Bosmans $E$, Kenis $G$, Maes $M$. Increased serum tumor necrosis factor alpha concentrations in major depression and multiple sclerosis. Eur Neuropsychopharmacol 2001 ; 1 I (3):203-8.

9. Zorrilla EP, Luborsky L, McKay JR, et al. The relationship of depression and stressors to immunological assays: a meta-analytic review. Brain Behav Immun 2001;15(3):199-226.

10. John CD, Buckingham JC. Cytokines: regulation of the hypothalamo-pituitaryadrenocortical axis. Curr Opin Pharmacol 2003;3(1):78-84.

11. Turnbull AV, Rivier CL. Regulation of the hypothalamic-pituitary-adrenal axis by cytokines: actions and mechanisms of action. Physiol Rev 1999;79(1):1-71.

12. Miller $D B, O^{\prime} C a l l a g h a n . J P$. Neuroendocrine aspects of the response to stress. Metabolism 2002; $51(6$ Suppl 1):5-10.

13. Gisslinger $H$, Svoboda $T$, Clodi $M$, et al. Interferon-alpha stimulates the hypothalamicpituitary-adrenal axis in vivo and in vitro. Neuroendocrinology $1993: 57(3): 489-95$.

14. Muller H, Hammes E, Hienke C, Hess G. Interferon-alpha-2-induced stimulation of ACTH and cortisol secretion in man. Neuroendocrinology 1991;54(5):499-503.

15. Barbarino A, Colasanti S, Corsello SM, et al. Dexamethasone inhibition of interferon-alpha 2 -induced stimulation of cortisal and growth hormone secretion in chronic myeloproliferative syndrome. J Clin Endocrinol Metab 1995;80(4):1329-32.

16. Shimizu H, Ohtani K, Sato N, Nagamine $T$, Mori $M$. Increase in serum interleukin-6, plasma ACTH and serum cortisol levels after systemic interferon-alpha administration.
Endocr J 1995;42(4),551-6.

17. Nemeroff $\mathrm{CB}$, Widerlow $\mathrm{E}$, Bissette $\mathrm{G}$, et all. Elevated concentrations of CSF corticotropinreleasing factor-like immunoreactivity in depressed patients. Science 1984;226(4680):

18. Holsboer F, Gerken A, von Bardeleben U, et al. Human corticotropin-releasing hormone in Biol Psychiatry 1986;21(7):601-11.

19. Gold PW, Loriaux DL, Roy A, et al. Responses to corticotropin-releasing hormone in the hypercontisolism of depression and Cushing's disease. Pathophysiologic and diagnostic
implications. N Engl J Med 1986:314(21):1329-35. 
20. Maes M, Lin A, Bonaccorso $S$, et al. Increased 24-hour urinary cortisol excretion in patients with post-traumatic stress disorder and patients with major depression, but not in patients with fibromyalgia. Acta Psychiatr Scand 1998;98(4):328-35.

21. Deuschle $M$, Weber B, Colla M, Depner M, Heuser I. Effects of major depression, aging and gender upon calculated diumal free plasma cortisol concentrations: a re-evaluation study. Stress 1998;2(4):281-7.

22. Pruessner M, Hellhammer DH, Pruessner JC, Lupien SJ. Self-reported depressive symptoms and stress levels in healthy young men: associations with the cortisol response to awakening. Psychosom Med 2003;65(1):92-9.

23. Bhagwagar $Z$, Hafizi $S$, Cowen PJ. Increase in concentration of waking salivary cortisol in recovered patients with depression. Am J Psychiarry 2003;160(10): 1890-1.

24. Carroll, Curtis GC, Mendels $J$. Neuroendocrine regulation in depression. I. Limbic systemadrenocortical dysfunction. Arch Gen Psychiatry 1976,33(9):1039-44.

25. Holsboer F. The corticosteroid receptor hypothesis of depression. Neuropsychopharmacology 2000;23(5):477-501.

26. Miller AH, Pariante CM, Pearce BD. Effects of cytokines on glucocorticoid receptor expression and function. Glucocorticoid resistance and relevance to depression. Adv Exp Med Biol 1999;461:107-16.

27. Rowe W, Steverman A, Walker M, et al. Antidepressants restore hypothalamic-pituitaryadrenal feedback function in aged, cognitively-impaired rats. Neurobiol Aging 1997;18(5): 527-33.

28. Wichers M, Koek $G$, Robaeys $G$, Praamstra A, Maes $M$. Early increase in vegetatiwe symptoms predicts IFN-alpha-induced cognitive-depressive changes. Psychological Medicine; $2005 ; 35: 433-41$.

29. Hamilton M. Development of a rating scale for primary depressive illness. Br J Soc Clin Psychol 1967;6(4):278-96.

30. Montgomery SA, Asberg M. A new depression scale designed to be sensitive to change. $\mathrm{Br}$ J Psychiatry 1979;134:382-9.

31. Gunnar MR, Morison SJ, Chisholm K., Schuder M. Salivary cortisol levels in children adopted from romanian orphanages. Dev Psychopathol 2001;13(3):611-28.

32. Schmidt-Reinwald A, Pruessner JC, Hellhammer DH, et al. The cortisol response to awakening in relation to different challenge tests and a 12 -hour cortisol rhythm. Life Sci 1999;64(18):1653-60.

33. Clow A, Thorn L, Evans $P$, Hucklebridge $F$. The awakening cortisol response: methodological issues and significance. Stress 2004;7(1):29-37.

34. Bonaccorso S, Puzella A, Marino V, et al. Immunotherapy with interferon-alpha in patients affected by chronic hepatitis $C$ induces an intercorrelated stimulation of the cytokine network and an increase in depressive and anxiety symptoms. Psychiatry Res 2001;105:4555.

35. Oppenheim JJ, Ruscetti FW, Faltynek C. Cytokines. In: Stites DP, Terr Al, Parslow T, eds. Basis \& clinical immunology. Stamford, Connecticut: Appleton \& Lange, 1994: 870.

36. Capuron L, Raison CL, Musselman DL, Lawson DH, Nemeroff CB, Miller AH. Association of exaggerated HPA axis response to the initial injection of interferon-alpha with development of depression during interferon-alpha therapy. Am J Psychiatry $2003 ; 160(7): 1342-5$.

37. Cassidy EM, Manning D, Byrne S, et al. Acute effects of low-dose interferon-alphat on serum cortisol and plasma interleukin-6. J Psychopharmacol 2002;16(3):230-4.

38. Roberts AD, Wessely S, Chalder T, Papadopoulos A, Cleare AJ. Salivary cortisol response to awakening in chronic fatigue syndrome. Br J Psychiatry 2004; 18:4:136-41. 
39. Niwolson WA, van Diest R. Sallvary cortisol palterns in vital exhaustion. I Psychosom Res $2000 ; 49(5) \cdot 335-42$

40. Hultgren $C$, Milich DR, Weiland $O$, Sallberg $M$. The antiviral compound ribavirin modulates the $\mathrm{T}$ helper (Th) $1 / \mathrm{Th} 2$ subset balance in hepatitis $\mathrm{B}$ and $\mathrm{C}$ virus-spectic immune responses. J Gen Virol 1998;79 ( $\mathrm{Pt} \mathrm{10):2381-91.}$

41. Kunz Ebrecht SR, Kirsehbaum C, Marmot M, Steptoe A. Differences in cortisol awakening response on work days and weekends in women and men from the Whitehall II cohort. Psychoneuroendocrinology $2004: 29(4): 516-28$. 


\section{Chapter 10}

\section{IDO and interferon- $\alpha$-induced depressive symptoms: a shift in hypothesis from tryptophan depletion to neurotoxicity}

Marieke Wichers, Ger Koek, Geert Robaeys, Robert Verkerk, Simon Scharpé, Michael Maes

Molecuiar Psychiatry 2004; advance online publication 


\section{Abstract}

\section{Background}

Studies show that administration of interferon (IFN)- $\alpha$ causes a significant increase in depressive symptoms. The enzyme indoleamine 2,3-dioxygenase (IDO), which converts tryptophan (TRP) into kynurenine $(\mathrm{KYN})$ and which is stimulated by pro-inflammatory cytokines may be implicated in the development of IFN- $\alpha$-induced depressive symptoms, first by decreasing the TRP availability to the brain and second by the induction of the kynurenine pathway resulting in the production of neurotoxic metabolites.

\section{Methods}

Sixteen patients with chronic hepatitis $\mathrm{C}$, free of psychiatric disorders and eligible for IFN-a treatment, were recruited. Depressive symptoms were measured using the Montgomery Depression Rating Scale (MADRS). Measurements of TRP, amino acids competing with TRP for entrance through the blood-brain-barrier, KYN and kynurenic acid (KA), a neuroprotective metabolite, were performed using high-performance liquid chromatography. All assessments were done at baseline and $1,2,4,8,12$ and 24 weeks after treatment was initiated.

\section{Results}

The MADRS score significantly increased during IFN- $\alpha$ treatment as did the KYN/TRP ratio, reflecting IDO activity, and the KYN/KA ratio, reflecting the neurotoxic challenge. The TRP/CAA (Competing Amino Acids) ratio, reflecting TRP avajlability to the brain, did not significantly change during treatment. Total MADRS score was significantly associated over time with the KYN/KA ratio, but not with the TRP/CAA ratio.

\section{Conclusions}

Although no support was found that IDO decreases TRP availability to the brain, this study does support a role for IDO activity in the pathophysiology of IFN- $\alpha$-induced depressive symptoms, through its induction of neurotoxic kynurenine metabolites. 


\section{Introduction}

Administration of interferon (IFN)- $\alpha$, a pro-inflammatory cytokine, is used in the treatment of cancer and hepatitis $\mathrm{C}(\mathrm{HCV})$, because of its strong immunomodulatory and antiviral effects. Neuropsychiatric side effects are common during IFN- $\alpha$ treatment. Recent clinical studies have shown that approximately 16 to $45 \%$ of patients treated with IFN- $\alpha$ developed depressive symptoms during the course of therapy ${ }^{1-4}$. Biological mechanisms underlying these IFN- $\alpha$-induced depressive side effects are still not clear.

Depressive disorders have been linked to a dysregulated serotonin (5-HT) system ${ }^{5-7}$. 5-HT is synthesized within the brain from the essential amino acid tryptophan (TRP). Other amino acids, notably tyrosine, valine, phenylalanine, leucine and isoleucine, affect 5-HT precursor availability by competing with TRP for transport across the blood-brain-barrier (BBB) and are also referred to as competing amino acids (CAA). Therefore, decreased TRP availability in relation to CAA reduces biosynthesis of 5-HT which may cause a depressive relapse in subjects susceptible for mood disorders ${ }^{8-10}$. Depression has also been linked with markers of increased immune activation. Increased number of biood leucocytes, increased serum levels of several indicators of activated immune cells, including neopterin, prostaglandin E2, increased concentrations of complement proteins, positive acute phase proteins (APPs) and proinflammatory cytokines and decreased concentrations of negative APPs were found in depressed patients ${ }^{11-14}$. The enzyme indoleamine 2,3-dioxygenase (IDO) constitutes a link between the 5 -HT system and immune activation ${ }^{15}$. This enzyme is located in nonhepatic organs throughout the body and is also present in monocytes, macrophages, and microglial cells within the brain parenchyma ${ }^{16}$. IDO activity is mainly induced by the pro-inflammatory cytokine IFN- $\gamma$ and converts TRP into kynurenine, which, in the case of overstimulation, may lead to lowered TRP concentrations ${ }^{15,17}$.

Kynurenine is further metabolised into a series of compounds (figure 10.1), some with neurotoxic properties. 3-Hydroxykynurenine (3-OH-KYN) leads to production of reactive oxygen species (ROS) that initiate neuronal apoptosis ${ }^{18,19}$. Quinolinic Acid (QA) is a potent $\mathrm{N}$-methyl-D-aspartate (NMDA) receptor agonist ${ }^{20-22}$. Overstimulation of NMDA receptors leads to neuronal damage ${ }^{23}$. Neurotoxicity of kynurenine (KYN) and its metabolites has been demonstrated in animal studies ${ }^{19,20,24}$ and studies using human cell cultures ${ }^{25,26}$. KYN is able to pass the $\mathrm{BBB}^{27}$ and human microglia have been shown capable of metabolising this substance into its toxic metabolite ${ }^{28}$. In addition, peripherally immune-induced IDO activation has been shown to increase QA in both plasma and CSF with a highly significant correlation between the two measurements ${ }^{29}$. This supports the hypothesis that peripherally induced IDO activation is able to cause a neurotoxic challenge.

In humans, increased concentrations of toxic KYN metabolites are seen in several neurodegenerative diseases, such as Huntington"s disease ${ }^{30,31}$, Parkinson's disease and AIDS-dementia complex as well as in depression ${ }^{32}$. In addition, depression is 
associated with diffuse cortical and subcortical atrophy. Studies reported changes in the hippocampus ${ }^{3,34}$, striatum ${ }^{35,36}$ and the prefrontal cortex ${ }^{37,38}$.

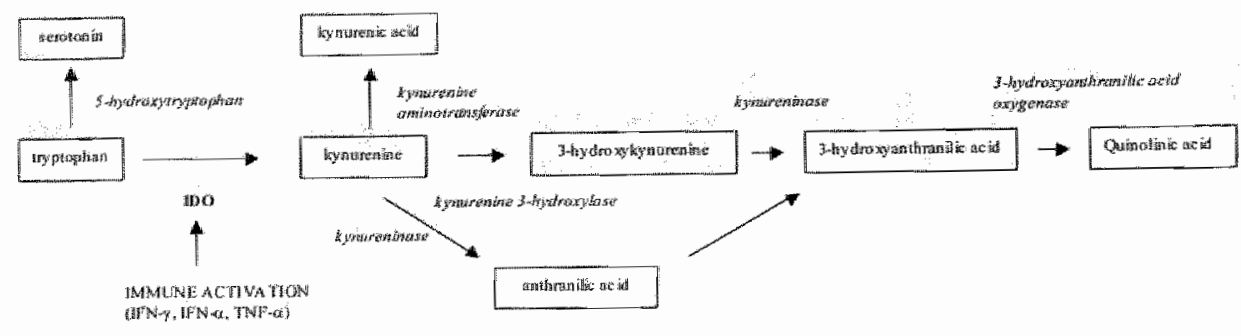

Figure 10.1 Modulation of tryptophan metabolism and induction of the kymurenine pathway by IDO

LDO induced neurotoxicity may be reduced by kynurenic acid (KA), another metabolite of kynurenine, which is known as an antagonist of the glutanate recognition site of the NMDA receptor and thus reduces NMDA overstimulation ${ }^{39}$. However, the activity of the KA synthesising enzyme, kynurenine aminotransferase (KAT), does not seem able to compete with the direct pathway to QA when in competition for the transformation of KYN into its metabolites ${ }^{40}$. Furthermore, Saito et al ${ }^{29}$ found that immune stimulation in gerbils which increased IDO activity, was also associated with increased activity of the enzyme kynureninase in brain and lung tissue, and with increased activity of kynurenine-3-hydroxylase in lung tissue (figure 10.1). In contrast, it was associated with decreased activity of KAT in the liver, while no changed KAT activity was observed in brain and lung tissue. Therefore, immune-induced IDO activity may alter the ratio of the toxic QA to the protective KA and may thus change the neurotoxic balance.

Since IFN- $\alpha$ treatment enhances immune activation we hypothesized that IDO activity during treatment increases and that it may play a role in the pathophysiology of IFN- $\alpha$ induced depressive symptoms 1) by decreasing the TRP/CAA ratio or 2) by induction of the kynumenine pathway that increases the neurotoxic challenge in the brain.

\section{Methods}

\section{Subjects}

In all, 21 patients with chromic HCV infection, aged $25-57$ years and eligible for IFN- $\alpha$ treatment, were recruited. Chronic HCV was defined as: antibodies to HCV positive, HCV-RNA positive and elevated transaminases at least once in the previous 6 months. Patients had a complete medical history, physical examination and laboratory blood check before study entry. In addition, an ultrasound of the upper abdomen, an ECG, 
and a pregnancy test (in women of childbearing potential) was carried out. A liver biopsy was performed in most patients.

Excluded were patients currently meeting eriteria of axis I psychiatric disorders as defined by DSM-IV or patients currently on antidepressant medication. In addition, patients who had co-infections with hepatitis B virus or human immunodeficiency virus, or patients with a diagnosis of neurological, cardiovascular, endocrine, hematological, signs of cirrhosis, hepatic or renal disease or patients with insuflicient knowledge of the Dutch language were excluded.

Patients were recruited from the Academic Hospital Maastricht (azM) in the Netherlands and from the Ziekenhuis Oost Limburg (ZOL) in Belgium. All patients received interferon- $\alpha$ treatment and ribavirin, both administered in a weight-dependent manner. One patient received interferon- $\alpha 2 \mathrm{~b}$ (Intron A), 3x3 MU weekly throughout the study period. Nine patients received Intron $A$ the first 12 days of treatment (10 MU daily in the first 6 days and $5 \mathrm{MU}$ daily after the $6^{\text {th }}$ day). Hereafter, they received a weekly injection of $\mathrm{PEG}$ interferon- $\alpha 2 \mathrm{~b} 80-180 \mu \mathrm{g}$. Six patients directly started with weekly injections of $\mathrm{PEG}$ interferon- $\alpha 2 \mathrm{~b} 80-180 \mu \mathrm{g}$. In all patients, ribavirin was administered orally, $1000-1200 \mathrm{mg} /$ day.

The study was approved by the standing Medical Ethics Committee of Maastricht University, and carried out in accordance with the Declaration of Helsinki (Hong Kong Modification, 1989). Written informed consent was obtained from each subject prior to participation.

\section{Biological and psychiatric assessments}

Biological and psychiatric assessments were done at 7 different time points during IFN- $\alpha$ treatment i.e. before and $1,2,4,8,12$ and 24 weeks after starting treatment. In all subjects fasting blood was sampled between 08.00 and 09.00 for the assay of serum TRP, CAA, KYN and KA. Blood samples were centrifuged at $1500 \mathrm{~g}$ for $10 \mathrm{~min}$ at 4 ${ }^{\circ} \mathrm{C}$. Serum was then stored at $-20^{\circ} \mathrm{C}$ until assayed. Total TRP, CAA, KYN and KA were assayed by means of a HPLC method as previously explained ${ }^{4 !}$. The intra- and interassay $\mathrm{CV}$ values obtained in our laboratory were less than $5 \%$ and $7 \%$, respectively. TRP, CAA and KYN are expressed as micromol/L and $\mathrm{KA}$ as nanomol/L. The KYN to TRP quotient was computed, since this ratio allows to estimate IDO activity ${ }^{42}$. In addition, the TRP to CAA quotient was computed to estimate the TRP availability to the brain and the $K Y N$ to $K A$ quotient was computed to estimate the neurotoxic challenge in the brain.

The presence of depressive symptoms was assessed by the 17-item Hamilton Depression Rating Scale (HAM-D) ${ }^{43}$ and the Montgomery Asberg Depression Rating Scale (MADRS) ${ }^{44}$.

\section{Statistical analysis}

The data were analyzed with the STATA computer program, version 7 (STATA, $2001)$. Since the two depression rating scales were highly correlated $(r=0.72)$ only 
results of the MADRS are shown. The MADRS was chosen as the main outcome because it has been used frequently to assess IFN- $\alpha$ induced depressive symptoms and therefore allows comparison with earlier studies in which this scale was used.

Because repeated measurements within the same person were used, the observations cannot be considered independent statistically. Therefore, multillevel random regression models were fitted, using the XTREG procedure in STATA (Statacorp, 2001). This takes into account the fact that level-one units (level of individual observations) were clustered into level-two units (levels of the subjects). Effect sizes of explanatory variables were expressed as regression coefficients $(\beta)$ from the multilevel models. All analyses were corrected for the following a priori hypothesised confounders: age, sex; smoking, hospital centre, benzodiazepine medication, use of marijuana during the study and mode of acquisition of infection. If necessary, variables were In-transformed in order to improve normality. First, an analysis was performed with time as a dummy variable to assess the effect of individual time points compared with baseline on the total MADRS score. The same analysis was done for the ratio KYN/TRP, reflecting IDO activity, in order to see if IDO activity is increased during IFN- $\alpha$ treatment, the ratio TRP/CAA in order to examine if TRP avallability to the brain declines and also for the ratio KYN/KA in order to examine if the balance between neurotoxic and neuroprotective metabolites, and thus the neurotoxic challenge, increases during IFN- $\alpha$ treatment. Then, total MADRS score was regressed on the TRP/CAA ratio and KYN/KA ratio in order to examine their relationships with depressive symptoms.

\section{Results}

\section{Subject characteristics}

In total, 21 patients were included in the study. Four patients dropped out during the study period due to problems unrelated to psychiatric side-effects. In addition, 1 patient was left out of the analyses because of insufficient data. The final study sample consisted of 16 patients, 12 men and 4 women. Their mean age was $42 \pm 7.7$ years. In 7 of 16 patients, a temporary dose-reduction or discontinuation of treatment was necessary due to severe side effects. No patients received antidepressant medication during the study period. Eleven patients $(68 \%)$ reported lifetime drug dependence these were patients who had acquired the virus by intravenous drug use (IVDU). Seven of the 16 patients ( $44 \%$ ) received low-dosage benzodiazepines during the study and 7 out of 16 patients were using some form of drugs: 5 were regular users of marijuana. Of these 5 individuals, I used heroin on a regular basis and 2 individuals were on methadone-substitution. Their drug habit was stable throughout the study period. 


\section{Depressive symptoms, IDO activity, TRP availability and neurotoxic challenge during IFN- $\alpha$ treatment}

Five out of 16 patients (31\%) fulfilled the criteria for Major Depressive Disorder (MDD) at least once during treatment. These 5 showed no significant difference in baseline MADRS score compared to those that did not develop MDD. Total MADRS score was significantly increased during IFN- $\alpha$ treatment compared to baseline, at all time points (table 10.1, figure 10.2). Table 10.2 shows the means and standard deviations of the measured biological variables during treatment at all time points. In order to improve normality the KYN/TRP ratio, reflecting IDO activity, was Intransformed. The KYN/TRP ratio was significantly increased compared to baseline at all time points measured during IFN- $\alpha$ treatment. The TRP/CAA ratio was not decreased at any time point after starting treatment, compared to baseline. The TRP/CAA ratio showed a non-significant increase during treatment. Post-hoc analyses showed that both TRP $(\beta=-1.22, p=0.006)$ and CAA concentrations $(\beta=-20.2, p=0.000)$ showed a significant decline during IFN- $\alpha$ treatment. The increase in the KYN/KA ratio, indicating higher neurotoxic challenge, was significant compared to baseline for all time points, except for week 2 .

Table 10.1 Multilevel regression analyses indicating differences on each dinnension for each time point, compared to baseline, with ' $\beta$ ' indicating the regression coefficient and ' $P$ " the level of significance.

\begin{tabular}{|c|c|c|c|c|c|c|c|c|c|c|c|c|}
\hline \multirow{2}{*}{ weeks } & \multicolumn{2}{|l|}{1} & \multicolumn{2}{|l|}{2} & \multicolumn{2}{|l|}{4} & \multicolumn{2}{|l|}{8} & \multicolumn{2}{|l|}{12} & \multicolumn{2}{|l|}{24} \\
\hline & $\beta$ & p & $\beta$ & $\mathrm{p}$ & $\beta$ & $\mathrm{p}$ & $\beta$ & $P$ & $p$ & $\mathrm{p}$ & $p$ & $\mathrm{p}$ \\
\hline $\begin{array}{l}\text { Total MADRS } \\
\text { score }\end{array}$ & 7.17 & $0.001^{2}$ & 11.0 & $0.0000^{\prime \prime}$ & 11.2 & $0.0000 \mathrm{a}$ & 13.8 & $0.000 \mathrm{a}$ & 12.5 & $0.000^{\mathrm{a}}$ & 12.2 & $0.000^{\mathrm{x}}$ \\
\hline $\begin{array}{l}\text { KYN/TRP } \\
\text { (nn-transformed) }\end{array}$ & 0.42 & $0.000^{\mathrm{m}}$ & 0.22 & $0.000 \mathrm{a}$ & 0.19 & $0.001 \mathrm{a}$ & 0.28 & $0.000 \mathrm{a}$ & 0).26 & $0,000 \mathrm{a}$ & 0.29 & $0.000^{n}$ \\
\hline IRRPCAA & 0.004 & 0.4 & 0.000 & 1.0 & 0.001 & 0.8 & 0.003 & 0.5 & 0.005 & 0.2 & 0.005 & 0.3 \\
\hline $\mathrm{KrN} / \mathrm{KA}$ & 0.114 & $0.00 \mathrm{f}^{\text {th }}$ & 0.005 & 0.1 & 0.007 & $0.04 .0^{2}$ & 0.016 & $0.000^{\mathrm{a}}$ & 0.017 & $0.0000^{\mathrm{is}}$ & 0.012 & $0.001^{\mathrm{B}}$ \\
\hline
\end{tabular}

00.05

Table 10.2 Means and standard deviations of TRP, CAA, KYN and KA for each time point.

\begin{tabular}{|c|c|c|c|c|c|c|c|}
\hline weeks & baseline & 1 & 2 & 4 & 8 & 12 & 24 \\
\hline \multicolumn{8}{|l|}{ Mean (sd) } \\
\hline TRP $(f \mu m o l L)$ & $71.4(7.7)$ & $69.1(13.7)$ & $65.7(1.3 .1)$ & $65.4(\| 1.8)$ & $64.1(13,8)$ & $63.8(13.9)$ & $64.00(15.0)$ \\
\hline CHA ( & $691.4(81)$ & $697.5(191)$ & $629.9(120)$ & $6233(101)$ & $598.8(103)$ & $586.4(116)$ & $577.5(81)$ \\
\hline $\mathbb{K Y N}(\mu \mathrm{mol} / \mathrm{L})$ & $2.50(0.52)$ & $3.60(0.57)$ & $2.79(0.48)$ & $2.70(0.29)$ & $2.95(0.66)$ & $2.84(0.38)$ & $2.97(0.53)$ \\
\hline $\mathrm{KA}(\mathrm{nmol} / \mathrm{L})$ & $40.5(10.1)$ & $48.3(9.4)$ & $40.6(6.8)$ & $39.4(7.9)$ & $38.1(9.1)$ & $37.0(8.3)$ & $40.6(6.2)$ \\
\hline
\end{tabular}



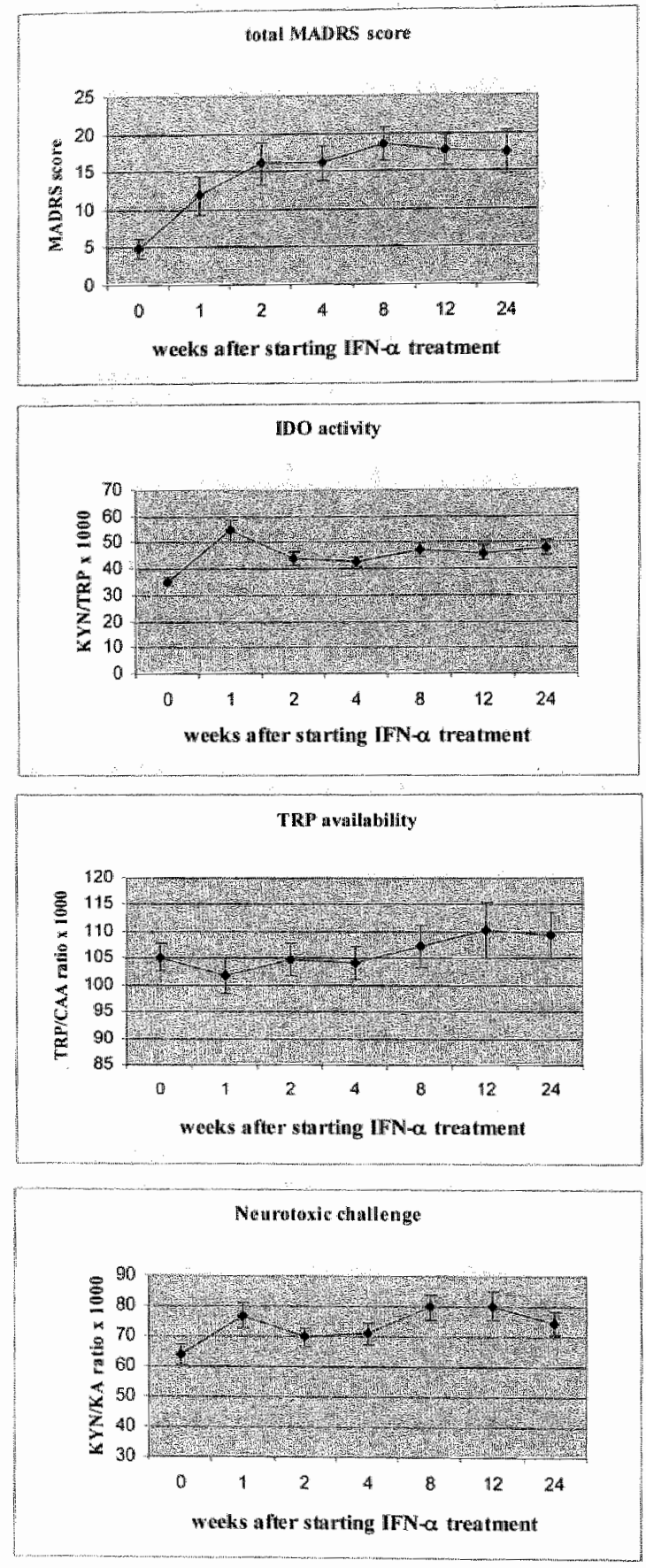

Figure 10.2 Changes in the MADRS score, the KYN/TRP ratio, the TRP/CAA ratio and the KYN/KA ratio during IFN- $\alpha$ treatment. 
TRP availability, neurotoxic challenge and their relationships with the MADRS score

The ratio TRP/CAA was not significantly associated over time with the total MADRS score $(\beta=84.6, p=0.2)$ whereas post-hoc analyses showed that TRP concentrations were associated over time with the total MADRS score $(\beta=0.16, p=0.03)$. In contrast to the TRP/CAA ratio, the KYN/KA ratio was significantly associated over time with the total MADRS score $(\beta=245.6, p<0.000)$. Post-hoc regression analyses were performed that regressed individual MADRS item scores on the KYN/KA ratio (table 10.3). Relationships with the KYN/KA ratio were significant for the items reflecting observed sadness, tension/irritability, sleep problems, reduced appetite, decreased concentration, decreased energy and decreased interest in social activities. The association of depressive symptoms with KXN concentrations was not significant in post-hoc analyses $(\beta=0.5, p=0.7)$.

No significant effects of treatment or marijuana use on TRP metabolism were observed during treatment, except that marijuana users exhibited increased KA concentrations. However, the KYN/KA ratio was not significantly different.

Table 10.3 Associations between individual MADRS items and KYN/KA ratio over all time points during IFN- $\alpha$ treatment.

\begin{tabular}{lcc}
\hline MADRS item & regression coefticient $(\beta)$ & significance $(p)$ \\
\hline Observed sadness & 21.1 & $\mathrm{p}<0.05$ \\
Reported sadness & 17.0 & $\mathrm{NS}$ \\
Tension/irritability & 37.1 & $\mathrm{p}<0.01$ \\
Sleep problems & 49.3 & $\mathrm{p}<0.001$ \\
Decreased appetite & 23.7 & $\mathrm{NS}$ \\
Problens with concentrating & 35.2 & $\mathrm{p}<0.01$ \\
Decreased energy & 29.0 & $\mathrm{p}<0.05$ \\
Decreased social interest & 33.2 & $\mathrm{p}<0.001$ \\
Feelings of guilt/inferiority & -9.98 & $\mathrm{NS}$ \\
Suicidal thoughts & 2.00 & $\mathrm{NS}$ \\
\hline
\end{tabular}

NS $=$ non - significant

\section{Discussion}

IFN- $\alpha$ administration sigmificantly increased the KYN/TRP ratio reflecting IDO activity. Although TRP concentrations declined during treatment, the TRP/CAA ratio, reflecting the TRP availability to the brain, did not decrease over time and was not associated with the MADRS score. However, IFN- $\alpha$ treatment induced a shift in the neurotoxic/neuroprotective balance towards a higher $\mathrm{KYN} / \mathrm{KA}$ ratio, resulting in a greater neurotoxic challenge. Furthermore, the KYN/KA ratio was significantly 
associated over time with higher MADRS seores. Relating depressive symptoms with KYN concentrations alone did not result in a significant association, showing that it may be the balance between neurotoxic and neuroprotective substances that is important in determining depressive outcome.

Few studies have been performed examining the relationship between the severity of depression and the amount of kynurenine metabolites. As early as 1974, Mangoni noted a positive correlation between depression scores and the amount of xanthurenic acid, which is metabolised from 3-OH-KYN, in the urine of depressed patients ${ }^{32}$. Recently, Maes et al. showed that pregnant women who responded to delivery with a high increase in anxiety or depression in the early puerperium, showed higher plasma kynurenine concentrations 3 days afler delivery than nonresponders ${ }^{45}$.

The finding of the relationship between the neurotoxic/neuroprotective balance and depressive symptoms fits well with the neurodegeneration hypothesis of depression as proposed by Myint and $\mathrm{Kim}^{46}$, who hypothesized a model which recognises the diversity of individual biological risk factors, and integrated them into a framework to explain the development of depression. Inability to maintain the balance between proand anti-inflammatory cytokines or to compensate for stress-induced changes in neuroendocrine and 5-HT metabolism, may result in higher HPA activity and increased IDO activity which both may augment neurodegeneration ${ }^{46}$. Reduced gray matter volume in the hippocampus ${ }^{47,45}$ and increased neuronal and glial cell packing has been reported, suggesting a decrease in the hippocampal neuropi ${ }^{49}$. In addition, studies show loss of prefrontal cortical glia and neurons in patients with mood disorders ${ }^{37,38}$. Although glucocorticoids have been proposed as possible candidates mediating these effects ${ }^{50}$, IDO-induced neurotoxicity may represent an additional mechamism by which atrophy is produced. According to the neurodegeneration hypothesis ${ }^{46}$, failure to compensate for the neurotoxic effects by increasing concentrations of antiinflammatory cytokines, altering 5-HT function and increasing neuroprotective substances such as KA, may result in depression ${ }^{46}$.

Results of this study support a role for IDO in the pathophysiology of depression through its modulation of the kynurenine pathway and not through its effect on TRP availability to the brain. This study as well as previous studies have shown that TRP concentrations decrease during IFN- $\alpha$ treatment and are correlated with depressive symptoms $^{4,51,52}$. Also, results of this study agree with the findings of Capuron et al. ${ }^{52}$ concerning changes in KYN and the KYN/TRP ratio, reflecting IDO activity. However, no decrease in TRP/CAA ratio was found and correlations with depressive symptoms did not reach significance for the TRP/CAA ratio. Although Bonaccorso et al." also reported no significant change in the TRP/CAA ratio, these results contrast with those found by Capuron et al. ${ }^{5 !}$, who did describe a decrease and a significant correlation between the TRP/CAA ratio and depressive symptoms. However, also in this study, a stronger relationship was found between pure TRP concentrations and depressive symptoms. In the absence of any changes in CAA as reported by Capuron et al. ${ }^{51}$ it is to be expected that pure TRP concentrations will show strong correlations 
with the TRP/CAA ratio. This could explain why the association between the TRP/CAA ratio and depressive symptoms is in contrast to our finding where changes in $\mathrm{CAA}$ alongside TRP changes were found.

An association of TRP concentrations with depressive symptoms may exist because TRP availability to the brain might also be dependent on total and free TRP concentrations aside from the ratio TRP/CAA ${ }^{53,54}$. Therefore, decreased TRP concentrations may have an additional negative effect on mood. Nonetheless, the association between depressive symptoms and TRP concentrations was less significant than that with the ratio reflecting the neurotoxic challenge. On the other hand, associations between TRP concentrations and depressive symptoms may also arise because decreased TRP concentrations could reflect TRP catabolism through IDO activity and therefore represent the increase in neurotoxic kynurenine metabolites.

There are a number of limitations. In the present study, the neurotoxic challenge was measured indirectly by assuming that, due to the inability of KA to compete with QA when in competition for the transformation of KYN into its metabolites ${ }^{4 / 0}, \mathrm{KYN}$ concentration reflects more the neurotoxic than the neuroprotective metabolites. For a more direct approach, future studies should measure concentrations of 3-OH-KYN and QA directly, as well as the activity of the kynurenine aminotransferases, the enzymes that metabolise KYN into KA.

Second, no clear conclusions can be drawn concerning the effect of treatment differences in IFN- $\alpha$ therapy and marijuana use on TRP metabolism and neurotoxicity, because of the small group size. Also, no study has been performed that examines the effect of ribavirin on TRP metabolism. However, it is known that ribavirin induces a shift from Th2 to Th1-mediated immune response. Therefore, ribavirin may contribute to the activation of IDO and subsequent depressive symptoms. Further studies should examine the effects of treatment and drug use on neurotoxicity and depressive symptoms. 


\section{References}

1. Dieperink $\mathrm{E}$, Ho SB, Thuras $\mathrm{P}$, Willenbring $\mathrm{ML}$. A prospective study of neuropsychtiatric symptoms associated with interferon-alpha-2b and ribavirin therapy for patients with chronic hepatitis C. Psychosomaties 2003;44(2):104-12.

2. Hauser $P$, Khosla $I$, Aurora $\mathbb{H}$, et al. A prospective study of the incidence and open-label treatment of interferon-induced major depressive disorder in patients with hepatitis $C$. Mol Psychiatry 2002,7(9):942-7.

3. Musselman DL, Lawson DH, Gumnick JF, et al. Paroxetine for the prevention of depression induced by high-dose interferon alfa. N Emgl I Med 2001;344(13):961-6.

4. Bonaccorso $\mathrm{S}$, Marimo $\mathrm{V}$, Puzella $\mathrm{A}$, et al. Increased depressive ratings in patients with hepatitis $\mathrm{C}$ receiving interferon-alpha-based immunotherapy are related to interferon-alphainduced changes in the serotonergic system. J Clin Psychopharmacol 2002;22(1):86-90.

5. Staley JK, Malison RT, Innis RB. Imaging of the serotonergic system: interactions of neuroanatomical and functional abnormalities of depression. Biol Psychiatry $1998 ; 44(7): 534-49$.

6. Graeff FG, Guimaraes $\mathbb{F S}$, De Andrade TG, Deakin JF. Role of 5-HT in stress, anxiety, and depression. Pharmacol Biochem Behav 1996;54(1):129-41.

7. Maes M, Meltzer H. The serotonin hypothesis of major depression. In: Bloom F, Kupfer D, eds. Psychopharmacology. New York: Raven Press, 1995: 933-944.

8. Salomon RM, Kennedy JS, Johnson BW, et al. Association of a critical CSF tryptophan threshold level with depressive relapse. Newropsychopharmacology 2003;28(5):956-60.

9. Young $S \mathrm{~N}$, Leyton $\mathrm{M}$. The role of serotonin in human mood and social interaction. Insight from altered tryptophan levels. Phamacol Biochem Behaw 2002;7l(4):857-65.

10. Booij $L$, Van der Does $W$, Benkelfat $C$, et al. Predictors of mood response to acute tryptophan depletion. A reanalysis. Neuropsychopharmacology 2002;27(5):852-61.

11. Maes M. Evidence for an immune response in major depression: a review and hypothesis. Prog Neuropsychopharmacol Biol Psychiarry 1995;19(1):11-38.

12. Sluzewska $A$, Rybakowski $\mathrm{J}$, Bosmans $\mathrm{E}$, et al. Indicators of immune activation in major depression. Psychiatry Res 1996;64(3):161-7.

13. Mikova $O$, Yakimowa $\mathbb{R}$, Bosmans $E$, Kenis $G$, Maes $M$. Increased serum tumor necrosis factor alpha concentrations in major depression and multiple sclerosis. Eur Neuropsychopharmacol 2001;11(3):203-8.

14. Zorrilla EP, Luborsky $L$, McKay JR, et al. The relationship of depression and stressors to immunological assays: a meta-analytic review. Bram Behav Immum 2001;15(3):199-226.

15. Wirleitner B, Neurauter G, Schrocksnadel K. Frick B, Fuchs D. Interferon-gamma-induced conversion of tryptophan: immunologic and neuropsychiatric aspects. Curr Med Chew 2003:10, 16): I 581-91.

16. Dale WE, Dang $Y$, Brown OR. Tryptophan metabolism through the kynurenine pathway in rat brain and liver slices. Free Radic Biol Med 2000;29(2):191-8.

17. Russo S, Kema IP, Fokkema MR, et al. Tryptophan as a لink between psychopathology and somatic states Psychosom Med 2003;65(4):665-71.

18. Stone TW. Endogenous neurotoxins from tryptophan. Toxicon 2001;39(1):61-73.

19. Okuda $S$, Nishiyama $N_{*}$ Saito $H$, Katsuki H. 3-Hydroxykynurenine, an endogenous oxidative stress generator, causes neuronal cell death with apoptotic features and region selectivity. I Neunochem 1998;70(1):299-307.

20. Santamaria A, Galvan-Arzate S, Lisy V, et al. Quinolinic acid induces oxidative stress in rat brain synaptosomes. Neuroreport $2001 ; 12(4): 871-4$. 
21. Behan WM, McDonald M, Darlington $L G$, Stone TW. Oxidative stress a a mechanism for quinolinic acid-induced hippocampal damage: protection by melatonin and deprenyll. $B r^{\prime}$. Pharmacoll 1999;128(8):1754-60.

22. Wu HQ, Guidetti P, Goodman JH, et al. Kynurenergic manipulations influence excitatory synaptic function and excitotoxic vulnerability in the rat hippocampus in vivo. Newroscience 2000;97(2):243-51.

23. Stone TW, Addae J. The pharmacological mamipulation of glutamate receptors and neuroprotection. Eur I Pharmacol 2002;447(2-3):285-96.

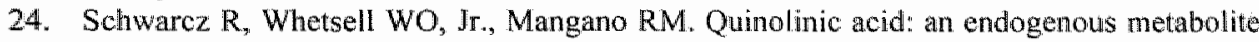
that produces axon-sparing lesions in rat brain. Science $1983 ; 219(4582): 316 \mathrm{\&}$.

25. Kerr SJ, Armati PJ, Guillemin GJ, Brew BJ. Chronic exposure of human neurons to quinolinic acid results in neuronall changes consistent with AIDS dementia complex. Aids 1998;12(4):355-63.

26. Jeang JH, Kim HJ, Lee TJ, Kim MK, Park ES, Choi BS. Epigallocatechin 3-gallate attenuates neuronal damage induced by 3-hydroxykynurenine. Toxicology 2004;195(1):5360.

27. Fukui S, Schwarcz R, Rapoport SI, Takada Y, Smith QR. Blood-brain barrier transport of kymurenines: implications for brain synthesis and metabolism. $J$ Neurochem $1991 ; 56(6): 2007-17$.

28. Heyes MP, Achim CL, Wiley CA, Major EO, Saito K, Markey SP. Human microglia convert 1-tryptophan into the neurotoxin quinolinic acid. Biochem J 1996;320 ( Pt 2):595-7.

29. Saito K, Crowley JS, Markey SP, Heyes MP. A mechanism for increased quinolinic acid formation following acute systemic immune stimulation. J Biol Chem 1993;268(21):15496503.

30. Reynolds GP, Pearson SJ, Halket J, Sandler M. Brain quinolinic acid in Huntington's disease. J Newrochem 1988;50(6):1959-60.

31. Reynolds GP, Pearson S.l. Increased brain 3-hydroxykynurenine in Huntington's disease. Lancet $1989 ; 2(8669): 979-80$.

32. Mangoni A. The "kynurenine shunt" and depression. Adv Biochem Psychopharmacol $1974 ; 11(0): 293-8$.

33. Sheline YI, Sanghavi M, Mintun MA, Gado MH. Depression duration but not age predicts hippocampal volume loss in medically healthy women with recurrent major depression. $f$ Neurosci 1999;19(12):5034-43.

34. Bremner JD, Narayan M, Anderson ER, Staib LH, Miller HL, Charney DS. Hippocampal volume reduction in major depression. Am J Psychiatry 2000;157(1):115-8.

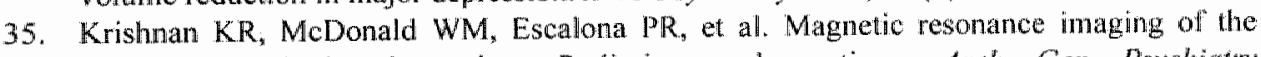
caudate nuclei in depression. Preliminary observations. Arch Gen Psychiciry 1992;49(7):553-7.

36. Husain MM, McDonald WM, Doraiswamy PM, et al. A magnetic resonance imaging study of putamen nuclei in major depression. Psychiatry Res $1991 ; 40(2): 95-9$.

37. Ongur D, Drevets WC, Price JL. Glial reduction in the subgenuat prefrontal cortex in mood disorders. Proc Natl Acad Sci US A 1998;95(22): 13290-5.

38. Rajkowska $\mathrm{O}$, Miguel-Hidalgo J, Wei J, et al. Morphometric evidence for neuronal and glial prefrontal cell pathology in major depression. Biol Psychiatry 1999;45(9): 1085-98.

39. Stone TW, Darlington LG. Endogenous kynurenines as targets for drug discovery and development. Nat Rev Drug Discov 2002;1(8):609-20.

40. Heyes MP, Mefford IN, Quearry BJ, Dedhia M, Lackner A. Increased ratio of quinolinic acid to kynurenic acid in cerebrospinal fluid of $D$ retrovirus-infected rhesus macaques: relationship to clinical and viral status. Ann Neurol 1990;27(6):666\%75. 
41. Herve C, Beyne P, Jamault H, Delacoux E. Determination of tryptophain and its kymuremine pathway metabolites in human serum by high-performance liquid chromatography with simultancous ultraviolet and fluorimetric detection. I Chromatogr B Biomed Appl $1996,675(1): 157-61$.

42. Widner $B$, Ledochowski $M$, Fuchs $D$. Interferon-gamma-induced tryptophan degradation: neuropsychiatric and immunological consequences. Cur Drug Metab 2000;1(2):193-204.

43. Hamilton M. Development of a rating scale for primary depressive illness. Br J Soc Chin Psychol 1967;6(4),278-96.

44. Montgomery $\$$ A, Asberg M. A new depression scale designed to be sensitive to change. $B r$ I Psychiatry 1979;134:382-9.

45. Maes M, Verkerk R, Bonaccorso S, Ombelet W, Bosmans E, Scharpe S. Depressive and anxiety symptoms in the early puerperium are related to increased degradation of tryptophan into kynurenine, a phenomenon which is related to immune activation. Life Sci 2002;71(16):1837.

46. Myint $\mathrm{AM}$, Kim $\mathrm{YK}$. Cytokine-serotonin interaction through IDO: a neurodegeneration hypothesis of depression. Med Hypotheses $2003 ; 61(5-6): 519-25$.

47. Sheline YI, Gado MH, Kraemer HC. Untreated depression and hippocampal volume loss. Am J Psychiatry 2003;160(8):1516-8.

48. Shah PJ, Ebmeier KP, Glabus MF, Goodwin GM. Cortical grey matter reductions associated with treatment-resistant chronic unipolar depression. Controlled magnetic resonance imaging study. Br.J Psychiatry 1998;172:527-32.

49. Stockmeier CA, Mahajan G, Konick LC, et al. Neuronal and glial density is increased and neuronal soma size is decreased in the hippocampus in major depressive disoder (MDD). Biol Psychiaty 2003;535:198.

50. Sapolsky $\mathbb{R M}$. Glucocorticoids and hippocampal atrophy in neuropsychiatric disorders. Arch Gen Psychiany 2000;57:925-35.

51. Capuron L, Ravaud A, Neveu PJ, Miller AH, Maes M, Dantzer R. Association between decreased serum tryptophan concentrations and depressive symptoms in cancer patients undergoing cytokine therapy. Mol Psychiarry 2002;7(5):468-73.

52. Capuron L, Neurauter $\mathrm{G}$, Musselman DL, et al. Interferon-alpha-induced changes in tryptophan metabolism. relationship to depression and paroxetine treatment. Biol Psychiatry 2003;54(9):906-14.

53. Pardridge WM. Tryptophan transport through the blood-brain barrier: in wivo measurement of free and albumin-bound amino acid. Life Sci 1979:25(17):1519-28.

54. Curzon $\mathrm{G}$, Sarna GS. Tryptophan transport to the brain: newer findings and older ones reconsidered. In: Schlossberger $\mathrm{HG}$, Kochen W, Linzen B, Steinhart H, eds. Progress in Tryptophan and Serotonin Research. Berlim: Walter De Gruyter, 1984:145-157. 


\section{Chapter 11}

\section{Baseline immune activation as a risk factor for the onset of depression during interferon- $\alpha$ treatment}

Marieke Wichers, Gunter Kenis, Ger Koek, Carsten Lewe, Geert Robaeys, Michael Maes

Submitted 


\begin{abstract}
Major depression thas been associated cross-sectionally with increased cell-mediated immune activation but causality has been difficult to establish. This study prospectively investigated the hypothesis that baseline level of immune activation predicts the development of depression over the course of interferon-alpha (IFN-o) treatment. Sixteen hepatitis $C$ patients without psychiatric disorder underwent IFN- $\alpha$ treatment. Pro- and anti-inflammatory cytokines were determined before starting treatment. Presence of a major depressive disorder (MDD) was assessed at week $1,2,4,8,12$ and 24 during IFN- $\alpha$ treatment. Baseline s]L-2R, IL-6 and IL-10 concentrations were significantly increased in the five subjects that developed MDD during treatment compared to those that did not, with standardized effect sizes of $1.08,1.16$ and 1.25 , respectively, controlling for marijuana use, cigarette smoking and baseline level of depressive symptoms. The results suggest that increased immune activation, rather than an epiphenomenon, is a causal risk factor for the development of MDD.
\end{abstract}




\section{Introduction}

Major depression has been associated with increased cell-mediated immune activation ${ }^{1-4}$. However, the question remains whether altered immune activation in depressed patients reflects a causal risk factor for the development of depression or an epiphenomenon. Studies have shown that interferon ([FN)- $\alpha$ treatment in hepatitis $\mathrm{C}$ patients results in major depressive disorder (MDD) in about $30 \%$ of the patients ${ }^{5-7}$. Although this finding suggests causality in the relationship between immune activation and depression, it is unclear whether natural occurring inflammation also has the potential of putting subjects at risk for depression. This study investigated whether baseline levels of immune activation in hepatitis $\mathrm{C}$ patients about to be treated with IFN- $\alpha$ were associated with the risk of developing MDD within 6 months after initiation of treatment.

\section{Methods}

Twenty-one patients with chronic active hepatitis $\mathrm{C}$ infection, aged 25-57 years, without current psychiatric disorder and eligible for IFN- $\alpha$ treatment, were recruited. The study was approved by the standing Medical Ethics Committee of Mastricht University. DSM-IV criteria ${ }^{8}$ were used to determine the presence of MDD at regular times during treatment (at week 1, 2, 4, 8, 12 and 24). In addition, the Montgomery Asberg Depression Rating Scale (MADRS) ${ }^{9}$ was administered and patients were asked questions concerning demographic characteristics, medication, drug use and cigarette smoking.

Blood samples were taken before the start of IFN- $\alpha$ treatment, after an overnight fast. After clotting at room temperature, samples were centrifuged, serum was collected and stored at $-80^{\circ} \mathrm{C}$ until determination of cytokines. Cytokines (interleukin-1 receptor antagonist (IL-1RA), soluble IL-2 receptor (sIL-2R), IL-6, sIL-6R, IL-8, IL-10 and tumour necrosis factor- $\alpha$ (TNF- $\alpha)$ ) were measured in serum using commercially available enzyme linked immunosorbent assays (ELISAs) as described elsewhere ${ }^{10}$. Cytokines (witl the exception of sIL-6R) were In-transformed to improve normality. Data were analysed in SPSS version 1.1.0 using an ANOVA design to compare baseline mean cytokine concentrations between patients that did and did not develop MDD during subsequent IFN- $\alpha$ treatment. Baseline MADRS score, marijuana use and cigarette smoking were included as covariates.

\section{Results}

Of the 21 patients, four dropped out during the study period due to problems unrelated to psychiatric side-effects and one subject was left out because of missing data. The 
final study sample thus consisted of 16 patients, 12 men and 4 women, with a mean age of $42 \pm 7.7$ years. Five out of 16 patients $(31 \%)$ developed $M D D$ at some point during treatment, five patients were regular marijuana users and seven were cigarette smokers. At baseline, no difference in MADRS score was apparent between the MDD (mean 3.0; standard error (SE) 1.30) and non-MDD group (mean 5.7; SE 1.67). All cytokines displayed higher mean plasma levels at baseline for MDD as compared to non-MDD patients (table 1 1.1). Baseline sIL-2R, IL-6 and IL-10 concentrations were significantly higher in patients that would develop MDD during IFN- $\alpha$ treatment than in those that would not (table 11.1). Standardized effect sizes of MDD on these baseline cytokine concentrations were 1.08, 1.16 and 1.25, respectively. Effects were independent of the a priori hypothesised confounding effects of baseline MADRS score, marijuana use or cigarette smoking.

Table II.1 Raw means (standard errors) of baseline cytokine concentrations for the patients that did and did not develop MDD during subsequent IFN-a treatment.

\begin{tabular}{|c|c|c|c|c|c|c|}
\hline \multirow[b]{2}{*}{ IL-IRA $(\mathrm{pg} / \mathrm{mI})^{\prime \prime}$} & \multirow{2}{*}{$\frac{\operatorname{MDD}(\mathrm{n}=5)}{56.4(9.1)}$} & \multirow{2}{*}{$\frac{\text { non-MDD }(n=11)}{50.2(3.5)}$} & \multicolumn{2}{|c|}{ F-value, $p$-value } & \multicolumn{2}{|c|}{$\begin{array}{c}\text { F-value, p-value (adjusted } \\
\text { for covariates) }\end{array}$} \\
\hline & & & $F=0.29$ & $p=0.6$ & $F=0.15$ & $\mathrm{p}=0.7$ \\
\hline sIL-2R (U/ml) ${ }^{8}$ & $584.2(128)$ & $288.6(53.1)$ & $F=6.03$ & $p=0.028^{6}$ & $F=5.96$ & $p=0.033^{\mathrm{s}}$ \\
\hline $\mathrm{IL}-6(\mathrm{pg} / \mathrm{ml})^{i}$ & $4.1 \quad(0,88)$ & $2.1(0.37)$ & $F=5.90$ & $p=0.030^{6}$ & $F=5.93$ & $p=0.035^{b}$ \\
\hline$s[\mathrm{~L}-6 \mathrm{R}(\mathrm{ng} / \mathrm{ml})$ & $190.2(10.4)$ & $175.5(14.0)$ & $F=0.44$ & $p=0.5$ & $F=0.04$ & $\mathrm{p}=0.9$ \\
\hline $1 \mathrm{~L}-8(\mathrm{pg} / \mathrm{m})^{\mathrm{t}}$ & $27.0(3.2)$ & $24.5(6.2)$ & $F=0.91$ & $\mathrm{p}=0.4$ & $F=0.78$ & $p=0.4$ \\
\hline $1 \mathrm{~L}-10(\mathrm{pg} / \mathrm{ml})^{\mathrm{a}}$ & $11.5(2.5)$ & $5.8(0.53)$ & $F=7.90$ & $p=0.014^{b}$ & $\mathrm{~F}=8.91$ & $p=0.012^{b}$ \\
\hline$[\mathrm{NF}-\alpha(\mathrm{pg} / \mathrm{m}])^{\mathrm{N}}$ & $19.6(2.4)$ & $17.5(1.0)$ & $F=0.74$ & $p=0.4$ & $F=1.24$ & $\mathrm{p}=0.3$ \\
\hline
\end{tabular}

"Unutransformed data are shown, data were In-transformed when for the purpose of the statistical analyses" $p<0.05$

\section{Discussion}

The results showed that higher levels of immune activation before exposure to an agent will immuno-modulatory effects puts subjects at risk for subsequent development of MDD. These findings add credence to the suggestion that increased immune activation is not just a consequence of depression, but instead exerts a true causal influence in the onset of depression since it may add to or interact with other risk factors in the causation of mood disorders.

The results indicate that further research is needed to establish whether heightened immune activation can be considered as an endophenotype for depression" "including research into the contribution of genes to personal differences in cell-mediated immune activation supplemented by work examining the frequency of immune endophenotypes in mon-affected (non-depressed) family members and the nomal population.

SIL-2R is a marker for in vivo T-cell activation ${ }^{12}$. IL-6 induces differentiation of $T$ cells and macrophages and increases IL-2 production and sIL-2R expression ${ }^{13}$. Thus, both 
stimulate cell-mediated immune activation. However, it should be noted that IL-10, an anti-inflammatory cytokine counteracting cell-mediated immune activation, was also significantly higher in the MDD compared to the non-MDD group. One explanation may be that the heightened cell-mediated immune activation triggered the antiinflammatory negative feedback $\operatorname{loop}_{s}$ involving $\mathrm{IL}-10$ production ${ }^{14}$, to dampen the immune response. Some limitations should be considered. Baseline immune activation, in this case, interacted with another major immune challenge, namely IFN- $\alpha$ treatment, in producing MDD. It is unknown whether it also interacts with other risk factors in causing depression. A further limitation of the study design is the small sample size. Further research should aim to replicate this finding in larger samples and include individuals in the four exposure cells of not only low and high baseline immune activation, but also with and without IFN- $\alpha$ treatment. 


\section{References}

1. Maes M. Evidence for an immune response in major depression: a review and hypothesis. Prog Neuropsychopharmacol Bial Psychiatry 1995;19(1):11-38.

2. Zorrilla EP, Luborsky L, McKay JR, et al. The relationship of depression and stressors to immunological assays: a meta-analytic review. Brain Behav Immun 2001,15(3):199-226.

3. Sluzewska A, Rybakowski $J$, Bosmans $E$, et al. Indicators of immune activation in major depression. Psychiatry Res 1996;64(3):161-7.

4. Mikova $O$, Yakimova $R$, Bosmans $E$, Kenis $G$, Maes $M$. Increased serum tumor necrosis factor alpha concentrations in major depression and multiple sclerosis. Eur Neuropsychopharmacol 2001:11(3):203-8.

5. Bonaccorso $S$, Marino $V$, Biondi $M_{3}$ Grimaldi F, Ippoliti $F$, Maes $M$. Depression induced by treatment with interferon-alpha in patients affected by hepatitis $\mathrm{C}$ virus. I Affect Disord $2002 ; 72(3): 237-41$

6. Dieperink $\mathbb{E}, \mathrm{Ho} \mathrm{SB}$, Thuras $\mathrm{P}$, Willenbring $\mathrm{ML}$. A prospective study of neuropsychiatric symptoms associated with interferon-alpha-2b and ribavirin therapy for patients with chronic hepatitis C. Psychosomatics 2003;44(2):104-12.

7. Hauser $\mathrm{P}$, Khosla J, Aurora $\mathrm{H}$, et al. A prospective study of the incidence and open-label treatment of interferon-induced major depressive disorder in patients with hepatitis $\mathrm{C}$. Mol Psychiatry 2002;7(9):942-7.

8. Sheehan DV, Lecrubier Y, Sheehan KH, et al. The Mini-International Neuropsychiatric Interview (M.I.N.I.): the development and validation of a structured diagnostic psychiatric interview for DSM-IV and ICD-10. J Clin Psychiatry 1998;59 Suppl 20:22-33; quiz 34-57.

9. Montgomery SA, Asberg M. A new depression scale designed to be sensitive to change. $B$ r I Psychiatry 1979;134:382-9.

10. Wichers MC, Kenis G, Koek GH, et al. Interferon-alpha-induced depressive symptoms are related to changes in the cytokine network but not to cortisol. submitted.

11. Gottesman, II, Gould TD. The endophenotype concept in psychiatry: etymology and strategic intentions. Am J Psychiaty 2003;160(4):636-45.

12. Oppenheim JJ, Ruscetti FW, Faltynek C. Cytokines. In: Stites DP, Terr AI, Parslow T, eds. Basis \& clinical immunology. Stamford, Connecticut: Appleton \& Lange, 1994: 870.

13. Nakn $T$, Nishomoto $\mathrm{N}$, Korshimoto $\mathrm{T}$. The paradigm of $\mathrm{L}$ - 6 : from basic science to medicne. Arthritis Res 2002;4 Suppl 3:\$233-42.

14. Meyaard L, Hovenkamp E, Otto SA, Miedema F. IL-12-induced LL-10 production by human $\mathrm{T}$ cells as a negative feedback for $1 \mathrm{~L}-12$-induced inmune responses. $J$ lmmmol $1996 ; 156(8): 2776-82$. 


\section{Part 3}

Genes, stress and immune function 


\section{Chapter}

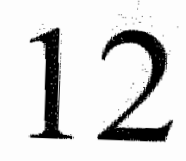

\section{Early adversity and genetic sensitivity to adult stress exposure}

Marieke Wichers, Nele Jacobs, Gunter Kenis, Philippe Delespaul, Frühling Rijsdijk, Nancy Nicolson, Catherine Derom, Robert Vlietinck, Jim van Os

Submitted 


\section{Abstract}

\section{Introduction}

Genetic and environmental risk factors may be important in determining individual variability in the stress-induced alterations in neuroendocrine and immune status that increase the risk for physical and mental health problems.

\section{Methods}

256 twin pairs, aged $18-45$ years, completed the Interview for Recent Life Events and the Childhood Trauma Questionnaire. In response to randomly timed "beeps" from a programmed wristwatch, salliwary cortisol was sampled 10 times per day for 5 consecutive days yielding Daily Average Cortisol (DAC). In addition, one saliwa sample was taken at 18.00 for the determination of IL $-6,1 \mathrm{~L}-8$ and $\mathrm{TNF}-\mathrm{N}$.

\section{Results}

Stressful life events (SLE) were negatively associated with TNF- $\alpha$ concentrations, but there was no association between SLE and DAC. High exposure to early adversity moderated these effects: in the group with high exposure to early adversity, association between SLE and TNF- $\alpha$ were stronger and a negative association between SLE and DAC became apparent. Influence of an additive genetic factor was found only for DAC, and exposure to SLE made genetic effects on DAC more apparent in the group with high levels of early adversity. Cylokines were determined by environmental factors only.

\section{Conclusion}

The adult immune and neuro-endocrine response to stress may be moderated by epigenetic changes brought about by early adverse experiences. These results await replication in adequately powered samples. 


\section{Introduction}

Persistence of stress over longer periods of time, including chronic stress caused by traumatic or other major life events, can have long-term consequences for both physical and mental health. Chronic stress is associated with increased risk for viral infections ${ }^{1,2}$, cardiovascular disease $e^{3,4}$, cancer ${ }^{5-7}$ and other health problems. Furthermore, stressful life events may play a role in the pathogenesis of anxiety and mood disorders and are known as precipitants of psychiatric illness ${ }^{8-10}$.

These effects may be mediated by the impact of stress on the immune and neuroendocrine systems. Psychological stress can down-regulate or dysregulate immune responses ${ }^{11-14}$, and impact of stress on immune function has been linked to increased vulnerability to illness ${ }^{15}$. While acute stress enhances natural and cell-mediated immunity, chronic stress has negative effects on almost all functional measures of the immune system, such as the inhibition of $T$ cell activation, antigen presentation, and production of inflammatory mediators ${ }^{16,17}$. Stress activates the hypothalamic-pituitaryadrenal (HPA) axis and the sympathetic nervous system (SNS) ${ }^{18}$ and the immune system, in turn, is able to respond to signals from the SNS and HPA axis ${ }^{19}$. Overactivity of the HPA axis has been linked to major depression. Depressed patients show increased corticotropin releasing hormone (CRH) concentrations in cerebrospinal fluid (CSF), a blunted adrenocorticotropic hormone (ACTH) response to a CRH challenge and non-suppression of cortisol secretion following administration of dexamethasone $\mathrm{e}^{20}$. Successful antidepressant treatment is associated with normalisation of the HPA axis activation ${ }^{21,22}$. Therefore, it seems likely that activation of the HPA axis has causal implications for the development of mood disorders.

The stress-reactivity hypothesis as proposed by Cacioppo ${ }^{23}$ states that heterogeneity exists between individuals in autonomic, neuro-endocrine and immune reaction in response to a stressor. According to the hypothesis, subjects with a high stress response show more extreme neuro-endocrine and immunological alterations and therefore are more at risk for the adverse consequences of chronic stress. Differential environmental and genetic influences contribute to heterogeneity in stress reactivity. Evidence for environmental influences comes from animal studies, which have shown that adverse experiences in utero or during early postnatal life (maternal separation) result in a sensitisation of HPA responses to subsequent stress $^{24,25}$. Furthermore, it has been shown that early social deprivation and maternal separation result in long-term alterations in Natural Killer (NK) cell activity ${ }^{25,27}$ and lymphocyte proliferative response $^{28,29}$ that persist through adult life in monkeys, although the direction of results differs across studies.

Apart from differential environmental influences, individuals differ in genetic vulnerability to stress-reactivity ${ }^{30}$. Thus, genetic factors and environmental risk factors may be important in determining individual vulnerability to stress-induced alterations in neuro-endocrine and immune changes that may increase the risk for physical and mental health problems. 
In this study, we examined 1) the effect of stressful life events on cortisol and cytokine concentrations in humans. A positive association between life events and cortisol concentration and a negative association between life events and cytokine concentrations was hypothesised; 2) interaction between stressful life events and trauma in early life, hypothesising that higher levels of early adversity would be associated with more extreme effects of life events on cortisol and cytokine concentrations; 3) interaction between stressful life events and genetic effects on cortisol and cytokine concentrations.

\section{Methods}

\section{Subjects}

The work presented here forms part of a longitudinal twin study on gene-environment interaction in stress-reactivity ${ }^{31,32}$. Twin pairs were all non-pregnant women aged 17-45 years. Of the 530 individuals ( 265 twin pairs) participating in the longitudinal project, 468 had collected saliva for immune parameter assessments. The great majority of twins were sampled from the East Flanders Prospective Twin Survey, which has recorded multiple births in the province of East Flanders since $1964^{33}$. Zygosity was determined by sex, placentation, blood groups and, if necessary, by examination of polymorphic DNA markers ${ }^{34}$. Zygosity of subjects recruited from other parts of Flanders was determined based on their mothers" responses to standard similarity questionnaires ${ }^{35-37}$ and, if necessary, on examination of five polymorphic DNA markers.

The study was approved by the university medical ethics committee and carried out in accordance with the Declaration of Helsinki (Hong Kong Modification, 1989). Written informed consent was obtained from each subject prior to participation.

\section{Procedures and questionnaires}

Subjects were asked to wear a digital wristwatch programmed to emit a signal ("beep") at an unpredictable moment in each of ten 90-minute time blocks between 7:30 and 22:30, for 5 consecutive days (Experience Sampling Method - ESM $^{-38-41}$ ). A saliva sample was collected at each beep during the ESM period, using a cotton swab (Salivette, Sarstedt, Etten-Leur, the Netherlands). An additional saliva sample was collected once at 18:00 for the assessment of the pro-inflammatory cytokines IL-6, IL-8 and TNF-a. Subjects were instructed to store collected swabs in the salivette tube in their home freezers until transported to the lab, where uncentrifuged samples were kept at $-20^{\circ} \mathrm{C}$ until analysis. Participants filled in two self-rating questionnaires. Life events were assessed using a list adapted from the Interview for Recent Life Events ${ }^{42}$, which measures 64 stressful life events in the past six months such as "death of child", "divorce" or "fired from work" etc. Three items were left out because they did not 
apply to the age range and the exclusively female sex of the population. For each item, subjects could respond "did happen" or "did not happen". The total score consisted of the sum of all items. Participants filled in a questionnaire based on a Dutch translation of the original 70 -item CTQ questionnaire ${ }^{43,44}$ to score the amount of early adversity. However, only the items of a more recent and shorter CTQ version ${ }^{45}$ were used and at the request of the Twin Registry, the most explicit items concerning sexual and physical abuse were omitted. The questionnaire thus consisted of 21 items with statements concerning early life experiences, such as "I felt protected" or "There was not enough food". Each item is scored 1 to 5 to the extent that subjects agree with the statement. Cronbach's alpha for this 21 item questionnaire was 0.93 . In addition, the Structured Clinical Interview for DSM-IV axis 1 disorders (SCID) was administered. Information was collected on possible confounders of salivary cytokine measurements, such as allergic reactions and infections in the past two weeks and having amalgam dental fillings.

\section{Cytokine and cortisol measurements}

For the cytokine analyses, salivette tubes were thawed at room temperature and centrifuged for $5 \mathrm{~min}$. at $1000 \mathrm{xg}$ and $10^{\circ} \mathrm{C}$. The clear saliva was transferred to an Eppendorf tube. Concentrations of cytokines in saliva were measured by enzyme linked immunosorbent assay (ELISA). A commercially available matched antibody pair for development of ELISA for IL-6 and IL-8 was obtained from BD-Biosciences (Erembodegem, Belgium) and for TNF- $\alpha$ from DiaMed-Eurogen (Turnhout, Belgium). Determinations were performed according to manufacturer's guidelines. Briefly, highbinding ELISA microtiterplates (Greiner bio-one, Alphen aan den Rijn, The Netherlands) were incubated with capture antibody (diluted in $0.1 \mathrm{M}$ sodium carbonate buffer) overnight at $4^{\circ} \mathrm{C}$. Plates were washed two times in phosphate buffered saline (PBS) $/ 0.05 \%$ Tween-20 (wash buffer), and blocked with assay diluent (provided by manufacturer) for $1 \mathrm{~h}$ at room temperature (IL-6 and $\mathrm{LL}-8$ ), or with $\mathrm{PBS} / 3 \%$ bovine serum albumin (BSA) for 1 h at $37^{\circ} \mathrm{C}$ (TNF- $\alpha$ ). After the plates were washed two times with washing buffer, standards and samples were added to the plates. Standards for lL6 and $I L-8$ were provided by the manufacturer and diluted in assay diluent. Natural human TNF- $\alpha$ (code 88/786) from NIBSC (Potters Bar, United Kingdom) served as standard for the TNF- $\alpha$ ELISA, and was diluted in PBS/1\% BSA. Samples were tested undilluted for IL- 6 and TNF- $\alpha$, but were ten times diluted in assay diluent for IL-8. Plates for IL-6 were incubated for $2 \mathrm{~h}$ at room temperature (RT) while shaking at 500 rpm; IL-8 plates for $2 \mathrm{~h}$ at RT without shaking; TNF-o plates for $2 \mathrm{~h}$ at $37^{\circ} \mathrm{C}$. After washing 5 times, plates were incubated with diluted biotinylated detection antibodies for th at RT while shaking (IL-6), or Ih at RT without shaking (IL-8), or th at $37^{\circ} \mathrm{C}$ $(T N F-\alpha)$. Plates were washed five times and incubated with streptavidin conjugated horse radish peroxidase for $30 \mathrm{~min}$. at RT (IL-6 and IL-8) or $37^{\circ} \mathrm{C}$ (TNF- $\alpha$ ). Plates were again washed five times and incubated with TMB substrate solution (BDBiosciences, Erembodegem, Belgium). After incubation for $25 \mathrm{~min}$. at RT, enzyme 
reaction was stopped by addition of $2 \mathrm{~N} \mathrm{H}_{2} \mathrm{SO}_{4}$. Absorbance was determined using a microtiterplate reader (Bio-Rad Laboratories; Veenendaal, The Netherlands) and cytokine concentration of each sample determined using the accompanying software. Assays were performed in a single run by the same operator. Detection limits were $0.7 \mathrm{pg} / \mathrm{ml}(\mathrm{IL}-6), 10 \mathrm{pg} / \mathrm{ml}$ (IL-8) and $0.3 \mathrm{pg} / \mathrm{ml}$ (TNF- $\alpha$ ). Intra-assay coefficient of variation was less then $10 \%$ for all assays.

Salivary free cortisol levels were determined in duplicate, using a time-resolved immunoassay with fluorescence detection ${ }^{46}$. The lower detection limit of the assay was $0.2 \mathrm{nmol} / 1$; mean intra- and interassay coefficients of variation were less than $10 \%$.

\section{Statistical analysis}

Data were analysed with the STATA computer program, version 8 (STATA, 2003).

As salivary cortisol was collected 10 times each day for five consecutive days, up to 50 cortisol measures were obtained for each subject. Cortisol values were In-transformed to normalize the distribution. To obtain an overall measure of cortisol secretion, mean levels for each subject were first calculated over samples taken at each of the diurnal sampling times. Daily average cortisol ${ }^{47}$ was calculated by first standardizing cortisol measures at each time of day over all subjects and then averaging the ten $z$-scores for each subject ${ }^{48}$. DAC was calculated if at least 8 out of 10 measurements were nonmissing, in order to obtain a valid summary measure. Cytokine values were also lntransformed to improve normality.

First, separate regression analyses were performed to examine individual scores of the effects of stressful life events on cortisol (DAC) and on each of the cytokines. In addition, associations between cytokine levels and DAC were examined. Multilevel random regression models were fitted, using the XTREG procedure in STATA (Statacorp, 2002). This takes into account the fact that individual observations (level 1) were clustered within twin pairs (level 2), and therefore compromising statistical independence of observations. Effect sizes of explanatory variables were expressed as regression coefficients (B) from the multilevel models. All analyses were corrected for the following a priori hypothesised confounders: age, medication for disorders of the central nervous system, allergic reactions and infections in the past two weeks, corticosteroid medication, contraceptive medication and having amalgam dental fill lings. Except for the continuous variable 'age', confounders were coded as dummy variables. For all analyses, subjects with a current DSM-III-R diagnosis of major depression based on the SCID-interview were excluded.

Second, multilevel regression analyses, as described above, were used to assess whether associations between stressful life events and the biological measures were moderated by early adversity (i.e. interaction effects). Subjects were divided into a group with "high' (coded as 1) or 'low' (coded as 0) early adversity exposure, using a median split. 


\section{Genetic Model Fitting}

In order to investigate whether associations between stressful life events and the measured biological data were moderated genetically, structural equation modelling was used ${ }^{49-5 !}$.

In the classical twin design, the differences between $M Z$ and $D Z$ intra-pair covariances provide the power to decompose the variation of a trait (individual differences) into parts caused by latent additive genetic factors ( $A$; the sum of the average effects of the individual alleles at all loci affecting the phenotype), shared (familial) environmental factors (C) and individual-specific factors ( $E$; envirommental influences that are not shared between family members) ${ }^{52}$. Maximum-likelihood parameters of the models were estimated by the Mx program ${ }^{53}$, which minimizes a goodness-of-fit statistic $\left(\chi^{2}\right)$ between observed and model-predicted variance-covariances. Raw data analysis was used to handle potential missing data problems. In this case, minus wice the loglikelihood $(-2 * \mathrm{LL})$ of the data for each observation is calculated. This implies that there is no overall measure of fit, but rather relative measures of fit, since differences in fit function between sub-models are distributed as $\chi^{2}$. The goodness-of-fit of e.g. the full ACE model is measured relative to a perfect fitting (saturated) model. In a saturated model, the maximum number of parameters is estimated to describe the correlational structure between variables. For example, for the covariance matrix in one group ( $M Z$ or $\mathrm{DZ}$ ) that would be 5 parameters: 2 variances (of twin 1 and twin2); 1 cross-twin covariance and 2 means. A non-significant $\chi^{2}$ value ( $>0.05$ ) suggests that the model is consistent with the data, and differences in $\chi^{2}$ between nested models that do not exceed the critical value for one df of 3.84 suggest that the dropped parameter is nonsignificant (at the .05 level). Confidence intervals of parameter estimates (and their explained variance) were obtained by maximum likelihood rather than standard errors $^{54}$. Before examining interactions, best-fitting genetic models for the covariate adjusted cortisol and cytokine variables were examined. First, adjusted values of the cortisol and cytokine data were obtained by regressing out variables that were significant or nearly $(\mathrm{p}<0.1)$ significant confounders of the association between cortisol and cytokine data and stressful life events, as assessed in previous regression analyses.

\section{Ordinal data analysis}

Mx provides a method for analysing categorical data by using raw ordinal maximum likelihood estimation. Essentially, the model predicts proportions of twin pairs that should exist for the various possible patterns of responses from two twins, assuning a multivariate normal distribution. Observed frequencies in each category are translated in proportions under an assumed normal distribution by estimating associated thresholds ( $z$-values). Since variances cannot be estimated when thresholds are estimated, they are constrained to unity, and the number of parameters and observed statistics per zygosity group reduces to 1 in the saturated model. Since the distribution of cytokine values was truncated due to the detection limit, the covariate regressed scores were recoded into 5 categories, with the lowest category containing all those that 
were under the detection limit. The scores showed a reasonable multiple threshold fit (i.e. no significant departures from bivariate normality).

\section{Interaction effects}

Next, interactions between genes and stressful life events in their effects on DAC and cytokines were examined. Analytically, this means examining the moderating influence of the continuous measurement of stressful life events (variable $\mathrm{M}$ ) on individual differences in DAC values and cytokine levels, i.e. the degree to which exposure to stressful life events modifies the genetic effect on phenotypic variance. This can be modelled by redefining the partial regression coefficient of the dependent variable (DAC or cytokine levels) on the latent factors so that it includes the potential effect of moderation by the variable $M$ (figure 12.1$)^{55,56}$. That is, at the level of the path coefficient, additive genetic influence can be decomposed into a mean part (a) and a moderator linked part $\left(\beta_{\mathrm{A}} \mathrm{M}_{1}\right)$. If the moderator has no effect, then $\beta_{\mathrm{A}}=0$. In addition to effects on latent variables, main effects of the moderator on DAC and cytokine are modelled to affect the means, indicated by the coefficient $\beta_{M}:\left[\left(m+\beta_{M} M_{1}\right)\left(m+\beta_{M} M_{2}\right.\right.$ ) in figure 12.1], where $m$ is the overall, moderator independent mean. Thus, a test for main moderator effects involves setting $\beta_{\mathrm{M}}$ to 0 . To test for interaction, two models were compared: one in which $\beta_{\mathrm{A}}, \beta_{\mathrm{C}}, \beta_{\mathrm{E}}$ and $\beta_{\mathrm{M}}$ were free parameters (full model) and one in which only $\beta_{C}, \beta_{E}$ and $\beta_{M}$ were estimated and $\beta_{A}$ was set to zero (test of genetic moderation). A full description of this model, including the implied covariance matrices, is available upon request ${ }^{55.56}$.

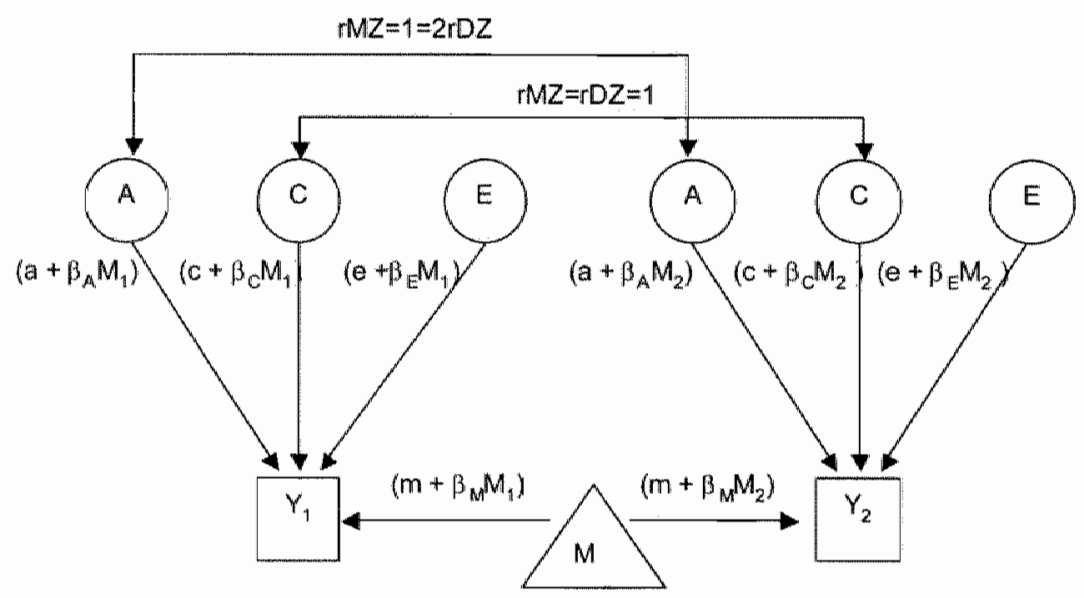

Figure 12.1 Path diagram showing a genetic twin model incorporating effects of a continuous moderator $M$. MZ: monozygotic, DZ: dizygotic, A: additive genetic influence, $C$ : shared environmental influence, $E$ : nonshared environmental influence, $M$ : individual value stressfull lufe events, $Y$ : dependent variable (cortisol or cytokine values); numbers 1 and 2 represent twin 1 and twin 2; $\beta_{\mathrm{A}}, \beta_{\mathrm{C}}, \beta_{\mathrm{E}}$ and $\beta_{\mathrm{M}}$ are the moderators of $\mathrm{A}, \mathrm{C}, \mathbb{E}$ and $M$ respectively. 


\section{Results}

\section{Subject characteristics}

of the 468 subjects who had collected additional salvia samples for the determination of immune parameters, 31 subjects were excluded because of insufficient saliva levels for assay reading and 26 subjects were exchuded because they met DSM-III-R critera for major depression. Mean age of the rest sample $(\mathrm{N}=411)$ was 26.2 years $(\mathrm{SD}=7.4$ ). Fifteen subjects were taking medication affecting the central nervous system, 38 subjects reported an allergic reaction and 64 subjects reported having had an infection within the two weeks before taking the saliva samples for determination of immune parameters. 118 subjects reported having dental fullings of amalgam ${ }_{r}$ and an additional 66 subjects did not know whether their dental hings contained amalgam or not. Corticosteroid medication and contraceptive use was reported by 253 women.

IL-6 was measurable in 382 samples, of which 54 were below the detection limit of 0.7 $\mathrm{pg} / \mathrm{ml}$. After in-transformation, 2 observations were excluded because of extreme values, leaving 326 observations (Mean $=0.84 ; \mathrm{SD}=0.8$ ). For IL $-8,405$ samples were measurable, of which 24 observations were below the detection limit of $10 \mathrm{pg} / \mathrm{ml}$ and another 6 were above the detection limit of $1200 \mathrm{pg} / \mathrm{ml}$, leaving 375 observations (Mean=4.75; $\mathrm{SD}=1.1$ ). For TNF- $\alpha, 401$ samples were neasurable, of which 216 were below the detection limit of $0.3 \mathrm{pg} / \mathrm{ml}$, leaving 185 observations (Mean $=1.78 ; \mathrm{SD}=2.1$ ). Three subjects had no cortisol data. Cortisol measurements of another four subjects were excluded from analyses because of extreme values $(z$-score $>3)$ and DAC was not calculated in six subjects because cortisol measurements were missing for more than two out of ten diumal sampling times. This resulted in 398 valid DAC values (Mean $=0.064 ; \mathrm{SD}=0.8$ ).

The Interview for Recent Life Events was completed by 404 subjects (Mean=3.39; Median $=3$; $S D=2.9$ ), with scores ranging from 0 to 18.408 subjects filled in the $C T Q$ (Mean $=34.4 ;$ Median $=31 ; \mathrm{SD}=12.1$ ), with scores ranging from 21 to 95 . Subjects were grouped into those with low and high occurrence of 1) stressful life events 2) exposure to early adversity, by splitting the distribution in two groups of similar size, in order to summarize the biological data for these separate groups (table 12.1).

\section{Associations between stress, cortisol and cytokine levels}

Regression results indicated a negative effect of stressful life events on TNF- $\alpha$ $(\mathrm{B}=-0.05, \mathrm{p}=0.024)$, but no significant effects on $\mathrm{L}-6, \mathrm{LL}-8$ or DAC. No large or significant associations were observed between cytokine concentrations and DAC values. The effect of stressful life events on TNF- $\alpha$ level remained significant after controlling for $\mathrm{DAC}(\mathrm{B}=-0.05, \mathrm{p}=0.033)$. 
Table 12.1 Means and SD's for IL-6, IL-8, TNF-a and DAC for groups with low and high.

\begin{tabular}{|c|c|c|c|c|c|}
\hline & \multirow[t]{2}{*}{ Exposure } & \multicolumn{2}{|c|}{ Reeent Life Events } & \multicolumn{2}{|c|}{ Early adversity } \\
\hline & & Mean (SD) & $\mathbb{N}$ & Mean (SD) & $\mathbb{N}$ \\
\hline \multirow[t]{2}{*}{$11-6$} & low & $0.85(0.7)$ & 149 & $0.86(0.8)$ & 161 \\
\hline & high & $0.8 \square(0.8)$ & 177 & $0.80 \quad(0.7)$ & 161 \\
\hline \multirow[t]{2}{*}{ IL -8} & low & $4.77(1.1)$ & 171 & $4.77(1.1)$ & 191 \\
\hline & high & $4.74(1.1)$ & 205 & 4.75 (1.1) & 182 \\
\hline \multirow[t]{2}{*}{$\mathbb{D N F}-\alpha$} & low & $0.22 \quad(0.8)$ & 92 & $0.19(0.8)$ & 94 \\
\hline & high & $0.13 \quad(0.9)$ & 93 & $0.16(0.9)$ & 90 \\
\hline \multirow[t]{2}{*}{$\mathrm{DAC}$} & low & $0.04(0.8)$ & 179 & $0.12(0.7)$ & 203 \\
\hline & high & $0.09 \cdot(0.7)$ & 219 & $0.002(0.8)$ & 192 \\
\hline
\end{tabular}

Exposure to Recent Life Events or Early adversity

\section{Interaction with early adversity}

When subjects were grouped into those with low and high exposure to early adversity according to the median split of the total distribution, the group with high exposure displayed a much stronger association $(B=-0.074, p=0.039)$ between stressful life events and TNF- $\alpha$ levels than those with low exposure $(B=-0.02, p=0.5)$ although the interaction did not reach statistical significance $(B=-0.063, p=0.150)$. No interactions with early adversity were found for the cytokines IL-6 and IL-8.

In the model of $\mathrm{DAC}$, a suggestive interaction was apparent between early adversity and stressful life events $(B=-0.040, p=0.076)$. The low early adversity exposure group showed a trend toward a positive effect of stressful life events on DAC values $(B=0.029, p=0.1)$, whereas the high exposure group displayed a significant negative effect $(B=-0.036, p=0.031)$.

\section{Interaction with genetic factors}

Table 12.2 shows the $\mathrm{MZ}$ and $\mathrm{DZ}$ correlations of the measured biological data. First, structural equation modelling was used to determine the best-fitting model for the cytokine levels and DAC values. For both TNF- $\alpha$ and IL-6, a CE model was the bestfitting model (table 12.3). For IL-8, neither monozygotic (MZ) nor dizygotic (DZ) correlations were significant and therefore the $\mathrm{E}$ model (in which the variance due to nonshared environment and that due to error cannot be separated from each other) showed the best fit. Because the best-fitting models did not contain a genetic component, no interaction with stressful life events was assessed. 
Within pair correlations of the measired biological parameters

\begin{tabular}{lccccc}
\hline & \multicolumn{2}{c}{ MZ } & N (MZ pairs) & $\mathrm{DZ}$ & N(DZ prairs) \\
\hline IL-6 & 0.22 & $\mathrm{p}=0.04^{\mathrm{a}}$ & 95 & $0.37 \mathrm{p}=0.007^{\circ}$ & 51 \\
LL-8 & 0.13 & $\mathrm{p}=0.2$ & 105 & $0.07 \mathrm{p}=0.6$ & 58 \\
INF-a & 0.22 & $\mathrm{p}=0.03^{\mathrm{a}}$ & 102 & $0.29 \mathrm{p}=0.03^{\mathrm{a}}$ & 56 \\
$\mathrm{DAC}$ & $0.62 \mathrm{p}<0.001^{\mathrm{a}}$ & 103 & $0.47 \mathrm{p}=0.001^{\mathrm{a}}$ & 54 \\
\hline
\end{tabular}

s $p<0.05$

The within-pair correlations of DAC values for $\mathrm{MZ}$ and $\mathrm{DZ}$ twin pairs were 0.62 and 0.47 , respectively, and the $\mathrm{AE}$ model (table 12.3) was found to represent the best compromise between goodness of fit and parsimony $(-2 \mathrm{LL}=1041.729$, df $=382)$. It could not be shown that this model was significantly better than the CE model $(-2 \mathrm{LL}=1042.330, \mathrm{df}=382)$.

Table 12.3 Univariate model fitting results of the measured biological parameters

\begin{tabular}{|c|c|c|c|c|c|c|c|c|c|}
\hline \multirow[t]{2}{*}{ Madel } & \multirow[t]{2}{*}{$-2 L L$} & \multirow[t]{2}{*}{ Df } & \multirow[t]{2}{*}{$y 2^{\circ}($ (ati) } & \multirow[t]{2}{*}{ 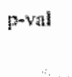 } & \multirow[t]{2}{*}{$\Delta \times x^{2 b}(\mathrm{df})$} & \multirow[t]{2}{*}{$p-$-wal } & \multicolumn{2}{|c|}{ Standardized Estimanes (95\% CD) } & \multirow[b]{2}{*}{$\mathrm{E}$} \\
\hline & & & & & & & $A$ & $\mathrm{c}$ & \\
\hline \multicolumn{10}{|l|}{$\| L-6$} \\
\hline Safturated & 1163.046 & 354 & $\cdot$ & - & - & - & & & \\
\hline ACE: & 1177.602 & 362 & $14.56(8)$ & 0.099 & - & - & $1.00[-6,(0-0.41)$ & $0.26(0.0 .42)$ & $0.74(0.97-0,92)$ \\
\hline CE: & 1177.6003 & 3.63 & $14,5649)$ & 0.14 & $0.01(1)$ & 1,0 & - & $0.26(0,0 \%-0,42)$ & $0.7400 .5800 .92)$ \\
\hline E & $1: 185.6699$ & 364 & $22.56(10)$ & 0.01 & $8.00(2)$ & 0.02 & - & 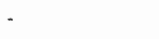 & $1(1-1)$ \\
\hline \multicolumn{10}{|l|}{$\mathbb{H L}-\mathbf{s}$} \\
\hline Saturated & 1237.101 & 385 & $*$ & - & - & - & & & \\
\hline$A C E$ & 1246.585 & 393 & $9.48(8)$ & 0.42 & - & - & $0.11(0-0.3)$ & $0.01(0-0.26)$ & $0.88(0.69-1)$ \\
\hline $\mathrm{AE}$ & 1246.592 & 39.4 & $9.49(9)$ & 0.52 & $0.0101(1)$ & 1.0 & $0.12(0-0.31)$ & $\cdots$ & $0.88(0.62 \%-1)$ \\
\hline $\mathrm{E}$ & 1248.137 & 395 & 1.1.04 (10) & 0.47 & $1.55(2)$ & 0.73 & . & - & $1(1+1)$ \\
\hline \multicolumn{10}{|l|}{ TNF-C } \\
\hline Safqurataed & $\$ 99.102$ & 3.71 & - & - & 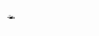 & . & & & \\
\hline $\mathrm{ACE}$ & 1012.062 & 379 & $12,96(8)$ & 0.116 & & & 9. $395-6(0)-(0)$ & $0.34(0.0 .51)$ & $0.66(0.490066)$ \\
\hline$C E$ & 1012.062 & 980 & 12969 & 0.23 & & & - & $0.34(0.14 \times 0.51)$ & $0.66(0.49-48.86)$ \\
\hline $\mathrm{E}$ & 1023.028 & 381 & $23.25(10)$ & 0.006 & & & . & - & $1(1-1)$ \\
\hline \multicolumn{10}{|l|}{ DAC } \\
\hline Saturated & 1033.945 & 375 & . & - & - & - & & & \\
\hline $\mathrm{ACE}$ & 1039.98 .5 & 381 & 6.040463 & 0.57 & & & $0.31 \cdot(0-0.69)$ & $0.290-0.61)$ & $0.30(0.300 .52)$ \\
\hline$M E$ & 1041729 & 382 & $7.78(7)$ & 0.49 & $1.74(1)$ & 9.46 & $0.62(0.50-0.71)$ & 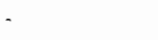 & $0.38(0.290,50)$ \\
\hline $\mathrm{CE}$ & 1042.330 & 382 & $8.79(7)$ & 0.42 & $2.35(1)$ & 0.31 & . & $0.55(0.44-0.65)$ & $0.45(0,35-0,56)$ \\
\hline $\mathrm{E}$ & 1102.344 .4 & 383 & $68.40(8)$ & 0.000 & $62.40)$ & 0.090 & . & . & $1(1+1)$ \\
\hline
\end{tabular}

${ }^{a}$ Difference in at conapared to saturated modet: ${ }^{\text {b }}$ Difference in fit compared to lull model

However, the $\mathrm{AE}$ model was chosen because $\mathrm{MZ}$ and $\mathrm{DZ}$ correlations and previous literature $^{57}$ both suggest a genetic component. Subsequently, it was examined whether stressful life event scores moderated the genetic effect on DAC values. The test of moderation was not significant (table 12.4). However, because previous regression 
analyses had suggested that the effect of stressful life events on DAC values depended on exposure to early adversity, analyses were stratified according to low and high early adversity exposure. In the high early adversity exposure group, but not the low early adversity exposure group, a positive interaction was apparent. The model that included a moderator of genetic influences on DAC showed a better fit than the one without (table 12.4). This means that for the high early adversity group, higher scores on stressfull life events made genetic effects on DAC values more apparent.

Table 12.4 Model comparison for continuous stressful life events exposure and interaction with DAC values.

\begin{tabular}{|c|c|c|c|c|}
\hline & Model & $\begin{array}{l}-2 \text { Log Likelihood } \\
\text { (df) }\end{array}$ & $\begin{array}{c}\text { model difference } \\
\text { chi-sq (df) }\end{array}$ & $P$ \\
\hline $\begin{array}{l}\text { Interaction of stressful life } \\
\text { events and genetic influences on }\end{array}$ & $\begin{array}{l}A E-\beta_{A} \cdot \beta_{E}-\beta_{M} \\
\text { (full model) }\end{array}$ & 862.861 & - & - \\
\hline DAC values & $\begin{array}{l}\text { AE- } \beta_{E} \cdot \beta_{M} \\
\text { (test moderation of A) }\end{array}$ & 866.195 & $3.334(1)$ & 0.2 \\
\hline $\begin{array}{l}\text { Interaction of stressful life } \\
\text { events and genetic influences on }\end{array}$ & $\begin{array}{l}\mathrm{AE}-\beta_{\mathrm{A}} \cdot \beta_{\mathrm{E}-} \beta_{\mathrm{M}} \\
\text { (full model) }\end{array}$ & 446.334 & $=$ & \\
\hline $\begin{array}{l}\text { DAC values." LOW score on } \\
\text { early adwersity }\end{array}$ & $\begin{array}{l}\mathrm{AE}-\beta_{\mathrm{E}} \beta_{\mathrm{M}} \\
\text { (test moderation of } \mathrm{A} \text { ) }\end{array}$ & 446.880 & $0.546(1)$ & 0.8 \\
\hline $\begin{array}{l}\text { Interaction of stressful life } \\
\text { events and genetic influences on }\end{array}$ & $\begin{array}{l}A E-\beta_{\mathrm{A}} \cdot \beta_{\mathrm{E}} \beta_{\mathrm{M}} \\
\text { (full model) }\end{array}$ & 221.137 & - & \\
\hline $\begin{array}{l}\text { DAC values: HIGH score on } \\
\text { early adversity }\end{array}$ & $\begin{array}{l}\mathrm{AE}-\beta_{E} \beta_{\mathrm{N}} \\
\text { (test moderation of } \mathrm{A} \text { ) }\end{array}$ & 227.355 & $6.218(1)$ & $0.01^{\mathrm{s}}$ \\
\hline
\end{tabular}

$p<0.05$

\section{Discussion}

Stressful life events were associated with reduced TNF- $\alpha$ values. This effect was stronger in the group that exhibited high levels of early adversity. Second, stressfull life events showed no main effect on DAC values. However, stressful life events and early adversity seemed to interact in their effect on DAC values. Contrary to expectation, stressful life events showed a negative effect on DAC values in subjects with high levels of early adversity, while in subjects with low levels of early adversity a positive albeit non-significant effect was apparent. Third, variation in cytokine levels was influenced by environmental factors only. Finally, there was positive gene-environment interaction in that in the high early adversity group, greater genetic influence on variation in DAC was observed in the group with higher levels of exposure to stressful life events. 


\section{Life event-early adversity interactions}

Stress alters some aspects of immune and endocrine function. The finding that life events, as a measure of more chronic stress, decreased TNF- $\alpha$ is in accordance with previous findings ${ }^{17,58}$. The current study suggests that these effects are dependent in part on genes and on early adversity. The effects of early life stress on immune function were in line with our expectations: the group with high levels of early adversity showed more extreme alterations, which may put this group more at risk for the negative health consequences of stress. For the effect of stress on cortisol measurements, a different pattern was found. Since stress is known to activate and sensitise HPA axis function ${ }^{18}$, an even stronger positive association, instead of the reported negative one, was expected between stressful life events and DAC values in the high compared to the low early adversity group. Nonetheless, in the past a number of studies have reported lower cortisol concentrations ${ }^{59,60}$ or enhanced cortisol suppression in response to dexamethasone ${ }^{61}$ in subjects with PTSD. Furthermore, in women with high levels of early life stress in the context of childhood abuse, a diminished production of cortisol in response to an ACTH challenge has been reported ${ }^{62}$. However, these women exhibited exaggerated ACTH responses to either a psychosocial stressor or $\mathrm{CRH}^{62,63}$, suggesting that hypocortisolism in these subjects represents an end organ (adrenal gland) adaptation to a sensitised response to stress at the level of the pituitary and/ or the hypothalamus $(\mathrm{CRH})^{64}$.

\section{Stress-gene interactions}

A potentially important finding is the large influence of shared and nonshared environmental factors on the cytokine concentrations for TNF- $\alpha$ and IL- 6 . In the past, only two reports ${ }^{65,66}$ have examined the influence of genetic and environmental influences on immune parameters in the context of psychosocial distress and depression. These also focussed on the importance of shared environmental factors, such as exposure to common antigenic stimuli, on current immunity as well as that of nonshared environmental factors, such as infection or stress affecting only one twin. However, in contrast to the current study, other work showed evidence of a heritability factor in other immune parameters, such as IL-10 production after LPS stimulation in whole blood ${ }^{67}$ and for the $\mathrm{CD} 4: \mathrm{CD} 8 \mathrm{~T}$ cell ratio and $\mathrm{CD} 3+, \mathrm{CD} 4+$ and $\mathrm{CD} 8+$ cell counts $^{68}$. Different immune parameters may be differentially subject to genetic influences and/or genetic influence on immune parameters may only become apparent after LPS stimulation-induced activation of intracellular signalling pathways and transcription factors that coordinate the induction of genes encoding inflammatory products. Since in the current study we initially found no evidence of a genetic effect on the cytokines, interactions with stress were not further tested.

For the daily average cortisol measurements, however, high exposure to stressful life events resulted in higher genetic loading on cortisol values. These findings suggest that stressful life events increase the expression of genes associated with cortisol regulation. Since this effect was found only in the group with high early adversity, it can be 
hypothesised that early adversity "primes", through epigenetic mechanisms, the potential of gene expression to react to stressful events. These results are compatible with evidence suggesting that the combination of (epi)genetics, early life stress, and ongoing stress may ultimately determine individual responsiveness to stress. Thus, it is known that early adversity can lastingly alter gene expression, which subsequently may determine sensitivity to the experience of stress later in life ${ }^{69}$, for example by influencing the expression of molecular determinants of cellular plasticity within selected brain regions 30 . These findings may thus reflect an accumulation of "allostatic load" in the high trauma group, i.e. the cumulative changes in body and brain that develop in response to the process of adaption to events in daily life (allostasis) ${ }^{71}$,

\section{Methodological issues}

Since glucocorticoids are immunosuppressive, changes in immune function may be attributable to changes in cortisol. In the current study, however, no associations were found between cytokine concentrations and DAC values, and the effect of stress on TNF- $\alpha$ remained significant after controlling for DAC values. In addition, since stress in the high early adversity group was associated with decreased DAC values one would have expected increased immune activation in this group. That cortisol does not mediate the suppressive effects of stress on the immune system has been reported before $^{72,73}$. It can be concluded that at least some of the effects of stress on immune function are mediated by another mechanism. A possible mechanism may be the activation of the sympathic nervous system. Since immune cells have receptors for the catecholamines epinephrine and norepinephrine, the neurotransmitters released in response to stress by the SNS have the potential to alter immune function ${ }^{19}$.

Unfortunately, since cytokines are more difficult to detect in saliva than in blood samples, the measurements, especially that of TNF-a, showed a large percentage of samples with values below the detection limit. Therefore, ordinal maximum likelihood estimation was used for the model fitting analyses. The regression analyses did not take into account the missing data. TNF $\alpha$ analyses were therefore performed again using ordinal regression analysis, which yielded similar results. "The possibility exists that, although accounted for in the analyses, the missing data still biased our results. However, it could only have biased our data in the case that these undetectable low TNF- $\alpha$ were highly associated with low levels of stressful life events. No other mechanism than pure chance can be conceived by which such a selection could have taken place.

In addition, the sample was cross-sectional and does therefore not allow us to draw causal inferences, although this does not apply to effects of early adversity.

The DAC gene-enviromment interaction analyses were based on the AE model of DAC. However, the $C E$ and $A E$ model did not show much difference in fit. It therefore remains possible that in reality the $C E$ model is better and that the observed interaction with genetic factors in this study actually reflects an interaction with common envitonmental influences, although we consider this less likely. Also, the number of 
whole pairs on which this interaction effect is based was reduced because of the selection for individuals scoring high or low on early adversity, leaving only 44 complete pairs $(34 \mathrm{MZ}$ and $10 \mathrm{DZ}$ ). Until replication in a larger sample size can be obtained, the reported interaction should be interpreted as hypothesis-generating.

There was no lack of power to detect effects of stressful life events on cytokine and cortisol concentrations. Given a sample size of 180 (for TNF- $\alpha$ ), 318 (for IL-6) 368 (for IL-8) and 391 (for DAC) we had a power above $95 \%$ at conventional alpha level $(5 \%)$ in the regression analyses to detect an effect of life events, with an explained variance of $3 \%$. For the main effects tested by structural equation models, the power to detect a genetic influence of $30 \%$, given a sample size of 384 observations, was less at $63 \%$. In addition, the interaction analyses are likely underpowered as they generally require four times the sample size required to detect main effects ${ }^{74}$. This might explain the fact that the early adversity $\mathrm{x}$ stress interaction effects on cytokines and cortisol did not reach statistical significance. Nevertheless, results of the interaction analyses may be useful for the generation of new hypotheses for further research.

Genetic influences on cortisol and cytokine measurements were estimated based on the assumption that differences between $\mathrm{MZ}$ twins are determined completely by environmental factors, since they share $100 \%$ of their genes. However, this is not necessarily true. Discordance between identical twins may also be determined by epigenetic factors, such as X chromosome inactivation in females, operating on genetic expression $^{75}$.

Finally, future studies should try to measure a more complete range of both pro- and anti-inflammatory cytokines in order to obtain a more complete picture of current immune functioning. 


\section{References}

1. Cohen S, Doyle WJ, Skoner DP. Psychological stress, cytokine production, and severity of upper respiratory illness. Psychosom Med 1999;61(2):175-80.

2. Cohen S, Tyrrell DA, Smith A.P. Psychological stress and susceptibility to the common cold. N Engl J Med 1991;325(9):606-12.

3. Black PH, Garbutt LD. Stress, inflammation and cardiovascular disease. Joumal of psychosomatic research 2002;52:1-23.

4. Rozanski A, Bllumenthal IA, Kaplan J. Impact of psychological factors on the pathogenesis of cardiovascular disease and implications for therapy. Circulation 1999;99(16);2192-217.

5. Thomas BC, Pandey M, Ramdas K, Nair MK. Psychological distress in cancer patients: hypothesis of a distress model. Eur J Cancer Prev 2002;1 1(2):179-85.

6. Bryla CM. The relationship between stress and the development of breast cancer: a literature review. Oncol Nurs Forum 1996;23(3);441-8.

7. Yang EV, Glaser R. Stress-induced immunomodulation: Implications for tumorigenesis. Brain Behav Irmmun 2003; 17 Suppl 1:S37-40.

8. Kendler KS, Karkowski LM, Prescott CA. Causal relationship between stressful life events and the onset of major depression. Am J Psychiatry 1999;156(6):837-41.

9. van Os J, Jones PB. Early risk factors and adult person--environment relationships in affective disorder. Psychol Med 1999;29(5):1055-67.

10. van Os J, Park SB, Jones PB. Neuroticism, life events and mental health: evidence for person-environment correlation. BrJ Psychiatry Suppl 2001;40:s72-7.

11. Song $C$, Kenis $G$, van Gastel $A$, et al. Influence of psychological stress on immuneinflammatory variables in normal humans. Part 11. Altered serum concentrations of natural anti- inflammatory agents and soluble membrane antigens of monocytes and $T$ Iymphocytes. Psychiatry Res 1999;85(3):293-303.

12. Maes $M$, Hendriks $D$, Van Gastel. $A$, et al. Effects of psychological stress on serum immunoglobulin, complement and acute phase protein concentrations in normal volunteers. Psychonewoendocinology 1997;22(6);397-409.

13. Glaser R, MacCallum RC, Laskowski BF, Malarkey WB, Sheridan JF, Kiecolt-Glaser JK. Evidence for a shift in the Th-1 to Th-2 cytokine response associated with chronic stress and aging. $J$ Gerontol A Biol Sci Med Sci 2001;56(8):M477-82.

14. Bawer ME, Vedhara $K$, Perks $P$, Wilcock GK, Lightman SL, Shanks N. Chronic stress in caregivers of dementia patients is associated with reduced lymphocyte sensitivity to glucocorticoids. I Neuroimmunol 2000; $103(1) ; 84-92$.

15. Yang EV, Glaser R. Stress-induced immunomodulation and the implications for health. Int Immunopharmacol 2002;2(2-3):315-24.

16. Zorrilla EP, Luborsky L, McKay JR, et al. The relationship of depression and stressors to immunological assays: a meta-analytic review. Brain Behav Immun 2001;15(3):199-226.

17. Segerstrom SC, Miller GE. Psychological stress and the human immune system: a meta* analytic study of 30 years of inquiry. Psychol Bull 2004:130(4):601-30.

18. Miller DB, OCaltaghan JP. Neuroendocrine aspects of the response to stress. Metabolism 2002;51:(6 Suppl 1):5-10.

19. Besedovsky HO, del Rey A. Immune-neuro-endocrine interactions: facts and hypotheses. Endoct Rev 1996;17(1):64-102.

20. Checkley S. The neuroendocrinology of depression and chronic stress. Br Med Bull 1996,52(3):597-617.

21. Rowe W, Steverman A, Walker $M$, et al. Antidepressants restore hypothalamic-pituitaryadrenal feedback function in aged, cognitively-impaired rats. Neurobiol Aging 1997;18(5): 527-33. 
22. Barden N, Reul JM, Holsboer F. Do antidepressants stabilize mood through actions on the hypothalamic- pituitary-adrenocortical system? Trends Newrosef 1995;18(1):6-11.

23. Cacioppo JT, Berntson GG, Malarkey WB, et al. Autonomic, neuroendochine, and immune responses to psycholagical stress: the reactivity hypothesis. Am NYAcad Sci 1998;840: 664-73.

24. Fride E, Dan $Y$, Feldon J, Halevy G, Weinstock $M$. Effects of prenatal stress on vulnerability to stress in prepubertal and adult rats. Physio Behan 1986;37(5):681-7.

25. Plotsky PM, Meaney MJ. Early, postnatal experience alters hypothalamic corticotropinreleasing factor (CRF) mRNA, median eminence CRF content and stress-induced release in adult rats. Brain Res Mol Brain Res 1993;18(3):195-200.

26. Lewis MH, Gluck JP, Petitto JM, Hensley LL, Ozer H. Early social deprivation in nonhuman primates: long-term effects on survival and cell-mediated immunity. Biol Psychiatry 2000;47(2):119-26.

27. Lubach $G R$, Coe $C_{\text {, }}$ Ershler WB. Effects of early rearing environment on immune responses of infant thesus monkeys. Brain Behav Immun 1995;9(1):31-46.

28. Coe CL, Lubach GR, Ershler WB, Klopp RG. Influence of early rearing on lymphocyte proliferation responses in juvenle rhesus monkeys. Brain Behav Immun 1989;3(1):47-60.

29. Laudenslager M, Capitanio JP, Reite M. Possible effects of early separation experiences on subsequent immune function in adult macaque monkeys. Am $J$ Psychiatry 1985;142(7): 862-4.

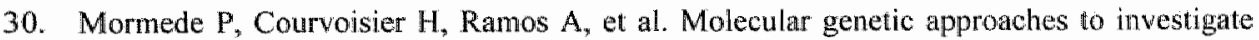
individual variations in behavioral and neuroendocrine stress responses. Psychoneuroendocrinology 2002;27(5):563-83.

31. Jacobs N, Myin-Germeys I, Nicolson NA, Derom C, Delespaul P, van Os J. Affective and neuroendocrine sensitivity to daily life stress. subrnitied.

32. Jacobs $N_{*}$ Rijsdijk $F$, Myin-Germeys 1 , et al. A new paradigm in Behaviour Genetics: Genotype-environment interaction in the flow of daily life. submitted.

33. Loos $R$, Derom $C$, Vllietinck $R$, Derom $R$. The East Flanders Prospective Twin Survey (Belgium): a population-based register. Twin Res 1998;1(4):167-75.

34. Derom $C$, Bakker $E$, Vlietinck $R$, et al. Zygosity deternination in newborn twins using DNA variants. J Med Genet 1985;22(4):279-82.

35. Christiansen L, Frederiksen $H$, Schousboe K, et al. Age- and sex-differences in the validity of questionnaire-based zygosity in twins. Twin Res 2003;6(4):275-8.

36. Peeters $H$, Van Gestel $S$, Vlietinck $R$, Derom C, Derom R. Validation of a telephone zygosity questionnaire in twins of known zygosity. Behav Genet 1998;28(3): 159.63.

37. Spitz E, Moutier R, Reed T, et al. Comparative diagnoses of twin zygosity by SSLP variant anallysis, questionnaire, and dermatoglyphic analysis. Behav Gener 1996;26(1):55-63.

38. Delespaul P. Assessing schizophrenia in daily life. Maastricht: Universitaire pers Maastricht, 1995.

39. DeVries MW. The experience of psychopathology: investigating mental disorders in their natural settings. Cambridge: Cambridge university press, 1992.

40. Larson R, Csikszentmihalyi $M$. The experience sampling method. New directions for methodology of social and behavional science 1983(15):41-56.

41. Csikszentmihalyi M, Larson $R$. Validity and reliability of the Experience-Sampling Method. INerv Ment Dis 1987;175(9):526-36.

42. Paykel ES. The Interwiew for Recent Life Events. Psychol Med 1997;27(2):301-10.

43. Arntz A, wessel 1. Jeugd Trauma Vragenligst (Dutch version of the Childhood Trauma Questionnaire). Maastricht, 1996.

44. Bernstein DP, Fink L, Handelsman L, et al. Initial reliability and validity of a new retrospective measure of child abuse and neglect. Am J Psychiary 1994;151(8):1132-6. 
45. Bernstein DP, Ahluvalia T, Pogge D, Handelsman L. Validity of the Childhood Trauma Questionnaire in an adolescent psychiatric population. $I$ An Acad Child Adolesc Psychiatry $1997 ; 36(3): 340-8$.

46. Dressendorfer RA, Kirschbaum C, Rohde W, Stahl F, Strasburger CI. Synthesis of a cortisol-biotin conjugate and evaluation as a tracer in an immunoassay for salivary cortisol measurement. I Steroid Brochem Mol Biol 1992;43(7):683-92.

47. Gunnar MR, Morison SJ, Chisholm K., Schuder M. Salivary cortisol levels in children adopted from romanian orphanages. Dev Psychopathol 2001;13(3):611-28.

48. Nicolson NA. Childhood parental loss and cortisol levels in adult men. Psychoneuroendocrinology $2004,29(8): 1012-8$.

49. Neale MC, Heath $\mathrm{AC}$, Hewitt JK, Eaves $\mathrm{LJ}$, Fulker DW. Fitting genetic models with LISREL: hypothesis testing. Behav Genet 1989;19(1):37-49.

50. Sham PC. Statistical methods in psychiatric genetics. Stat Methods Med Res 1998;7(3): 279-300.

51. Rijsdijk FV, Sham PC. Analytic approaches to twin data using structural equation models. Brief Bioinform 2002;3(2):119-33.

52. Neale $M C$, Cardon LR. Methodology for genetic studies of twins and families. Dordrecht: Kluwer academic publishers, 1992.

53. Neale MC, Boker SM, Xie G, Maes HH. Mx: Statistical modeling. 5th ed. Box $126 \mathrm{MCV}$, Richmond: Va 23298: Department of Psychiatry, 1999.

54. Neale $\mathrm{MC}_{\mathrm{m}}$ Miller $\mathrm{MB}$. The use of likelihood-based confidence intervals in genetic models. Behav Genet 1997;27(2):113-20.

55. Purcell $\mathrm{S}$. Variance components models for gene-environment interaction in twin analysis. Twin Res 2002;5(6):554-71.

56. Wichers MC, Purcell S, Danckaerts M, et al. Prenatal life and post-niatal psychopathology: evidence for negative gene-birth weight interaction. Psychol Med 2002;32(7):1 165-74.

57. Bartels M, Van den Berg M, Sluyter F, Boomsma DI, de Geus EJ. Heritability of cortisol levels: review and simultameous analysis of twin studies. Psychonewroendocrinology $2003 ; 28(2): 121-37$.

58. Bartolomucci A, Palanza P, Parmigiani $S$, et al. Chronic psychosocial stress down-regulates central cytokines mRNA. Brain Res Bull 2003;62(3):173-8.

59. Rohleder $N$, Joksimovic L, Wolf $\mathrm{JM}$, Kirschbaum C. Hypocortisolism and increased glucocorticoid sensitivity of pro-Inflammatory cytokine production in Bosnian war refugees with posttraumatic stress disorder. Biol Psychiary 2004;55(7):745-51.

60. Luecken LJ, Dausch B, Gulla V, Hong R, Compas BE. Alterations in moming cortisol associated with PTSD in women with breast cancer. I Psychosom Res 2004;56(1):13-5.

61. Yehuda R, Halligan SL, Golier JA, Grossman R, Bierer LM. Effects of trauma exposure on the cortisol response to dexamethasone administration in PTSD and major depressive disorder. Psychonewroendocrinology 2004;29(3):389-404.

62. Heim C, Newport DJ, Bonsall R, Miller AH, Nemeroff CB. Altered pituitary-adrenal axis responses to provocative challenge tests in adult survivors of childhood abuse. $A m J$ Psychiatry 2001;158(4);575-81.

63. Heim $\mathrm{C}$, Newport DJ, Heit S, ef al. Pituitary-adrenal and autonomic responses to stress in women after sexual and physical abuse in childhood. Jama 2000;284(5):592-7.

64. Raison CL, Miller AH. When not enough is too much: the role of insufficient glucocorticoid signaling in the pathophysiology of stress-related disorders. Am w Psychiamy
$2003 ; 160(9): 1554-65$.

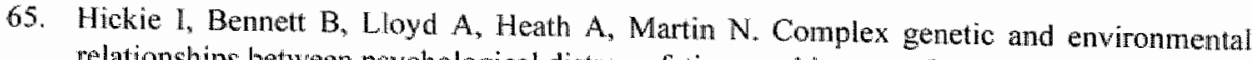
relationships between psychological distress, fatigue and immune functioning: a twin study. Psychol Med 1999;29(2):269-77. 
66. Hickie IB, Bansal AS, Kirk KM, Lloyd AR, Martin NG. A twin study of the etiology of prolonged fatigue and immune activation. Twin Res 2001;4(2);94-102.

67. Reuss $E$, Fimmers R, Kruger A, Becker $C$, Rittner $C$, Hohler $T$. Differential regulation of interleukin-10 production by genetic and environmental factors-a him study. Genes limmun 2002;3(7):407-13.

68. Hall MA, Ahmadi KR, Norman $P$, et al. Genetic influence on peripheral blood $T$ lymphocyle levels. Genes Immum 2000;1(7):423-7.

69. Caspi A, Sugden K, Moffitt TE, et al. Influence of life stress on depression: moderation by a polymorphism in the 5-HTT gene. Science 2003;301(5631):386-9.

70. Roceri M, Hendriks W, Racagni G, Ellenbroek BA, Riva MA. Early maternal deprivation reduces the expression of BDNF and NMDA receptor subunits in rat hippocampus. Mol Psychiatry 2002;7(6):609-16.

71. McEwen BS. Mood disorders and allostatic load. Biol Psychiaty 2003;54(3):200-7.

72. Garland MR, Lavelle $E_{y}$ Doherty $D$, et al. Cortisol does not mediate the suppressive effects of psychiatric morbidity on natural killer cell activity: a cross-sectional study of patients with early breast cancer. Psychol Med 2004;34(3):48 1-90.

73. Miller GE, Cohen S, Ritchey AK. Chronic psychological stress and the regullation of proinflammatory cytokines: a glucocorticoid-resistance model. Health Psychol 2002;21(6): $531-41$.

74. Breslow N, Day N. Statistical Methods in Cancer Research, Volume I: The analysis of Case-Control studies. New York: Oxford University Press, Inc., 1994.

75. Salvetti M, Ristori G, Bomprezzi R, Pozzilli P, Leslie RD. Twins" mirrors of the immune system. Imwunol Today 2000;21(7);342-7. 


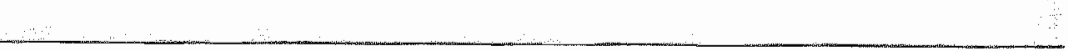




\section{Chapter 13}

General discussion 
Shapter 1 


\section{General discussion}

Many biological, genetic and social risk factors are involved in the aetiology of depression. This thesis was written in order to gain more insight in the risk factors of depression, the pathophysiology and the complex interactions between risk factors that may lead to increased vulnerability. It is now clear that there is not just one cause, but many component causes that may bring about changes in biological systems in a way that predisposes subjects to depression.

\section{Genes, environment and child psychopathology}

Several studies have shown that the intrauterine environment may be of major importance in its contribution to the development of later physical ${ }^{1-3}$ and mental problems ${ }^{4,5}$. As described in the introduction, corticosteroids and cytokines may pass the placenta and influence systemic regulation of the foetus' physiology and have a long-lasting impact since they may interfere with normal development of the neuroendocrine and immune system. Previous studies ${ }^{6-8}$ as well as the study reported in this thesis show that birth weight (being small for gestational age) is associated with increased psychopathology. Since 1) child psychopathology is correlated with depresssion and other mental problems in adulthood ${ }^{6,9,10}$ 2) depression in adulthood is also associated with birth weight ${ }^{4,11,12}$ and 3) plausible biological mechanisms exist that explain the relationship between low birth weight and later mental disorders ${ }^{5,13,14}$, it may be postulated that low birth weight acts as a shared risk factor to both child psychopathology and psychopathology in adulthood with the same underlying biological pathophysiology. Therefore, knowledge about the impact of genetic and environmental factors may be of great significance to adult psychopathology. A new aspect presented in this thesis was the insight into gene-birth weight correlation and interaction. Chapter 4 showed that within-pair birth weight discordance predicts discordance in child psychopathology, with no evidence for interaction with zygosity. Genetic differences within DZ pairs did not contribute to within pair differences in psychopathology. Therefore, it was concluded that gene-environment correlation plays no role and that birth weight is a causal environmental risk factor for child psychopathology. A more recent study ${ }^{8}$ examined effects of birth weight and family loading of uni- or bipolar disorder on psychopathology in children of bipolar parents. The results are in concordance with our study in that birth weight and family loading of unipolar disorder were each independently associated with psychopathology. Family loading did not modify the association between birth weight and psychopathology. The information that birth weight acts as a causal environmental risk factor is important, since it implies that prenatal stress and undernutrition are indeed likely candidates at the beginning of a cascade of events and interactions that lead to increased vulnerability to mental disorder, and do not represent epiphenomena. However, some caution is warranted. Although resuits in this thesis and the study by Wals et al. ${ }^{8}$ exclude the possibility that genetic factors influence both birth weight and psychopathology and act 
as a possible confounder for the association, it cannot be ruled out that another, environmental factor, such as matenal life style, acts as a third variable influencing the other two. Another possibility is that birth weight interacts with genetic factors in the risk for child psychopathology. Chapter 5 describes a gene-birth weight interaction in which the association between genetic factors and child psychopathology is modified by exposure to low birth weight. Increased exposure to low birth weight resulted in less genetic influence on child psychopathology. Therefore, it seems that birth weight and genetic factors are both causal to, and compete with each other in bringing about child psychopathology. This explanation fits well with the idea of allostatic load in that the accumulation of vulnerabilities may lead to the development of a disease. If subjects are more exposed to the risk factor that low birth weight represents, they may not need much additional genetic vulnerabillity develop a mental disorder. On the other hand, if subjects exhibit high genetic vulnerability, they may develop psychopathology also when they have no, or less, additional exposure to low birth weight:

One of the methodological problems in twin research is that the assumption of equal environments between $\mathrm{MZ}$ and $\mathrm{DZ}$ twins can be questioned, since $\mathrm{MZ}$ may share more of their intrauterine environment than $\mathrm{DZ}$ twin pairs. Since the prenatal environment may be a significant factor in the development of later mental disease, violation of this assumption may cause substantial problems in the interpretation of twin data. Difference in chorionicity is assumed to be the major inducer of intrauterine differences between $M Z$ and $D Z$ twins, since chorionicity is associated with degree of sharing of the same placenta (nutrition) and blood supply as a result of vascular anastomoses in the monochorionic placenta ${ }^{15,16}$. In this thesis, the effect of chorionicity on child psychopathology was examined (Chapter 2). Since no effect of chorionicity was detected on the outcome of psychopathology it seems plausible to assume that chorionicity differences did not confound our results and that variance components were rightly distributed to either genetic or environmental causes.

Structural equation modelling of twin data is a method that provides information on how much variance in the outcome variable can be attributed to either genetic, shared or nonshared environmental factors. However, two remarks can be made. As mentioned in the introduction, the nonshared environmental component contains also error of measurement, which means that the pure effect of the nonshared enviromment cannot be adequately calculated. Second, instead of knowing that something is caused by either genes or enviromment or the interaction between these two, it is as important to know what environmental risk factor or what gene is involved. In this thesis, nonshared environment was directly measured and associated with child psychopathology. More jealousy, sibling antagonism, matemal or paternal control, peer delinquency and less peer college orientation, compared to his or her sibling, was associated with externalising behaviour. Less peer popularity, less peer delinquency and more jealousy was related to internalising behaviour. In addition, jealousy, maternal affection and less peer popularity was related specifically to the dimension of depression. The majority of these relations were not genetically mediated (implicating that gene-environment 
correlation does not play a role in mediating the association), except for the associations between less peer delinquency with internalising symptoms and matemal affection with depression. However, since this concerns a cross-sectional study we camnot readily conclude that these aspects of the nonshared environment cause the reported differences in behaviour. The study gives no information on the direction of effect. For example, it is equally logical to conclude that having externalising symptoms provokes more matemal and paternal control instead of the other way around. Also, the association between peer popularity and depression may be bidirectional, although it appears very plausible that less peer popularity induces depression. Being unpopular can be considered as a major social stressor ${ }^{17.19}$ which is likely to impact on vulnerability to depression. The explanation that some genetic factor influences both peer popularity and depression is also plausible, but can be excluded since no genetic mediation was found for this association. Longitudinal studies should be performed to get insight into direction of effects.

Apart from examining environmental risks, current research efforts also move more into the direction of specific gene targeting. Variants of certain polymorphisms have been identified that are associated with increased depressive symptoms. These concern gene polymorphisms coding for the 5-HT transporter ${ }^{20}$, neurotrophin receptor p $75^{21}$, muscarinic acetylcholine receptor $\mathrm{M}^{22}$ and the proinflammatory cytokines $\mathrm{IL}-1 \beta^{23,24}$ and $T N F-\alpha^{25}$, and others. A recent molecular study reports a gene-environment interaction $^{26}$ in the causation of depression. Subjects with the short allele variant of the 5-HT transporter were more prone to developing depression when exposed to stressful life events than those with the long allele variant. Knowledge about the biological determinants of psychopathology is needed in order to make hypotheses about the genes involved in the specific disorder and possible treatment strategies. In this thesis, the pathophysiology of depression was further examined, in more specific terms: the rolle of immune activation in the development of depressive symptoms.

\section{Is immune activation causally related to depressive symptoms?}

In this thesis, we tried to find evidence for the involvement of the immune system in the pathophysiology of depression. The notion that immune activation increases susceptibility to depressive symptoms has biological plausibility. Since the immune system has multiple bi-directional links with the HPA axis and the 5-HT system, it could be argued that it would be illogical to assume that immune imbalance would nor have any effect on aspects of central regulation of experience, including mood. In addition, it fits in with the finding that low birth weight increases risk for depression. This association may arise due to the effect of prenatal stress on HPA ax is functioning. but permanent changes in immune functioning after prenatal stress may also contribute to the vullnerability for depression.

Another argument in favour of a supposed role of immune activation in depression is that physical diseases in which the immune system is involved often tend to co-occur with mood disturbance, more than other kinds of chronic physical diseases. Vascular 
disease (coronary heart disease and chronic heart failure) is associated with increased rates of depressive symptoms ${ }^{27-30}$. The co-occurrence may results from a shared pathophysiology involving immune activation". A twin study showed that this association was partly explained by common genetic factors ${ }^{32}$. Depression is associated as well with inflammatory bowel disease (IBD) ${ }^{33.35}$, rheumatoid arthritis ${ }^{36,37}$, multiple sclerosis $^{38}$ and epilepsy ${ }^{38}$. Furthermore, depressed patients show increased concentrations of CRP, pro-inflammatory cytokines ${ }^{39-41}$. LPS-induced production of pro-inflammatory cytokines ${ }^{42,43}$ and other inflammatory mediators ${ }^{44}$. In addition, selective serotonin reuptake inhbitors (SSRIs) exhibit anti-inflammatory effects ${ }^{45}$.

Although the above mentioned findings suggest that the hypothesis of immune activation contributing to depressive symptoms is plausible, most data merely show cross-sectional associations between depression and immune activation, and provide few arguments for causality. Prospective studies on changes in cytokines related to depressive symptoms are very scarce. An alternative explanation could be that depression increases immune activation instead of the other way around, explaining the fact that depressed patients show increased cytokine concentrations and that depression may contribute to risk for the onset of inflammatory diseases. Efferent vagus nerve stimulation inlhibits the production of pro-inflammatory cytokines in peripheral organs, such as the liver, heart and spleen ${ }^{6 / 6}$. It could be postulated that the state of depression causes an impaiment in efferent vagus nerve signalling, thereby increasing peripheral inflammation as an epiphenomenon. However, considering immune activation as a non-causal side effect of depression does not explain the fact that experimentallyinduced immune activation, for example in IFN- $\alpha$ treatment, has been shown to increase depressive symptoms. Many studies have examined the depressive effect of IFN- $\alpha$ treatment ${ }^{47.52}$ and, although there are differences in the reported percentage of patients that develop depression during treatment, there is agreement on the fact that some biological mechanism induced by IFN- $\alpha$ must be responsible for the subsequent mood changes. Recently, one study ${ }^{53}$ reported on the increase in cytokine concentrations in relation to depressive symptoms. In this thesis, it was similarly shown that an increase in the concentrations of three cytokines with pro-inflammatory actions (IL-2R, TNF- $\alpha$ and IL-6), was associated with an increase in depressive symptoms over the course of treatment. Subsequently, the mechanism by which cytokines could affect mood changes was examined. We could not find any evidence for the notion that cytokine-induced HPA axis activation was responsible for the development of depressive symptoms. The hypothesis that an IFN- $\alpha$ - induced decrease in TRP availability to the brain, causing decreased central 5-HT synthesis, induced depressive symptoms was also not supported, since the ratio between TRP and competing amino acids did not decrease during treatment. Important, however, was the finding that the ratio between kynurenine (KYN), which is metabolised for the greatest part into toxic metabolites (quinolinic acid and 3-hydroxykynurenine), relative to kynurenic acid (KA), which has neuroprotective properties, increased during treatment. Furthermore, this sign of increased neurotoxicity was associated with increased depressive symptoms 
over the course of treatment. These findings support the following hypothesis: IFN $\alpha$ increases concentrations of other pro-inflammatory cytokines. These activate the enzyme IDO, which converts TRP into $\mathrm{KYN}$. The altered balance in neurotoxicity caused by the toxic $\mathrm{KYN}$ metabolites relative to the neuroprotective metabolite $\mathrm{KA}$, is then thought to induce depressive symptoms.

Some critical marks can be made regarding the investigation of depressive symptoms in IFN- $\alpha$ treatment. First, one could argue that rates of depression increase because depression rating scales contain items of appetite, sleep problems, energy etc. Since most patients undergoing treatment are feeling flu-like, in particular during the first week, this may influence the ratings on a depression scale. Cytokines are inducers of fever in case of infection and also cause symptoms people experience during illness (sickness behaviour) that resemble the vegetative symptoms of depression, such as changes in appetite, sleeping pattern and energy/motivation ${ }^{54}$. However, this is not a likely explanation for the increase in depressive symptoms reported during IF $N-\alpha$. treatment. In chapter 8 , it is shown that flu-like symptoms were reported mostly in the first week of treatment, while reported 'depressive feelings' increased only later during treatment. In addition, we separated vegetative from cognitive symptoms. Indeed, a direct increase in vegetative symptoms was observed already in the first week of treatment, which probably reflects the direct action cytokines have on sickness behaviour. However, later during treatment, cognitive-depression symptoms developed, in addition to the vegetative-depressive symptoms, leading to a total MADRS score that shows the highest score only 8 weeks after starting treatment. Therefore, flu-like symptoms are no plausible explanation for the research findings concerning depression during $\rrbracket$ FN $-\alpha$ treatment.

A second point of discussion concerns the fact that immune activation is experimentally induced in these subjects, which may have different etiological implications with regard to depression, than naturally occurring immune activation. This type of immediate immune challenge might exert other effects on bodily systems than a naturally occurring increase in immune activation would have. For research concerning the aetiology of depression it is important to know whether naturally occurring inflammation also puts subjects at risk for the development of depression. In the current thesis, (Chapter 11), we showed that this was indeed the case. Naturally occurring immune activation, at baseline, was prospectively linked to the development of depression during IFN- $\alpha$ treatment. A question that is not yet answered is whether naturally occurring inflammation only increases risk for depression when the subsequent stressor is another immune challenge or whether it also increases risk in interaction with other kinds of stressors.

Another remark is that immume activation does not need to be causal to all kinds of depression. It is likely that there are multiple pathways leading to the development of depression, only some of which may primarily involve the immune system. A dysfunctional 5-HT system and/or HPA axis regulation may also lie at the beginning of vulnerability to mood disorders. What would be the final biological dysfunction that is 
determining depressive outcome, if there is one? From the current thesis we may infer that increased neurotoxicity is a likely candidate. An interesting bypothesis is that other social and biological risk factors also impact on the balance of neurodegeneration/ neuroprotectivity and thereby increase the risk for depression. This hypothesis will be examined in more detail below.

\section{Accumulation of allostatic load throughout life}

The current scientific knowledge suggests that dysfunctions in the 5-HT system, the HPA axis and the immune system are all involved in aspects of the pathophysiology of depression. Already in prenatal life, individuals may be exposed to events that increase the risk for later depression.

Prenatal stress, including malnutrition, has been shown to impact on corticosteroid, brain 5-HT and cytokine levels. Risk factors, such as low birth weight, are therefore thought to increase vulnerability through the effects of malnutrition on these biological systems, interfering with normal development. The same reasoning applies to stress during child- and adulthood. Early stress significantly increases the risk for later depression, and additional exposure to adult stress may render subjects even more vulnerable. One would hypothesize that exposure to both early and current stress would cause even greater disturbance in biological systems. In Chapter 12, the effect of early and current stress on cortisol and cytokines was examined. Furthermore, gene-stress and early-current stress interactions in the effect on the biological parameters were examined. Chronic current stress was associated with a decrease in concentrations of the pro-inflammatory cytokine TNF- $\alpha$, and this effect was stronger for subjects with high levels of early stress. Chronic current stress was also associated with lower cortisol concentrations. However, this was true only for subjects with high levels of early stress. Genetic influence on cortisol was found and for subjects with high levels of early stress, current stress affected genetic influence on cortisol. Early stress seems to "prime" the potential of gene expression to react to stressful events.

From all knowledge available and from the current results one can conclude that very complex gene-environment interactions are operating in bringing about depression. During the whole life course trajectory individuals may be exposed to risk factors, which have the greatest effect most early in life and which continuously interact with genetic factors. "Together they increase vulnerability" through accumulation of biological changes, called allostatic load ${ }^{55,56}$.

Chapter 12 raised some issues, however. Current stress affected cortisol negatively in subjects exposed to high levels of early life stress. Apparently, HPA axis response to stress is changed in exposed subjects. It could be argued that the expectation would be for a sensitised HPA axis resulting in increased cortisol secretion. However, in depression, mixed results have been reported: increased as well as decreased cortisol concentrations. In trauma exposure, most literature suggests lower cortisol levels. Probably, not all kinds of stress result in exactly the same adaptive changes of the various types of receptors at the various levels (hypothalamus, pituitary gland and 
adrenal gland), involved in the HPA axis function. Also, impact of stress on the HPA axis may differ depending on the subject's age ${ }^{57-59}$. Therefore, early stress may induce different receptor changes than later stress and the final outcome, as measured by cortisol levels, may thus differ depending on the exact adaptive changes at each level.

Second, the negative association reported between chronic current stress and TNF- $\alpha$ is in accordance with other studies that have shown a negative effect of chronic stress on immune activation. However, if the hypothesis is correct that stress increases risk for depression through its effect on immune function, then this result does not fit within the notion that increased immune activation enhances vulnerability to depression. The associations between stress, depression and immune activation should therefore be further clarified in future research.

\section{Future directions}

As mentioned in the last paragraph, it is unclear whether immune functioning is a mediating factor between stress and risk for depression. Chronic stress deregulates the immune system in another way than depression does. One possibility, of course, is that immune function plays no role and is not the mediating factor. However, since evidence accumulates that immune function is instrumental in mood disorders, other hypotheses should also be examined. It may be hypothesized that subjects vulnerable to depression (because of genetic or environmental factors) already have an HPA axis, 5-HT system and/or immune system functioning in a somewhat different way than other subjects. It is possible that they are vulnerable because they react differently to stress. Their system may be primed in a way that immune activation increases in response to stress, which would make the difference with non-vulnerable subjects in whom immune activation decreases in similar circumstances. This hypothesis is worthy of further investigation in the future. Second, from the current results one could hypothesize, as mentioned above, that neurotoxicity is the biological change responsible for the development of depressive symptoms (figure 13,1).

In this thesis, we saw that immune activation may cause depressive symptoms through its effect on neurotoxicity. Neurotoxicity could be the common factor that is affected by all other biological systems and risk factors. The HPA axis may induce neurotoxicity since glucocorticoids increase excitatory amino acid concentrations in hippocampal synapses, causing NMDA receptor overstimulation ${ }^{60}$. However, complete elimination of GCs by adrenalectomy leads to apoptotic loss of dentate granule neurons ${ }^{61}$. Therefore, both pathologic hypersecretion and hyposecretion can be damaging to the hippocampus ${ }^{60}$. The serotonergic system influences the neurotoxicity/protectivity balance as well. 5-HT controls functions in brain development such as neurite outgrowth, synaptogenesis and cell survival ${ }^{62}$; it also promotes the survival of neurons in the adult brain by protecting neurons against excitotoxic and ischemic injury in animal models ${ }^{63,64}$. 5-HT and brain-derived neurotrophic factor (BDNF) stimulate each other and function in a collaborative 
manner to regulate neuronal plasticity and survival ${ }^{63}$. Furthermore, prenatal, early infe stress and adult stress in rats decreases neurogenesis in adulthood ${ }^{66-68}$.

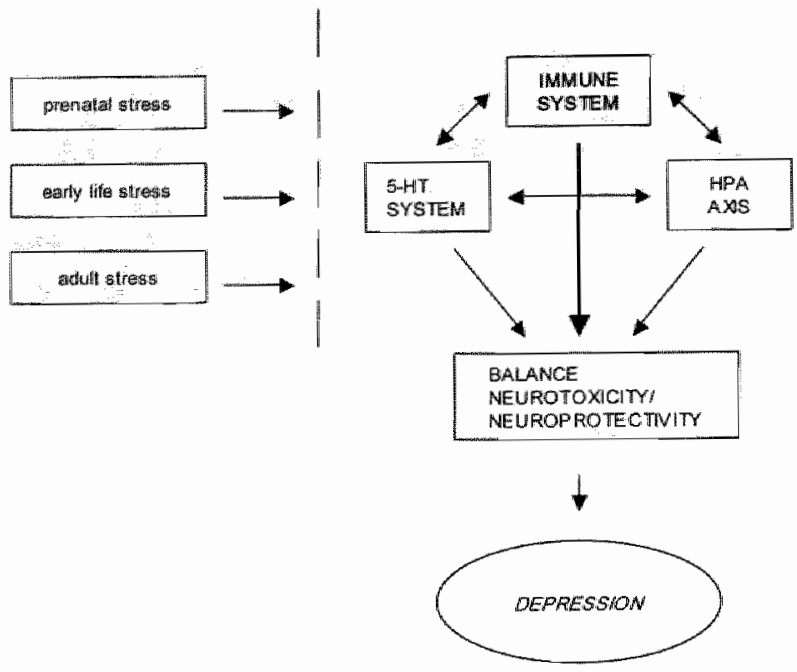

Figure 13.1 Prenatal, early life and adult stress affect the balance between the immune and 5-HT systems, as well as the HPA axis. Imbalance in these biological systems increases the neurotoxicity/neuroprotectivity balance, resulting in depressive symptoms.

The hypothesis that neurotoxicity is causal in the development of depressive symptoms should be firther investigated. Genetic factors that affect vulnerability to neurotoxicity may play role in the risk for depression. Genes hypothesized to be involved in the above-mentioned vulnerability are, for example, the short variant of the 5-HT transporter, since it may affect 5-HT concentrations which function neuroprotectively, as well as functional variants of the IL-1 $\beta$ and TNF- $\alpha$ genes associated with increased production of these cytokines, since immune activation would be increased thus favouring the balance towards neurotoxicity. Also, the role of the vitamin D receptor polymorphism ( $(a q)$ ) that is associated with increased susceptibility to infection ${ }^{69}$, should be examined. Vitamin. D activates neuroprotective mechanisms that may attenuate injuries caused by oxidative stress ${ }^{70}$. For some of these polymorphisms, studies have been done showing associations with depressive symptoms ${ }^{20,23-25}$. It is likely that GE interaction plays a role in that subjects vulnerable to neurotoxicity, because of their genetic make-up, are more prone to developing depression after exposure to stress. Therefore, it would be interesting to examine whether exposure to stress interacts with these polymorphisms in inducing neurotoxicity and depression.

Finally, in this thesis, we showed that increased 'naturally occuring' immune activation predicted prospectively the development of depression during IFN-a treatment. However, the sample size was rather small and the subjects were patients infected with 
the hepatitis $\mathrm{C}$ virus. Replication of the finding that immune activation can predict future depressive symptoms should be a priority for future research. However, a larger sample size must be used and healthy individuals, for example first degree relatives of patients with a heritable infectious disease and presumed higher baselune levels of immune activation, should participate to examine if immune activation in natural circumstances can predict the occurrence of depressive symptoms. 


\section{References}

1. Barker OJ. The developmental origins of adult disease. Eur J Epidemiol 2003;18(8):733-6.

2. Poulter NR. Birthweights, maternal cardiovascular events, and Barker hypothesis. Lancet $2001 ; 357(9273): 1990-1$.

3. Warner JA, Jones CA, Jones AC, Wamer JO. Prenatal origins of allergic disease. $J$ Allergy Clin Immunol 2000;105(2 Pt 2):\$493-8.

4. Brown AS, wan Os J, Driessens C, Hoek HW, Susser ES. Further evidence of relation between prenatal famine and major affective disorder. Am J Psychiatry 2000;157(2):190-5.

5. Bertram $\mathrm{CE}$, Hanson MA. Prenatal programming of postnatal endocrine responses by glucocorticoids. Reproduction 2002;124(4):459-67.

6. Salgal S, Pinelli $J$, foult L, Kim MM, Boyle M. Psychopathology and social competencies of adolescents who were extremely low birth weight. Pediarrics 2003;111(5 Pt 1):969-75.

7. Eatton WW, Mortensen $\mathrm{PB}$, Thomsen $\mathrm{PH}$, Frydenberg M. Obstetric complications and risk for severe psychopathology in childhood. J Autism Dev Disord 2001; 31 (3):279-85.

8. Wals M, Reichart CG, Hillegers $M H$, et all. Impact of birth wieight and genetic liability on psychopathology in children of bipolar parents. I Am Acad Child Adolesc Psychiatry 2003;42(9):1116-21.

9. Wilcox HC, Anthony JC. Child and adolescent clinical features as forerunners of adultonset major depressive disorder; retrospective evidence from an epidemiological sample. $J$ Affect Disord 2004;82(1):9-20.

10. Mason WA, Kosterman $R$, Hawkins JD, Herrenkohl TI, Lengua LJ, McCauley $E$. Predicting depression, social phobia, and violence in early adulthood from childhood behavior problems. I Am Acad Child Adolesc Psychiatry 2004;43(3):307-15.

11. Gale CR, Martyn $\mathrm{CN}$. Birth weight and later risk of depression in a national birth cohort. $\mathrm{Br}$ $J$ Psychiatry 2004;184:28-33.

12. Patton GC, Coffey $\mathrm{C}$, Carlin JB, Olsson CA, Morley R. Prematurity at birth and adolescent depressive disorder. Br I Psychiatry 2004; 184:446-7.

13. Hampton $T$. Fetal environment may have profound long-term consequences for health. Jama 2004;292(11):1285-6.

14. Urakubo A, Jarskog LF, Lieberman JA, Gilmore JH. Prenatal exposure to maternal infection alters cytokine expression in the placenta, amniotic fluid, and retal brain. Schizophr Res 2001;47(1):27-36.

15. Foley DL, Neale MC, Kendler KS. Does intra-uterine growth discordance predict differential risk for adult psychiatric disorder in a population-based sample of monozygotic twins? Psychiat Genet 2000;10(1):1-8.

16. Reed T, Pfefferbaum A, Sullivan EV, Carmelli D. Influences of chorion type on measurements of the corpus callosum in adult monozygotic male twins? Am a Hum Biol $2002 ; 14(3): 338-46$.

17. Bjorkquist K. Social defeat as a stressor in humans. Physiol Behow 2001;73(3):435-42.

18. Okayasu T, Takayama I. Psychological stress of victims and bullies in junior high school. Japanese Joumal of Educational Psychology 2000;48(4):410-421.

19. Nangle DW, Erdley CA, Newman JE, Mason CA, Carpenter EM. Popularity, friendship quantity, and friendship quality: interactive influences on children's loneliness and depression. I Clin Child Adolesc Psychol 2003;32(4):546-55.

20. Ogilvie AD. Battersby $\mathrm{S}$, Bubb VJ, et al. Polymorphism in serotonin transporter gene associated with susceptibility to major depression. Lancet 1996;347(9003):731-3.

21. Kunugi H, Hashimoto R, Yoshida M, Tatsumi M, Kamijima K. A missense polymorphism (S205L) of the low-affinity neurotrophin receptor p75NTR gene is associated with depressive disorder and attempted suicide. Am J Med Gener 2004;129B(1):44-6. 
22. Wang JC, Hinrichs AL, Stock $\mathrm{H}$, et al. Evidence of cominon and specific genetic effects: association of the muscarinic acetyloholine receptor M2 (CHRM2) gene with alcolnol dependence and major depressive syndrome. Hum Mol Genet 2004, 13(17):1903-11.

23. MoCulley MC, Day IN, Holmes C. Association between interleukin 1-beta promoter ( -511 ) polymorphism and depressive symptoms in Alzheimer's disease. Am $J$ Med Genet B Neuropsychiatr Genet 2004:124(1):50-3.

24. Rosa $A_{3}$ Peralta V, Papiol S, et al. Interleukin-I beta (IL-Ibeta) gene and increased risk for the depressive symptomi-dimension in schizophrenia spectrum disorders. Am I Med Genet B Newropsychiats Genet 2004;124(1):10-4.

25. Jun TY, Pae CU, Hoon H, et al. Possible association between -G308A tumour necrosis factor-alpha gene polymorphism and major depressive disorder in the Koream population. Psychiatr Genet 2003;13(3):179-81.

26. Caspi A, Sugden $\mathrm{K}$, Moffitt TE, et al. Influence of life stress on depression: moderation by a polymorphism in the 5-HTT gene. Science 2003;301(5631):386-9.

27. Joynt $\mathrm{KE}$, Whellan $\mathrm{DJ}, \mathrm{O}^{\prime} \mathrm{Com}$ or $\mathrm{C} \mathrm{M}$. Why is depression bad for the failing heart? $\mathrm{A}$ review of the mechanistic relationship between depression and heart failure. $J$ Card Fail $2004 ; 10(3): 258-71$.

28. Thomas AJ, Kalaria RN, O'Brien JT. Depression and vascular disease: what is the relationship? I Affect Disord 2004;79(1-3):81-95.

29. Mast BT, Neufeld S, MacNeill SE, Lichtenberg PA. Longitudinal support for the relationship between vascular risk factors and late-life depressive symptoms. Am I Geriat Psychiatry 2004;12(1):93-101.

30. Schins A, Honig A, Crijns H, Baur L, Hamulyak K. Increased coronary events in depressed cardiovascular patients: 5-HT2A receptor as missing link? Psychosom Med 2003;65(5):729-37.

31. Wirleitner $B$, Rudzite $V$, Neurauter $G_{3}$, et al. Immune activation and degradation of tryptophan in coronary heart disease. Eur J Clin Invest 2003;33(7):550-4.

32. Scherrer JF, Xian H, Bucholz KK, et al. A twin study of depression symptoms, hypertension, and heart disease in middle-aged men. Psychosom Med 2003;65(4):548-57.

33. Kurina LM, Goldacre MJ, Yeates D, Gill LE. Depression and anxiety in people with inflammatory bowel disease. J Epidemiol Community Health 2001;55(10):716-20.

34. Elsehety A, Bertorini TE. Neurologic and neuropsychiatric complications of Crohn's disease. Souh Med J 1997;90(6):606-10.

35. Mittermaier $\mathrm{C}$, Dejaco $\mathrm{C}$, Waldhoer $\mathrm{T}$, et al. Impact of depressive mood on relapse in patients with inflammatory bowel disease: a prospective 18-month follow-up study. Psychosom Med 2004;66(1):79-84.

36. Zautra AJ, Yocum DC, Villanueva I, et al. Immune activation and depression in women with rheumatoid arthritis. I Rhenmatol 2004;31(3):457-63.

37. Dickens $C$, Jackson J, Tomenson B, Hay E, Creed F. Association of depression and rheumatoid arthritis. Psychosomarics 2003;44(3):209-15.

38. Patten SB, Beck CA, Williams JV, Barbui C, Metz LM. Major depression in multiple sclerosis: a population-based perspective. Neurology 2003;61(11):1524-7.

39. Sluzewska A, Rybakowski J, Bosmans. E, et al. Indicators of immune activation in major depression. Psychiatry Res 1996;64(3):161-7.

40. Tuglu C. Kara SH, Caliyurt O, Vardar E, Abay E. Increased serum tumor necrosis factoralpha levels and treatment response in major depressive disorder. Psychopharmacology (Berl) $2003 ; 170(4): 429-33$.

41. Hestad KA, Tonseth S, Stoen CD, Ueland T, Aukrust P. Raised plasma levels of tumor necrosis factor alpha in patients with depression: normalization during electroconvulsive therapy. $J$ Ect 2003; 19(4): 183-8. 
42. Suarez EC, Krishnan RR, Lewis JG. The relation of severity of depressive symptoms to monocyte-associated proinflammatory cytokines and chemokines in apparenty healthy men. Psychosom Med 2003;65(3):362-8.

43. Suarez EC, Lewis JG, Krishnan RR, Young KH. Enhanced expression of cytokines and chemokines by blood monocytes to in vitro lipopolysaccharide stimulation are associated with hostility and severity of depressive symptoms in healthy women. Psychonewroendocrinology $2004 ; 29(9): 1119-28$.

44. Maes M. Evidence for an immene response in major depression: a review and hypothesis. Prog Neuropsycho-pharmacol Biol Psychiatry 1995;19(1): 1. 1-38.

45. Kenis $\mathrm{G}$, Maes $M$. Effects of antidepressants on the production of cytokines. Im $J$ Neuropsychophamacol $2002 ; 5(4): 401-12$.

46. Tracey KJ. The inflammatory reflex. Nature 2002;420(6917):853-9.

47. Capuron L, Gumnick JF, Musselman DL, et al. Neurobehavioral Effects of Interferon-alpha in Cancer Patients. Phenomenology and Paroxetine Responsiveness of Symptom Dimensions. Neuropsychopharmacology 2002,26(5),643-52.

48. Trask PC, Paterson AG, Esper P, Pau J, Redman B. Longitudinal course of depression, fatigue, and quality of life in patients with high risk melanoma receiving adjuwant interferon. Psychooncology 2004;13(8):526-36.

49. Hauser P, Khosla J, Aurora H, et al. A prospective study of the incidence and open-label treatment of interferon-induced major depressive disorder in patients with hepatitis C. Mol Psychiatry 2002;7(9):942-7.

50. Dieperink E, Ho SB, Thuras P, Willenbring ML. A prospective study of neuropsychiatric symptoms associated with interferon-alpha-2b and ribavirin therapy for patients with chronic hepatitis C. Psychosomatics 2003;44(2):104-12.

51. Horikawa $N$, Yamazaki $T$, Izumi $N$, Uchihara $M$. Incidence and clinical course of major depression in patients with chronic hepatitis type $\mathrm{C}$ undergoing interferon-alpha therapy: a prospective study. Gen Hosp Psychiatry 2003;25(1):34-8.

52. Bonaccorso S, Marino V, Biondi M, Grimaldi F, Ippoliti F, Maes M. Depression induced by treatment with interferon-alpha in patients affected by hepatitis $\mathrm{C}$ virus. $J$ Affect Disord 2002; $72(3): 237-41$.

53. Bonaccorso S, Puzella A, Marino V, et al. Immunotherapy with interferon-alpha in patients affected by chronic hepatitis $\mathrm{C}$ induces an intercorrelated stimulation of the cytokine network and an increase in depressive and anxiety symptoms. Psychiatry Res 2001;105:4555 .

54. Kelley KW, Bluthe RM, Dantzer $\mathrm{R}_{\text {" }}$ et al. Cytokine-induced sickness behavior. Brain Behav Immin 2003;17(1 Suppl):112-8.

55. McEwen BS. Mood disorders and allostatic load. Biol Psychiatry 2003;54(3):200-7.

56. McEwen BS, Wingfield JC. The concept of allostasis in biology and biomedicine. Horm Behav $2003 ; 43(1): 2-15$.

57. Reul JM, Rothuizen J, de Kloet ER. Age-related changes in the dog hypothalamic-pituitaryadrenocortical system: neuroendocrine activity and corticosteroid receptors. I Sferoid Biochent Mol Biol 1991:40(1-3):63-9.

58. Rohleder N, Kudielka BM, Hellhammer DH, Wolf JM, Kirschbaum C. Age and sex steroid-related changes in glucocorticoid sensitivity of pro-inflammatory cytokine production after psychosocial stress. I Neumoimmunol 2002;126(1-2):69-77.

59. Maines LW, Keck BJ, Dugar A, Lakoski JM. Age-dependent loss of corticosterone modulation of central serotonin 5-HTIA receptor binding sites. I Neurosci Res 1998;53(1):86-98.

60. Sapolsky RM. Glucocorticoids and hippocampal atrophy in neuropsychiatric disorders. Arch Gen Psychiarry 2000;57:925-35. 
61. Sloviter RS, Valiquette G, Abrams GM, et al. Selective loss of hippocampal granule cells in the mature rat brain after adrenalectomy. Science $1989 ; 243(4890) 535-8$.

62. Gaspar $P$, Cases $O$, Maroteaux L. The developmental role of serotonin: news from mouse molecular genetics. Nar Rev Newrosci 2003;4(12):1002-12.

63. Semkova 1, Wolz P, Krieglstein J. Neuroprotective effect of 5-HTI A receptor agonist, Bay $X$ 3702, demonstrated in vitro and in vivo. Eur J Pharmacol 1998;359(2-3):251-60.

64. Duan $W$, Guo $Z$, Jiang $H$, et al. Paroxetine retards disease onset and progression in Huntingtin mutant mice. Ann Neurol 2004;55(4):590-4.

65. Mattson MP, Maudsley S, Martin B. BDNF and 5-HT: a dynamic duo in age-related neuronall plasticity and neurodegenerative disorders. Trends Neurosci 2004;27(10):589-94.

66. Lemaire V, Koehl M, Le Moal M, Abrous DN. Prenatal stress produces learning deficits associated with an inhibition of neurogenesis in the hippocampus. Proc Natl Acad ScI US A 2000;97(20):11032-7.

67. Mirescu C, Peters JD, Gould E. Early life experience alters response of adult neurogenesis to stress. Nat Neurosci 2004;7(8);841-6.

68. Malberg JE, Duman RS. Cell proliferation in adult hippocampus is decreased by inescapable stress: reversal by fluoxetine treatment. Neuropsychopharmacology $2003 ; 28(9): 1562-71$.

69. Simmons JD, Mullighan $\mathrm{C}$, Welsh $\mathrm{Kl}$, Jewell DP. Vitamin D receptor gene polymorphism: association with Crohn's disease susceptibility. Gut 2000;47(2):211-4.

70. Chen KB, Lin AM, Chiu TH. Systemic vitamin D3 attenuated oxidative injuries in the locus coeruleus of rat brain. Ann N Y Acad Sci 2003;993;313-24; discussion 345-9. 
Summary 


\section{Summary}

Exposure to stressors in the intrauterine environment, in early childhood or in adulthood, but also genetic make-up, can make subjects vulnerable to depression, since environmental and genetic factors impact on biological systems that are linked to the regulation of mood. Evidence is accumulating that the immune system is implicated in the pathophysiology of depression. Mechanisms by which immune activation leads to depressive symptoms are examined, as well as effects of prenatal stress on psychopathology in children, effects of early life and adult stressors on biological systems linked to depression and the interaction with genetic factors.

Chapter 1 is a general introduction to this thesis and outlines the scientific background of the hypotheses and research designs. The epidemiology and risk factors of depression are described. Furthermore, twin methodology and structural equation modelling are explained as well as the concepts of gene-environment interaction and correlation. In addition, a short introduction is given concerning the biological determinants of depression, the role of immune activation in depression and impact of stressors on the hypothalamic-pituitary-adrenal (HPA) axis, immune system and the serotonergic system.

In Chapter 2 the effect of zygosity and chorionicity on child psychopathology was assessed in a twin study. Prenatal environments of monozygotic (MZ) and dizygotic (DZ) twins are not similar, because a higher proportion of $M Z$ twins than $D Z$ twins share their chorion. Therefore, estimates of heritability may be unreliable. However, we found no significant effect of chorionicity on child psychopathology, which suggest that it does not confound estimates of genetic and environmental contributions.

In Chapter 3 a twin study on the associations between nonshared environment and child psychopathology is described. A direct measure of the nonshared environment (the Sibling Inventory of Differential Experience - SIDE) was used and associations with child psychopathology were tested for genetic mediation. Results revealed significant associations between SIDE dimensions on the one hand, and degree of internalising, externalising, depression and total symptom scores on the other. There was no strong evidence for genetic mediation of associations between nonshared environment and symptoms. We concluded that genetically unconfounded relationships may exist between nonshared environment on the one hand and behavioural differences on the other, although longitudinal data are necessary to determine the direction of effects.

Chapter 4 examines whether low birth weight constitutes a causal risk factor for child psychopathology. If, within-pair birth weight discordance predicts discordance for child psychopathology, then a causal explanation is likely. In addition, when birth weight discordance predicts discordance for psychopathology in the same degree for both $\mathrm{MZ}$ and $\mathrm{DZ}$ twins, the mechanism whereby birth weight affects childhood 
psychopathology is likely to be causal and environmentall. Results showed that lower birth weight was a continuous risk factor for later child psychopathology and that greater within-pair birth weight discordance was associated with greater within-pair psychopathology discordance, which was similar in $\mathrm{MZ}$ and $\mathrm{DZ}$ twins. We concluded that birth weight is a causal and environmental risk factor for child psychopathology.

Pregnancy and birth complications (PBCs) are environmental. risk factors for child psychopathology. Chapter 5 examined the possibility of gene-environment interaction in a twin design. Using structural equation modeling, ACE models assuming additive genetic (A), shared environmental (C) and unique environmental (E) influences, were compared in order to examine whether the contribution of genetic factors to parentrated child problem behaviour varied as a function of exposure to dichotomously and continuously defined PBCs. We found an interaction between genetic influence and birth weight (corrected for gestational age), in that being smaller for gestational age resulted in less influence of additive genetic factors on individual differences in problem behaviour.

Chapter 6 provides a review on the psychoneuroimmuno-pathophysiology of cytokine-induced depression in humans. Administration of interferon- $\alpha$ (IFN- $\alpha$ ) and interleukin (IL)-2 is used for the treatment of cancer and hepatitis C. The most serious side-effects are depressive symptoms and cognitive changes, however prevalence of these symptoms varies across studies. Variables that may explain this variation are discussed. Furthermore, the biological changes in depression regarding the serotonergic, noradrenergic system and the HPA axis are reviewed. It is hypothesized that cytokines exert their depressive effect through influence on these systems.

In Chapter 7 the role of indoleamine 2,3 dioxygenase (IDO) in the pathophysiology of depression is reviewed. IDO is induced by pro-inflammatory cytokines and converts tryptophan, the precursor of serotonin, to kynurenine. First, activation of IDO may lead to depleted levels of brain serotonin. Second, neurotoxic kynurenine metabolites are produced. Therefore, two possible ways exist whereby IDO may induce depressive symptoms.

Chapter 8 presents data concerning depressive symptoms during IFN- $\alpha$ treatment. Sixteen patients were evaluated for depressive symptoms at baseline and at six time points during treatment. Depression scores increased significantly. Vegetativedepressive symptoms (changes in appetite, sleep, energy, motivation) increased before cognitive-depressive symptoms (sadness, feelings of guilt, being worried) did and predicted these cognitive-depressive symptoms. This finding suggests that low mood state may in part be driven by the increase in early vegetative-depressive symptoms in the course of IFN- $\alpha$ treatment.

In Chapter 9 we examined whether cytokine concentrations were associated with depressive symptoms during IFN- $\alpha$ treatment. Furthermore, it was investigated whether increase in cortisol would mediate the association between increased cytokine concentrations and depressive symptoms. Results showed that soluble IL-2 receptor, 
tumour necrosis factor (TNF)- $\alpha$ and L-6 co-varied sigmificantlly over time with depression scores. However, no associations were found between daily average cortisol and awakening response on the one hand and depressive symptons on the other. In addition, associations between cytokine concentrations and depressive symptoms did not weaken when controlled for either of the cortisol measures. We concluded that changes in IFN- $\alpha$-induced depressive symptoms are accompanied by cytokine changes, however, the cortisol response to administration of IFN- $\alpha$ does not play a mediating role in the induction of depressive symptoms during treatment.

Chapter 10 concerns the role of IDO in IFN- $\alpha$-induced depressive symptoms. Two hypotheses were investigated: 1) decreased tryptophan availability leads to decreased brain serotonin concentrations which is causal to depressive symptoms and 2) increased production of toxic kynurenine metabolites induces depressive symptoms. The ratio of tryptophan to its competing amino acids did not increase during IFN- $\alpha$ treatment and was not associated with depressive symptoms. However, the ratio of kynurenine, which is mostly metabolised into neurotoxic substances, to kymurenic acid, a neuroprotective metabolite, increased, and was significantly associated with depressive symptoms over the course of treatment. This study supports a role for IDO in the pathophysiology of IFN- $\alpha$-induced depressive symptoms, through its induction of neurotoxic kynurenine metabolites.

Majot depression has been associated cross-sectionally with increased cell-mediated immune activation but causality has been difficult to establish. Chapter 11 prospectively investigated the hypothesis that baseline level of immune activation predicts the development of depression over the course of $1 F N-\alpha$ treatment. Sixteen hepatitis $C$ patients without psychiatric disorder underwent IFN- $\alpha$ treatment. Pro- and anti-inflammatory cytokines were determined before starting treatment. Presence of a major depressive disorder (MDD) was assessed at several time points during IFN- $\alpha$ treatment. Baseline soluble IL-2 receptor, IL-6 and IL- 10 concentrations were significantly increased in the five subjects that developed MDD during treatment compared to those that did not, with standardized effect sizes of $1.08, \mathbb{1} .16$ and 1.25 , respectively, controlling for marijuana use, cigarette smoking and baseline level of depressive symptoms. The results suggest that increased immune activation, rather than an epiphenomenon, is a causal risk factor for the development of MDD.

Genetic and environmental risk factors may be important in determining individual variability in stress-induced alterations in neuroendocrine and immune status that increase the risk for physical and mental health problems. Chapter 12 concerns the effects of early life and adult stress on DAC, cytokine concentrations and possible interactions with genetic factors. 256 twin pairs, aged $18-45$ years participated in the study. Stressfull life events (SLE) were negatively associated with TNF- $\alpha$, but there was no association between SLE and DAC. High exposure to early life stress moderated these effects: in the group with high exposure to early life stress, association between SLE and TNF- $\alpha$ were stronger and a negative association between SLE and 
DAC became apparent. Influence of an additive genetic factor was found only for DAC, and exposure to SLE made genetic effects on DAC more apparent in the group with high levels of early life stress. Cytokines were determined by environmental factors only. We concluded that the adult immune and neuro-endocrine response to stress may be moderated by epigenetic changes brought about by early adverse experiences.

In Chapter 13, all the results presented in this thesis are critically discussed and an attempt is made to integrate findings with respect to their role in the pathophysiology of depression. 
Samenvatting 


\section{Samenvatting}

Blootstelling aan stress, zowel in de intra-uterine omgeving, in de kindertijd, als op volwassen leeftijd, maar ook de genetische samenstelling, kunnen personen kwetsbaar maken voor het ontwikkelen van een depressie, omdat zowel ongevings- als genetische factoren een effect hebben op de biologische systemen die betrokken zijn bij depressie. De mechanismen waardoor immunactivatie kan leiden tot depressieve symptomen worden in deze thesis onderzocht, evenals de effecten van prenatale stress op psychopathologie bij kinderen, de effecten van stressoren uit de kindertijd en op volwassen leeftijd op biologische systemen betrokken bij depressie, en hun interactie met genetische factoren.

Hoofdstuk 1 geeft een algemene inleiding op deze thesis en beschrijft de wetenschappelijke achtergrond van de hypotheses en onderzoeksdesigns. De epidemiologie en risicofactoren van depressie worden beschreven. Daarnaast geeft het een uitleg over tweelingmethodologie, "structural equation modelling" en de concepten gen-omgevingsinteractie en correlatie.

Verder bevat het een korte introductie betreffende de biologische determinanten wan depressie, de rol van immunuactivatie in depressie en het effect van stress op de hypothalamic-pituitary-adrenal (HPA) as, het immuun- en het serotonine systeem.

In Hoofdstuk 2 wordt het effect van zygositeit en chorioniciteit op psychopathologie bij kinderen onderzocht in een tweelingstudie. De prenatale omgeving van monozygote (MZ) en dizygote (DZ) tweelingen is niet gelijk, omdat een grotere proportie $\mathrm{MZ}$ tweelingen dan DZ tweelingen hetzelfde chorion delen. Daardoor kunnen schattingen van erfelijkheid onbetrouwbaar zijn. Echter, we vonden geen significant effect van chorioniciteit op psychopathologie bij kinderen, wat het waarschijnlijk maakt dat chorioniciteit niet de schattingen van de genetische en de omgevingseffecten verstoort.

Hoofdstuk 3 beschrijft de associaties tussen niet-gedeelde omgeving en psychopathologie bij kinderen. We gebruikten een directe maat van niet-gedeelde omgeving (de Sibling Inventory of Differential Experience- SIDE) en we testten de associaties tussen SIDE dimensies aan de éne kant en de mate van internaliserende, externaliserende, depressie en totale symptoom scores aan de andere kant. Er werd geen sterk bewijs gevonden dat genetische factoren de associaties tussen niet-gedeelde omgeving en de symptomen beïnvloedt. We concludeerden dat relaties bestaan tussen niet-gedeelde omgeving aan de éne kant en gedragsverschillen aan de andere kant, die niet door een genetisch effect beïnvloed zijn. Longitudinale data zijn nodig om de richting van het effect in deze associaties te bepalen.

In hoofdstuk 4 wordt onderzocht of een laag geboortegewicht een causale risicofactor is voor psychopathologie bij kinderen. Als, binnen paren, het verschil in geboortegewicht het verschil in psychopathologie voorspelt, dan is een causale verklaring waarschijnlijk. Bovendien, als het verschil in geboortegewicht het verschil 
in psychopathologie in gelijke mate voorspelt voor zowel $\mathrm{MZ}$ als $\mathrm{DZ}$ tweelingen, dan is het mechanisme waarmee geboortegewicht psychopathologie bij kinderen beïnvloedt waarschijnlijk zowel causaal als afkomstig van omgevingsfactoren. De resultaten laten zien dat een lager geboortegewicht een continue risicofactor was voor toekomstige psychopathologie en dat grotere verschillen binnen paren in geboortegewicht waren geassocieerd met grotere verschillen in psychopathologie. Dit effect was gelijk voor $M Z$ en $D Z$ tweelingen. Onze conclusie was dat geboortegewicht een causale omgevingsrisicofactor is voor psychopathologie bij kinderen.

Het is bekend dat ook zwangerschaps- en geboortecomplicaties (PBCs) omgevingsrisicofactoren zijn voor psychopathologie bij kinderen. In hoofdstuk 5 wordt de mogelijkheid van gen-omgevingsinteractie onderzocht met behulp van het tweelingdesign. Structural equation modelling werd gebruikt om ACE modellen weer te geven, die additief genetische invloed $(A)$, gedeelde omgevingsinvloed $(C)$ en nietgedeelde omgevingsinvloed (E) veronderstellen. Vervolgens werden modellen vergeleken om te onderzoeken of de bijdrage van genetische factoren aan psychopathologie bij kinderen varieert als functie van blootstelling aan dichotoom en continu gedefinieerde PBCs. We vonden een interactie tussen genetische invloed en geboortegewicht (gecorrigeerd voor zwangerschapsduur). Een laag gewicht in verhouding tot de zwangerschapsduur resulteerde in minder invloed van additief genetische factoren op individuele verschillen in psychopathologie.

Hoofdstuk 6 bevat een review over de psychoneuroimmuno-pathofysiologie van cytokine-geïnduceerde depressie bij mensen. Toediening van interferon- $\alpha$ (IFN- $\alpha$ ) en interleukin (IL)-2 wordt gebruikt voor de behandeling van kanker en hepatitis C. De meest ernstige bijwerkingen zijn depressieve symptomen en cognitieve veranderingen. Echter de prevalentie van deze symptomen varieert over de verschillende studies. Variabelen die deze variatie kunnen verklaren worden bediscussieerd. Daarnaast wordt een overzicht gegeven van de biologische veranderingen bij depressie wat betreft het serotonine, het noradrenerge systeem en de HPA as. De hypothese is dat cytokines een depressieve uitwerking kunnen hebben doordat ze de regulatie van deze systemen beünvloeden.

Hoofdstuk 7 bevat een review over de rol van indoleamine 2,3 dioxygenase (IDO) in de pathofysiologie van depressie. IDO wordt geïnduceerd door pro-inflammatoire cytokines en transformeert tryptofaan, de precursor van serotonine, in kynurenine. In de eerste plaats kan activatie van IDO leiden tot verminderde concentraties van serotonine in de hersenen. In de tweede plaats worden er neurotoxische kynurenine metabolieten geproduceerd. Dus er zijn twee mogelijke manieren waarop IDO depressieve klachten kan induceren.

In hoofdstuk 8 worden de resultaten beschreven betreffende depressieve symptomen tijdens IFN- $\alpha$ behandeling. Zestien patienten werden onderzocht op depressieve symptomen bij baseline en op 6 tijdstippen tijdens de behandeling. Depressiescores stegen significant. Vegetatief-depressieve klachten (veranderingen in eetlust, slaap, 
energie, motivatie) stegen voordat cognitief-depressieve klachten (droevig, schuldgevoelens, zich zorgen maken) stegen en voorspelden deze cognitief-depressieve klachten. Deze bevinding maakt het waarsehijnligk dat een lage stemming deels veroorzaakt kan worden door de stijging in eerdere vegetatief-depressieve klachten tijdens IFN- $\alpha$ behandeling.

In hoofdstuk 9 hebben we onderzocht of cytokine concentraties geassocieerd waren met depressieve symptomen gedurende IFN- $\alpha$ behandeling. Bovendien hebben we gekeken of een stijging in cortisol de associatie tussen cytokine concentraties en depressieve klachten zou kunnen verklaren. De resultaten toonden aan dat de oplosbare L-2 receptor, tumour necrosis factor (TNF)- $\alpha$ en $L-6$ concentraties significant positief geassocieerd waren over tijd met de depressie scores. Echter, er werden geen associaties gevonden tussen 'daily average cortisol' en de 'awakening response' aan de éne kant en depressieve symptomen aan de andere kant. Bovendien werden de associaties tussen cytokine concentraties en depressieve symptomen niet zwakker wanneer er gecorrigeerd werd in de analyse voor deze cortisol maten. We concludeerden dat veranderingen in IFN-a-geinduceerde depressieve klachten samengaan met veranderingen in cylokine concentraties, maar dat de cortisol respons na toediening van IFN- $\alpha$ geen invloed heeft op de verhoging van depressieve symptomen gedurende de behandeling.

Hoofdstuk 10 gaat over de rol van IDO in IFN- $\alpha$-geinduceerde depressieve symptomen. Twee hypotheses werden onderzocht: 1) verminderde tryptofaan beschikbaarheid leidt tot verminderde brein concentraties van serotonine wat causaal is voor de depressieve symptomen en 2) verhoogde productie van toxische kynurenine metabolieten induceert depressieve symptomen. De ratio van tryptofaan ten opzichte van de competerende aminozuren was niet verhoogd tijdens IFN- $\alpha$ behandeling en was niet geassocieerd met depressieve symptomen. Echter, de ratio van kynurenine (wat vooral wordt omgezet in neurotoxische stoffen) ten opzichte van kynurenine zuur (een neuroprotectieve metaboliet), verhoogde en was significant geassocieerd met depressieve symptomen gedurende de behandeling. Deze studie steunt de hypothese dat IDO een rol speelt bij de pathofysiologie van depressie door de inductie van neurotoxische kynurenine metabolieten.

Cross-sectioneel is in studies aangetoond dat depressie samengaat met verhoogde " $T$ cel gestuurde immunactivatie, maar causaliteit is moeilijk vast te stellen. Hoofdstuk 11 onderzocht prospectief de hypothese dat baseline concentraties van cytokines de ontwikkeling van depressie voorspelt tijdens het beloop van IFN-a behandeling. Zestien hepatitis $\mathrm{C}$ patiënten zonder psychiatrische diagnose ondergingen IFN- $\alpha$ behandeling. Pro- en anti-inflammatoire cytokines werden bepaald voor het begin van de behandeling. De aanwezigheid van een depressieve stoomis werd gemeten op verschillende tijdstippen tijdens de IFN- $\alpha$ behandeling. Baseline oplosbare IL-2 receptor, IL-6 en IL-10 concentraties waren significant hoger in de vijf personen die depressie ontwikkelde tijdens de behandeling vergelleken met hen die geen depressie ontwikkelden. De gestandaardiseerde effectgroottes waren respectievelijk $1.08,1.16 \mathrm{en}$ 
1.25, gecontroleerd voor marijuana gebruik, roken en baseline waarden van depressie symptomen. Deze resultaten laten zien dat verhoogde immuunactivatie niet een epifenomeen, maar een causale risicofactor is voor het ontwikkelen van een depressie.

Genetische en omgevingsfactoren zijn belangrijk bij het bepalen van de individuele variabiliteit in stress-geïnduceerde veranderingen in het neuro-endocriene en immuunsysteem die het rísico voor fysieke en mentale gezondheidsproblemen verhogen. Hoofdstuk 12 gaat over de effecten van stress in de kindertijd en als volwassene op DAC, cytokine concentraties en mogelijke interacties met genetische factoren. In totaal namen 256 tweelingparen, in de leeftijd van 18-45 jaar, deel aan deze studie. Stressvolle levensgebeurtenissen (SLE) waren negatief geassocieerd met TNF- $\alpha$, maar er was geen associatie tussen SLE en DAC. Een hoge mate van blootstelling aan stress in de kindertijd beînvloedde deze effecten: in de groep met hoge mate van blootstelling aan stress in de kindertijd waren de associaties tussen SLE en TNF- $\alpha$ sterker. Bovendien werd een negatieve associatie tussen SLE en DAC gevonden. Effect van een additief genetische factor werd slechts gevonden voor DAC.Een blootstelling aan SLE vergrootte de genetische effecten op DAC in de groep met een hoge blootstelling aan stress tijdens de kindertijd. Cytokine concentraties werden slechts door omgevingsfactoren beïnvloed. We concludeerden dat de volwassen immuun- en neuro-endocriene respons op stress werd beïnvloed door epigenetische veranderingen die ontstaan door vroege stressvolle ervaringen.

In hoofdstuk 13 worden alle resultaten van dit proefschrift op kritische wijze bediscussieerd en geïntegreerd ten aanzien van hun bijdrage aan de kennis van de pathofysiologie van depressie. 
Dankwoord 


\section{Dankwoord}

Gedurende de periode van een promotieonderzoek duiken er altijd moeilijkheden, onmogelijke planningsopgaven en probleempjes van allerlei aard op. Zeer blij ben ik dan ook met alle mensen die voor mij in deze periode een steun waren; mensen die zich op sommige momenten flexibel opstelden, mensen die op het juiste moment kwamen met een oplossing, en mensen die door hun aanwezigheid en vriendschap het werk nog extra leuk maakten. Een aantal mensen wil ik in het bijzonder noemen.

Allereerst wil ik Jim, mijn promotor, heel hartelijk danken. Zonder hem was dit proefschrift er nooit gekomen. Jim, al werd jij pas in een later stadium van mijn promotietraject mijn promotor, toch heb ik gedurende alle jaren jouw betrokkenheid en steun gevoeld in wat ik deed, vooral omdat jij op cruciale momenten klaar stond met een oplossing. Jouw optimisme en enthousiasme staken mij altijd aan met nieuwe motivatie en inspiratie. Je bent een bijzondere begeleider en je hebt mij, naast puur onderzoek, ook geïnspireerd met jouw manier van werken, met elkaar omgaan en mens zijn.

Heel veel dank gaat ook uit naar mijn copromotor, Ger Koek. Heel erg bedankt voor de energie die jij gestoken hebt in dit project. Bovendien was het zonder jou niet gelukt om zoveel mensen enthousiast te krijgen om deel te nemen aan ons onderzoek. Ondanks alle drukte van het artsenleven maakte je altijd tijd vrij en toonde je oprechte interesse in het onderzoek.

Ook andere mensen vanuit de afdeling interne geneeskunde bij het azM en het ziekenhuis in Genk zijn betrokken geweest bij dit onderzoek. Annemarie Wensing en Geert Robaeys, hartelijk dank ook voor jullie inzet en flexibiliteit bij het rekruteren van proefpersonen.

Michael Maes wil ik ook bedanken dat hij mij de gelegenheid heeft gegeven om verder te gaan in het interessante onderwerp van de psychoneuroimmunologie. Ik kan me nog leuke discussies herinneren over de verbanden tussen de biologische systemen van lichaam en geest.

Een onmisbare persoon bij de totstandkoming van dit onderzoek was Gunter. Gunter, jij stond altijd voor me klaar met je hulp als er weer een proefpersoon op een andere tijd of een verkeerde dag kwam via het opvangen van het labwerk, je belangenloze betrokkenheid bij mijn onderzoek, en mentale steun. Ook was het erg fijn dat jij jouw kennis en expertise in onderzoek en cytokine bepalingen met mij hebt gedeeld. Dankzij jouw hulp zijn de bepalingen van dit onderzoek zeer goed verlopen. Eigenlijk ben jij al vier jaar mijn paranimf. 
Dan zijn er de mensen die mij hebben geholpen met het invries-klaar maken van mijn bloedsamples, terwijl ik bezig was met het onderzoek bij de proefpersonen; Sabine en Belinda, wat moest ik zonder jullie?! Ook Marjanne Markerink en Aye-Mu Myint wil ik heel erg bedanken dat ze in "noodsituaties", tijd hebben vrij gemaakt om mij hierbij te helpen. Thanks a lot!

Esmeralda en Bert, er valt tijdens een onderzoek zoveel te regelen en er zijn zoveel proefpersonen die onderzocht moeten worden... Ik wil jullie enorm bedanken voor jullie hulp hierbij. Ik vond het fijn om met jullie samen te werken. Bert, ik vond het erg leuk om met jou te discussiëren over het onderzoek en je hebt me hierbij zeker geïnspireerd. Jij hebt ook heel wat over gehad woor het onderzoek om elke keer in de vroegte op weg te gaan naar Genk om daar proefpersonen te zien. Jouw hulp was onmisbaar. Daarnaast was het ook heel gezellig om af en toe wat van jouw kookkunsten op te steken!

Dit proefschrift bevat ook een aantal tweelingstudies. Ik dank Prof. R. Derom, Dr. C. Derom en Prof. R. Vlietinck dat ik de kans heb gekregen om te werken met het grote databestand van het Oostvlaamse tweelingregister.

Frühling and Shaun, it was very nice to get acquainted with the statistical side of twin data with help of you. Thanks for using your expertise to increase my knowledge in this field of research. Your efforts contributed greatly to the quality of the twin papers.

Ook alle andere co-auteurs, bedankt voor jullie inzet.

Robert Verkerk, het was leuk en inspirerend om met u te discussiëren. Ik heb genoten van de informatie die a af en toe stuurde over de recente ontwikkelen op het gebied van het enzym IDO.

Nancy, hartelijk dank voor het meedenken, de betrokkenheid en de kritische blik op de artikellen. Dit kwam de kwaliteit zeker ten goede.

Prof. B. Leonard, thank you for your support and help. It is very pleasant when people give you the feeling that you can always come to them in case of a problem. I hope we can continue discussions about the interesting topic of psychoneuroimmunology in the future.

Als je denkt dat het proefschrift af is, dan komt er toch nog eén en ander bij kijken voordat het naar de drukker kan. Tiny, ontzettend bedankt voor jouw hulp hierbij.

En dan natuurlijk, mijn kamergenoten!! Tessa en Bart, de eerste drie jaren heb ik met jullie de kamer gedeeld. Ik vond dit een hele leuke periode die ik niet snel zal vergeten.

Tessa, helemaal fijn is het als kamergenoten ook goede vriendinnen worden! $1 \mathrm{k} z a l$ nog 
lang denken aan al die leuke dingen die we ook buiten werktijd samen hebben gedaan, zoals die vakantie in Turkije.

En dan, Annique, collega, vriendin en huisgenoot! Met jou was het nooit saai. lk heb genoten van onze levendige discussies tijdens de lunch, het samen zingen, samen leuke uitstapjes bedenken, en noem maar op. Ook al zitten wij vol tegenstellingen, jij hebt mij diepgaand geïnspireerd.

Het laatste jaar van mijn AIO periode kwam ik weer terug op de plek, waar ik ooit mijn wetenschappelijke carrière begon als stagiaire: de afdeling sociale psychiatrie. Het voelde alsof ik niet was weggeweest! Alle SP collega's hartelijk dank hiervoor! Ik voe] me bij jullie echt thuis. Nele en Tineke, ik vond het erg leuk om terug, samen met jullie, weer in mijn oude kamer te zitten. Nele, ik heb genoten van de wetenschappelijke reisjes die we in de afgelopen 4 jaar samen gemaakt hebben en ik denk dat we goed op elkaar zijn ingespeeld. We hebben heel wat kunnen delen samen, vooral ook in de afgelopen periode waarbij we zo gelijk opliepen met onze werkzaamheden. Nele, heel veel succes en ik hoop nog lang met jou te kunnen samenwerken.

Ook buiten het onderzoek zijn er vrienden die voor mij erg belangrijk waren in de afgelopen periode. Gea en Gabrielka, dank voor jullie aanwezigheid, steun en vriendschap! Ook de mensen met wie $\mathrm{ik}$ gedurende een groot deel van mijn AlO periode het huis heb gedeeld, bedankt voor de steun en gezelligheid en Maaike, ik vind het erg leuk dat jij bovendien ook mijn paranimf bent!

Liesbeth en Bas, heel veel dank voor jullie artistieke en technische bijdragen.

En tot slot, mijn ouders, bedankt voor de onvoorwaardelijke steun en het aanhoren van alle problemen die af en toe opdoemden. Jullie zijn de basis van waaruit ik in staat was dit te volbrengen. 


\section{List of publications}




\section{Present thesis}

Wichers MC, Koek GH, Robaeys G, Verkerk R, Scharpe S, Maes M. IDO and interferon- $\alpha$-induced depressive symptoms: A shift in hypothesis from tryptophan depletion to neurotoxicity. Molecular Psychiatry 2004; advance online publication

Wichers MC, Koek GH, Robaeys G, Praamstra AJ, Maes M. Early increase in vegetative symptoms predicts interferon- $\alpha$-induced cognitive-depressive changes. Psychological Medicine 2005;35:433-41

Wichers $M$, Maes $M$. The role of indoleamine 2,3 dioxygenase (IDO) in the pathoplaysiology of interferon-alpha-induced depression. Jourmal of Psychiatry and Neuroscience $2004 ; 29(1): 1.1-17$.

Wichers M, Maes M. The psychoneuroimmuno-pathophysiology of cytokine-induced depression in humans. Intemational Journal of Neuropsychopharmacology $2002 ; 5(4): 375-88$.

Wichers MC, Purcell S, Danckaerts M, Derom C, Derom R, Vlietinck R, van Os J. Prenatal life and post-natal psychopathology: evidence for negative gene-birth weight interaction. Psychological Medicine 2002;32(7):1165-74.

Wichers MC, Danckaerts M, Van Gestel S, Derom C, Vlietinck R, van Os J. Chorion type and twin similarity for child psychiatric symptoms. Archives of General Psychiatry 2002;59(6):562-4.

Wichers MC, van Os J, Danckaerts M, Van Gestel S, Derom C, Vlietinck R. Associations between nonshared environment and child problem behaviour. Social Psychiatry and Psychiatric Epidemiology $2001 ; 36(7): 319-23$.

Van Os $J$, Wichers $M$, Danckaerts $M$, Van Gestel S, Deron C, Vlietinck R. A prospective twin study of birth weight discordance and child problem behavior. Biological Psychiatry 2001;50(8):593-9.

Wichers MC, Kenis, G. Koek GH, Robaeys, G. Maes, M. van Os, J. Baseline immune activation is risk factor for developing depression during interferon-alpha treatment, submitted.

Wichers MC, Kenis G, Koek GH, Robaeys G, Sulon J, Nicolson N, Maes M. Interferon-alpha-induced depressive symptoms are related to changes in the cytokine network, but not to cortisol, submitted. 
Wichers MC, Jacobs $N$, Delespaul Ph, Kenis $G_{,}$Rijsdijk F, Nicolson N, Derom C, Vlietinck $\mathrm{R}$, van $\mathrm{Os} \mathrm{J}$. Early trauma and genetic sensitivity to adult stress exposure.

\section{Other}

Schiepers O, Wichers MC, Maes, M. Cytokines and major depression, Progress in Neuropsychopharmacology and Biological Psychiatry 2005;29(2):201-17.

Ryan BM, Russel MG, Schurgers L, Wichers M, Sijbrandij J, Stockbrügger RW, Schoon E. Effect of antitumour necrosis factor-alpha therapy on bone turnover in patients with active Crohn's disease: a prospective study. Alimentary Phamacology and Therapeutics $2004 ; 20(8): 851-7$.

Wichers $M$, van der Ven A, Maes $M$. Central nervous system symptoms related to the use of efavirenz in HIV-seropositive patients. Current Opinion in Psychiatry $2002 ; 15: 643-647$.

Wichers M, Maes M. Mechanisms of interferon-alpha induced depression. Acta Neuropsychiatrica 2002, 14:103-105. 
Curriculum vitae 


\section{Curriculum vitae}

Marieke Wichers werd geboren op 6 december 1977 te Deventer. Na afronding vin liet Gymnasium (bèta) in Zutphen (Baudartius College), begon ze in 1996 met de studic Psychologie (afstudeerrichting Neuropsychologie) aan de Universiteit Maastricht, waar $z e$ in 2000 'cum laude' afstudeerde. Voor haar afstudeerscriptie ontving zij de studentenprijs van de Stichting Wetenschapsbeofening Universiteit Maastricht woor de Faculteit der Psychologie. In september 2000 werd ze assistent in opleiding bij de capaciteitsgroep Psychiatrie \& Neuropsychologie van de Universiteir Mastricht en verrichtte ze onderzoek naar de rol van het immunsysteen bij het ontstatn van depressieve klachten. Daanaast is ze ook betrokken bij onderwijsactiviteiten binnen de faculteit. Dankzij het Kootstra Fellowship 2004 blijft Marieke ook het komende jaar verbonden aan dezelfde capaciteitsgroep. 